\title{
Authority, Justice, and Public Law: A Unified Theory
}

\author{
by \\ Jacob Weinrib \\ A thesis submitted in conformity with the requirements \\ for the degree of Doctor of Philosophy \\ Department of Philosophy \\ University of Toronto \\ C Copyright by Jacob Weinrib 2013
}




\section{Abstract \\ A Theory of Public Law \\ Jacob Weinrib \\ Doctor of Philosophy \\ Department of Philosophy \\ University of Toronto}

2013

In articulating the juridical relationship between the individual and the state, a theory of public law must confront a fundamental problem. The practice of public law involves appeals to ideas of both authority and justice, but these ideas appear to be antagonistic rather than complementary. On the one hand, persons must act in conformity with legal obligations enacted through the contingent exercise of public authority. On the other, persons must act in conformity with timeless ideals of public justice. The theoretical puzzle at the core of public law stems from the incompatibility of these convictions. Because enacted laws are often unjust and just laws are rarely enacted, persons often find themselves simultaneously pulled in one direction by the demands of public authority and pulled in another by the demands of public justice. To escape this tension, the leading theories invariably fragment their subject matter by reducing the whole of public law to one of its aspects, authority in abstraction from justice or justice in abstraction from authority.

The purpose of this project is to articulate a unified theory of public law that integrates the distinctive claims of authority and justice into a common framework. My central claim is that once authority and justice are appropriately conceived and justified, they are neither antithetical virtues of opposing theoretical frameworks nor isolated notions. Instead, authority and justice are the mutually implicating principles of a legal system: the right of rulers to exercise public authority is always accompanied by a duty to govern justly; the right of the ruled to just governance 
presupposes the presence of publicly authoritative institutions. By setting out the character and interrelation of the fundamental components of a legal system, the unified theory illuminates the general practice of public law from the legal systems of the ancient world to the inner workings of modern constitutional states. 


\section{Acknowledgements}

I am grateful to everyone who contributed to this project.

It is difficult to overstate Arthur Ripstein's impact on this project and on my philosophic and legal education more generally. Arthur introduced me to Kantian legal philosophy as an undergraduate. As a graduate student, he invited me to the Law and Philosophy Discussion Group at the University of Toronto, where we spent several years reading Kant's legal philosophy, sentence by sentence, week by week. The ideas in this dissertation stem from an interpretation of Kant's theory of public right that I developed in those years. Later, I worked for Arthur as a research assistant and took courses from him in law school. Arthur's endless energy, generosity, and insight have been an inspiration to me at every stage of my university education. I am incredibly fortunate to have had such remarkable supervision.

I also wish to thank David Dyzenhaus for his many helpful interventions, which significantly improved the clarity and breadth of this project.

This project was supported by the Ontario Graduate Scholarship and the Vanier Canada Graduate Scholarship. In particular I would like to thank Mohammadreza Alaeddini, Peter Benson, Ken Boyd, Alan Brudner, Bruce Chapman, Peter da la Costas, Stephen Coyne, Mary Frances Ellison, Chris Essert, Harry Fox, Philip Kremer, Joseph Heath, Louis-Philippe Hodgson, James Hunter, Joanna Langille, Andrew Max, Sophia Moreau, Margaret Opoku-Pare, Jim Phillips, Sareh Pouryousefi, Diana Raffman, Gurpreet Rattan, Geoffrey Read, Arie Rosen, Kristen Rundle, Scott, Shapiro, Hamish Stewart, Manuel Wörsdörfer, and Ariel Zylberman. I am grateful to Aharon Barak for generously sharing his vast 'dignity library' with me. Dieter Grimm provided insightful comments on an earlier draft of Chapter Four and valuable guidance on Chapter Five. Components of this project were presented at the University of Toronto Legal Theory Workshop, the Princeton Graduate Conference in Political Theory, the MANCEPT Workshops in Political 
Theory at the University of Manchester, the Graduate Forum in Philosophy at the University of Toronto, the Center for Ethics, the Political Theory Research Workshop at the University of Toronto, and the Ontario Legal Philosophy Partnership Student Conference at the Osgoode Hall Law School.

Finally, I am deeply grateful to my parents who in so many ways made this project possible and to Debra for putting up with me while I worked through it. 


\section{Table of Contents}

Introduction: The Unified Theory of Public Law.....................................................1

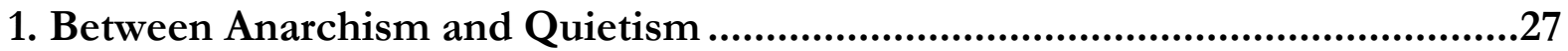

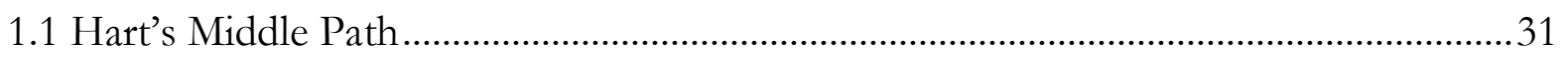

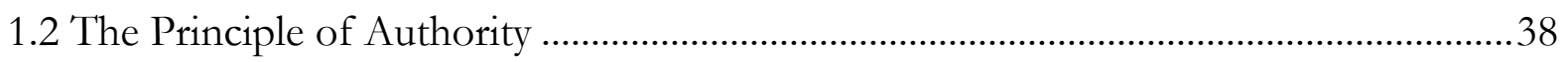

1.3 The Principle of Justice ...............................................................................................4

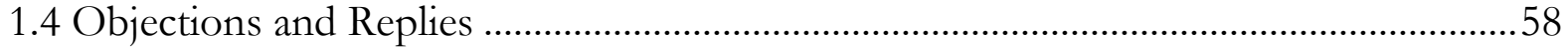

2. Public Authority and Private Violence .............................................................66

2.1 The Distinction in Postwar German Legal Theory..........................................................72

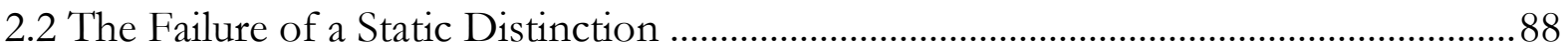

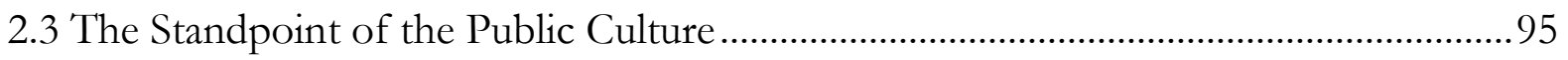

2.4 The Barbarism of Nazi Power .................................................................................103

3. A Progressive Theory ...................................................................................... 113

3.1 The Progressive Ambition of Rawls's Justice as Fairness ..............................................114

3.2 The Progressive Ambition of Hart's Legal Positivism ...................................................122

3.3 The Progressive Character of the Unified Theory ……………………………...........126

3.4 Progress and Particularity …………………………………………………………...136 
4. The Modern Constitutional Paradigm ................................................................. 147

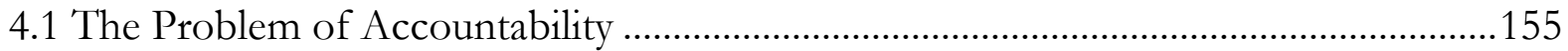

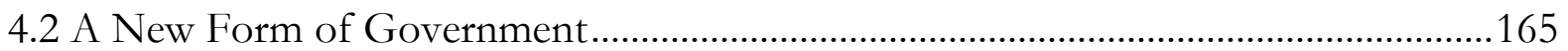

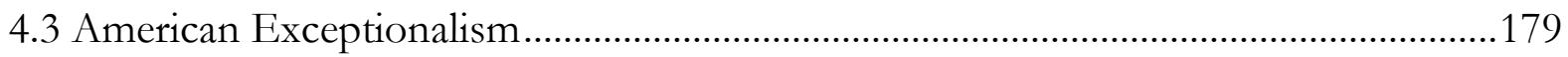

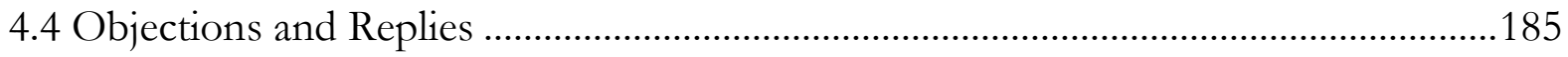

5. Rights and Limits in a Constitutional State ...................................................... 196

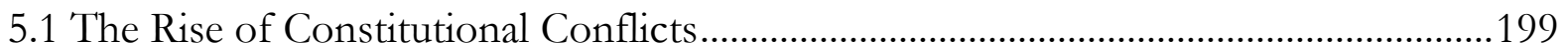

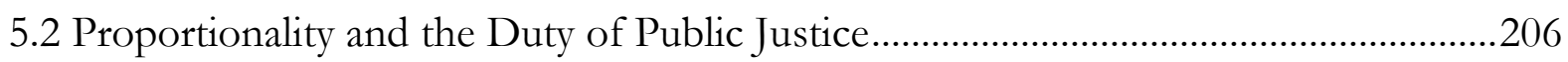

5.3 Alexy's Theory of Proportionality ………………….............................................219

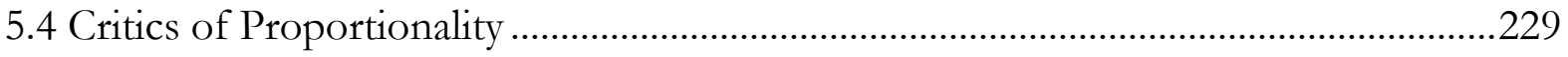

Conclusion: Public Law in the Postwar World ..................................................242

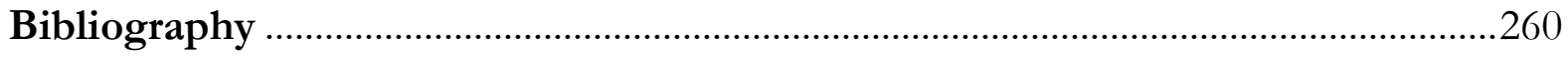




\section{List of Figures}

The Principles of Public Law 


\title{
INTRODUCTION: THE UNIFIED THEORY OF PUBLIC LAW
}

\begin{abstract}
"When we deal with law, not in terms of definitions and authoritative sources, but in terms of problems and functions, we inevitably see that it is compounded of reason and fiat, of order discovered and order imposed, and that to attempt to eliminate either of these aspects of the law is to denature and falsify it."
\end{abstract}

\section{Lon L. Fuller ${ }^{1}$}

$\mathrm{I}$

$\mathrm{n}$ articulating the juridical relationship between the individual and the state, theoretical accounts

of public law invariably attempt to reduce their subject matter to one of its aspects. For some,

the fundamental insight that a theory must capture is that public law is simply the sum of norms validated through the contingent exercise of an authoritative fiat. Others maintain that a theory of public law must account for the timeless character of reason or justice, to which the actions of all private persons and public officials must conform.

The dispute between these conceptions of public law extends from the legal consciousness of the ancient world to the leading theories of the present day. The central difficulty that any theory of public law must confront is, on the one hand, that the practice of public law involves the interplay of what Fuller called 'fiat' and 'reason' - or what I will call 'authority' and 'justice' - and, on the other, that these components appear to be antagonistic rather than complementary. ${ }^{2}$ Justice denies the

\footnotetext{
1 “Reason and Fiat in Case Law," Harvard Law Review 59 (1946): 382 [Fuller, "Reason and Fiat"].

${ }^{2}$ Harold J. Berman, Law and Revolution: The Formation of the Western Legal Tradition (Cambridge: Harvard University Press, 1983), 21-22 (noting the inherent contradiction in Western legal systems between conceiving of law as order and conceiving of law as justice). See also Stefano Bertea, "How Non-Positivism can Accommodate Legal Certainty," in Law, Rights, and Discourse: The Legal Philosophy of Robert Alexy, ed. George Pavlakos (Oxford: Hart Publishing, 2007), 70: "[A]t the core of law lies an essential dichotomy between the principle of legal certainty and the claim to justice. This feature of certainty and justice-both of them being fundamental values in law, and yet each colliding with the other-has been a source of serious theoretical problems. And the reason is not far to seek: because both bear a fundamental status, any comprehensive theory of law needs to make sense of both, no matter if the relationship they stand in its conflictive or otherwise. Different general approaches to law have dealt with the essential dichotomy, but by and large they have been skewed toward either certainty or justice, giving only a partial account of the other..."
} 
adequacy of what authority establishes. Authority denies the actuality of what justice demands. Since the norms that are authoritative within a given legal system are often unjust, while just norms too often fail to be legally authoritative, a theory of public law cannot hold that persons are simultaneously bound both by the sum of validly enacted norms and by the eternal precepts of justice: for the demands of authority and justice might pull in opposite directions and no one can serve two masters.

Fuller observed that in responding to the antinomy "that lies at the heart of the whole legal order", ${ }^{3}$ the "main effort of the various schools of legal philosophy has been to obliterate one of its branches." This observation is as true now as it was in Fuller's day. In what follows I will illustrate Fuller's observation by showing how two leading theorists respond to the antinomy. I begin with Martin Loughlin, who assimilates public law to the notion of an authoritative fiat. For Loughlin, public law consists not in the unfolding of a theory of justice, but in the prudential activity through which a state maintains and augments its own power. Ronald Dworkin's interpretive theory of law takes the opposite approach by claiming that one cannot understand what law is apart from what it ought to be. Although Loughlin and Dworkin respond to the antinomy between authority and justice by taking opposite paths, I believe that their theories share a common flaw. Since the practice of public law involves the interplay between authority and justice, any theory that fails to provide a coherent integration of these components ultimately fails to illuminate the practice of public law. The overarching aim of this project is to resolve this antinomy and, in so doing, to formulate a theory capable of illuminating and guiding the practice of public law.

${ }^{3}$ Fuller, "Reason and Fiat," 383.

4 Ibid. 
In The Idea of Public Law and Foundations of Public Law, ${ }^{5}$ Martin Loughlin argues that public law "rests on the singular character of its object - the activity of governing." As Loughlin sets out his position:

What I want to argue is that public law - the law relating to the activity of governing - must be conceived as an assemblage of rules, principles, canons, maxims, customs, usages, and manners that condition and sustain the activity of governing. More specifically, public law is neither a system of general principles nor a code of rules. Rather, it is a vernacular language... Public law is generated through usage (by a variety of governmental actors); it is not simply the creation of grammarians (i.e. judges and jurists). In this sense, the law relating to the activity of governing is not solely a mechanism for determining judgments about conduct but is a practice within which criteria about right conduct are elicited. ${ }^{\top}$

Language, like law, operates in accordance with its own conventions. In language, the standard for the correct pronunciation of a word or the grammatical construction of a statement reflects the conventions of the existing practice. For Loughlin, public law too is an activity governed by its own conventions: "Just as the standard of correctness about the way we pronounce words is just the way we do, so too in relation to the activity of governing the appropriate mode of conduct is that of adherence to the ways it is conventionally carried on." " Public law is autonomous because it answers to

${ }^{5}$ Foundations of Public Law (Oxford: Oxford University Press, 2010). For reviews and discussions, see David Dyzenhaus, "The End of the Road to Serfdom?” University of Toronto Law Journal 63 (2013): 310-326; James Grant, "Control and SelfControl," The Times Literary Supplement (2010); C. Thornhill, Public Law (2011): 651-657; and Mark D. Walters, “Is Public Law Ordinary?" The Modern Law Review 75 (2012): 894-913. On The Idea of Public Law (Oxford: Oxford University Press, 2003), see J.W.F. Allison, The Modern Law Review 68 (2005): 344-348; N.W. Barber, "Professor Loughlin's Idea of Public Law," Oxford Journal of Legal Studies 25 (2005): 157-167; Emilios Christodoulidis, "Public Law as Political Jurisprudence: Loughlin's 'Idea of Public Law'," in Public Law and Politics: The Scope and Limits of Constitutionalism, ed. Christodoulidis and Stephen Tierney (Burlington, VT: Ashgate Publishing Company, 2008), 47-65 [Public Law and Politics]; Matthew Dyson, The Cambridge Law Journal 64 (2005): 503-4; Tom R. Hickman, "In Defence of the Legal Constitution," University of Toronto Law Journal 55 (2005): 981-1025; Ethan J. Leib, Law \& Politics Book Review 14 (2004): 458-464; Robert Shelley, "Stuntman for the State: Loughlin's Idea of Public Law," Ratio Juris 19 (2006): 479-488; Stephen Tierney, "Sovereignty and the Idea of Public Law," in Public Law and Politics, 15-26; Scott Veitch, "Authority, Exploitation and the Idea of Public Law," in Public Law and Politics, 27-34.

${ }^{6}$ The Idea of Public Law, 152; 1, 29-30, and 155.

${ }^{7}$ Ibid., 30; cf. 155.

${ }^{8}$ Ibid., 29-30. 
no moral standard of right or wrong beyond the conventions at work in the practice of governing. ${ }^{9}$ Thus, public law is not an "explication of the science of political right". ${ }^{10}$ Because human beings "live in a world comprising a multiplicity of moral maps," 11 which inevitably culminate in conflict, the resulting conflicts cannot be resolved through recourse to an "authoritative morality". ${ }^{2}$ In a world in which morality offers no objective answers, ${ }^{13}$ governance resolves the conflicts that moralities create but are powerless to address. ${ }^{14}$

Loughlin unpacks the fundamental components of his theory in a series of chapters concerning politics, representation, sovereignty, constituent power, rights, and method. But as Loughlin elaborates the components of his theory by drawing on a wide array of thinkers scattered across the history of political and legal thought, tensions arise. Although the autonomy of public law is intended to exclude considerations of morality, justice, or non-positive rights, these considerations creep back into Loughlin's theory as he elaborates its central components. In his account of representation, Loughlin alludes to legal systems in general as resting on a "set of reciprocal duties and rights" binding rulers and ruled. Loughlin's admission that the ruled have rights that correspond to the duty of the ruler is puzzling in light of his preceding account of the autonomy of public law or his subsequent claim that the sovereign, "as bearer of supreme power, is not subject to any rights claims. To the extent that individuals hold rights under a legal order, these are conferred solely through the law-making action of the sovereign." ${ }^{\prime 5}$ Similarly, Loughlin's account of sovereignty indicates that

\footnotetext{
${ }^{9}$ Ibid., 1 and 153-5.

${ }^{10}$ Foundations of Public Law, 158.

11 The Idea of Public Law, 155-6.

12 Ibid., 148.

13 Ibid., 40.

${ }^{14}$ For a critical discussion of Loughlin's distinction between morality and politics, see N.W. Barber, "Professor Loughlin's Idea of Public Law," 157-165.

15 The Idea of Public Law, 86.
} 
political power presupposes the equality of the persons who are governed by it. ${ }^{16}$ Unfortunately, this statement is an isolated occurrence and does not inform Loughlin's account of how public authority must be exercised. A similar problem arises in Loughlin's discussion of the method of public law:

Although reason of state takes the well-being of the state and its people - the salus populi - as its ultimate value, the precept cannot be reduced to that of the power impulse tout court. Reason of state requires not only that the state act to promote the public good, but also with due regard to issues of morality and justice. ${ }^{17}$

Loughlin does not explain why the state must act with due regard for morality and justice, what it would mean for the state to do so given his insistence that morality and justice offer no objective answers, or how such a duty is compatible with his conception of autonomy of public law. After all, the autonomy of public law consists in the denial that transcendent notions of morality and justice are apposite to the practice of governance. At times Loughlin seems to suggest that the state is strengthened by acting morally and justly because it fosters the "confidence and allegiance" of the people. ${ }^{18}$ But if morality and justice are simply a pretense for the exercise of political power, as Loughlin repeatedly indicates (and as I discuss below), then it is not clear why such specious practices would be so fervently demanded and so favorably received. As Durkheim wrote in another context, "if the peoples themselves have been the artisans of these systems of erroneous ideas, at the same time that they were their dupes, how has this extraordinary hoax been able to perpetuate itself throughout the course of history?" 19 In formulating a theory of public law out of diverse schools of philosophic and political thought, Loughlin introduces incompatibilities between his general conception of public law as a political practice, on the one hand, and the particular components of

\footnotetext{
${ }^{16} \mathrm{Ibid} ., 78$. In this passage, Loughlin suggests that private law, unlike public law, does not conceive of persons to be equal. While I find Loughlin's claims that private law denies equality and that public law involves a different conception of the person than private law to be problematic, I cannot pursue these issues here.

${ }^{17}$ Ibid., 149.

${ }^{18}$ Ibid., 156.

${ }^{19}$ Cited in Raymond Aron, Main Currents of Sociological Thought, vol. 2 (New Brunswick, NJ: Transaction Publishers, 2009), 56. Durkheim directed his question towards attacks alleging the irrationality of religion.
} 
that practice, on the other. Because the general and particular aspects of his view stand in tension, they cannot form a larger whole.

Perhaps Loughlin might respond with a softer account of the distinction between public law and morality. By drawing on the analogy between the evolving practice of language and the ongoing practice of public law, Loughlin might argue that it is through the exercise of public law that moral claims are incorporated into the practice of particular legal systems. Loughlin suggests such an approach when he writes: "Rather than treating public law as the unfolding of some science of political right...public law should be understood to involve an exercise in political jurisprudence, whose task is to negotiate between the various conflicting accounts of political right that form part of its evolving discourse. ${ }^{20}$ On this view, public law does not exclude morality, but provides the conditions of its inclusion. Moral judgments concerning "the practice of public law are not laid down from above but are generated internally." 21 While such an argument could be developed, it is inconsistent with Loughlin's conception of morality as a domain of irresolvable claims and his conception of public law as a domain of unconstrained prudence. Loughlin acknowledges that the "language of public law often presents itself as a language of propriety," but maintains that even "this language is governed by precepts of prudence." ${ }^{22}$ Because prudence is not susceptible to moral constraint, to the extent that moral concepts and forms of reasoning are introduced into the practice of public law, that practice is a sham. ${ }^{23}$ Although Loughlin sometimes makes the moderate claim that governmental power should be exercised with "due regard for issues of morality and justice" 24 or even the strong claim that governmental power should be directed solely to the "public good", ${ }^{25}$ he is also explicit that appeals to morality are nothing more than a smokescreen through which the state asserts the rightfulness of

${ }^{20}$ Foundations of Public Law, 164.

21 The Idea of Public Law, 155.

22 Ibid., 30.

23 Ibid., 157.

24 Ibid., 149.

${ }^{25}$ Foundations of Public Law, 171. 
its own conduct while drawing attention away from the pursuit of its own interests: "In public law, we make use of a variety of devices-rhetorical tricks, silences, accommodations, self-imposed jurisdictional limitations and the like_- that enable us to pay lip-service to the universal ideals of justice while according due recognition to the interests of the state." ${ }^{26}$ In dismissing the possibility that the prudential exercise of power admits the possibility of moral constraints, Loughlin disregards a significant feature of the actual practice of public law. While Loughlin insists that the practice of public law resembles a language, it does not resemble the language in which public law is actually practiced. In Loughlin's eyes, public law cannot be explained in its own terms because public law is not what it purports to be. Public law may clothe itself in the moral language of justice and fundamental rights, but the prudential cut and thrust of political expediency is all that lies beneath its façade. If we wish to understand the practice of public law, Loughlin is adamant that we must dismiss the ways in which that practice presents itself and the distinctive discourse through which it justifies its own activity.

Loughlin is also dismissive of the existing practice of public law in his treatment of the rights revolution in modern constitutional law, in which a growing number of states around the world have enacted democratic constitutions that require all branches of government, including the legislature, to respect and protect the dignity and fundamental rights of all persons subject to its governance. Since Loughlin conceives of his project "as a theory of public law in general", ${ }^{27}$ one might expect him to relate his theory to the dominant mode in which public law is practiced in the contemporary world. But the hostile relationship between politics and morality in Loughlin's account renders modern constitutionalism mysterious. Whereas Loughlin conceives of public law as an exercise in political statecraft that is not constrained by moral standards, the modern constitutional paradigm directs all

26 The Idea of Public Law, 157.

27 Ibid., 153. 
exercises of political statecraft to the realization of constitutional norms. ${ }^{28}$ When confronted by legal concepts and forms of reasoning that limit and direct the prudential exercise of political power, Loughlin falls back on his claim that the practice of public law is not what it purports to be:

Although public law discourse revolves around a common core of general principlessuch as necessity, rationality, propriety, reasonableness, and proportionality - the application of these principles to specific cases remains indeterminate. This is because public law is not an exercise in moral reasoning built on philosophical premises, but a form of political reasoning driven by prudential considerations. The prudential method makes use of analogical reasoning and the techniques of casuistry to yield decisions rooted in particular circumstances. Although such decisions may subsequently be justified in the generalized forms of constitutional adjudication, these rational forms do not yield the substance of public law decision. ${ }^{29}$

Loughlin's claim that the distinctive legal concepts and forms of reasoning that characterize the practice of public law merely conceal political calculations does not rest on an exploration of the reasoning in pivotal public law cases from a variety of jurisdictions. It rests on his assertion that politics is the sole arbiter of the conflicting social claims that divergent moralities generate. Similarly, when Loughlin considers constitutional rights he acknowledges that they have the potential to transform public law, but he maintains that they too are not what they appear to be. While citizens, lawyers, and judges understand constitutional rights as constraining the government's exercise of public authority with respect to its own members, Loughlin declares that constitutional rights are political claims ${ }^{30}$ that strengthen the power of the state. ${ }^{31}$ To the extent that the modern constitutional paradigm subordinates the exercise of politics to the fulfillment of constitutional norms, it is to be rejected rather than illuminated. The theory that Loughlin offers is alien to the contemporary practice

\footnotetext{
28 Article 1(1) of Germany's Grundgesetz is representative. See The Basic Law for the Federal Republic of Germany (Berlin: German Bundestag, 2001): "Human dignity shall be inviolable. To respect and protect [human dignity] shall be the duty of all state authority."

${ }^{29}$ The Idea of Public Law, 163; 43 and 69 ("constitutional discourse is political, not moral”). See also, Loughlin, Foundations of Public Law, 366.

${ }^{30}$ The Idea of Public Law, 87 and 129.

31 Ibid., 149, 151, and 156; Foundations of Public Law, 12.
} 
of public law, including the discourse that it employs, the reasoning that it invokes, and the aspirations that it seeks to realize.

A fundamental distortion runs through Loughlin's theory. Since the whole of public law is assimilated to the prudential practice of governing, when Loughlin encounters claims of justice, morality, and rights he must treat them as augmenting political power. In doing so, Loughlin's theory of public law effaces a fundamental juridical distinction. The activity of governing concerns the right of rulers to represent the ruled by imposing legal obligations upon them through its lawgiving. In contrast, claims regarding "universal ideals of justice" 32 concern not the right of government and the corresponding duty of persons, but rather the right of persons to just governance and the corresponding duty of government. Loughlin's account of the autonomy of public law culminates in treating all considerations that purport to limit political power as covertly extending its domain. As Loughlin puts the point in relation to "modern constitutional structures", "constraints on power generate power." 33 Not even the distinction between right and duty can survive Loughlin's exposition of public law.

In order to formulate a realistic theory that captures the actual practice of public law, Loughlin banishes all considerations of morality or justice. Since the actual practice of public law appears to involve the interrelationship between authoritative acts of governance, on the one hand, and considerations of justice or morality, on the other, Loughlin's theory bears the same defect as the wholly moralized theories that he rejects: the failure to shed light on the actual practice of public law.

While Loughlin denies that public law is "an exercise in moral reasoning built on philosophical premises," ${ }^{34}$ Ronald Dworkin's interpretive model of law elaborates the opposing position. For

\footnotetext{
32 The Idea of Public Law, 157.

33 Foundations of Public Law, 12.

34 The Idea of Public Law, 163.
} 
Dworkin, "volumes of [moral] philosophy speak in the fall of every judge's gavel." ${ }^{35}$ Dworkin's purpose is to "define and defend a liberal theory of law" that integrates moral reasoning and legal practice by showing that what law is in a particular legal community cannot be understood apart from what it ought to be. ${ }^{36}$ Thus, Dworkin's theory purports to integrate the very components that Loughlin's theory separates: the general practice of law in its historical and comparative dimensions and a liberal conception of morality. In what follows, I explore whether Dworkin's moralized model of law successfully integrates these components into a unified whole or whether it too collapses into a fragmentary account that fails to illuminate the practice of public law in its comparative and historical dimensions.

For Dworkin, law is an interpretive concept that involves the interplay between practice and purpose. $^{37}$ The interpretation of law proceeds through three sequenced stages in which the interpreter observes a practice, reflects on the purposes or values that the practice "can be taken to serve or express or exemplify", ${ }^{38}$ and finally reforms the practice in light of its immanent purpose. In the first stage, the interpreter identifies the subject matter that comprises a practice. ${ }^{39}$ Legal practice is comprised of the "brute facts of legal history" that confront an interpreter situated in a particular place and time. ${ }^{40}$ In the American context, the practice on which Dworkin focuses, these brute facts include the decisions of legal institutions such as legislatures, courts, and administrative agencies, as well as the constitutional text and accepted legal doctrines. ${ }^{41}$ In the second stage, the interpreter ascribes a

\footnotetext{
35 “Law's Ambitions for Itself," Virginia Law Review 71 (1985): 187.

36 Taking Rights Seriously (Cambridge: Harvard University Press, 1978), vii; A Matter of Principle (Cambridge: Harvard University Press, 1985), 4; Law's Empire (Cambridge: Harvard University Press, 1986), 52; "Law's Ambitions for Itself," Virginia Law Review, 175-6; and Freedom's Law: The Moral Reading of the American Constitution (Cambridge: Harvard University Press, 1997), 37-8.

${ }^{37}$ Law's Empire, 52.

${ }^{38} \mathrm{Ibid}$.

${ }^{39}$ Ibid., 66.

${ }^{40}$ Ibid., 255 and 90-1.

${ }^{41}$ Ibid., 91.
} 
value that justifies the general features of the practice identified in the prior stage. ${ }^{42}$ Since the justification must engage the features of the practice that it purports to interpret, the practice itself "constrains the available interpretations of it." 43 Interpretation, as opposed to invention, must fit the general features of the practice that it seeks to illuminate. If the practice admits a plurality of divergent justifications that satisfy the requirement of fit, Dworkin asserts that the interpreter is to affirm the interpretation that casts the coercive practice of law in its best light by showing it "as the best course of statesmanship possible." ${ }^{44}$ In the third and final stage, the interpreter considers how the practice identified in the first stage can be reformed in order to conform more closely to the justification provided in the second. ${ }^{45}$ From the standpoint of the interpretive model, law encompasses "not only the narrow explicit content of [past collective] decisions but also, more broadly, the scheme of principles necessary to justify them."46 Integrity is the virtue of an interpretation that both fits and justifies an existing practice.

Dworkin argues that because the interpretive model involves requirements of both fit and justification, the interpretive model neither reduces law to justice (as in natural law theories) nor to the sum of positive laws (as in legal positivist theories). As Dworkin explains, justice "is a matter of the correct or best theory or moral and political rights", while law "is a matter of which supposed rights supply a justification for using or withholding the collective force of the state because they are included in or implied by actual political decisions of the past."47 Accordingly, Dworkin’s interpretive model can be distinguished from natural law, as he understands it, which fails to fit the contingent body of procedures and decisions that characterize the practice of law within an existing legal system. ${ }^{48}$

\footnotetext{
42 Ibid., 66.

43 Ibid., 52.

44 "Law's Ambitions for Itself," 178. On Dworkin's view that law is a justification of coercion based on past practice, see Law's Empire 93, 97, and 103.

${ }^{45}$ Law's Empire, 66.

46 Ibid., 227 and "Law's Ambitions for Itself," 176.

${ }^{47}$ Law's Empire, 97. See also Freedom's Law: The Moral Reading of the American Constitution, 36-38.

48 Law's Empire, 378, 397, and 404-407.
} 
Whereas Dworkin invokes the requirement of fit to distinguish the interpretive model from natural law, he invokes the requirement of justification to distinguish the interpretive model from legal positivist theories, which reduce the whole of law to the sum of norms that issue from an authoritative exercise of fiat. The interpretive model recognizes that law includes the sum of positive laws enacted and enforced within a particular community, but the interpretive model denies that law is reducible to the sum of positive laws. The interpretive model "distinguishes between the positive law- the law in the books, the law declared in the clear statements of statutes and past court decisions — and the full law, which it takes to be the set of principles of political morality that taken together provide the best interpretation of the positive law."49

Because the interpretive model is a theory of law rather than a theory of justice, ${ }^{50}$ the standard of justification that is appropriate for a particular legal community cannot be determined apart from the practices that inhere within it. Unlike natural law theories that articulate "an abstract and timeless political morality" applicable to legal systems in all times and places, ${ }^{51}$ the interpretive model calls for the adoption of a standard of justification from among the purposes immanent to the legal practice of a particular community. Thus, in discussing American law, Dworkin defends an "interpretation of [American] political culture" by selecting the best standard of justification available from among those that satisfy the requirement of fit. These justificatory standards include Dworkin's conception of integrity, which "provides the best constructive interpretation of the community's legal practice" by upholding the legality of legal propositions that "figure in or follow from the principles of justice, fairness, and procedural due process", ${ }^{52}$ but also other illiberal justificatory standards, such as

\footnotetext{
49 “Law's Ambitions for Itself," 176.

${ }^{50}$ Law's Empire, 97.

51 Ibid., 216.

52 Ibid., 225.
} 
communitarianism and utilitarianism. ${ }^{53}$ Dworkin asserts that other justificatory standards, such as those of Marxism and fascism, are ineligible from the standpoint of the interpretive model because they fail to satisfy the requirement of fit in the American context. ${ }^{54}$ But since the appropriate standard of justification emerges from the interpreter's engagement with the existing practice rather than from some transcendent conception of political morality, Dworkin does not exclude the possibility that illiberal ideologies may serve as the justificatory standards for legal systems with divergent practices.

For Dworkin, what law is in a particular legal system depends in part on what law ought to be. A less welcome feature of his interpretive model is that what law ought to be in a particular legal system depends in part on what law is. When the interpretive model is directed towards a legal community "constructed in the bright morning of liberal thought," 55 in which the positive laws bind public institutions to protect the fundamental rights of all of its members, the elements of the interpretive model are consonant because the existing legal practice sets the stage for a rigorous justification of the coercive practices of the legal community in light of liberal principles. ${ }^{56}$ In the American legal system, as Dworkin interprets it, the appropriate standard of justification is not identical to political morality, but it approximates political morality closely enough to justify the coercive character of legal practice. ${ }^{57}$ But when the interpretive model is deployed in illiberal or even wicked societies, the relevant standard of justification must be drawn from among those principles that fit the existing legal practice. ${ }^{58}$ The application of the interpretive model to such societies poses a dilemma in which Dworkin's model of law and his liberalism pull in opposite directions. Dworkin

\footnotetext{
53 Ibid., 216.

54 Ibid., 408.

55 Freedom's Law: The Moral Reading of the American Constitution, 38.

56 Law's Empire, 216.

${ }^{57}$ Ibid., 404-407 (distinguishing between pure integrity and inclusive integrity). On the failure of the American Constitution to fully embody Dworkin's liberalism, see Freedom's Law: The Moral Reading of the American Constitution, 36-38.

58 As Hart remarked, Dworkin's approach to justification may amount to nothing more than the "least odious of morally unacceptable principles". See Hart, Essays on Bentham: Jurisprudence and Political Theory (Oxford: Oxford University Press, 1982), 151 and Philip Soper, “Dworkin’s Domain," Harvard Law Review 100 (1987): 1167.
} 
responds to the dilemma in two different ways, each of which is fatal to the connection that his interpretive model seeks to establish between law and liberalism.

The first response retains Dworkin's liberal commitments by jettisoning the notion of justification apposite to the interpretive model. In his discussions of wicked legal systems, Dworkin sometimes suggests that interpreters should be guided not by the justificatory standard immanent to the practice, but by the demands of political morality. Suppose that a judge in a wicked legal system recognizes that a serious conflict obtains between the demands of law (as delineated from the standpoint of the interpretive model), on the one hand, and the demands of morality, on the other. In these circumstances, Dworkin concedes that the demands of morality require the judge to forsake the demands of law. Since the judge, in his official role, cannot identify what law demands only to set it aside, Dworkin holds that the judge must lie about what the law demands because "he cannot be of any help unless he is understood as saying, in his official role, that the legal rights are very different from what he believes they are."59 This noble lie enables the judge in a wicked legal system to act in light of liberal norms, but it unravels Dworkin's theory by holding participants not to a standard of justification immanent to the practice of the relevant community, but to the extrinsic standard of political morality. By insisting that participants within a practice act in light of an extrinsic standard, Dworkin indicates his willingness to abandon his own interpretive model when it clashes with his liberal commitments. But once Dworkin denies that justification must fit an existing legal practice, his view becomes an instance of natural law rather than an alternative to it. With this, Dworkin's theory collapses into a mirror image of Loughlin's. Where Loughlin offers a theory of law divorced from conceptions of morality, Dworkin offers a vision of morality divorced from his theory of law.

\footnotetext{
59 Taking Rights Seriously, 326-7 and Law's Empire, 106. What Fuller says about Hart's approach to adjudication in wicked legal systems applies equally to Dworkin. See "Positivism and Fidelity to Law," Harvard Law Review 71 (1958): 655: "Surely moral confusion reaches its height when a court refuses to apply something it admits to be law."
} 
Dworkin offers a further response to the problem of illiberal or wicked legal systems, which is equally fatal to his interpretive model. Whereas the noble lie enabled Dworkin to retain his liberalism by abandoning his interpretive model, a subsequent discussion retains the interpretive model but abandons its supposed liberalism. In discussing whether Nazi Germany was a legal system or a lawless power, Dworkin emphasizes that "[i]nterpretive theories are by their nature addressed to a particular legal culture, generally the culture to which their authors belong. Unless these theories are deeply skeptical, they will treat that legal system as a flourishing example of law, one that calls for and rewards the interpretive attitude." ${ }^{\circ 0}$ Dworkin's point is that because the interpretive model is addressed to a particular legal culture, we need not hold that Nazism would have been either lawful or lawless in all times and places. Thus, Dworkin argues that Nazism could be a legal system from the standpoint of the interpretive community in which it arose, although it could not be a legal system from the standpoint of a more liberal public culture. ${ }^{61}$ The difficulty with this line of argument is that it merely underscores the illiberal core of Dworkin's interpretive model. Recall that, for Dworkin, a justificatory standard must fit the practice that it assesses. If the concrete practices of a particular legal community determine the range of moral standards appropriate to it, then the variability of legal practice inevitably culminates in the variability of moral standards. The more a practice deviates from political morality, the more the interpreter must dilute the justificatory standard by which the adequacy of that practice is to be assessed.

Dworkin might respond that it is not the case that the interpretive model culminates in the justification of all coercive practices. For it remains possible that a coercive practice may be so wicked that it precludes the very possibility of justification: "We might decide that the interpretive attitude is wholly inappropriate there, that the practice, in the shape it has reached, can never provide any

${ }^{60}$ Law's Empire, 102.

${ }^{61}$ Ibid., 103-4. 
justification at all, even a weak one, for state coercion." ${ }^{2}$ Dworkin is, of course, correct, that the interpretive imperative to search for the justification of a coercive practice does not mean that an adequate justification will inevitably be found. However, it is important to emphasize that, given the logic of the interpretive model, whether a justification for a coercive practice is adequate turns not on that justification's conformity to the requirements of some timeless conception of justice or political morality, as in theories of natural law, which Dworkin rejects for introducing a justificatory standard that is extrinsic to the contingent practices of existing legal systems. Rather, an interpretive theory requires a justification that makes sense of the immanent purpose or value at work within the relevant practice. On this view, an illiberal or wicked legal system may be defective from the extrinsic standpoint of political morality, but it is not thereby defective from the immanent standpoint of the interpretive model. With this, Dworkin's theory elides with Loughlin's because both conceive of liberal morality as a transcendent standard for assessing the coercive practices for a particular community. Although Dworkin presents the interpretive model as a liberal theory of law, the interpretive model has no resources for explaining why legal systems are defective on their own internal moral standard to the extent that they fail to realize liberal norms and values.

Dworkin's varied discussions of illiberal or wicked legal systems employ two divergent notions of justification, the notion of justification as immanent to a particular legal practice and the notion of justification as transcendent liberal morality that legitimates coercion and binds persons independently of the contingent features of the particular legal practice in which they find themselves. So long as Dworkin confines his remarks to a liberal legal system, this discrepancy is not apparent because the justificatory standard immanent to the legal practice closely resembles the transcendent liberal one. But the more Dworkin's interpretive model is directed towards the theoretical illumination

\footnotetext{
${ }^{62}$ Ibid., 105. On the tension between Dworkin's interpretive model and his theory of law's authority, see T.R.S. Allan, "Law, Justice, and Integrity: The Paradox of Wicked Laws," Oxford Journal of Legal Studies 29 (2009): 705-728.
} 
of illiberal or even wicked legal systems, the more the legal and the liberal notions of justification come apart leaving Dworkin to uphold his interpretive model of law at the expense of his liberalism or his liberalism at the expense of his interpretive model. The discrepancy between these two notions of justification indicates that Dworkin's interpretive model is not what it purports to be. Dworkin presents the interpretive model as a "liberal theory of law", ${ }^{63}$ but it is either a liberal version of natural law that imposes obligations unrelated to the distinctive practices of particular legal systems or a theory of legal practice that is unconstrained by liberal norms and values. Instead of a liberal theory of law, Dworkin defends a liberalism that is not legal and a theory of law that is not liberal.

Ultimately, the theories that Dworkin and Loughlin advance fail to illuminate the general practice of public law. Loughlin offers his prudential account "as a theory of public law in general" but his deflationary conception of morality leaves him unable to account for the dominant mode in which public law is practiced around the world today. In the proliferation of legal systems committed to the fulfillment of dignity and fundamental rights, Loughlin is confronted by an array of puzzling practices in which the prudential politics that he affirms is circumscribed by the moral considerations that he repudiates. Dworkin's interpretive model raises the opposite problem. Dworkin readily applies the interpretive model to liberal societies committed to fulfilling fundamental rights, but the interpretive and the liberal aspects of his theory come apart when he considers illiberal and wicked legal systems. ${ }^{65}$ Since the practice of public law arises within societies that are liberal and illiberal, just and wicked, a general theory cannot confine itself to some constellation of preferred instances. The inability of these very different theories to account for the general practice of public law can be traced to their common failure to provide an integrated account of the components that lie at the heart of

63 Taking Rights Seriously, vii.

64 The Idea of Public Law, 153.

65 On this point, see David Dyzenhaus, Hard Cases in Wicked Legal Systems: Pathologies of Legality (Oxford: University Press, 2010), 185 (arguing that Dworkin's “theory of the rule of law is contingent on judges' finding themselves in a legal order in which the substantive principles are not badly out of line with liberal morality"). 
public law: authority and justice. Loughlin makes no attempt to reconcile these components, while the reconciliation that Dworkin forges is illusory.

Fuller held that when "we deal with law, not in terms of definitions and authoritative sources, but in terms of problems and functions, we inevitably see that it is compounded of reason and fiat, of order discovered and order imposed, and that to attempt to eliminate either of these aspects of the law is to denature and falsify it." ${ }^{\prime 66}$ After so many attempts to render the practice of public law intelligible by reducing the whole to one of its parts - reason or fiat, justice or authority - my purpose in this project is to begin to formulate and defend a theory that situates each of these aspects within an integrated whole, thereby retaining the distinctiveness of each aspect while illuminating the relationship that obtains between them. Because this framework rejects the fragmentation of competing theories that reduce public law to either the exercise of authority or the norms of justice, I call it the unified theory of public law. My claim is that in articulating an integrated account of the relationship between authority and justice, the unified theory of public law succeeds where its fragmented counterparts fail. The unified theory illuminates the general practice of public law from the legal systems of the ancient world to the inner workings of the modern constitutional state. I explore public law - from its normative structure to its institutional and doctrinal fulfillment in modern constitutional states - in five Chapters.

Chapter One begins with a justification of Loughlin's central assumption, that a ruler (or rulers) has the right to exercise public authority by changing the normative situation of the ruled. Public authority is a perplexing notion because the very possibility of public authority seems to unduly augment the freedom of the ruler and to unduly diminish the freedom of the ruled. If every person has a right to freedom, conceived of as independence from the constraint of another's choice, then each person is his or her own ruler and any theory that divides persons into rulers and ruled stands in

${ }^{66}$ Fuller, "Reason and Fiat in Case Law," 382. 
need of justification. I begin by arguing that the right of government to exercise public authority is justified because private persons must interact with one another on terms of equal freedom but can do so only in a condition in which public institutions exercise authority by establishing, interpreting, and enforcing legal obligations. While public law involves a principle of authority that relates the right of government to rule to the corresponding obligation of the ruled, this principle does not exhaust the public law relationship. The principle of justice requires that government exercise public authority in a manner that conforms to the terms on which that right is justified. Since the right to exercise public authority is premised on the freedom of every person bound by it, all exercises of public authority must be directed towards bringing the existing legal system itself into the deepest possible conformity with the freedom of every person subject to its lawgiving. So conceived, public justice or equal freedom under law is the internal standard of adequacy for a legal system as such.

Together, the principles of authority and justice indicate the rights and duties of the parties to the public law relationship. The principle of authority relates the right of government to the corresponding duty of private persons. The principle of justice traverses the ground between right and duty from the opposite direction by relating the duty of government to the corresponding right of every person who is bound by public authority to just governance. Within the unified theory, these juridical principles are not antithetical virtues of opposing theoretical frameworks but mutually implicating norms. Public authority over independent persons does not exist in the absence of a duty to govern justly. Public justice cannot be realized in the absence of publicly authoritative institutions.

Such a juridical framework marks a fundamental departure from those of both Loughlin and Dworkin. While Loughlin holds that public law "must be conceived of as an assemblage of rules, principles, canons, maxims, customs, usages, and manners that condition and sustain the activity of governing", ${ }^{67}$ the unified theory holds that public law involves two distinct but mutually implicating

${ }^{67}$ The Idea of Public Law, 30. 
principles that emerge from a systematic elaboration of the juridical conditions in which a plurality of independent persons can interact in accordance with the independence of each. Together, these principles establish that the right of government to exercise public authority must always be directed towards public justice or the realization of equal freedom under law. The unified theory departs from Dworkin's interpretive model for the same reason. In affirming that the right to exercise public authority is always accompanied by a duty to govern in accordance with the terms on which that right is justified, the unified theory of public law offers what Dworkin's theory lacks, a rigorous liberal standard of justification that is internal to every legal system as such.

In Chapters Two and Three, I elaborate on the normative structure of public law by considering a pair of enduring problems in legal and political philosophy.

Chapter Two explores the distinction between a legal system and a condition of lawless violence. While Loughlin notes that "political power must be distinguished from violence or coercion" ${ }^{68}$ and Dworkin distinguishes law from "ordered brutality", ${ }^{69}$ neither theorist provides a workable account of the distinction. Loughlin suggests that governance involves a legitimate form of domination, but once Loughlin excludes considerations of morality from public law, it is not clear what remains to legitimate the state's coercive power. In turn, Dworkin conceives of 'ordered brutality' as consisting in the denial of basic rights that constrain majority rule. But Dworkin cannot intend the protection of basic rights to serve as the distinguishing mark of legality in all times and places because Dworkin's interpretive model recognizes the legality of societies in which the majority lacks the right to govern and in which basic rights are neither recognized nor protected. ${ }^{70}$ In this Chapter I begin by noting some of the difficulties that various German theorists, in the aftermath of Nazism, encountered in forging a distinction between legal authority and organized violence. I then

\footnotetext{
68 The Idea of Public Law, 159 and 77.

${ }^{69}$ Dworkin, Taking Rights Seriously, 205.

70 See, for example, 102 and 107.
} 
attempt to formulate the distinction from the standpoint of the unified theory of public law. Within this theory, the concept of a legal order involves the exercise of coercive power, but it is not reducible to it. Rather, a valid legal order is a condition in which public legislative, executive, and judicial institutions make it possible for private persons to enjoy their freedom in relation to one another by securing each from the arbitrary power of every other. It follows that when force is exercised in such a way that one or more persons cannot enjoy freedom in relation to others, that force cannot be lawful. I elaborate on how private persons can distinguish between a lawful public authority, which all must obey, and the mere exercise of violence, which all may resist. I then apply this framework to the concrete circumstances of Nazi power and argue that, from the standpoint of public law, the problem with Nazism was not that it was an unjust legal order, but rather that it was not a legal order at all. Nazism cast off every legal norm and procedure that secured the independence of private persons in relation to one another until violence was the only aspect of law that remained, which is to say that there was no law at all.

Chapter Three takes up a series of theoretical problems surrounding the reform of existing societies or legal systems, which are, to varying extents, mired in injustice. A central feature of contemporary political and legal philosophy is its rejection of earlier approaches that sought to illuminate either the theoretical basis of an existing society or the nature of a perfectly just society. The aspiration of contemporary theories is to articulate a framework for thinking about the progressive transformation of the actual societies in which we live into the increasingly just societies we seek to realize. In this chapter I attempt to articulate the structure that a theory must have in order to satisfy this progressive ambition. I then note that the leading theories in political and legal philosophy whether John Rawls's theory of justice as fairness or H.L.A. Hart's legal positivism - do not possess the requisite structure for illuminating the progressive development of existing societies. Once the tension between the structure of these theories and the progressive aspiration that they share is 
evident, I explain how the unified theory of public law instantiates the structure that any progressive theory must bear. I close by explaining why legal systems that share a common ideal of public justice need not enact laws and create institutional arrangements that are identical.

Chapters Four and Five address the relationship between the normative structure of public law, as articulated in the prior chapters, and the distinctive postwar practice of public law taking shape in modern constitutional states around the world.

In Chapter Four I argue that modern constitutionalism is a legal and institutional response to a problem latent in the normative structure of public law. In all precursors to the modern constitutional state, all persons subject to public authority have a right to just governance, but government can nevertheless violate this right with impunity. Such legal systems do not necessarily exercise public authority unjustly, but they necessarily leave one of more persons entitled to just governance susceptible to the unjust exercise of public authority. The modern constitutional project consists in the creation, maintenance, and refinement of legal systems that transform the right of every person to just governance from a mere moral duty that accompanies the exercise of all public authority into a legal reality. This transformation is effected by creating the constitutional, institutional, and doctrinal conditions in which any person who believes that his or her right to just governance has been violated may hold government to account. In such a legal order, just governance is a justiciable condition for the valid exercise of all public power. Modern constitutionalism is neither a pretense that obscures the unconstrained practice of power politics, as Loughlin alleges, nor is it merely the replication of the eighteenth century American experiment in self-government, as Dworkin claims and Loughlin echoes. ${ }^{71}$ Instead, modern constitutionalism is what it purports to be: the most sophisticated regime of public law yet designed to enable each and every person subject to public authority to

\footnotetext{
${ }^{71}$ Dworkin, Freedom's Law: The Moral Reading of the American Constitution, 6 and Loughlin, Foundations of Public Law, 358.
} 
constrain its exercise to the terms of its justification. ${ }^{72}$ By illuminating the problem in public law to which modern constitutional law responds, the unified theory provides a theoretical standpoint for grasping why the transition to modern constitutionalism is necessary and what is necessary within a modern constitutional state.

Chapter Five presents a theory of proportionality, the leading doctrine of constitutional rights adjudication in modern constitutional states around the world. It is striking that even as proportionality is adopted by an ever-growing body of constitutional states, neither Loughlin nor Dworkin give it much thought. Loughlin dismisses proportionality with the assertions that "[r]ights adjudication is intrinsically political" 73 and that proportionality merely "imposes a structural discipline over what are essentially pragmatic judicial methods of resolving constitutional rights questions." ${ }^{74}$ Dworkin maintains that because rights are trumps that enjoy priority over considerations of collective benefit pertaining to convenience or expediency, rights are not taken seriously when they are limited for the sake of realizing those considerations. ${ }^{75}$ What Dworkin and his followers overlook is that proportionality is a doctrine that recognizes the priority of rights over considerations of collective benefit, while articulating the duty of government in cases in which constitutional rights conflict with obligatory purposes integral to the perpetuation and refinement of a rights protecting state. Thus the doctrine of proportionality admits the possibility of limiting a constitutional right only in cases in which there is a genuine conflict between competing constitutional commitments or, in Dworkin's terms, in cases in which a trump can be found on each side of the dispute. I begin by explaining why constitutional conflicts arise so frequently in modern constitutional states. I then present the various steps that jointly comprise proportionality analysis as a doctrinal distillation of what public justice

\footnotetext{
72 I focus on modern constitutional law because it provides an overarching account of the normative relationship between the individual and public authority - whether legislative, executive, or judicial. Such an account provides the normative setting for considering other branches of public law, including administrative and criminal law.

${ }^{73}$ Loughlin, The Idea of Public Law, 129.

${ }^{74}$ Loughlin, Foundations of Public Law, 366.

${ }^{75}$ Dworkin, Taking Rights Seriously, 197-8.
} 
requires in cases of constitutional conflict. By employing proportionality analysis, constitutional states distinguish between those cases in which the duty to govern justly requires that a constitutional right be upheld from those in which that same duty justifies the limitation of a constitutional right through law. Proportionality takes rights seriously by determining their limits in accordance with the purposes that underlie their elevated status in a modern constitutional state.

The central purpose of this project is to begin to articulate and defend a unified theory that illuminates the general practice of public law. To make sense of the general practice of public law, one must recognize the legal personality of its participants, develop this conception of legal personality into an integrated justification of public authority and public justice, indicate the implications of public authority and public justice for the rights and duties of the parties to the public law relationship, and specify the institutional and doctrinal framework in which those rights and duties are jointly fulfilled. Of course, a unified theory of public law should not be confused with an exhaustive theory that canvasses every theoretical problem that arises within public law. My hope is that the unified theory provides the standpoint from which more fine-grained problems can be productively explored. ${ }^{76}$

The unified theory of public law lies emerges from an interpretation and extension of Immanuel Kant's mature theory of public right. For many, Kant's thought will seem an unsuitable inspiration for a theory of public law that seeks to give both notions of public authority and public justice their due. After all, Kant is typically interpreted as either a conservative defender of the status quo who dismisses the demands of justice when they fail to conform to the positive law ${ }^{77}$ or a utopian liberal who dismisses positive law when it fails to conform to the demands of justice. ${ }^{78}$ Neither interpretation considers the integrative possibility that Kant's theory of public right justifies the

\footnotetext{
${ }^{76}$ On the role of theory as providing "a framework of thought" for the further consideration of questions that arise within it, see John Rawls, Justice as Fairness, 12.

77 Robert Alexy, The Argument From Injustice: A Reply to Legal Positivism, trans. Bonnie Litschewski Paulson and Stanley L. Paulson (Oxford: Clarendon Press, 2002), 116-121; “On the Concept and Nature of Law," Ratio Juris 21 (2008): $288-290$.

${ }^{78}$ Jürgen Habermas, Between Facts and Norms: Contributions of a Discourse Theory of Law and Democracy, trans. by William Rehg (Cambridge: MIT Press, 1999), 120-1.
} 
authority of existing states over their members, elucidates the nature of a just state, and expounds the ongoing duty of government to bring itself into the deepest possible conformity with public justice. Since the central purpose of the present project is to provide a philosophic exposition of public law, I formulate Kant's striking insights into public law in abstraction from the challenging texts and terminology through which he expressed them.

In the fourth and fifth Chapters, I attempt to extend Kant's thought by offering it as a theoretical basis for the legal, institutional, and doctrinal features of the modern constitutional state. While Kant did not discover modern constitutionalism, I believe that his thought elucidates the relationship between authority and justice that the modern constitutional state strives to realize. Perhaps Kant would be receptive to this proposal. In his Preface to the Doctrine of Right, Kant emphasizes the somewhat provisional character of his theory of public right:

Toward the end of the book I have worked less thoroughly over certain sections than might be expected in comparison with the earlier ones, partly because it seems to me that they can be easily inferred from the earlier ones and partly, too, because the later sections (dealing with public right) are currently subject to so much discussion, and still so important, that they can well justify postponing a decisive judgment for some time. $^{79}$

One of the reasons that Kant presents for failing to fully develop his theory of public right is that the discussions in his day had not reached a decisive conclusion. The meaning of such a comment might be evident if uttered by another philosopher, but coming from Kant it is puzzling. The Doctrine of Right appears in a work entitled The Metaphysics of Morals, and concerns the a priori norms governing the external interaction of purposive beings. How could the elaboration of a system of a priori norms be hindered by the discussions that were occurring in Kant's day (or any other)? I suspect that the answer lies in the distinction between the normative domain of right and the empirical domain of political

\footnotetext{
79 Doctrine of Right in Practical Philosophy, trans. Mary J. Gregor (Cambridge: Cambridge University Press, 1996), 6:209. This page reference refers to the pagination of the Prussian Academy.
} 
knowledge. Kant takes himself to have provided an exhaustive account of the norms that animate the juridical domain of public right, but seems aware of his own inability to present the legal, institutional, and doctrinal conditions in which these norms would be most adequately realized. As I argue in Chapter Four, the norms of public right are most deeply fulfilled in the modern constitutional state. In this setting, the right of every person to public justice is transformed from a mere moral ideal into a legal reality. Each person subject to the authority of law has a justiciable right to insist that its exercise conform to the terms of its own justification. In Kant's day, ideas of human rights had begun to percolate into public consciousness, but the modern constitutional paradigm was not yet evident. It emerged following the indignities of the Second World War when peoples finally began to confront the challenge of designing legal systems in which the requirements of justice formed an effective constraint on the coercive exercise of public authority. While Kant had no knowledge of these future developments, his general theory of public right provides a powerful framework for illuminating their groundbreaking significance. 


\section{CHAPTER 1: \\ BETWEEN ANARCHISM AND QUIETISM}

n "Positivism and the Separation of Law and Morals," H.L.A. Hart advanced three enduring
theses about the relationship between law and morality.

The first is that an adequate theory of law steers a middle course between anarchism and quietism. ${ }^{1}$ Anarchism is the view that what is unjust cannot impose legal obligations. Quietism is the view that what imposes legal obligations cannot be unjust. Neither the anarchist nor the quietist can endorse Bentham's "motto of a good citizen" under "a government of laws": "To obey punctually; to censure freely."2 For the anarchist, the criticism of a legal system's adequacy leaves nothing to obey. For the quietist, the duty to obey a legal system excludes the possibility of criticizing its adequacy. Thus, from their diverging outlooks, anarchists and quietists both deny the truism that a legal system might be unjust. The disagreement between anarchists and quietists is confined to the issue of whether the absence of justice indicates the absence of legality or whether the presence of legality indicates the presence of justice.

The second thesis is that legal positivism avoids the twin pitfalls of anarchism and quietism by separating the question of whether something is legally valid from the question of whether it is just:

What both Bentham and Austin were anxious to assert were the following two simple things: first, in the absence of an expressed constitutional or legal provision, it could not follow from the mere fact that a rule violated standards of morality that it was not a rule of law; and, conversely, it could not follow from the mere fact that a rule was morally desirable that it was a rule of law. ${ }^{3}$

By distinguishing the question of whether something is a law from the question of whether it is just, legal positivism jointly rejects anarchism and quietism. Anarchism is rejected because justice is not

\footnotetext{
${ }^{1}$ Hart, "Positivism and the Separation of Law and Morals," Harvard Law Review 71 (1958): 597-8.

2 Bentham, A Fragment on Government (Cambridge: Cambridge University Press, 2001), 10.

${ }^{3}$ Hart, "Positivism and the Separation of Law and Morals," 599.
} 
the standard of legal validity. Quietism is rejected because legal validity is not the standard of justice. ${ }^{4}$ The separation thesis is the key to the progressive orientation to which legal positivism aspires. The distinction between law and morals enables positivist reformers to recognize the injustice of existing laws and to seek the enactment of better ones.

The third thesis is that nonpositivist theories of law inevitably collapse into anarchism or quietism. ${ }^{5}$ Since positivism is premised on the separation of law and morals, its proponents invariably suppose that nonpositivism must be premised on their unity. On this view, whether one is an anarchist or a quietist depends on whether one assimilates law to morality or morality to law. The anarchist bends the concept of law to fit the concept of justice, while the quietist bends the concept of justice to fit the concept of law. The claim that nonpositivist theories are either anarchist or quietist extends through the positivist corpus from the works of Bentham to the present day. As Hart notes, Bentham attributed to Blackstone the anarchic view that human laws were invalid if they conflicted with divine laws and an "obsequious quietism" that fails to admit a distinction between what the law is and what it ought to be. ${ }^{6}$ Similarly, Kelsen argued that nonpositivist theories were either revolutionary or conservative. In its revolutionary guise, which Kelsen attributed to Locke, nonpositivism calls "into question the validity of the positive law by claiming that the positive law contradicts some presupposed absolute order." In In conservative guise, which Kelsen ascribed to Kant, nonpositivism shows "that the positive law is simply the emanation of a natural or divine order or of a system of reason-the emanation of an absolutely 'right', just order." With these one-sided accounts of nonpositivism in

\footnotetext{
4 Ibid., 598.

${ }^{5}$ Ibid., 597-8.

${ }^{6}$ Ibid., 598.

${ }^{7}$ Kelsen, An Introduction to the Problems of Legal Theory, trans. Bonnie Litschewski Paulson and Stanley L. Paulson (Oxford: Oxford University Press, 1997), 18. See also Kelsen, “The Natural-Law Doctrine before the Tribunal of Science,” Western Political Science Quarterly 2 (1949): 493.

${ }^{8}$ Kelsen, An Introduction to the Problems of Legal Theory, 18 and"The Natural-Law Doctrine before the Tribunal of Science," 493.
} 
hand, positivists dismiss nonpositivist theories as blind to a fundamental aspect of law's nature. Since nonpositivist theories are either anarchist or quietist, and each of these frameworks denies the truism that a valid system of law may be unjust, positivists conclude that nonpositivist theories cannot account for a fundamental aspect of law's nature. The objection continues to be raised by positivists today. ${ }^{9}$

In this chapter, I accept Hart's first thesis denying the adequacy of both anarchism and quietism, but reject both his second and third. I start with the second thesis by considering whether Hart's version of legal positivism succeeds in steering a middle path between the twin pitfalls of anarchism and quietism. I argue that Hart's positivism offers an explanation of how certain persons in a legal system could perceive themselves to be under obligations with respect to enacted laws, but does not explain how a legal system could actually have the authority to impose obligations on persons. In the absence of such an account, Hart's theory collapses into the very anarchism that led him to reject the theories of his predecessors in both the positivist and nonpositivist camps. I then turn to consider Hart's third thesis that nonpositivist theories of law inevitably collapse into anarchism or quietism. The central purpose of this chapter is to provide a sketch of a nonpositivist legal theory, the unified theory of public law, which provides an alternative to anarchist and quietist paradigms by formulating an integrated justification of two distinctive aspects of legal systems generally, public authority and public justice. My claim is that by reconceptualising the relationship between public authority and public justice, the unified theory is able to reject the positivist separation of law and

\footnotetext{
${ }^{9}$ See, for example, Jules L. Coleman and Brian Leiter, "Legal Positivism," in A Companion to Philosophy of Law and Legal Theory, ed. Dennis Patterson (Oxford: Blackwell Publishing, 1999), 230-1; Scott Shapiro, Legality (Cambridge: Harvard University Press, 2010), 49: "By insisting on grounding legal authority in moral authority or moral norms, natural law theory rules out the possibility of evil legal systems....Just as theologians have struggled to explain how evil is possible given the necessary goodness of God, the natural lawyer must account for the possibility of evil legal systems given that the law is necessarily grounded in moral facts." For an account of the criticism from the nonpositivist camp, see David Dyzenhaus, Hard Cases in Wicked Legal Systems: Pathologies of Legality (Oxford: Oxford University Press, 2010$), 283$ (explaining that positivists take wicked legal systems to be a decisive counterexample to the nonpositivist claim that there is a necessary connection between law and morality).
} 
morals while avoiding the collapse into anarchism or quietism. If my argument is correct, then Hart gets things backwards. Hart's positivism collapses into the very anarchy that he derides, while the nonpositivist paradigm offers the middle path that he sought.

I present my argument in four sections. In the first section, I explain why Hart fails to steer a middle course between anarchism and quietism. The remaining sections unpack the unified theory of public law by elaborating a conceptually sequenced account of the right of persons to interact with others on terms of equal freedom. In the second section, I sketch a justification of the principle of authority, which relates the right of government to impose, interpret, and enforce valid legal obligations to the corresponding duty of private persons to obey public lawgiving. I then argue, in the third section, that the justification of the right of government to exercise public authority implicates a distinctive moral standard for assessing the adequacy of existing legal systems and directing their reform. The principle of justice relates the right of persons to just governance to the corresponding duty of government to exercise its authority justly. The distinguishing feature of the unified theory is its claim that when authority and justice are appropriately conceived, they are neither antithetical virtues of opposing theoretical frameworks nor isolated notions. Instead, authority and justice are the mutually implicating constitutive and regulative aspects of the public law relationship between rulers and ruled. The right of rulers to exercise public authority is always accompanied by a duty to govern justly, while the right of the ruled to just governance presupposes the presence of publicly authoritative institutions. In the fourth section, I defend the unified theory from an objection raised by generations of legal positivists from Bentham to the present day, which claims that any theory that appeals to moral concepts to elucidate the concept of law must inevitably fail to recognize a legal truism: a particular law or a legal system might be valid even though it is unjust. I argue that the unified theory is not vulnerable to this objection because in articulating what a legal system is, it provides resources for thinking about what makes a particular law or a legal system as a whole just. The justification of the 
right to exercise public authority implicates the relevant moral standard for assessing the adequacy of its instances.

Although I present the unified theory as a nonpositivist view, I do not deny positivism's core theses that positive law must be enacted by an appropriate public institution in order to be valid or that positive law is neither validated by its justice nor invalidated by its injustice. ${ }^{10}$ As I argue below, such a platitude is compatible with both positivist and nonpositivist theories. The central dispute between positivists and nonpositivists lies elsewhere.

\section{HART'S MidDLE PATH}

The problem of legal obligation traverses Hart's thought from the criticism of his positivist and nonpositivist predecessors to his own innovative contributions. On the one hand, Hart seeks to distinguish his own view from Austin's command theory by introducing legal obligation into the positivist framework. On the other, Hart seeks to provide an alternative to nonpositivist theories by differentiating notions of legal and moral obligation. In this section, I consider Hart's conception of legal obligation in the context of his criticism of competing theories. My claim is that the conception of legal obligation that Hart formulates is too thin to overcome the central problem that animates his project, the problem of steering a middle path between anarchism and quietism.

Hart dismissed Austin's legal positivism because it lacked the resources to distinguish between the coercive power of a legal system and the violence of an outlaw. For Austin, law is the command of a legally unconstrained sovereign. A command is an expression of a desire that another commit or forego a certain action, coupled with a threat to be imposed in the event of non-compliance. ${ }^{11}$ The violation of a threat is likely to result in a sanction. ${ }^{12}$ A command is issued by a sovereign, that is, an agent

\footnotetext{
10 See, for example, John Gardner, "Legal Positivism: 51ㄹ Myths," The American Journal of Jurisprudence 46 (2001): $200-1$.

${ }^{11}$ John Austin, Lectures on Jurisprudence (New York: Henry Holt and Company, 1875), 13.

12 Ibid., 12.
} 
that is habitually obeyed by others but that does not habitually obey others. ${ }^{13}$ The issuance of a command is correlative to a duty or obligation, which consists in being liable to an evil for failing to comply with a command. Whenever a command is issued, an obligation is present; whenever an obligation is present, a command has been issued. ${ }^{14}$ The affinity between Austin's account of a legal system and naked violence led Hart to remark:

The situation which the simple trilogy of command, sanction, and sovereign avails to describe, if you take these notions at all precisely, is like that of a gunman saying to his victim, 'Give me your money or your life.' The only difference is that in the case of a legal system the gunman says it to a large number of people who are accustomed to the racket and habitually surrender to it. Law surely is not the gunman situation writ large, and legal order is surely not to be thus simply identified with compulsion. ${ }^{15}$

When subjected to the whims of a gunman, a victim who is eager to secure his life may readily surrender his money. Prudence may even oblige the victim to comply with the gunman's wish, but, as Hart notes, the victim has no obligation to comply. ${ }^{16}$ Austin fails to distinguish the lawgiving of the sovereign from the violence of the gunman because he lacks an account of how one person, the sovereign, could have the public authority to impose a legal obligation on another. In the absence of such an account, the coercive power of a legal order doubles as a description of mere violence.

Whereas Hart's positivist predecessors lacked an account of legal obligation, Hart's nonpositivist predecessors failed to draw a distinction between legal obligations and moral ones. The failure to distinguish between legal and moral obligation culminated in two kinds of intellectual confusion, quietism and anarchism. ${ }^{17}$ Some nonpositivist theories collapsed into quietism by holding that any norm that was legally obligatory was also morally obligatory and thereby precluded the

\footnotetext{
13 Ibid., 82.

14 Austin, The Province of Jurisprudence Determined (London: John Murray, 1832), 7.

${ }^{15}$ Hart, "Positivism and the Separation of Law and Morals," 603. Of course, Hart raised other criticisms against Austin's view, which I do not consider here.

${ }^{16}$ Hart, The Concept of Law (Oxford: Clarendon Press, 1961), 6-7 and 80-1. See also Hart, "Legal and Moral Obligation," in Essays in Moral Philosophy, ed. A.I. Melden (Seattle: University of Washington Press, 1958), 89-91 and 95-99.

${ }^{17}$ Hart, "Positivism and the Separation of Law and Morals," 597-8.
} 
possibility of criticizing valid law. Other nonpositivist theories collapsed into anarchism by holding that if a norm was not morally obligatory, it could not be legally obligatory. The problem with anarchism is not that the principled anarchists always break the law, but that they always act in accordance with their own understanding of what morality requires. If positive law is not present, then they act in accordance with their moral obligations. If positive law is present, then it may conform to or deviate from the requirements of morality. Positive law that conforms to what morality requires is superfluous because one is already under a moral obligation to do what it enjoins. Alternately, positive law that deviates from what morality requires is reprehensible and should not be obeyed. Having rejected these approaches, Hart's aim was to formulate a theory of law that avoided the confusions of anarchism and quietism. But as Hobbes once observed, "beset with those that contend, on one side for too great liberty, and on the other side for too much authority, 'tis hard to pass between the points of both unwounded."18 Hart believed that the key to passing between these points lay in maintaining what anarchists and quietists both denied, that a valid legal norm might depart from what morality requires. Thus, Hart set out to formulate an innovative account of legal obligation that was not reducible to the idea of moral obligation.

The basis of Hart's theory lies in a bifurcated account of rules and the perspectives that public officials and private persons adopt towards them. Law is the union of primary and secondary rules. Primary rules establish standards of behaviour that impose legal obligations requiring human beings to commit or omit certain actions. ${ }^{19}$ How does a primary rule acquire the authority to impose legal obligations? Hart's answer lies in his account of secondary rules, which, in addition to conferring the power to change primary rules and adjudicate disputes, establish the conditions of the validity of primary rules. The rule of recognition provides persons within a society, whether private citizens or

\footnotetext{
${ }^{18}$ Leviathan, ed. Edwin Curley (Indianapolis: Hackett Publishing, 1994), 1.

${ }^{19}$ Hart, On the Concept of Law, 80-81.
} 
public officials, with "authoritative criteria for identifying primary rules of obligation". ${ }^{20}$ Primary rules are valid because the mode of their enactment conforms to the criteria specified by the rule of recognition. As the foundational rule of a legal system, the rule of recognition cannot be validated by a more fundamental rule. Rather, the rule of recognition exists as a social fact demonstrated in the convergent practice of "courts, officials, and private persons in identifying the law by reference to a certain criteria." 21 The criteria specified by the rule of recognition are binding simply because they are accepted as establishing a standard of behaviour that is obligatory. Those who accept that a rule establishes an obligatory standard of behaviour adopt, what Hart terms, the internal point of view towards a rule. From the perspective of those who take the internal point of view towards a rule, the violation of that rule is "not merely a basis for the prediction that a hostile reaction will follow but a reason for hostility."22

On Hart's account of legal obligation, officials deem the primary rules enacted in accordance with the rule of recognition to be obligatory because they adopt the internal perspective towards the rule of recognition. In a legal system, officials act as though legal enactments emerging from a convergent social practice are obligatory because they believe those enactments to be obligatory. In turn, private citizens too might adopt the internal perspective towards the same social practice and thus deem themselves to be under obligation with respect to the primary rules that issue from it.

When Hart discusses the rule of recognition, he sometimes suggests that both public officials and private citizens adopt the internal point of view towards it. ${ }^{23}$ But Hart is clear that from a descriptive standpoint, the existence of a legal system entails only that officials accept the rule of recognition. Hart explains that there are

\footnotetext{
${ }^{20}$ Ibid., 97.

21 Ibid., 107.

22 Ibid., 88.

${ }^{23}$ Ibid., 97, 107, and 110.
} 
two minimum conditions necessary and sufficient for the existence of a legal system. On the one hand those rules of behaviour which are valid according to the system's ultimate criteria of validity must be generally obeyed, and, on the other hand, its rules of recognition specifying the criteria of legal validity and its rules of change and adjudication must be effectively accepted as common public standards of official behaviour by its officials. The first condition is the only one which private citizens need satisfy: they may obey each 'for his part only' and from any motive whatever...The second condition must also be satisfied by the officials of the system. They must regard these as common standards of official behaviour and appraise critically their own and each other's deviations as lapses. ${ }^{24}$

The two minimum conditions of a legal system are that private citizens generally obey primary rules (even if motivated entirely by fear) and that officials adopt the internal perspective towards the rule of recognition and the primary rules that issue from it. ${ }^{25}$ In a legal system, it is not the case that private citizens must accept that primary rules establish legally obligatory standards of behaviour. However, a condition in which primary rules are not generally obeyed by private citizens is not a legal system.

The possibility that officials alone will perceive legal norms as imposing legal obligations prompts Hart to remark:

In an extreme case the internal point of view with its characteristic normative use of language ('This is a valid rule') might be confined to the official world. In this more complex system, only officials might accept and use the system's criteria of legal validity. The society in which this was so might be deplorably sheeplike; the sheep might end in the slaughter-house. But there is little reason for thinking that it could not exist or for denying it the title of a legal system. ${ }^{26}$

That the internal point of view may be confined to the official world indicates a fundamental feature of Hart's account. Hart does not seek to justify how it is possible for public officials to have public authority, that is, a right to change the normative situation of private citizens by, for example, imposing

\footnotetext{
${ }^{24}$ Ibid., 113.

25 On the function of the internal point of view in Hart's legal theory, see Coleman and Leiter, "Legal Positivism," 247; Scott J. Shapiro, "What is the Internal Point of View?" Fordham Law Review 75 (2006): 1165-7; and Benjamin C. Zipursky, "Legal Obligations and the Internal Aspect of Rules," Fordham Law Review 75 (2006): 1241.

${ }^{26}$ Hart, On the Concept of Law, 114 (my emphasis).
} 
coercible obligations upon them. Rather, Hart seeks to describe the disposition of public officials towards their own activities. In a legal system, officials believe both that primary rules validated by the rule of recognition impose obligations on private persons and that the violation of a primary rule is a justification for a coercive response.

Hart's innovation consists in introducing a structured normativity into legal positivism. While Austin conceived of law in terms of specific commands issued by a superior power, Hart conceived of law in terms of general rules that officials regard to be obligatory and bring to bear on particulars. From the standpoint of the public officials of a legal system, Hart's account marks a fundamental departure from Austin's because it incorporates what Austin's excludes: an explication of the role that general and obligatory rules play in the thoughts and actions of officials. But from the standpoint of private citizens, Hart's normative innovation presents a trivial departure from Austin's. The objection that Hart raises against Austin is that a threat backed by force might compel performance, but it imposes no obligation on another. The question that Hart's own account raises is why a private citizen confronted by a public official who adopts the internal point of view towards a threat is any different. Surely the deficiency of Austin's framework is not that the gunman (or his entourage) fails to adopt the appropriate disposition toward his own threats, but that it is not clear how the unilateral imposition of threats can impose an obligation on another. Hart's fails to address this problem. No matter how many officials believe a rule to be obligatory and to justify coercion - and no matter how fervent their beliefs - private persons are not thereby placed under an obligation rather than merely compelled or obliged. In the absence of an account of how one person can have the authority to impose and enforce legal obligations on others, Hart's account fails to escape from the coercive shadow cast by Austin's 
framework. A gunman who believes that he is acting in accordance with a general and obligatory rule is still a gunman. ${ }^{27}$

Hart's account culminates in a defect that prompted his rejection of nonpositivist theories. Since positivists maintain that considerations of legal validity are independent of considerations of justice, they are sometimes accused of quietism, that is, of holding that valid law is not subject to moral criticism. This accusation must be mistaken, although not for the reason that positivists claim. ${ }^{28}$ The problem of quietism is that a law is presumed to be just simply because it is obligation imposing. Hart, however, never explains how laws can impose an obligation. In the absence of such an account, what is obligatory is not the primary rules to which officials adopt the internal perspective, but moral norms that are obligatory apart from the dispositions that persons have towards them. Thus, when Hart discusses wicked legal systems, in which supposed legal obligations come into conflict with moral obligations, Hart insists that public officials should consult morality to determine whether a valid law should be applied ${ }^{29}$ and private citizens should consult morality to determine whether a valid law should be followed..$^{30}$ Whether one is a public official or a private citizen, the question of how one should act in relation to a valid law is a moral question. Similarly, when positive law is absent (perhaps because a legal system does not exist or because the existing legal system contains a gap), persons must act in conformity with the dictates of morality. Whether positive law is present or absent, just or

\footnotetext{
${ }^{27}$ On this point, see Kenneth Einar Himma, "Positivism and the Problem of Explaining Legal Obligation," American Philosophical Association Newsletter 5 (2006): 17.

${ }^{28}$ For responses to this criticism from within the positivist camp, see John Gardner, "Legal Positivism: 51/2 Myths," 209210 and Brian Leiter, "The Radicalism of Legal Positivism," Guild Practitioner, 2010; U of Chicago, Public Law Working Paper No. 303. Available at SSRN: http://ssrn.com/abstract=1568333.

${ }^{29}$ Hart, "Positivism and the Separation of Law and Morals," 617-8.

${ }^{30}$ Hart, On the Concept of Law, 206: "What surely is most needed in order to make men clear-sighted in confronting the official abuse of power, is that they should preserve the sense that the certification of something as legally valid is not conclusive of the question of obedience, and that, however great the aura of majesty or authority which the official system may have, its demands must in the end be submitted to moral scrutiny."
} 
unjust, everyone is under an obligation to do what morality requires in their own eyes. Surely this is not the concept of law but a vision of anarchy. ${ }^{31}$

Legal positivism stems from the insight that law often commands what morality forbids. Accordingly, Hart attempted to provide an account of legal obligation that was wholly independent of moral considerations. In place of an account of how legal systems could have the right to impose and enforce obligations on private persons, Hart instead offered an account in which officials perceived rules to impose legal obligations. The difference between an obligatory rule and a rule that some perceive to be obligatory is critical. In the absence of an account of how it is possible for a legal system to impose legal obligations on its members, Hart's framework resurrects the very difficulties that he discerned in his positivist and nonpositivist predecessors. If we wish to overcome this difficulty, we must explain not how law could be perceived to impose obligations, but how it could actually do so. To overcome the specter of anarchy, what is required is not a theory of de facto authority, but a theory of de jure authority.

\section{The PRINCIPLE OF AUthority}

Public authority is a troubling idea. It is the idea that the ruler (or rulers) of a legal system has the right to change the normative situation of the ruled by conferring rights, powers, or immunities,

\footnotetext{
31 On this point, see Hart, "Legal and Moral Obligation," 104: "The recognition of an obligation to obey the law must as a minimum imply that there is at least some area of conduct regulated by law in which we are not free to judge the moral merits of particular laws and to make our obedience conditional on this judgment."

Since the positivist holds that the obligation to obey law does not follow from the validity of law, when Raz reflects on whether there is a general obligation to obey the law, he looks beyond law to various moral and prudential grounds that might generate such a duty. The grounds that Raz considers furnish conclusions that are too narrow to ground a general obligation to obey the law. For Raz, as for Hart, whether one should act in conformity with a particular law does not hinge on its legal validity, but on the moral and prudential reasons that persons have to commit or forego a certain action. See The Authority of Law (New York: Oxford University Press, 2009), 233-249. The same holds for Raz's account of social coordination problems. Social coordination problems are undesirable for moral or prudential reasons. The government's solution to a social coordination problem does not change the obligations that are incumbent on private persons but rather changes the context in which private persons act pursuant to the moral and prudential reasons that obtain independently of the legal system. Law is not obligatory, although it may facilitate (or frustrate) the pursuit of ends that are independently obligatory. See Authority, ed. Joseph Raz (New York: New York University Press, 1990), 1-19.
} 
or - more problematically still - by imposing coercible obligations. ${ }^{32}$ The reason that public authority is a troubling idea is that it seems to unduly augment the freedom of the ruler and to correspondingly diminish the freedom of the ruled. The very notion of public authority, apart from how it is exercised in particular instances, seems to conflict with our considered conviction that each person has a right to independence, conceived as the freedom to determine and pursue his or her own purposes, and a duty to respect the right of all others to the same. If each person is free and equal in the sense that each is his or her own ruler, then any division of persons into those who rule and those who are ruled stands in urgent need of justification.

The reason why public authority is problematic indicates the basis on which it must be justified. An adequate justification must establish that public authority is consistent with the right and the duty of each person to interact with every other on terms of equal freedom. In this section, I will provide a sketch of the justification of the principle of authority by arguing that in the absence of publicly authoritative legislative, executive, and adjudicative institutions that establish, interpret, and implement law, private persons could not interact with one another on terms of equal freedom. Since persons must interact on such terms, they must interact in the presence of publicly authoritative institutions. ${ }^{33}$

Suppose that private persons interact in a condition devoid of public institutions that establish, enforce, and interpret legal norms.

In the absence of a legislative institution capable of enacting general laws that publicly establish what is permitted, prohibited, or required, private persons might offer their own proposals about the norms that are appropriate for ordering interaction on terms of equal freedom. The problem that

\footnotetext{
32 Stephen R. Perry, "Political Authority and Political Obligation," in Oxford Studies in Philosophy of Law, vol. II, eds. Leslie Green and Brian Leiter (forthcoming) [Perry, "Political Authority"].

33 The ensuing account of the conceptual problems that pervade private interaction in the absence of public institutions relies on Arthur Ripstein, Force and Freedom (Cambridge: Harvard University Press, 2009), 145-181 and Ripstein, "Authority and Coercion" Philosophy and Public Affairs 32 (2004) 2-35.
} 
such an arrangement raises is not that persons are unlikely to make proposals in good faith or that given certain human tendencies the proposals are likely to disappoint, but that any proposal is simply a unilateral assertion. Since each person is the equal of every other, no one has the standing to unilaterally impose obligations on others or confer rights that all others must respect. And since each person is free, persons may assert whatever norms seem appropriate in their own eyes. In a condition in which every juridical agent is a private person, the problem of unilateral lawgiving is irresolvable: if one accepts the unilateral lawgiving of another private person, then one subordinates one's own independence by allowing another to determine how one must act; if one rejects the unilateral lawgiving of all other private persons, one nevertheless remains in a condition in which each person decides the standards by which every other is to be treated. In a condition in which each person decides the rights that all others possess and the duties that all others owe, the right of each person to equal freedom and the duty of each person to respect the right of others to the same are jointly violated. The solution to the problem of unilateral lawgiving is institutional. Private persons must submit to a publicly authoritative legislative institution that possesses a right that all private persons lack, the right to place all private persons under a common set of norms governing conduct.

Now suppose that there is a public legislative institution that enacts general laws but no institution capable of interpreting those laws in cases in which their meaning is disputed. Disputes regarding the meaning of legal norms remain possible because if norms are to govern action, they must be more general than the particulars to which they apply. Thus, even when legal norms are publicly promulgated through a legislative institution, disputes may arise about their meaning with respect to a contingent occurrence. We may have a dispute about who owns a particular piece of property or about where your property ends and mine begins. Or we may have a dispute about whether we have entered into a contract or about how the terms of that contract are to be interpreted. In the absence of a public adjudicative institution, legal disputes cannot be resolved rightfully. The 
reason that disputes cannot be resolved rightfully is not that private persons are selfish or averse to cooperation, but that the parties to the dispute, being free, are each entitled to assert their own interpretation of the rights and duties apposite to their interaction, and being equal, are not required to yield to another's judgment about the rights that one possesses and the duties that one owes. In the event of a legal dispute, I am entitled to stand on my right and refuse to capitulate to your contrary claim. But the same is true for you. The result is a deadlock in which each of us may insist on our own unilateral judgment about what law requires and refuse to defer to the other. Just as each party has a right to reject the unilateral judgment of the opposing party to the dispute, so too each party to the dispute has a right to reject the unilateral judgment of any other private person. When persons interact in a condition populated exclusively by private persons, disputes cannot be resolved rightfully. The solution to the problem of unilateral judgment is to submit private disputes to the authority of a public judiciary. The judiciary resolves disputes not by enabling one private person to unilaterally determine the rights and duties of another, but by providing an impartial public forum for the interpretation of a disputed legal norm. Because the judiciary is not a private party, it enables disputes to be resolved without subjecting either party to the unilateral judgment of another private person or imposing a unilateral judgment through a violent act.

Finally, suppose that there are legislative and adjudicative institutions but no executive institution empowered to implement and enforce the law. I may limit myself to exercising my freedom in a manner that respects your own, as established by a legislature or determined by the verdict of a court. But by acting in a manner that respects your independence, I have no assurance that you will reciprocate by acting in a manner that respects mine. In the absence of an executive power that protects the independence of each person with respect to every other, the independence of each person remains subject to the choice of other private persons. Others need not violently interfere with my rights, but whether they do so depends not on my entitlements as a member of a system of 
equal freedom, but on the particular purposes that they happen to have. In the absence of a public executive institution, the independence of each person remains subject to the unilateral acts of all others. Like the problems of unilateral lawgiving and unilateral judgment, the solution to the problem of unilateral enforcement is institutional. By exercising public coercion to protect the independence of private persons in relation to one another, an executive institution distinguishes public authority from an empty recommendation: public legislation is to be implemented, verdicts handed down by courts are to be enforced, and violations of law are to be prevented, detected, and prosecuted. In a legal system, private rights are secured through public coercion.

Regardless of whether a state of nature ever existed, private persons have a coercible obligation to interact with others in a legal condition. The public institutions that constitute the public law relationship between rulers and ruled create the conditions in which each person can enjoy his or her right to independence in relation to every other. Because interacting with others in a condition of public law is compatible with the right of every person to independence and interacting in a lawless condition is incompatible with the independence of anyone, every person must interact with all others in a condition of public law. The person who seeks to engage in lawless interaction rejects the legal condition in which all can enjoy their independence in relation to one another for a lawless condition in which none can. Persons who interact with others but refuse to submit to the public authority of a legal system may be compelled to do so because their refusal is incompatible with the independence of everyone, while their inclusion within a legal system is compatible with the independence of everyone, including their own.

Having justified the legislative, executive, and judicial institutions that jointly comprise a government, we can now characterize the relationship between government and the private persons who are bound by it. 
The principle of authority relates the right of government to rule, that is, to exercise public authority over its members, to the corresponding duty of the ruled to obey. A government is the sum of publicly authoritative institutions that represent the people as a whole by subjecting each of its members to common lawgiving, adjudication, and enforcement. A people is the totality of private persons subject to common governance. The presence of publicly authoritative institutions distinguishes a lawless condition from a condition of public law. In a lawless condition, every juridical actor is a private person. In a condition of public law, all private persons are subject to the authority of public institutions. The people acts not through the unilateral actions of its particular members, which being unilateral are incapable of imposing obligations on all others, but through the powers of the publicly authoritative institutions that comprise its government. ${ }^{34}$

The rule of law consists in the lawful exercise of public authority. The rule of law is possible only in a condition of public law, that is, a condition in which there is an authoritative process for the

\footnotetext{
${ }^{34}$ Stephen R. Perry has argued that political authority involves the Hohfeldian correlates of a power to impose duties on the part of government and "not a duty" on the part of private persons "but, rather, a liability, meaning in this context a liability to be subjected to duties." Perry explains that the distinction is not merely of technical significance. It matters because if the correlate of a power to impose a duty was itself a duty, then in the absence of a duty incumbent on the ruled, one might conclude that there was no corresponding power of the rulers. But such a conclusion would be erroneous because it overlooks the possibility that public authority exists prior to its exercise, in which case private persons are not subject to duties but rather liable to be subject to duties. Perry's point, which he formulates as the prospectivity condition, is that the liability to be subject to a duty must exist at the time of that duty's enactment. Thus, any theory in which the "argument for the conclusion that a given state possesses legitimate moral authority which depends on facts that only come into being at a time subsequent to the enactment of laws must be treated as suspect." See Perry, "Political Authority".

The unified theory retains the correlates of right and duty without violating Perry's prospectivity condition. Private persons who interact with others have a duty to interact in the presence of publicly authoritative institutions. This duty obtains both in a lawless condition and in a condition of public law. In a lawless condition, private persons have a duty to enter into a legal condition. The violation of this duty is a wrong because it is incompatible with the formation and maintenance of a legal condition in which all can enjoy their independence in relation to every other. In a condition of public law, the same duty requires that private persons submit to the existing public authority. A public authority is not present whenever persons have a duty to submit to it, for such a duty obtains both in a lawless condition and in a lawful one. Within the justification of public authority supplied by the unified theory, that persons are under a duty rather than a liability to be subjected to duties is evident because persons can act wrongfully prior to the public authority's enactment, for example, by doing what lies in their power to perpetuate a lawless condition. Whereas Perry notes that public authority can exist prior to the particular duties enacted through its exercise, the unified theory holds that the duty to submit to the governance of public institutions precedes the existence of public authority. Since both of these positions retain the possibility that public authority (whether conceptualized as a right or a power) is not dependent on facts that contingently materialize after its exercise, neither violates the prospectivity condition. I am grateful to Stephen Perry for discussing this issue with me.
} 
promulgation of legal rules. Under the rule of law, all private persons are subject to publicly enacted standards of behavior. These standards demarcate a publicly knowable domain of permissible action in which each person may formulate, develop, and pursue their own purposes in relation to every other. Interaction between private persons occurs in accordance with the rights that each is publicly known to possess and the duties that each is publicly known to owe. If persons are to conduct their affairs in accordance with law, lawgiving must be, inter alia, general, publicly knowable, prospective, clear, consistent, possible to obey, and relatively stable. ${ }^{35}$ In turn, if the acts of public officials are to be distinguished from the lawless actions of the private persons who occupy their offices, the action of public officials must itself be authorized by law. Action that is not legally authorized is nothing more than a unilateral assertion of private power, which cannot place another under a legal obligation. Thus, the formal principles that make up Fuller's internal morality of law enter the unified theory neither in terms of a duty that government owes to those that it binds by exercising public authority nor as the aspiration internal to exercises of public authority, ${ }^{36}$ but rather as conditions under which persons who occupy public offices exercise public authority rather than private power.

The rule of law can be realized through a broad array of legislative arrangements that subjects the people as a whole to common lawgiving. In an autocratic society, legislative power is held by a single individual. In such a society, all private persons are passive subjects who are bound by law but unable to contribute to its enactment. In an aristocratic society, legislative power is held by the plurality of individuals who comprise the aristocracy. All private persons excluded from the ranks of the nobility are passive. Finally, in a democratic society, legislative power is held by the totality of its adult citizens, who are not passive subjects bound by laws of another's making, but are active citizens

\footnotetext{
${ }^{35}$ For discussions of the indicia of the rule of law, see Lon L Fuller, The Morality of Law (New Haven: Yale University Press, 1964) at 33-94; Joseph Raz, The Authority of the Rule of Law (Oxford: Oxford University Press, 2002) at 212-219; and Michael Oakeshott, "The Rule of Law" in On History and Other Essays (Oxford: Basil Blackwell, 1983) at 140 and 159; Oakeshott, On Human Conduct (Oxford: Clarendon Press, 1975) at 128 and 153.

${ }^{36}$ Fuller, The Morality of Law, supra note \# at 42: "The inner morality of law...embraces a morality of duty and a morality of aspiration."
} 
who contribute to the creation of the laws by which they are bound. The rule of law does not require that laws be promulgated democratically through representative institutions. Whether legislative power is held by a single person, a few persons, or the citizenry acting collectively through its representatives, private persons are subject to the governance of public institutions. A just democratic order cannot exist without the rule of law, but the rule of law does not entail the existence of a just democratic order. The distinction between the lawful exercise of public authority and the lawless imposition of private power does not indicate the mode through which laws should be promulgated.

Nor does this distinction determine the appropriate content of enacted laws. The justification of the principle of authority establishes that lawgiving cannot be publicly authoritative if it is incompatible with the interaction of private persons on terms of equal freedom or if its secrecy, vagueness, or ad hoc character prevents persons from acting in light of it. But apart from these formal conditions of the exercise of public authority, the principle of authority does not impose a duty on government to give laws of a certain kind. The principle of authority imposes no such duty on government because it imposes no duty on government at all. The principle concerns the right of government to give law and the corresponding duty of private persons to obey, not the right of private persons and the corresponding duty of government.

Private persons must act in conformity with valid public laws enacted by a public authority. The refusal to do so is a public wrong, that is, a wrong against the condition in which a plurality of persons can interact with one another in a manner that is consistent with the independence of everyone. Whereas wrongs that private persons commit against each other may be remedied by public institutions, a condition of public law could neither be created nor sustained if private persons had a right to disobey valid lawgiving. This claim is conceptual, not empirical. It would be empirical if it suggested that a causal relationship obtains between disobedience and the dissolution of society. Thus David Hume argued that a "small degree of experience and observation suffices to teach us, that 
society cannot possibly be maintained without the authority of magistrates, and that this authority must soon fall into contempt where exact obedience is not paid to it." ${ }^{37}$ Such an empirical claim is susceptible to the empirical rebuttal that, in fact, legal systems persist even when obedience is not ubiquitous. $^{38}$ The conceptual claim focuses on the contrast between a legal system and a lawless condition. A legal system - comprised of legislative, adjudicative, and executive institutions that together subject a plurality of private persons to common norms - is the condition in which private persons can enjoy their independence in relation to one another. Such a condition would not be possible if private persons possessed the right to disregard laws that they deemed objectionable because such a right would regenerate the problems of lawless interaction by subjecting private persons to the unilateral lawgiving, judgment, and enforcement of other private persons. Private persons cannot interact with others on terms of equal freedom in the absence of the public institutions that comprise a legal system.

Perhaps Hart's anarchic natural lawyer would object as follows: the principle of authority is too rigorous insofar as it imposes a duty on private persons to obey a regime of public law regardless of whether it is just. But why should private persons respect the right of government to rule when the government fails to create a just democratic order in which the authority of law secures not only the private rights of persons in relation to one another, but also the independence of each person as a citizen of a just democratic order? Perhaps, the anarchist concludes, the duty to obey public authority should be suspended until that public authority satisfies its own duty to govern justly. In this way, public authority and public justice would be jointly realized: private persons would act in conformity with valid laws promulgated by a democratic government committed to the enactment of just norms.

\footnotetext{
${ }^{37}$ Hume, "Of the Original Contract," in Essays, Moral, Political, Literary, ed. E. F. Miller (Indianapolis: Liberty Classics, 1985), 480.

${ }^{38}$ Leslie Green, "Law and Obligations" in The Oxford Handbook of Jurisprudence and Philosophy of Law, eds. Jules Coleman and Scott Shapiro (Oxford: Clarendon Press, 2001), 537 and Green, The Authority of The State (Oxford: Clarendon Press, 1990), 87.
} 
The anarchist's objection frustrates the achievement of its own end, the realization of a just legal order. If each private person had the right to determine what norms are obligatory, then private persons would not be subject to common lawgiving and the problem of lawlessness, in which the independence of each is subject to the arbitrary choice of every other, would resurface. If private persons enjoyed the right to act in accordance with what is just and good in their own eyes, there could neither be a government nor a people. There could be no government because there would be no public authority with the capacity to impose legal obligations upon a multitude of persons. In turn, there could be no people because the multitude would not be unified by their shared subjection to common legal institutions. The claim that the right and duty imposed by the principle of authority do not engage until a fully just democratic order is present obliterates the anarchist's aim of realizing a just society. By rejecting the principle of authority, the anarchist is committed to a principle that would annihilate the very condition in which the realization of public justice is possible. The objection thereby culminates not in the joint realization of public authority and public justice but in the ongoing subjection of human beings to the indignity of lawless interaction.

Legal and political philosophers invariably maintain that "no respectable theory of political obligation ever claimed that a person is obligated no matter what to obey the laws of a legal system to which he or she is subject." 39 This is exactly what the unified theory claims in its justification of public authority: all private persons must obey all valid laws. This does not mean, however, that anything that calls itself a legal system thereby is one or that any decree buttressed by violence is a valid law. After all, the justification of public authority at work in the unified theory provides its own ground for distinguishing between the public authority of a legal system, which all must obey, and private violence, which all may resist. Public authority is that which secures the independence of each person from

${ }^{39}$ Stephen Perry, “Associative Obligations and the Obligation to Obey the Law" in Exploring Law's Empire: The Jurisprudence of Ronald Dworkin, ed. Scott Hershovitz (Oxford: Oxford University Press, 2006), 183. 
the arbitrary power of every other. It follows that arrangements that fail to secure the right of each person to independence in relation to every other cannot be publicly authoritative. In such cases, the principle of authority does not require persons to capitulate themselves to the powerful - for the mere exercise of power, however organized, imparts no corresponding obligation. Rather, persons must submit themselves to the public authority of a legal system, in which each person can enjoy independence from the arbitrary power of every other. I return to this point below in contrasting the legal pathology that results from the violation of the principle of authority (barbarism) with the legal pathology that results from the violation of the principle of justice (injustice).

\section{The PRINCIPLE OF JUSTICE}

Legal and political philosophers often think about justice by taking the existence of publicly authoritative institutions for granted and then asking, all things considered, what purpose (or purposes) they should pursue. The diverse suggestions that ensue have a common structure. Each stakes a claim to how public authority should be exercised that is isolated from the terms on which public authority is justified. The unified theory of public law adopts a different approach in which the question of how public authority should be exercised is considered from the standpoint of its justification.

The justification of the principle of authority establishes that government has the right to enact, interpret, and enforce legal obligations that bind private persons. If the government has the right to exercise public authority over private persons, why may the government not exercise its power by using persons as instruments to further the purposes of those who occupy public offices? Perhaps societies of human beings are nothing more than "so many herds of cattle, each with its ruler, who keeps guard over them for the purpose of devouring them." ${ }^{40}$

\footnotetext{
${ }^{40}$ Jean-Jacques Rousseau, On the Social Contract in The Basic Political Writings, trans. Donald A. Cress (Indianapolis: Hackett Publishing Company, 1987), 142.
} 
Within the unified theory, the right of government to exercise public authority over persons does not exist in a justificatory vacuum. The justification of public authority rests on the recognition that every person possesses a right to independence, that is, to freely determine and pursue his or her own purposes in a manner compatible with the right of others to the same. Government is not the owner of a thing, which has no rights, imposes no duties, and suffers no wrongs. Rather, it is the representative of a totality of independent persons, who must subject themselves to public lawgiving because rightful interaction is impossible without it. Since the right to exercise public authority presupposes the right of each person to independence, internal to the justification of public authority is an account of what it would mean for a system of publicly authoritative institutions to be fully adequate and what it would mean for public institutions to exercise their authority in a fully adequate manner. A legal system is adequate on its own internal standard to the extent that it reconciles the authority of law with the independence of every person bound by it. In turn, the exercise of public authority conforms to the terms of its justification to the extent that it is directed towards bringing the existing legal system into the deepest possible conformity with its own internal standard of adequacy, independence under law. Because the right of government to exercise public authority presupposes the right of every private person to independence, government cannot deny the right of persons to independence without thereby denying the justificatory basis of its own authority.

The principles of public law differentiate the juridical situation of the parties to the public law relationship. The principle of authority relates the right of government to the corresponding duty of persons to obey all valid lawgiving. The principle of justice traverses the public law relationship from the opposite direction by relating the right of every person to just governance to the corresponding duty of the government. Since the duty to govern justly accompanies the mere exercise of public authority, all branches of government - legislative, adjudicative, and executive - must bring the existing legal order into the deepest possible conformity with the independence of every person 
subject to its lawgiving. Accordingly, the juridical situation of a private person differs from that of government. Every private person has a right to independence, that is, to formulate his or her own purposes and pursue them with his or her own means, subject to the systematic constraint that each person respects the same right of all others. Unlike a private person, a government lacks the right to determine its own end. Government enters the world with a single obligatory end, the realization of a system of law that conforms to the terms of its own justification. While private persons may direct their means towards the fulfillment of their own self-determined ends, the publicly authoritative means of government do not exist apart from their obligatory end.

The principles of public law address two distinctive problems that arise in a conceptually sequenced exploration of the implications of the right of persons to independence. The problem that the principle of authority addresses is that, in the absence of public institutions, the right of each person to interact with every other on terms of equal freedom remains subject to the arbitrary power of others. The solution to this horizontal problem of independence between private persons is, as I argued in the prior section, solved by the submission of private persons to a system of publicly authoritative institutions that establish, interpret, and enforce private rights. The second problem of independence presupposes the solution to the first. While the principle of authority addresses a problem that is unavoidable in the absence of public institutions, the principle of justice addresses a problem that can arise only when the public institutions comprising a government are present. The very public institutions that solve the problem of horizontal independence by securing the right of each person to equal freedom in relation to every other create a problem of vertical independence because public institutions might themselves impose arbitrary restrictions on the freedom of one or more persons, that is, restrictions that a legal system does not itself require. These restrictions might concern the way in which laws are enacted or the content of enacted laws. The problem of vertical independence is addressed by the principle of justice, which requires that all public authority be 
directed towards bringing the legal order as a whole into conformity with the independence of each person bound by it.

Recall that the principle of authority requires that private persons submit to public lawgiving, but it draws no distinctions concerning the adequacy of autocratic, aristocratic, or democratic forms of lawgiving. In contrast, the principle of justice calls for the lawful transition to (and ongoing refinement of) a democratic legal order. That the principle of justice calls for a democratic order follows from the requirement that all public authority, including legislative authority, conform to the independence of those who are bound by it. In an autocracy, all persons are passive with respect to the legislative power. Autocracy is a defective mode of lawgiving because an arrangement in which persons are bound by laws that they cannot themselves enact imposes a constraint on the freedom of the ruled that freedom does not itself require. It thus fails to reconcile the public authority of the legal condition with the independence of all who are bound by it. In contrast, in an aristocracy some are passive with respect to the legislative power, while others are active. This distinction is defective because it establishes ranks that defy the equality of independent persons insofar as some possess the right to contribute to the enactment of laws, while others are merely bound by laws of another's making. Democracy is the only mode of lawgiving in which citizens are both rulers and ruled, sovereign and subject. Democracy alone is capable of reconciling the independence of persons with legislative authority because it does not impose an arbitrary constraint on freedom by denying persons the right to contribute to the laws by which they are bound. Nor does it violate equality by extending this right to some persons but withholding it from others.

The duty to govern justly extends from the mode through which public legislation is to be enacted to its content. Because the right to exercise public authority over independent persons is always accompanied by a duty to govern justly, the duty applies in cases in which public authority is exercised by autocrats or aristocrats, but also in the case of democracy, in which citizens collectively 
exercise legislative power through their representatives. Each citizen who contributes to public lawgiving must give laws to which all others, conceived of as free and equal members of a legal system, could consent. In a fully just democratic order, the system of laws that citizens collectively enact is fully congruent with the undiminished independence of each person bound by it. The ideal of public law is a democratic legal order in which each person contributes to and, in turn, is bound by lawgiving that leaves the independence of each person bound by it undiminished.

Perhaps one might object that the principle of justice is overly demanding because it requires government do the impossible by creating a democratic utopia in which the exercise of authority leaves the independence of each person bound by it undiminished. If the creation of such an order is impossible, then it cannot be obligatory. Thus, the objection concludes, the principle of justice must be rejected.

This objection overlooks a crucial distinction between the principles of public law. The principle of authority calls for the creation and maintenance of a legal system. The principle of authority is a constitutive principle: it articulates what a legal system is and thereby enables a legal system to be distinguished from other entities within and beyond the juridical world. A legal system consists in the publicly authoritative institutions under which private persons can interact with one another on terms of horizontal independence. In contrast, the principle of justice is a regulative principle: it articulates a standard for assessing the adequacy of a particular kind of entity. The principle of justice holds that a legal system is adequate to the extent that it conforms to its own justificatory basis by uniting the authority of law with the vertical independence of all who are bound by it. Accordingly, the duty incumbent on government is not to do the impossible by transforming itself into a perfectly just legal order, whether in a single act or a finite series of acts. Rather, the duty of government is to exercise public authority in accordance with the terms on which that right is justified by bringing the existing legal system into the closest possible conformity with its own internal ideal of equal freedom 
under law. Regardless of whether a perfectly just legal system can be realized, it is certainly possible for existing legal systems to approximate the ideal of equal freedom under law to a greater or lesser extent. Because the principle of justice is a regulative principle that calls for the ongoing approximation of a just legal system rather than a constitutive principle that calls for the realization of a perfectly just one, the duty to govern justly does not exceed the boundaries of possibility.

The bifurcated structure of public law enables a distinction to be drawn between two distinct kinds of pathologies of public law that are often blurred, injustice and barbarism. Injustice consists in the violation of the regulative principle of public law. A legal condition is unjust to the extent that it fails to reconcile the authority of law with the vertical independence of every person bound by it. In an unjust legal condition, public institutions must realize a legal order that to the greatest possible extent reconciles the authority of law with the independence of each person who is bound by it. In contrast, barbarism consists in the violation of the constitutive principle of public law. Barbarism is the pathology of a condition that fails to secure horizontal independence and thereby subjects the independence of one or more persons to the arbitrary power of others. In such a condition, all private persons are under a duty to submit themselves to public institutions, which render rightful interaction possible. Insofar as the pathologies of public law emerge from the violation of distinct relations of independence, the difference between injustice and barbarism is not a matter of degree, as those who conceptualize barbaric lawlessness as an extreme instance of injustice claim. ${ }^{41}$ Rather, the pathologies are different in kind insofar as each stems from a different aspect of the public law relationship. The question of whether private persons occupy a lawful or a lawless order concerns the presence of public institutions that secure the horizontal independence of each person in relation to every other. The

\footnotetext{
41 Gustav Radbruch, "Statutory Lawlessness and Supra-Statutory Law (1946)," (2006) 26 OJLS 1 at 7: "The conflict between justice and legal certainty may well be resolved in this way: The positive law, secured by legislation and power, takes precedence even when its content is unjust and fails to benefit the people, unless the conflict between statute and justice reaches such an intolerable degree that the statute, as 'flawed law', must yield to justice."
} 
question of whether a legal order is just concerns the adequacy of the vertical relationship between publicly authoritative arrangements and the independence of each individual subject to them. I discuss barbarism in Chapter Two and injustice in Chapter Three.

The unified theory of public law consists in the principles that constitute and regulate the juridical relationship between a government and its members. The distinctive features of the principles are elaborated in the following chart: 


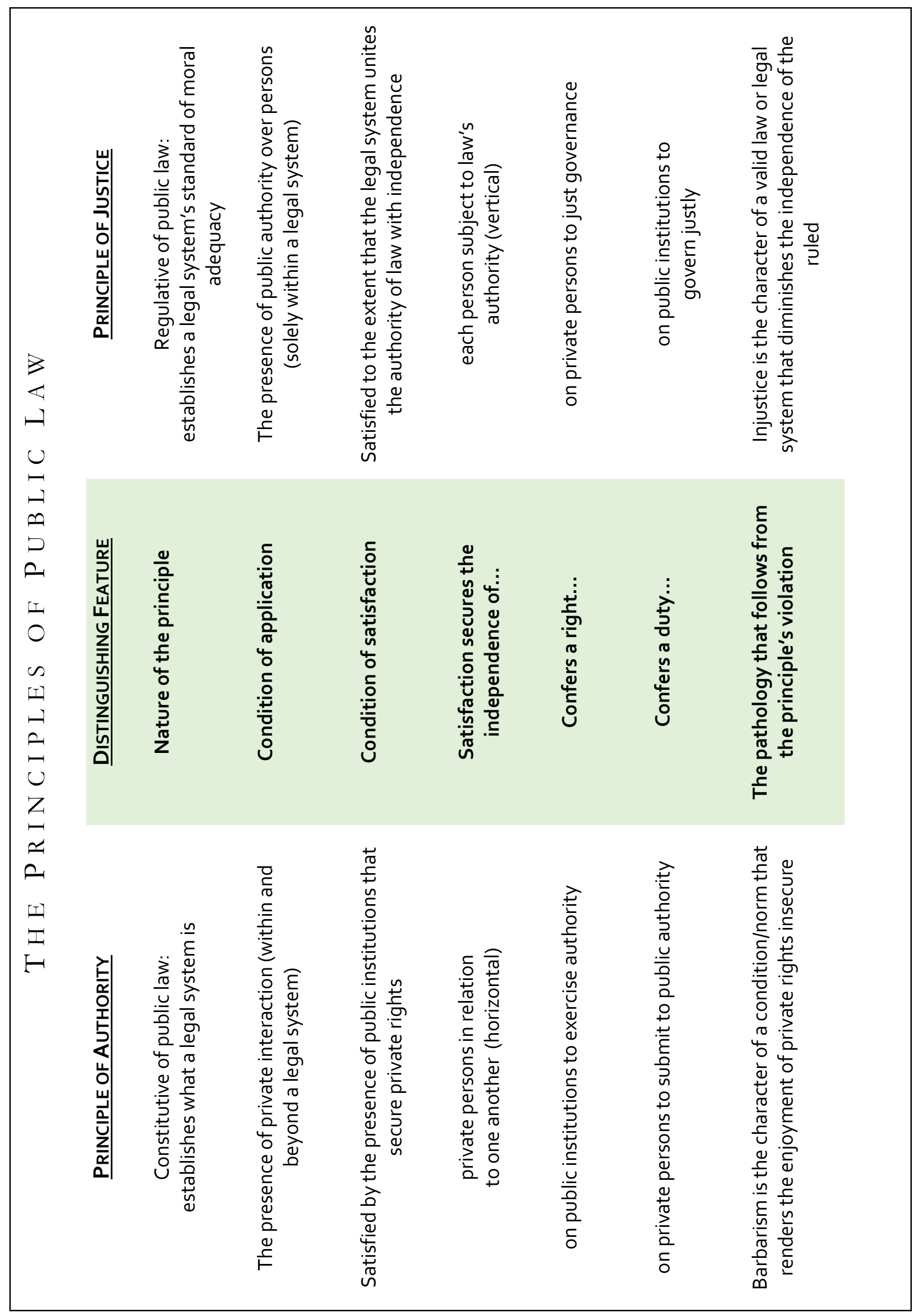


The principles of authority and justice form the normative architecture of a legal system as

such. ${ }^{42}$ That these principles are apposite to legal systems in general distinguishes the unified theory from competing frameworks that attempt to ground the right of government to exercise public authority or the right of persons to a just democratic order on particular facts or states of affairs that might be present in one legal system but absent in another. As I argued in the prior section, the principle of authority emerges from the systematic implications of the right of each person to equal freedom rather than, as other theorists propose, the justice of the rules, ${ }^{43}$ the superior wisdom of the

42 The unified theory of public law can be contrasted with David Dyzenhaus' reconstruction of Hobbes's legal theory. See "Hobbes on the Authority of Law," in Hobbes and the Law, ed. Dyzenhaus and Thomas Poole (Cambridge: Cambridge University Press, 2012), 186-209 and Dyzenhaus, "How Hobbes Met the "Hobbes Challenge," Modern Law Review 72 (2009): 488-506. Dyzenhaus formulates two conditions of law's authority (205). The validity proviso empowers the sovereign to make valid law by acting in accordance with the relevant "public criteria for law-making" (198). The legality proviso holds that subordinate judges owe a duty to the sovereign to interpret the laws enacted in accordance with the validity proviso (197). The legality proviso has two ends. The "duty end" requires judges to invalidate laws that though enacted in accordance with the validity proviso, nonetheless cannot be interpreted in accordance with the laws of nature (206-7). The "aspiration end" requires that in cases in which the enacted law can be interpreted in accordance with the laws of nature, judges adopt the interpretation that brings the enacted law into the closest possible conformity with the natural law or the principles that underwrite law's authority (206-7).

The unified theory makes a series of departures from Dyzenhaus' Hobbesian-Fullerian framework. The most significant concerns the character of the principles at work in each theory. Whereas the unified theory has a constitutive principle that empowers public institutions to exercise public authority by enacting, interpreting, and enforcing valid legal obligations and a regulative principle for assessing the adequacy of all exercises of public authority, both of Dyzenhaus' provisos concern the authority of law (205). This distinction generates others, which I discuss throughout this project. Because Dyzenhaus' legality proviso includes an aspirational dimension, the distinction between validity and invalidity is not binary but instead admits of "varying degrees of strength" (207). I discuss this conception of validity, as it pertains to Lon L. Fuller's legal philosophy, in Chapter Two. Further, within Dyzenhaus' Hobbesian framework, the right of the sovereign to exercise public authority is not accompanied by a duty to bring the legal order into conformity with the independence of all who are bound by it by creating a democratic order accountable to the independence of each of its members. Within this Hobbesian paradigm, the sovereign owes no duty to subjects in the making of law (199) and no subject can "claim that the sovereign has injured him or treated him unjustly" (493)". While Dyzenhaus's framework explains that subjects can challenge the validity or authority of law, it provides no resources for thinking about how subjects can be wronged by a valid exercise of public authority. In contrast, the unified theory holds that the right to exercise public authority is always accompanied by a duty to govern justly that is owed to every inhabitant of the legal order. Consequently, persons can be wronged through the valid exercise of public authority. The failure of government to direct public authority towards the creation and refinement of a democratic order committed to the freedom of each of its inhabitants is a public wrong. I discuss the duty to govern justly in Chapter Three. Finally, the aspirational component of Dyzenhaus' theory departs from the robust ideal of public justice at work within the unified theory. I expand on this point in the Conclusion to this project in a discussion of Fuller's more modest conception of dignity. For Fuller, dignity consists in the capacity to be subject to the governance of rules. In contrast, within the unified theory, dignity or independence culminates in the requirement that the rules to which human conduct is subject be compatible with the independence of all who are bound by them.

${ }^{43}$ See, for example, the discussion of Dworkin's interpretive model in the Introduction to this project. See also John Rawls, A Theory of Justice (Cambridge: Harvard University Press, 1971), 115: "From the standpoint of justice as fairness, a fundamental natural duty is the duty of justice. This duty requires us to support and to comply with just institutions that exist and apply to us." 
rulers, ${ }^{44}$ or some voluntary act on the part of the ruled, whether consent ${ }^{45}$ or the acceptance of a benefit. ${ }^{46}$ Such justifications culminate in a patchwork in which the presence of public authority is always a matter of degree that varies from law to law and from individual to individual. ${ }^{47}$ The unified theory departs from these frameworks by holding that in every legal system all private persons must obey all valid laws. In this respect, the principle of justice resembles the principle of authority. The duty to govern justly follows from a feature common to legal systems as such - the mere presence of publicly authoritative institutions governing persons - rather than states of affairs that might obtain in one legal system but not in another, such as the presence of a democratic form of lawgiving, a rights-protecting constitution, or a public culture committed to ideas of free and equal citizenship. Theories that generate the duty to govern justly from such features might succeed in explaining why a legal system characterized by liberal practices should govern in accordance with a liberal conception of justice. $^{48}$ What they do not explain is why a legal system that lacks these practices must adopt them. Instead of treating these practices as conferring justification upon a conception of justice, the unified theory instead articulates a conception of justice that indicates why the adoption of practices of this kind is itself obligatory.

\footnotetext{
${ }^{44}$ Joseph Raz, "Authority and Justification," Philosophy and Public Affairs 14 (1985): 18-19 (emphasis in original): “the normal and primary way to establish that a person should be acknowledged to have authority over anotherperson involves showing that the alleged subject is likely better to comply with reasons which apply to him (other than the alleged authoritative directives) if he accepts the directives of the alleged authority as authoritatively binding and tries to follow them, rather than by trying to follow the reasons which apply to bim directly."

45 See, for example, Leslie Green, The Authority of the State (Oxford: Clarendon Press, 1990), 18.

46 Simmons, "The Principle of Fair Play," Philosophy and Public Affairs 8 (1979): 307.

47 See, for example, Raz, The Morality of Freedom (Oxford: Clarendon Press, 1986), 80 (arguing that the service conception of authority "invites a piecemeal approach to the question of authority of governments, which yields the conclusion that the extent of governmental authority varies from individual to individual, and is more limited than the authority governments claim for themselves in the case of most people." For a criticism of this aggregative approach, see Perry, "Political Authority".

48 See, for example, Rawls, Justice as Fairness: A Restatement (Cambridge: Harvard University Press, 2001), 39: “D]ustice as fairness is framed for a democratic society. Its principles are meant to answer the question once we view a democratic society as a fair system of social cooperation between citizens regarded as free and equal, what principles are most appropriate to it. Alternatively: which principles are most appropriate for a democratic society that not only professes but wants to take seriously the idea that citizens are free and equal, and tries to realize that idea in its main institutions."
} 


\section{OBJECTIONS AND REPLIES}

For centuries, positivists have claimed that nonpositivist legal theories distort their subject matter in one of two ways. In Hart's formulation of the criticism, discussed above, nonpositivism culminates either in the confusions of an anarchism that denies that what is unjust can be valid or a quietism that denies that what is valid can be unjust. ${ }^{49}$ Whether nonpositivism appears in its anarchist or quietist guise, it rejects a fundamental truism that any adequate theory of law must illuminate: a law or legal system might be unjust. The present section argues that this criticism relies on a presupposition that the unified theory of public law displaces. The presupposition is that nonpositivist theories of public law are reducible to either an account of public authority or to an account of public justice. Since the unified theory of public law holds that public authority and public justice are mutually implicating but distinctive aspects of public law, the positivist criticism poses no threat to it.

The unified theory of public law gives rise to an exhaustive classification of the ways in which authority and justice relate to particular legal systems and laws. A just legal condition satisfies the principles of authority and the internal ideal of public justice by uniting the authority of law with the independence of all who are bound by it. An unjust legal condition satisfies the principle of authority but fails to satisfy the ideal of public justice. Existing legal systems are instances of this category and

\footnotetext{
${ }^{49}$ Hart raised other criticisms against nonpositivist theories, or as he called them, theories of natural law. In The Concept of Law, Hart claimed that natural law is fallacious because it overlooks the difference between descriptive and prescriptive law. Descriptive laws, which concern regularities in nature, are formulated following rational reflection on empirical observations. Prescriptive laws, which hold that persons should conduct themselves in certain ways, cannot be formulated in the same way as descriptive laws. A prescriptive law may survive its violation, for example, in a case in which a person fails to conduct himself in the requisite manner. But if a descriptive law fails to describe its subject, it is not adequate and must be revised. The fallacy of natural law consists in the failure to understand that the meanings of words like 'must', 'ought' and 'should' diverge in the descriptive and prescriptive contexts. By making this fallacy explicit, natural law receives its "deathblow". See The Concept of Law, 182-3 and Raz, The Authority of Law, 130-1. It is not clear why Hart believes that nonpositivist theories must commit this fallacy. Consider, for example, the nonpositivist theory of Immanuel Kant, whose entire philosophic edifice is built on the distinction between empirical laws of nature and moral laws of freedom, or - in Kant's well-known formulation - between the "starry heavens above me and the moral law within me." Whatever difficulties Kantian legal theory raises, surely it is not the case that it fails because it lacks a distinction between descriptive and prescriptive laws. See Kant, Critique of Practical Reason in Practical Philosophy, trans. Mary Gregor (Cambridge: Cambridge University Press, 1996), 5:161. On the juridical significance of this distinction, see Doctrine of Right in Practical Philosophy, 6:214.
} 
satisfy the ideal of public justice to varying extents. The duty of the public authority of such legal systems is to bring the legal order as a whole into the closest possible conformity with the vertical independence of each person bound by the authority of law. Finally, a lawless condition fails to satisfy the principle of authority because the horizontal independence of private persons has not been secured. These three possibilities are exhaustive: a legal condition can be valid and just, valid but unjust, or simply invalid. A legal system cannot be both invalid and just because public justice concerns the adequacy of the public law relationship between a people and its government. If the parties to this relationship are not present then questions about the adequacy of this relationship cannot arise. The same classification obtains with respect to particular norms: a norm can be valid and just, valid but unjust, or simply invalid.

The claim that nonpositivist theories collapse into anarchism or quietism rests on a peculiar distinction drawn by legal positivists. If positivism consists in the separation of considerations of legal validity from those of morality or justice, then surely nonpositivism collapses this wall. The direction in which the wall is collapsed distinguishes anarchism from quietism. The quietist holds that what is valid must be just. The anarchist holds that what is just must be valid. For each, the domain of validity and justice are coextensive. The anarchist and the quietist may disagree about many issues, but their conception of the relationship between validity and justice generates a shared conclusion about the relationship between authority and justice: it is not possible for a valid condition of public law to be unjust. $^{50}$

The anarchist and quietist denial of the legal truism that a valid law or legal system might be unjust stems from a common confusion. I noted above that the principle of authority is the constitutive

\footnotetext{
50 See, for example, Joseph Raz, The Authority of Law, 130: "Kelsen correctly points out that according to natural law theories there is no specific notion of legal validity. The only concept of validity is validity according to natural law, i.e. moral validity. Natural lawyers can only judge a law as morally valid, that is, just, or morally invalid, i.e. wrong. They cannot say of a law that it is legally valid but morally wrong. If it is wrong and unjust, it is also invalid in the only sense of validity they recognize."
} 
principle of public law and that the principle of justice is its regulative principle. The former concerns what it means for a norm or condition to be lawful; the latter concerns what it means for a law or legal system to be adequate. The mistake that underlies both anarchism and quietism involves reducing the whole of public law to either its constitutive or its regulative aspect. The anarchist holds that the regulative principle of a legal system is also its constitutive principle. On this view, the ideal of public justice is not only the standard of a law or legal system's moral adequacy but the condition of its authority. That which is not perfectly just cannot be publicly authoritative. The quietist commits the opposing error by asserting that the constitutive principle of a legal system is also its regulative principle. On this view, the features of a particular law or legal system form the standard for assessing its moral adequacy, which means that no publicly authoritative arrangement can fail to be just. Because the unified theory distinguishes the constitutive principle of the public law relationship (the principle of authority) from its regulative principle (the principle of justice), the unified theory avoids collapsing into either anarchism or quietism.

Because the unified theory appeals to morality to formulate mutually implicating principles of authority and justice that constitute and regulate the public law relationship, it is neither anarchist nor quietist. Recall that anarchism is the view that what is unjust cannot be publicly authoritative. The unified theory cannot be anarchist because public justice is the standard for assessing the adequacy of a publicly authoritative arrangement. Thus, the claim than an arrangement is unjust presupposes that it is publicly authoritative. Further, the unified theory is not quietist. Recall that quietism is the view that what imposes legal obligations cannot be unjust. The unified theory is not quietist because the justification of the right of government to exercise public authority over human beings implicates a distinctive moral standard for assessing the adequacy of all exercises of public authority. The right to exercise public authority is always accompanied by a duty to bring the existing legal order into the 
closest possible conformity with the ideal of public justice. Thus, the unified theory of public law jointly rejects the uncritical resignation of the quietist and the lawless freedom of the anarchist.

While the positivist objection threatens one-sided nonpositivist theories that reduce public law to either public authority or public justice, the objection poses no threat to theories that appeal to morality in order to delineate the distinction between public authority and public justice. The unified theory thereby offers what positivists have long insisted was impossible, a nonpositivist theory that explains how a law or a legal system might be valid even though it is unjust. One need not be a positivist to capture positivism's twin insights that what is just is not necessarily valid and that what is valid is not necessarily just.

The positivist objection follows from a chronic misconception regarding the dispute between positivist and nonpositivist approaches. Positivists endorse the thesis that the concept of law is exhausted by its positivity. Accordingly, positivists invariably conceive of nonpositivists as adopting the opposite view, which holds that a norm is legally valid not because it has been posited by the relevant institution but because it is moral. ${ }^{51}$ But nonpositivist thought need not adopt this approach. The principle of authority captures legal positivism's central claim: positive law is authoritative or valid not by virtue of its justice, but by virtue of its institutional enactment by the relevant public authority. On this central point, positivists and nonpositivists may stand in agreement, albeit for their own distinctive reasons. Positive law is not valid by virtue of some non-institutional event or state of affairs, whether "objective moral truth or God or the spirit of an age or the diffuse will of the people

\footnotetext{
51 See, for example, Joseph Raz, “Kelsen's Theory of the Basic Norm” American Journal of Jurisprudence 19 (1974): 100: "Kelsen correctly points out that according to natural law theories there is no specific notion of legal validity. The only concept of validity is validity according to natural law, i.e. moral validity. Natural lawyers can only judge a law as morally valid, that is, just, or morally invalid, i.e. wrong. They cannot say of a law that it is legally valid but morally wrong. If it is wrong and unjust, it is also invalid in the only sense of validity they recognize."
} 
or the tramp of history through time, for example." ${ }^{52}$ The real disagreement between positivist and nonpositivist theories lies elsewhere.

The disagreement between positivists and nonpositivists concerns whether the concept of law is exhausted by positive law..$^{53}$ As a nonpositivist framework, the unified theory contends that there are two respects in which the concept of law extends beyond its positivity. The first concerns the principle of authority. The authority to impose and coercively enforce obligations on independent persons through the enactment of positive law must be justified. The second disagreement, which concerns the principle of justice, follows from the first. The unified theory holds that the justification of public authority provides the internal standard for assessing the adequacy of every legal system and indicates the duty that accompanies the exercise of all public authority. Thus, the unified theory affirms what positivism denies, that a legal system or a valid law within one can be defective on its own internal standard of adequacy. I draw out the implication of this point for the reformist ambitions of each theory in Chapter Three.

Once the principles of authority and justice are distinguished, questions about their compatibility might arise. Let us consider an objection from a scholar whose conception of the rule of law "hovers over the reflections of many so-called 'positivist' modern jurists." ${ }^{54}$ The objection alleges that notions of public authority and public justice are not mutually implicating, as I have suggested, but mutually exclusive. In his magnificent essay “The Rule of Law," Michael Oakeshott argues that an adequate account of the authority of the rule of law excludes considerations of its justice. Oakeshott characterizes the rule of law as a "mode of association in which lex (a rule understood in terms of its authenticity) and jus (a rule understood in terms of the 'rightness' or 'justice'

\footnotetext{
52 Ronald Dworkin, “Thirty Years On,” Harvard Law Review 115 (2002): 1655.

${ }_{53}$ Martin Stone, "Legal Positivism as an Idea about Morality," University of Toronto Law Journal 61 (2011): 327.

${ }^{54}$ Michael Oakeshott, On History and Other Essays, 162.
} 
of what it prescribes) are both recognized but not confused." 55 As Oakeshott explains, a legal rule is authentic or authoritative if it was enacted through the appropriate public procedure. ${ }^{56}$ Whereas the lex or authority of a rule concerns whether it was appropriately enacted, the jus or justice of a rule concerns whether it was appropriate to enact it given its moral character. ${ }^{57}$ Since an authoritative rule may fail to be just and a just rule may fail to be authoritative, Oakeshott writes that "the only 'justice' the rule of law can accommodate is faithfulness to the formal principles inherent in the character of lex" ${ }^{58}$ These formal principles include the requirements that laws be both public and prospective. ${ }^{59}$ For if persons are to interact on the basis of common legal rules, then those rules must be publicly established at the moment of action; they can neither be secret nor retrospective. Oakeshott describes these formal principles as the "jus postulated in the rule of law". 60

Oakeshott claims that by appealing to a conception of jus that is external to lex, nonpositivist theories supplant the rule of law with anarchy. Nonpositivist theories, as Oakeshott conceives of them, are distinguished by two claims. The first is that there is a jus external to lex, a standard of right conduct that obtains independently of the promulgation of legal rules. ${ }^{61}$ Nonpositivist theories conceive of this standard of conduct in a range of different ways: conscience, divine will, human deliberation, absolute values, inalienable rights, unconditional liberties, or a fundamental law. ${ }^{62}$ The second is that the authority of lex hinges on its conformity to this external conception of jus. ${ }^{63}$ Oakeshott refers to the nonpositivist view that conformity to jus is a prerequisite for "the obligation

\footnotetext{
55 Ibid., 136.

56 Ibid., $137-8$ and 143.

${ }^{57}$ Ibid., 141; cf. 135.

58 Ibid., 159.

${ }^{59}$ Ibid., 140, 143, and 159.

${ }^{60}$ Ibid., 140.

${ }^{61}$ Ibid., 142-3.

62 Ibid., 135-6, 142, 156 and 158.

${ }^{63}$ Ibid., 135-6, 142 and 155-6.
} 
to observe the conditions prescribed by lex" as "the recipe for anarchy." ${ }^{64}$ Nonpositivism is anarchic because it renders lex either redundant or irrelevant. If lex conforms to jus, then lex simply echoes a norm that exists independently of it and is therefore "redundant". ${ }^{5}$ Alternately, if lex departs from jus, then lex imposes no obligation constraining conduct and is therefore irrelevant. ${ }^{66}$ In either case, persons are bound not by the shared standards imposed on all by legislative institutions, but by the various contested conceptions of jus to which persons might appeal. In the nonpositivist world that Oakeshott envisions, the only way for persons to interact on the basis of common rules of conduct would be if the opinions of a multiplicity of persons regarding the moral merits of a rule happened to converge. The nonpositivist commitment to a jus external to lex, Oakeshott concludes, cannot be reconciled with the authority of the rule of law. Expressed in the terminology of the unified theory, Oakeshott's objection alleges that the principle of justice undercuts the principle of authority.

Oakeshott's claim that nonpositivist theories are anarchic stems from a conception of nonpositivism that the unified theory does not share. ${ }^{67}$ Unlike the nonpositivist theories that Oakeshott discusses, the unified theory neither posits a conception of justice that obtains independently of law's authority nor claims that conformity to this conception of justice is a condition of law's authority. Rather, as I have argued, the right of government to exercise public authority by imposing legal obligations on private persons must be justified. The justification of this right implicates a moral standard for assessing the adequacy of all valid legal obligations, the principle of

\footnotetext{
${ }^{64}$ Ibid., 160; cf. 156 (referring to the "threat of anarchy"). Here Oakeshott's argument echoes Kelsen, "The Natural-Law Doctrine before the Tribunal of Science," 488: "If the positive law is, as all followers of the natural-law doctrine assert, valid only insofar as it corresponds to the natural law, any norm created by custom or stipulated by a human legislator which is contrary to the law of nature must be considered null and void. This is the inevitable consequence of the theory which admits the possibility of positive law as a normative system inferior to natural law."

${ }^{65}$ Oakeshott., 136 (referring to natural lawyers who "have gone the whole hog and have declared the notion of authenticity redundant").

${ }^{66}$ Ibid., 160.

${ }^{67}$ For an overview of Oakeshott's account of the rule of law and its relation to positivist and nonpositivist theories, see Richard Friedman, "Michael Oakeshott and the Elusive Identity of the Rule of Law," in The Intellectual Legacy of Michael Oakeshott, ed. Corey Abel and Timothy Fuller (Charlottesville: Imprint Academic, 2005), 160-181.
} 
justice. Unlike the conceptions of jus that Oakeshott canvasses, the principle of justice cannot be extrinsic to law's authority because the ideal of equal freedom under law can neither be conceived of nor realized apart from a legal system. ${ }^{68}$ The distinction between the principles of authority and justice further distinguish the unified theory from the kinds of nonpositivist theories that Oakeshott criticizes. Whereas Oakeshott's nonpositivist theories conceive of conformity to jus as the condition of the authority of lex, the principles of public law occupy distinctive planes. As the constitutive principle of public law, the principle of authority concerns whether a given norm or social order is legally authoritative or valid. As the regulative principle of public law, the principle of justice concerns the extent of a legal norm or legal system's moral adequacy. Far from making the anarchist claim that conformity to public justice is the condition for recognizing law's authority, the unified theory holds instead that the presence of public authority is the condition for assessing the extent of its justice.

\section{CONCLUSION}

I have argued that public law is a juridical relationship.

By relationship I mean an association between two parties, neither of which can be considered in isolation from the other. Such relationships arise in various spheres of human life. By referring to someone as a brother or a sister, one conceives of a person as party to a relationship with another. A single child can be a boy or a girl, but cannot be a brother or a sister. The very notion of being a sibling is inherently relational because each party is situated within the context of an association. In some relationships, the parties are situated symmetrically. This is the case in relationships between siblings, friends, colleagues, and spouses. In others, the parties to the relationship are situated asymmetrically, as in the relationships between a doctor and a patient, a parent and a child, and a teacher and a student.

\footnotetext{
${ }^{68}$ I return to this point, below in Chapter Three, in contrasting the principle of justice with the ideal of an instrumental
} theory. 
Public law is the asymmetric juridical relationship between a people and its government. A people is a plurality of persons considered as a whole insofar as its members are subject to common lawgiving. A government consists in the sum of institutions that subject a people to a common lawgiving. Public law is not reducible to either of these parties taken singly. In the absence of common lawgiving, one may find a crowd but one cannot find a people. In the absence of a people that is subject to lawgiving, one may witness an act in which persons gather in a hall, give speeches, stand up and sit down, but one cannot find a government enacting law. The relational significance of the parties cannot be eliminated.

The character of the relationship between the parties is juridical. By juridical I mean that the relationship is comprised of rights and corresponding duties that regard each party not as an isolated entity, but as the participants in a common association. The juridical character of this relationship can be unfolded by considering it from two interrelated standpoints. The principle of authority concerns the obligation of private persons to interact in a condition in which government has the right to establish, implement, and adjudicate law. Whereas the first standpoint relates the right of government to the obligation of private persons, the second relates the obligation of government to the right of persons. The principle of justice requires government to bring the existing legal system into the closest possible conformity with its own underlying justification. Each of these principles emerges from a systematic elaboration of the inherent right of every person to independence. The principles of public law are mutually implicating: there can be no public authoritative institutions in the absence of a duty to govern justly and public justice cannot be realized in the absence of publicly authoritative institutions.

The unified theory of public law departs from Hart's legal positivism in order to redeem its original aspiration. This departure has two aspects. First, the unified theory presents public authority not as a belief that officials have in the obligation-imposing character of their own conduct, but as a juridical implication of the right of every person to independence. The second departure follows from 
the first. Internal to the account of public authority is the standard for assessing its adequacy. Public justice is not "a brooding omnipresence in the sky", ${ }^{69}$ a transcendent value extrinsic to the public law relationship. Rather, public justice is the internal measure of the adequacy of every legal system and all public authority must be exercised in accordance with the terms on which it is justified. Because the unified theory of public law provides an integrated justification of public authority and public justice that retains the distinctiveness of each, it affirms what positivists have long insisted that all nonpositivist theories must deny: a legal system (or a particular law within it) may be valid even though it is not perfectly just.

${ }^{69}$ Southern Pac. Co. v. Jensen, 244 U.S. 205, 222 (1917) (Holmes J., dissenting). 


\section{CHAPTER 2:}

Public Authority AND Private Violence

Whe problem of distinguishing the authority of law from a mere exercise of arbitrary power
acquired renewed interest among legal and political philosophers in the aftermath of the Holocaust, but the problem can be traced back to Plato. A public authority imposes legal obligations upon its subjects; violence merely compels and may be rightfully counteracted. In the Crito, Socrates forgoes the opportunity to escape from prison and avoid his impending execution because it is impossible for a city not to be "destroyed if the verdicts of its courts have no force but are nullified and set at naught by private individuals". ${ }^{1}$ But even though Socrates recognizes that an unjust law or legal system can impose obligations on its members, he denies that legal authority is unlimited. When an Athenian dictatorship demands that Socrates contribute to the murder of an innocent man, he refuses to cooperate. ${ }^{2}$

The purpose of this chapter is to explain how the unified theory distinguishes between public authority and private violence. At the core of the unified theory lies a distinction between two moral standpoints apposite to the public law relationship between rulers and ruled, the principle of authority and the principle of justice. The principle of authority is the constitutive principle of public law because it establishes what a legal system is. As I argued in the prior chapter, a legal system consists in the sum of publicly authoritative institutions and laws that enable private persons to interact with one another on terms of equal freedom. The principle of justice is the regulative principle of public law because it concerns the moral standard for assessing the adequacy of a valid law or a legal system. A legal system is adequate to the extent that it leaves the independence of each person bound by it undiminished.

${ }^{1}$ Plato, Complete Works, ed. J.M. Cooper and D.S. Hutchinson (Indianapolis: Hackett Publishing, 1997), 50a-b.

2 Apology in Complete Works, 32a-e. 
The distinction between the principles of public law generates the possibility of two distinctive kinds of legal pathology, lawless violence (or what I will call barbarism) ${ }^{3}$ and injustice. A legal system is unjust to the extent that it violates the regulative principle of public law by failing to reconcile law's authority with the independence of each individual who is bound by it. In turn, barbarism consists not in a defective legal system that violates public law's regulative principle, but in a violation of its constitutive principle. A condition is barbarous if it fails to maintain the conditions in which private persons can interact rightfully with one another. Thus, the distinction between a legal condition and a barbarous one turns on the character of private interaction, while the distinction between a just legal condition and an unjust one turns on the character of the relationship between the exercise of public authority and each of the persons bound by it. This chapter will explore the pathology of barbarism; the subsequent chapter focuses on injustice.

By conceiving of barbarism as a violation of the principle of authority, the unified theory departs from the familiar ways that leading theories in the positivist and nonpositivist traditions think about the limits of legality. Legal positivists argue that since legal validity is grounded in social facts rather than moral norms, legal validity may be coupled with extreme immorality. In the event that one's legal and moral obligation conflict, individual conscience is to arbitrate the dispute. In contrast, nonpositivists conceive of law as grounded in moral norms that bind conduct, whether of private persons or public officials. Because law is grounded in morality, nonpositivists typically argue that law forfeits its validity once it crosses a certain threshold of immorality. Whereas positivists hold that

\footnotetext{
${ }^{3}$ I follow Kant in using the term barbarism to refer to lawless violence. Kant held that barbarism is "brutishly degrading to humanity" because it subjects the rights of one or more private persons to the arbitrary force of another. See Perpetual Peace in Immanuel Kant: Practical Philosophy, trans. Mary Gregor (Cambridge: Cambridge University Press, 1996), 8:354. In Anthropology from a Pragmatic Point of View (Cambridge: Cambridge University Press, 2006), 330-1, Kant explains that in cases of barbarism, force prevails in the absence of law and freedom, while in cases of despotism (or what I call injustice), force and law prevail in the absence of freedom. While Kant formulates a distinction between barbarism and despotism, he does not elaborate on how the distinction can be drawn in concrete circumstances by the very persons whose rights and duties are implicated by it. For Kant's discussions of barbarism, see Doctrine of Right 6:308, 6:337, 6:339, 6:351 and Towards Perpetual Peace 8:354-5, 8:357; 8:359; 8:376.
} 
any norm can be legally valid but not every valid norm should be obeyed, nonpositivists hold that all valid norms should be obeyed but not all norms can be legally valid.

The unified theory parts with the positivist approach by establishing a moral justification for a legal system to exercise public authority over its members. A legal system consists in a set of publicly authoritative institutions that establish, interpret, and implement law. The public authority of a legal system can be justified because private persons must interact with one another on terms of equal freedom, but cannot do so in the absence of publicly authoritative institutions. Such a justification of public authority indicates the limits of legality. Since public authority is that which enables private persons to interact with one another on terms of equal freedom, that which is incompatible with such interaction cannot be publicly authoritative. The justification of public authority establishes that public authority must be obeyed, but denies that any mode of social ordering can be publicly authoritative or legally valid.

The unified theory also diverges from its nonpositivist counterparts. The leading nonpositivist theories conceive of the limits of legal validity in terms of a departure from a regulative ideal of legality. Nonpositivists theorists have pursued this line of thought in different ways. Lon Fuller held that legal validity diminishes to the extent that a legal norm or a legal order departs from the principles that make up the internal morality of law. Gustav Radbruch famously argued that extreme injustice cannot be legally valid. Robert Alexy maintains that law forfeits its validity when it fails to make a claim to moral correctness. Each of these views unites around the idea that the validity of law is to be understood in reference to a standard of law's moral adequacy. On this view, understanding what law ought to be is a prerequisite for making determinations about the validity of particular laws and legal systems. The unified theory of public law generates an alternative approach from within the nonpositivist paradigm. From the standpoint of the bifurcated structure of the unified theory, the question of whether a particular norm or legal order is valid turns not on the extent of its conformity 
to the regulative principle of public law (the principle of justice), but on its consistency with the constitutive principle of public law (the principle of authority). I will argue that by consulting a regulative principle to answer the constitutive question of whether a supposed law or legal order is valid, the leading nonpositivist theories commit a fundamental error that leaves them unable to distinguish paradigmatic instances of legality from paradigmatic instances of barbarism. Accordingly, in formulating the distinction between legality and barbarism from the standpoint of the unified theory, I will focus solely on the distinctive moral problem involved in satisfying the constitutive principle of public law, the principle of authority. Such an approach provides the resources to vindicate the nonpositivist theses that all valid laws must be obeyed and that not all norms can be legally valid.

I explore the distinction between legality and barbarism in four sections. The first explains how German legal theorists, in the aftermath of Nazism, distinguished instances of legality from instances of barbarism. I argue that by conflating the constitutive and regulative dimensions of public law, Radbruch and Alexy are unable to establish a workable distinction between legality and barbarism. In search of such a distinction, I turn to the neglected framework of Julius Ebbinghaus. While Ebbinghaus rightly maintains that barbarism consists in a violation of the constitutive principle of legality rather than its regulative principle, I argue in the second section that he wrongly conceives of arrangements that are compatible with legality and that are indicative of barbarism as the same in all times and places. Accordingly, in the third section I explain how private persons in different contexts can distinguish instances of legality (which must be obeyed) from instances of barbarism (which may be rightfully resisted). The fourth and final section applies the framework developed in the prior sections to the concrete circumstances of Nazi Germany. I argue that the barbarism of Nazi Germany was evident not merely from our standpoint, as is often suggested, but from the prevailing standpoint of the public culture in which it arose. As Nazism divested itself of all vestiges of legality, it became 
increasingly apparent that Nazism was not a lawful authority that protected the freedom of each person in relation to every other, but a lawless power to which all were subject.

\section{The Distinction in Postwar German Legal Theory}

In the aftermath of the Holocaust, German legal theorists sought to formulate a framework that would indicate the barbarism of Nazi power and regulate the development of the postwar legal order. In this section, I argue that this project was undermined by the failure to draw a distinction between the constitutive and regulative dimensions of a legal system. This failure culminates in theories that either affirm the justice of barbarous regimes or deny the legality of highly just legal systems. A more promising approach appears in the work of the Marburg Kantian, Julius Ebbinghaus. For Ebbinghaus, the problem with Nazism was not that it violated the regulative principle of legality, but that it violated the constitutive principle of legality. Legality is the condition in which each private person can enjoy his or her freedom in relation to every other. It follows that any condition that fails to satisfy this standard cannot be a legal system. Similarly, within a legal system, a norm that is incompatible with the possibility of private persons interacting on terms of equal freedom cannot be valid.

\section{Radbruch on Statutory Lawlessness}

Radbruch's theory begins with the insight that law involves the exercise of force but is not reducible to it. Force compels but it generates no obligation to obey. To explain how law can impose obligations, Radbruch appeals to a series of legal values: certainty, purposiveness, and justice. ${ }^{4}$ Certainty makes the positive law knowable to those who are under an obligation with respect to it. If the law is knowable, persons can adjust their conduct in light of what the law requires and thereby avoid the law's coercive sanction. Alternately, if there is no law or if what is called law is unknowable

\footnotetext{
${ }^{4}$ Radbruch, "Statutory Lawlessness and Supra-Statutory Law (1946)," Oxford Journal of Legal Studies 26 (2006): 6.
} 
— as was the case when the emperor Caligula posted the laws in small print at the summit of a tall pillar ${ }^{5}$ - persons cannot know what actions are permitted. The second value of law is purposiveness, which Radbruch conceives of as the benefit of the people. Since the greatest injustices of the Nazi years were alleged to be for the benefit of the people, Radbruch holds that it is not the case that what benefits the people is law; rather, "what law is benefits the people." $\mathrm{Law}$, in turn, is defined as legal certainty and the striving for justice. Radbruch conceives of justice as the equal treatment of equal persons: "Justice means: To judge without regard to the person, to measure everyone by the same standard."

Legal certainty can be found in unjust statutes, while laws need not be enacted simply because they are just. The potential schism between legal certainty and justice prompts Radbruch to introduce his famous formula. The formula is often divided into two parts. ${ }^{8}$ The first concerns the distinction between unjust and invalid statutes. As Radbruch explains, the distinction between an unjust law and an invalid one concerns the degree that the supposed law departs from justice:

The conflict between justice and legal certainty should be resolved in that the positive law, established by enactment and power, has primacy even when its content is unjust and improper. It is only when the contradiction between positive law and justice reaches an intolerable level that the law is supposed to give way as a 'false law' [unrichtiges Recht to justice. It is impossible to draw a sharper line between the cases of legalised injustice and laws which remain valid despite their false content. ${ }^{9}$

\footnotetext{
${ }^{5}$ Fuller, The Morality of Law (New Haven: Yale University Press, 1964), 93.

${ }^{6}$ Radbruch, "Five Minutes of Legal Philosophy," Oxford Journal of Legal Studies 26 (2006): 14.

7 Ibid.

${ }^{8}$ On the distinction between the two parts of Radbruch's' formula, see Frank Haldemann, “Gustav Radbruch vs. Hans Kelsen: A Debate on Nazi Law," Ratio Juris 18 (2005): 166; Stanley L. Paulson, “On the Background and Significance of Gustav Radbruch's Post-War Papers," Oxford Journal of Legal Studies 26 (2006): 26; Thomas Mertens, "Nazism, Legal Positivism and Radbruch's Thesis on Statutory Injustice," Law and Critique 14 (2003): 288; Mertens, "Darker Legacies of Law in Europe: The Shadow of National Socialism and Fascism over Europe and its Legal Traditions," Ratio Juris 18 (2005): 286; Robert Alexy, "A Defence of Radbruch's Formula," in Recrafting the Rule of Law: The Limits of Legal Order, ed. David Dyzenhaus (Oxford: Hart Publishing, 1999), 16; and Alexy, "On the Concept and the Nature of Law," Ratio Juris 21 (2008): 282. For an interpretation that seeks to retain the unity of the formula, see David Dyzenhaus, "The Juristic Force of Injustice," in Calling Power to Account: Law, Reparations and the Chinese Head Tax, eds. Dyzenhaus and Mayo Moran (Toronto: University of Toronto Press, 2005), 279-280.

${ }^{9}$ Quoted in Alexy, “A Defence of Radbruch's Formula,” 15-16.
} 
The positive law takes precedence even when it is unjust and unbeneficial to a people because legal certainty enables persons to conduct themselves in accordance with what is publicly known to be lawful. But because law is the will to justice, when positive law conflicts with justice to an intolerable degree, positive law forfeits its validity. The second part of Radbruch's formula is typically interpreted as an elaboration of the nature of invalid law: "Where justice is not even aimed at, where equality the core of justice - is deliberately disavowed in the enactment of positive law, the law is not simply 'false law,' it has no claim at all to legal status." ${ }^{10}$ A valid law is not necessarily fully just, but justice prescribes the limits of valid lawgiving. Since law is the will to justice, the repudiation of justice cannot be law.

Radbruch terms invalid lawgiving statutory lawlessness. Nazi lawgiving was an instance of statutory lawlessness because it renounced justice by treating equal persons unequally:

If one applauds the assassination of political opponents, or orders the murder of people of another race, all the while meting out the most cruel and degrading punishment for the same acts committed against those of one's own persuasion, this is neither justice nor law. If laws deliberately betray the will to justice-by, for example, arbitrarily granting and withholding human rights - then these laws lack validity, the people owe them no obedience, and jurists, too, must find the courage to deny them legal character. ${ }^{11}$

By denouncing equality as a legal value, Nazism reduced itself into an arbitrary power, which compelled but imposed no obligations. In the absence of a valid legal power, both public officials and private persons are bound by suprastatutory law, which consists in what justice demands regardless of whether it has been enacted in positive law. ${ }^{12}$

\footnotetext{
10 Ibid., 16.

11 Radbruch, "Five Minutes," 14. See also Radbruch, "Statutory Lawlessness," 8.

12 Radbruch, "Statutory Lawlessness," 5.
} 
In the aftermath of Nazism, Radbruch's distinction between statutory lawlessness and suprastatutory law was repeatedly invoked by German courts. On one occasion, the Federal Constitutional Court considered the validity of the Reich's Citizenship Law, ${ }^{13}$ enacted 25 November 1941, which established that Jews would lose their German nationality by taking up residence abroad. In 1968, a Jewish lawyer, who had been deported to Amsterdam in 1942 and who was presumed to have been murdered in a concentration camp, returned to Germany to establish his German nationality, which was a precondition for receiving his inheritance. The Federal Constitutional Court held that the plaintiff had never lost his citizenship because the Reich's Citizenship Law was invalid from the moment of its enactment. Although the Reich's Citizenship Law was enacted and enforced by the relevant institutions, the Court denied its validity because it conflicted with "fundamental principles of justice". ${ }^{14}$ Echoing the first part of Radbruch's formula, the Court held that the conflict between justice and the Reich's Citizenship Law "has reached so intolerable a level that" the law "must be regarded as void from the outset." 15

Radbruch's claim that Nazi laws were invalid cannot stand on his account of justice. For Radbruch, a law is invalid if it repudiates justice to an intolerable degree. Throughout his career, Radbruch conceived of justice as formal equality: "[W] hile justice directs us to treat equals equally, unequals unequally, it does not tell us anything about the viewpoint from which they are to be deemed equals or unequals in the first place; moreover, it determines solely the relation, and not the kind, of

\footnotetext{
13 RGB1. I. p. 722.

14 BVerfGE 23, 98 (106).

15 Ibid.
} 
the treatment." 16 Justice is indeterminate with respect to two issues: "whom to consider equal or different, and how to treat them". ${ }^{17}$

A problem arises with respect to each of these indeterminacies. I will consider each singly and then note their joint implication. First, justice does not determine who is an equal. Whether Aryans are equal to non-Aryans is not a question that justice addresses. Since justice does not determine who is an equal, laws that acknowledge the superiority of Aryans and the inferiority of non-Aryans cannot constitute an extreme injustice that indicates invalidity. Second, Radbruch's conception of justice merely requires that equals be treated alike but does not determine how persons are to be treated. ${ }^{18}$ On this view, what is objectionable about Nazism was that it treated Jews and other persecuted groups differently than it treated Aryans. Nazi treatment of persons could have been just, then, if only its persecution was not limited to Jews and other persecuted groups. Thus, an implication of Radbruch's account is that those who risked their lives to save the persecuted could have instead served justice by making Nazi persecution more inclusive. ${ }^{19}$ Bringing these strands together, a Nazi could purport to

\footnotetext{
${ }_{16}$ Radbruch, Legal Philosophy in The Legal Philosophies of Lask, Radbruch, and Dabin, trans. Kurt Wilk (Cambridge: Harvard University Press, 1950), 107. See also Radbruch's postwar article, "Statutory Lawlessness," in which justice is defined as "the equal treatment of equals" (8).

Radbruch characterized his later writings not as a dramatic reorientation of his worldview, but rather as a shift in accent that brought "into the light what formerly stood in shadow." See Radbruch, in Kulturlebre des Sozialismus, ed. Arthur Kaufmann (Frankfurt: Athenäum, 1970), 79. For a discussion of the supposed transformation in Radbruch's thought, see Stanley L. Paulson, "Radbruch on Unjust Laws: Competing Earlier and Later Views?" Oxford Journal of Legal Studies 15 (1995): 489-500. Paulson argues that the shift in accent corrected "a mistake in his earlier position, namely, the assignment of a disproportionate weight to legal certainty at the expense of justice" (493-4). While Radbruch famously revised the interrelationship between the legal values he articulates, it seems that the conception of justice that he employs remains constant. I direct my criticism to the relationship between this conception of justice and Radbruch's conclusion that Nazism was not a lawful power.

${ }^{17}$ Radbruch, Legal Pbilosophy, 90-1.

${ }^{18}$ The absurdity of conceiving of justice as mere equal treatment can be illustrated with an anecdote about the philosophy professor, Sidney Morgenbesser: "He was once asked if it was unfair that the police hit him on the head during the riot. 'It was unfair but not unjust,' he pronounced. Why? 'It's unfair to be hit over the head, but it was not unjust since they hit everybody else over the head." So long as Professor Morgenbesser is equal to other protesters, if the police treat protesters alike by hitting all of them on the head, then justice requires that Professor Morgenbesser be hit on the head too. See Douglas Martin, "Sidney Morgenbesser, 82, Kibitzing Philosopher, Dies" The New York Times, http://www.nytimes.com/2004/08/04/us/sidney-morgenbesser-82-kibitzing-philosopher-dies.html (accessed October 17, 2011).

${ }^{19}$ On this point, see Bernard Loesener, Legislating the Holocaust: The Bernard Loesener Memoirs and Supporting Documents, ed. Karl A. Schleunes, trans. Carol Scherer (Boulder, Colorado: Westview Press, 2001), 95: "Thus far, I have described the efforts and battles over a period of almost 10 years. Their goal was to influence legislation so that the largest possible
} 
act in accordance with Radbruch's conception of justice by treating his Aryan equals according to one criterion and non-Aryans according to another. Radbruch's conception of justice is simply too thin to justify the conclusion that Nazi violence was lawless.

The shortcoming in Radbruch's theory can be traced to the way that he conceptualizes the relationship between the constitutive and regulative dimensions of legality, validity and justice, respectively. Radbruch conceives of legality as a spectrum in which justice lies at one end and invalidity at the other. When the distinction between justice and invalidity is conceptualized as one of degree rather than kind, a problem arises regardless of whether the theorist introduces a demanding or a permissive conception of justice. The more demanding a conception of justice is, the more existing conditions and norms will significantly depart from it, with the result that the validity of an extensive array of laws and legal systems will come into question. While such an approach would culminate in the desired conclusion that Nazism is barbarous, the approach would also impugn the legality of other less controversial norms and modes of legal ordering. The problem cannot be solved by formulating a more permissive conception of justice. For the more easily a conception of justice is satisfied, the more existing conditions and norms will closely conform to it. The result, instantiated by Radbruch's theory, is that the most horrific Nazi laws are deemed to be not only valid but also just. Each of these possibilities fails to satisfy the aim of Radbruch's legal theory. Radbruch's aspiration was to formulate a legal theory that would identify the barbarism of Nazi power and direct the legal reform of postwar Germany. By conceptualizing validity and justice as arising on a single plane, Radbruch left himself to choose between a framework that denies both the validity of Nazism but also Germany's postwar order and a framework that rightly recognizes the relative justice of

number of people would, from the outset, be spared from the clutches of antisemitic legislation." Given Radbruch's conception of justice, perhaps Loesener should have directed his efforts towards making Nazi persecution more inclusive. 
Germany's postwar order but also affirms the justice of Nazi law. Each of these possibilities are equally fatal to Radbruch's theoretical ambitions.

Alexy's Theory of Moral Claim

Robert Alexy seeks to defend Radbruch's thesis that extreme injustice cannot be law by introducing an innovative conceptual framework. As a nonpositivist, Alexy defends a version of the connection thesis, which defines the concept of law as encompassing moral elements. ${ }^{20}$ The connection thesis affords a number of interpretations. On one interpretation, which Alexy terms exclusive nonpositivism, "every moral defect yields legal invalidity."21 Alexy rejects this nonpositivist paradigm because its emphasis on the ideal or critical dimension of law excludes the "factual or authoritative dimension". ${ }^{22}$ The opposite position, super-inclusive non-positivism, which Alexy attributes to Kant, holds that moral defects have no bearing on legal validity. ${ }^{23}$ Each of these positions provides a mirror image of the other's vice: exclusive non-positivism overemphasizes the ideal dimension of law at the expense of its factual dimension; super-inclusive non-positivism overemphasizes the factual dimension of law at the expense of its ideal dimension. Alexy endorses what he calls inclusive non-positivism, the moderate thesis that "legal validity is lost in some cases of moral defects... and not in others." ${ }^{24}$ Radbruch's formula that extreme injustice is not law is perhaps the most well-known instance of inclusive nonpositivism. For Alexy, the formula captures something fundamental about the relationship between

\footnotetext{
20 Alexy, The Argument from Injustice: A Reply to Legal Positivism, trans. Bonnie Litschewski Paulson and Stanley L. Paulson (Oxford: Clarendon Press, 2002), 4, 21 ff.; see also Alexy, "On the Concept and the Nature of Law," 285.

21 Alexy, "On the Concept and the Nature of Law," 287. See also Alexy, "Effects of Defects-Action or Argument? Thoughts about Deryck Beyleveld and Roger Brownsword's Law as Moral Judgment," Ratio Juris 19 (2006): 169-179 and Stanley L. Paulson, “Law as a Moral Judgment," Ratio Juris 7 (1994): 111-116.

22 Alexy, "On the Concept and the Nature of Law," 287. Alexy attributes this position to Deryck Beyleveld and Roger Brownsword, Law as Moral Judgment (Sheffield: Sheffield Academic, 1994), 76: "[]mmoral rules are not legally valid."

23 To my knowledge, Alexy does not discuss Kant's conception of barbarism or its significance within his broader framework.

${ }^{24}$ Alexy, "On the Concept and the Nature of Law," 287. Alexy also refers to this position as the weak connection thesis. See The Argument from Injustice: A Reply to Legal Positivism, trans. Bonnie Litschewski Paulson and Stanley L. Paulson (Oxford: Clarendon Press, 2002), 47.
} 
law and morality in an adequate nonpositivist framework: a legal system (or an appropriately enacted law) may impose obligations even though it is not perfectly just. ${ }^{25}$ Such an insight cannot be accommodated by exclusive non-positivist frameworks (which deny that legal validity is compatible with even a trace of injustice) or by super-inclusive non-positivist frameworks (which assert that validity is compatible with even the most extreme injustice). This set of distinctions is familiar. Just as Hart held that an adequate theory of law must avoid anarchism and quietism by explaining how positive law could be valid but nevertheless immoral, so too Alexy seeks to develop a framework that integrates the factual and ideal dimensions of law. ${ }^{26}$

The basis of Alexy's inclusive-nonpositivist framework is his theory of claim, which holds that a legal order (or a particular law within one) necessarily makes a claim to moral correctness. ${ }^{27}$ If the claim to moral correctness is made but unfulfilled, Alexy asserts that the legal order is defective or unjust. But if the claim to moral correctness is not made at all, then Alexy maintains that no legal order exists. Alexy illustrates how his theory of claim distinguishes between an unjust legal order and a condition of lawless violence through a series of examples. The first involves a senseless order in which a violent group rules haphazardly by issuing "partly contradictory, ever-changing, and partly unfulfillable single orders to the subjects." 28 This order is not a legal system because the only general rule is that the rulers are permitted to impose violence, and no claim is made with respect to the moral correctness of this arrangement. The second example involves general rules but no claim to moral correctness. In what Alexy calls a predatory order, a wholly exploitative system of rules obtains in which subjects are killed for the financial benefit of the rulers. ${ }^{29}$ Because no claim to moral correctness is

\footnotetext{
25 Alexy, "On the Concept and Nature of Law," 282.

${ }^{26}$ Ibid., 290 and 292.

27 Alexy, "On the Necessary Relations Between Law and Morality,” Ratio Juris 2 (1989): 178. On Alexy's theory of claim, see Maeve Cook, "Law's Claim to Correctness," in Law, Rights, and Discourse: The Legal Philosophy of Robert Alexy, ed. George Pavlakos (Oxford: Hart Publishing, 2007), 225-248.

28 Alexy, "On the Necessary Relations Between Law and Morality," 176.

29 Ibid.
} 
made, Alexy denies that the predatory order is a legal system. In this final example, a ruler-system, rulers kill and exploit their subjects in light of general rules and procedures. The rulers claim, and the majority of subjects accept, that the practice is justified because it somehow serves the purpose of developing the people. Alexy concludes that the ruler-system is a legal order, albeit a highly unjust one. What makes the ruler-system a legal order is that "a claim to correctness is rooted in the practice of the rulers' system and raised against everyone."30

Alexy's theory of claim cannot support his conclusion that Nazism was not a legal system. As historians have noted, part of what is so troubling about Nazism was that it made a claim to moral correctness:

The Final Solution did not develop as evil incarnate but rather as the dark side of ethnic righteousness. Conscience, originally seen to protect the integrity of the individual from the inhumane demands of the group, in the Third Reich became a means of underwriting the attacks by the strong against the weak. To Germans caught up in a simulacrum of high moral purpose, purification of racial aliens became a difficult but necessary duty. ${ }^{31}$

Since Nazism made a claim to moral correctness, Alexy's conclusion that Nazism was not a valid legal system cannot stand.

Alexy's argument cannot be saved by invoking a distinction between de facto and de jure claims to moral correctness. If the theory of claim is revised to hold that a valid legal system makes a claim to de facto moral correctness, that is, to what persons might suppose is morally correct, then Germany's

\footnotetext{
${ }^{30}$ Ibid., 177. Alexy's examples in this passage are somewhat ambiguous. For instance, it is not clear what significance the people's acceptance of the moral claim has within Alexy's framework. In his example of the senseless order, Alexy indicates that the subjects obey only because they are afraid of coercion. In the example of the predatory order, it seems to be the case that the people deem the rules to be exploitative. Finally, in his example of the legal order of the ruler-system, Alexy indicates that the majority of rulers and ruled accept the moral claim. Does Alexy conceive of legality as involving a practice informed by general rules that is merely claimed to be morally correct by the supposed rulers? Or does legality also require that the claim be accepted? And if the claim must be accepted, who must accept it? Must is be accepted merely by the rulers or must it also be accepted by a majority of the ruled? If the latter, does Alexy mean to exclude the possibility that a social order that operates in accordance with general rules and makes a claim to moral correctness that is accepted by the majority of persons might nevertheless be barbaric?

${ }^{31}$ Koonz, The Nazi Conscience (Cambridge: Harvard University Press, 2003), 273.
} 
postwar order must be a valid legal system, but Nazism must be as well. On this interpretation, Alexy's theory dovetails with Radbruch's because both conceive of barbarism in terms of a departure from a moral ideal that is easily approximated. Alternately, if Alexy's position is that a valid legal system makes a claim to de jure morality, that is, to what is actually morally correct, then Nazism would be invalid because its conception of morality was appalling. But such a position proves too much. While a standard of de facto morality culminates in an underinclusive conception of barbarism in which any social order that makes a claim to moral correctness is valid, a standard of de jure morality culminates in an overinclusive conception of barbarism because it renders invalid not only Nazism, but also any social order that appeals to an inadequate conception of morality. The attempt to salvage Alexy's position by introducing a distinction between de facto and de jure morality offers only the unacceptable possibilities that any social order that makes a claim to moral correctness cannot be barbaric or that every social order that fails to make a claim with respect to the appropriate conception of morality is barbaric. Neither of these possibilities is consistent with the core insight that Alexy's inclusive nonpositivism seeks to illuminate, that legal validity is lost in some cases of moral defect but not in others.

By failing to identify the problem in Radbruch's theory, Alexy resurrects it within his own. Both Radbruch and Alexy treat the question 'What does it mean for law to be valid?' as derivative of the question 'What does it mean for law to be just or morally correct? This approach generates two equally problematic paths. The employment of a rigorous conception of justice or moral correctness culminates in anarchism (or what Alexy calls exclusive non-positivism), which denies the validity of a wide range of uncontroversial legal instances. The employment of a lax conception of justice or moral correctness culminates in quietism (or what Alexy calls super-inclusive non-positivism), which affirms that paradigmatic instances of barbaric violence are not only lawful but just.

To draw a distinction between barbarism and legality, what is needed is not an account of what a purported legal system claims. After all, the example of Nazism indicates that even the most 
pernicious violence can be coupled with claims of the utmost moral purity. Rather, what is needed is a moral exposition of the basis of legality. Such an exposition can be found in the legal theory of Julius Ebbinghaus, which follows the broad features of the unified theory of public law, as elaborated in Chapter One.

\section{Ebbinghaus on Inhumanity}

For Ebbinghaus, legality is a system of equal freedom in which each person may engage in any action that is consistent with the freedom of others. The system secures the freedom of each person by placing reciprocal limits on conduct. Because these limits are to be determined by general rules that apply to all persons, Ebbinghaus calls this system of equal freedom the law of humanity. ${ }^{32}$ Ebbinghaus develops the law of humanity in a conceptually sequenced argument that proceeds from an account of private interaction to a theory of state power.

The law of humanity imposes a two-fold duty upon each person with respect to every other. ${ }^{33}$ First, persons have a duty to make their freedom expressive of their own purposes rather than the purposes of another. While one person may choose to further another's purposes, the freedom of persons cannot be reconciled if some persons subordinate themselves to serve as instruments for the achievement of another's purposes. Such subordination would negate the freedom of some persons rather than harmonize it with the freedom of all others. Second, persons have a duty to exercise their freedom in a manner that is consistent with the freedom of others. Whereas the first duty requires persons to make their freedom expressive of their own purposiveness, the second requires persons to act in a manner that respects the purposiveness of others. The institution of slavery, for example, violates both duties. Serving as a slave is inconsistent with the duty to exercise one's own freedom in a manner that is expressive of one's own purposes. Acting as a master is inconsistent with the duty

\footnotetext{
32 Ebbinghaus, “The Law of Humanity and the Limits of State Power," Philosophical Quarterly 3 (1953): 15-16.
}

33 Ibid., 16. 
to exercise one's own purposes in a manner that respects the purposiveness of others. The master violates the law of humanity by seeking to determine the limits of another's freedom through the imposition of his own physical power. Such a determination treats a human being as a thing, that is, as lacking the moral capacity to limit the freedom of another. The two-fold duty incumbent on persons is expressed in the imperative: "Do not reduce yourself to an object of other men's arbitrary power, nor other men to objects of your own." 34

Even if persons discern and act in accordance with the law of humanity, so long as they remain in a lawless condition there can be no guarantee that others will do the same. In the absence of assurance that all others will act in accordance with the limits established by the law of humanity, any person that follows the law of humanity subjects their freedom to the arbitrary choices of others. But subjecting one's freedom to the arbitrary choices of others is exactly what the law of humanity forbids. Thus, the law of humanity requires that persons interact in a condition in which there is assurance that the law of humanity will be respected. Accordingly, the duty of persons to assert one's own freedom and to respect the freedom of others gives rise to a further duty: "They must submit themselves to a common authority which has the power to impose laws upon them, and whose sole objective is the universal assurance of rights." 35

In providing the justification for entering a legal condition, the law of humanity reveals the regulative ideal of such a condition. Public power is exercised justly when it is directed towards securing the freedom of all who are bound it. In contrast, public power is exercised unjustly when it imposes or fails to alleviate arbitrary limits on the freedom of persons bound by law. A limit on freedom is arbitrary if it is not required to reconcile the freedom of persons under law. So, for example, an arbitrary law might compel citizens to "salute the governor's hat" or forbid them to "sniff the perfume

${ }^{34}$ Ibid.

${ }^{35}$ Ibid., 17. 
of violets". ${ }^{36}$ Although such laws are arbitrary, they are nevertheless valid and demand the obedience of persons. That an unjust law is valid follows from the law of humanity. Persons have a duty to interact in a condition of public law, in which limits on the freedom of private persons are determined and enforced by an impartial authority. The existence of such an authority is incompatible with the right of private persons to exempt themselves from valid laws on the basis that they are, to some extent, unjust. While a condition of public law might enact arbitrary restrictions on freedom, these restrictions are — from the perspective of the law of humanity — preferable to a lawless condition in which the domain of each person's freedom can neither be publicly established nor impartially enforced because in such a condition the freedom of each person is necessarily subject to the arbitrary choices of every other.

From the standpoint of the law of humanity, the problem surrounding Nazi power is not that it was unjust but that it was inbuman. Nazism sought not to limit the freedom of persons subject to law on arbitrary grounds that freedom itself did not require, but to negate the freedom of particular persons in relation to others. The persecuted were reduced from the legal status of human beings to that of things lacking the legal capacity to restrict the freedom of others. For Ebbinghaus, the fundamental inhumanity of Nazism consisted not in the commission of genocide, but in the antecedent denial that certain persons had the capacity to suffer legal wrongs:

Those positive laws which we have accused of violating the law of humanity are laws which reduce men to the status of material things... The same type of violation would be involved in a law which annulled the right of specified persons to enter into contracts legally binding on others; or again, in any law which condemned men to death for their religious creed or their racial origin. For here also it is evident that such laws deny to the persons concerned all possibility of legal action. And in the latter case the denial is particularly monstrous, since what is denied is the legal possibility of life itself. Their very life is made illegal, because the acts whereby it might acquire legality are not within their power. It is as little within the power of a man's will to become convinced of what he does not believe as it is to change his

\footnotetext{
36 Ibid., 20.
} 
racial origin. Such persons therefore are condemned to death unconditionally; for they are deprived, in principle, of any power at all to restrict the liberty of others in such a way that they could live among them. ${ }^{37}$

Nazi power conceived of Jews as possessing a strange form of legal personality in which wrongs could be imputed to Jews but Jews could not suffer wrongs. Wrongs could be imputed to Jews because Nazism recognized that Jews could owe duties. Wrongs could not be suffered by Jews because Nazism denied that Jews had the moral capacity to have rights. ${ }^{38}$ As beings without rights, Jews lacked the legal status to restrain the conduct of others with respect to them.

This conception of the legal personality of Jews pervaded the adjudication of private disputes by Nazi courts. Contracts between Jews and Germans could be voided at the request of the latter. ${ }^{39}$ Divorce proceedings invariably gave custody of the child to the Aryan parent despite a law that held that custody was to be awarded to the innocent partner. While the landlord-tenant law indicated that a lease could be terminated only "if the behavior of the tenant is such that a continuation of the lease would represent an unreasonable hardship for the landlord," Nazi courts held that the 'racial qualities' of the tenant itself constituted such a hardship. ${ }^{40}$ It soon became "pointless for Jews to appeal to [courts] for the protection of their rights." ${ }^{41}$ Turning from the denial that Jews were capable of having rights to the Nazi conception of their duties, Nazi power sought not to prohibit particular actions but to deny the legality of particular actors by making their very existence wrongful. Laws that prohibit what one is rather than what one does cannot be followed because agents cannot abide by norms that render their very existence wrongful. ${ }^{42}$ The barbarism of Nazi power consisted in the denial that Jews

\footnotetext{
37 Ibid., 21.

38 R.C. van Caenegem, An Historical Introduction to Western Constitutional Law, trans. David Johnston (Cambridge: Cambridge University Press, 1996), 289.

${ }^{39}$ Ingo Müller, Hitler's Justice (Cambridge: Harvard University Press, 1991), 116.

40 Ibid., 117.

${ }^{41}$ Ernst Fraenkel, The Dual State: A Contribution to the Theory of Dictatorship (New York: Oxford University Press, 1941$), 92$.

42 See Kristen Rundle, “The Impossibility of an Exterminatory Legality: Law and the Holocaust," University of Toronto Law Journal 59 (2009): 65-125.
} 
could be treated wrongfully by others and in the insistence that they did wrong independently of their actions. $^{43}$

In a barbaric condition, what purports to be law is no more than private violence. When private violence prevails, the law of humanity imposes a fundamental obligation on every person: enter into a legal condition in which the freedom of each person in relation to every other is assured by an impartial public authority. Each person in a lawless condition - whether a victim of violence or a supposed official empowered to carry it out - is under an overriding legal obligation to enter into a legal condition that secures each person from the violence of other private persons.

By distinguishing the problem of inhumanity or barbarism from that of injustice, Ebbinghaus' framework avoids the difficulties that arise in the theories of Radbruch and Alexy. Radbruch's distinction between law and barbarism breaks down because it conceives of barbarism as the failure to treat equals equally, but leaves open the question of who is an equal and how equals are to be treated. In contrast, Ebbinghaus' framework establishes the conception of equality relevant to the existence of a legal system, the interaction of private persons on the basis of reciprocal limits on freedom. Since a legal system is that which secures the freedom of each in relation to every other, violence may be deemed barbaric regardless of whether it targets a single person, a class of persons, or persons generally. Ebbinghaus' theory also avoids a problem that arises in Alexy's. Alexy conceptualizes the distinction between barbarism and legality in terms of how those who exercise power happen to characterize their own violent activity. Ebbinghaus instead focuses on the distinction between public authority and private violence by asking whether the activity of the supposed public authority satisfies the constitutive dimension of legality by securing the freedom of each private person in relation to every other. Further, by distinguishing between the constitutive and the regulative

${ }^{43}$ Given the theoretical orientation of his article, Ebbinghaus does not speculate about the historical moment in which Nazism crossed the threshold from a condition of injustice to one of barbarism. 
dimensions of a legal system, Ebbinghaus provides a framework that enables the barbarism of Nazi power to be acknowledged without following Radbruch in denying the validity of other paradigmatic instances of legality or diluting the conception of justice apposite to assessing their adequacy.

Ebbinghaus' theory shares its normative architecture with the unified theory of public law. What Ebbinghaus calls injustice consists in the violation of the regulative principle of public law, the principle of justice. A state is unjust when public authority imposes constraints on the freedom of those who are bound by law that freedom itself does not require. In contrast, what Ebbinghaus calls inbumanity consists in the violation of the constitutive principle of public law, the principle of authority. An inhuman or barbaric law or condition violates the principle of authority because it is not compatible with the possibility of private persons interacting with one another on terms of equal freedom.

The notion of barbarism does not swallow up the principle of authority. As I argued in the prior chapter, the principle of authority imposes a duty on private persons to submit themselves to the governance of a legal system. A legal system consists in the institutions and laws that make it possible for private persons to interact rightfully with one another on terms of equal freedom. On this view, every legal system is a form of social ordering, but not every form of social ordering is a legal system. When persons find themselves in a legal system, the principle of authority requires them to obey all valid lawgiving enacted within it, regardless of the extent to which the legal system conforms to the ideal of public justice. But when persons find themselves in a barbarous condition, the principle of authority requires the formation of a legal condition. Private persons do no wrong when they forcibly resist private violence in order to enter a condition of public law. For the principle of authority requires private persons to submit themselves to the governance of public institutions, which secure the rights of each private person in relation to every other; not to the arbitrary power of other private persons. 


\section{The FAILURE of A Static Distinction}

Ebbinghaus' account of barbarism escapes the difficulties that the theories of Radbruch and Alexy encounter, but it raises a critical difficulty of its own. Ebbinghaus conceives of the threshold that separates barbarism from legality as static. The distinction separating those practices that are compatible with legality and those that are indicative of barbarism - such as the denial that persons can acquire proprietary or contractual rights that place others under a corresponding obligation obtains now and for all time. Since Ebbinghaus formulates the distinction between legality and barbarism in abstraction from historical circumstances, the distinction is unaffected by any contingent state of affairs, including the way in which persons in particular times and places conceive of legality. Whether one resides in a polis of the ancient world, a feudal society of the Middle Ages, or a modern constitutional state, the line that separates a lawful condition from a barbarous one remains unmoved.

One might object to the location of the threshold that Ebbinghaus posits. Some might take issue with the implication of Ebbinghaus' view that one must wait until the purported authority reduces one to the status of a thing before its lawful power dissolves into arbitrary violence that may be rightfully resisted. Perhaps Ebbinghaus conceives of barbarism too narrowly and legality too broadly. Others might reverse this criticism by alleging that Ebbinghaus conceives of legality too narrowly and barbarism too broadly by suggesting that the denial of the right to own property or to enter into contracts is not itself barbaric. But criticisms that target the precise location of the threshold that separates public authority from private violence overlook a deeper problem in Ebbinghaus' approach, which concerns not the particular location of the threshold that separates law from lawlessness but its static character. Because a static distinction between legality and barbarism abstracts from the conceptions of legality that private persons themselves hold, it might depart from the conceptions of legality that actual situated persons hold. But if the distinction is alien to private persons, perversity follows. As we have seen, the distinction between legality and barbarism 
determines the rights and duties of private persons: private persons have a duty to submit to public authority and a right to resist private violence. If the boundary that separates law from lawlessness is not evident to private persons, how could it be incumbent upon them to act in light of it?

The present section reflects on how the distinction between legality and barbarism can be rendered determinate in the wide range of instances to which it applies. I retain one aspect of Ebbinghaus' distinction between legality and barbarism but reject another. In keeping with the justification of public authority that appears in Chapter One, I retain Ebbinghaus' binary distinction between legality and barbarism. The principle of authority imposes a duty on persons in a legal system to obey its authority and to persons who are not in a legal system to enter into one. However, I reject the static character of Ebbinghaus' account, which holds that the practices compatible with legality or indicative of barbarism are the same in all times and places. I will argue that while the distinction between public authority and private violence is binary, it is not static. All persons must interact with others in a legal condition that secures the rights of every person from the arbitrary power of every other, but the practices that are compatible with legality, or indicative of barbarism, are not the same in all times and places.

Suppose that a public culture regards certain practices that Ebbinghaus deems to be barbarous as such to be natural and unobjectionable aspects of social ordering. I will consider whether, in the context of such a public culture, it would be possible for a valid legal order to incorporate such practices. My discussion of this question is framed around historical illustrations of what Ebbinghaus would treat as paradigmatic example of barbarism, slavery. Two important clarifications must precede this discussion. First, the purpose of the discussion of slavery is not to establish any particular historical claim, but to illustrate a philosophic one: the practices that are compatible with legality or indicative of barbarism must admit of variation. Second, at issue in this discussion is the possible legality of slavery, that is, its compatibility with the principle of authority. My claim is that there are 
circumstances in which even slavery may be compatible with securing the rights of private persons in relation to one another. But insofar as slavery binds one person to the choice of another, it is not an arrangement that unites the authority of law with the independence of all who are bound by it, as the principle of justice demands. Thus, even if there are cases in which slavery is compatible with the principle of authority, it must ultimately be abolished through legal reforms directed towards bringing the existing legal order into conformity with a regime of equal freedom. The duty of a defective legal order to reform itself is the central topic of Chapter Three.

The static threshold that Ebbinghaus employs suggests that wherever slavery is present, it is an unlawful arrangement. From the perspective of contemporary societies premised on the recognition of the inherent dignity of every person, Ebbinghaus' position is deeply intuitive. As Abraham Lincoln remarked, "If slavery is not wrong, nothing is wrong." "44 Although Ebbinghaus' view coincides with the modern sensibilities about slavery, a difficulty develops as we broaden our view of legality to encompass societies with public cultures more distant from our own. If slavery is incompatible with legality, then it must be the case that wherever slavery obtains, legality is absent. In its American incarnation, slavery existed in the shadow of a society committed to enlightenment precepts and the self-evident truths of the Declaration of Independence. ${ }^{45}$ In this context, slavery became increasingly recognized as the paradigmatic example of barbarism. ${ }^{46}$ Now suppose that in ancient times the prevailing view was not that slavery was a justified legal arrangement but that slavery

\footnotetext{
${ }^{44}$ Letter to A.G. Hodges, April 4, 1864, The Collected Works of Abraham Lincoln, ed. Roy P. Basler (New Brunswick: Rutgers University Press, 1953), 7:281-283.

${ }^{45}$ See, for example, Thomas Paine, “African Slavery in America," March 8, 1775, Pennsylvania Journal and the Weekly Advertiser and James Madison, Records of the Federal Convention, vol. 1, ed. Max Farrand (New Haven, Yale University Press, 1966), 135: "We have seen the mere distinction of colour made in the most enlightened period of time, a ground of the most oppressive dominion ever exercised by man over man."

46 William Freehling, The Road to Disunion: Secessionists at Bay: 1776-1854 (Oxford: Oxford University Press 1990), 124: "The American Revolution, by focusing American Enlightenment thought on the problem of tyranny and liberty, raised to higher consciousness the new awareness of slavery as an evil."
} 
was an arrangement that required no justification. ${ }^{47}$ The presence of slavery in social life was accepted

by masters and slaves alike. ${ }^{48}$ Such acceptance does not deny that slavery in the ancient world was

often cruel, violent, and degrading. Yet among the Greeks, slavery was accepted as a fact that

occasioned no "moral horror". 49 Among the Romans, "those who made up the slave population, in

all its diversity, were concerned with improving their lives as individuals or as members of small groups

through whatever means of self-help they could find, so that it was personal, not collective,

independence that was their object." 50 In antiquity, slaves dreamt of a world in which they were

${ }^{47}$ Although slavery was overwhelmingly accepted in the ancient world, its acceptance was not unanimous. For example, when Aristotle canvasses opinions about slavery in his Politics, he refers to those who believe that "the rule of a master over slaves is contrary to nature and that the distinction between slave and freeman exists by law only, and not by nature; and being an interference with nature is therefore unjust." Alcidamas, a student of the sophist Gorgias, is known to have held this view. On this point, see C.C.W. Taylor, “A Note on Ancient Attitudes Towards Slavery” Analysis 43 (1983): 40; Aristotle, Politics in Hippocrates G. Apostle and Lloyd P. Gerson, eds. and trans., Selected Works (Grinnell: The Peripatetic Press, 1991), 562. For a critical discussion of Aristotle's claim that slavery is natural, see Bernard Williams, Shame and Necessity (Berkeley: University of California Press, 2008), 103-129.

In Ideas of Slavery from Aristotle to Augustine (Cambridge: Cambridge University Press, 1996), Peter Garnsey sets out to challenge the assumption of historians "that ancient societies were tolerant and accepting of slavery, neither questioning nor justifying its existence" (xv; my emphasis). His strongest evidence comes from a homily by Gregory of Nyssa, who believed slavery to be a sin of pride against God's law that human beings shall have dominion over animals, but not over one another (80-5). But even Gregory of Nyssa does not suggest that slavery should be abolished. He conceives of slavery as a sin that a virtuous person does not engage in, like drunkenness or the love of money. As for the other critics of slavery in the ancient world whom Garnsey discusses, their concern was not the existence of slavery but peripheral features of it. Such concerns include that slave revolts can be dangerous, that managing a large number of slaves is time consuming, and that masters are sometimes too violent towards their human property.

48 William Linn Westermann, "Between Slavery and Freedom," American Historical Review 50 (1945): 215: "The institution of slavery was a fact of ancient Mediterranean economic life so completely accepted as a part of the labor structure of the time that one cannot correctly speak of a slave 'problem' in antiquity."

49 Westermann, "Slavery and the Elements of Freedom in Ancient Greece," in Slavery in Classical Antiquity: Views and Controversies, ed. M.I. Finley (Cambridge: Heffer, 1964), 32.

${ }^{50}$ Keith Bradley, Slavery and Society in Rome (Cambridge: Cambridge University Press, 1994), 130. 
masters rather than a world in which no one was a slave. ${ }^{51}$ The ancient world contained many masters and many more slaves, but no abolitionists. ${ }^{52}$

For both ancients and moderns, the legality of slavery is uncontroversial. In the ancient world, slavery was a ubiquitous feature of social ordering and the legality of slave societies was uncontroversial. In the modern world, the recognition of the dignity of every person culminates in deeming the barbarism of slavery to be uncontroversial. Where the ancients saw an unproblematic practice tied up with the right of persons to own property, we see the same practice as a denial of legality that subjects one person to the arbitrary choice of another. These conflicting conclusions raise a problem for any theorist who draws a static distinction between the practices that are compatible with legality and those that are indicative of barbarism. For the static theorist, slavery is either compatible or incompatible with legality, here and now and in all times and places. If slavery is incompatible with legality, then it could not have been lawful even in the paradigmatic legal systems of the ancient world, such as Rome. Alternately, if slavery can possess legal validity, then its reintroduction into contemporary society could culminate in valid arrangements. For the static

${ }^{51}$ David Brion Davis, The Problem of Slavery in Western Culture (Oxford: Oxford University Press, 1966), 62: “[F]rom the ancient world we find no assertion that slavery was an intolerable evil that should be eradicated by any civilized nation."

In The Class Struggle in the Ancient Greek World: From the Archaic Age to the Arab Conquests (Ithaca: Cornell University Press, 1981), Ste. Croix sets out to explain and illustrate "the value of Marx's general analysis of society in relation to the ancient Greek world". While Ste. Croix provides a meticulous exposition of exploitation in the ancient world, it is not clear that he would disagree with the general way in which I have characterized the disposition towards slavery in the ancient world. When Ste. Croix invokes the term class struggle, he is explicit that the term includes the exploitation of classes and resistance towards exploitation, but need not involve any "explicit common awareness of class on either side, no specifically political struggle at all, and perhaps even little consciousness of struggle of any kind." (57 (emphasis in original); for similar passages, see $3,44,57$, and 62-3). Ste. Croix provides an exposition of an exploitative practice, not of a practice that its participants regarded as exploitative, let alone incompatible with legality.

52 The slave revolts in the ancient world are often misconceived as early abolition movements. For a succinct rebuttal, see Fábio Duarte Joly, "Spartacus Revolt," in Encyclopedia of Antislavery and Abolition, ed. Peter Hinks, John McKivigan, and R. Owen Williams (Westport: Greenwood Press, 2007), vol. II, 650-1: “[N]either Spartacus' revolt nor earlier slave rebellions in Sicily offered any critique of slavery as a social institution. The rebels led by Spartacus desired to leave Italy and return to their homelands. It was only in Europe in the eighteenth century as slave revolts erupted in European overseas colonies that Spartacus acquired the image of a revolutionary who had fought for universal freedom... [Spartacus'] aim as a rebel slave-leader was not to abolish slavery, but to struggle to escape the life of a slave." On this point, see also Bradley, Slavery and Society in Rome, 130: "Rebelliousness, however, must not be confused with notions of class solidarity among slaves, and there is no indication that resistance was fuelled by ideological programmes rooted in the desire to secure radical alteration to the structure of society. There was certainly never anything at Rome comparable to the movement that led in St. Domingue to the creation of the state of Haiti." 
theorist, it is impossible to conceive of slavery as a valid legal arrangement in ancient Rome and as an arrangement that is incapable of legal authorization in the contemporary world. If slavery is indicative of barbarism, then Ebbinghaus must reject the legality of a central practice in the most sophisticated legal system in the ancient world.

The distinction between legality and barbarism is pivotal to the determination of the rights and duties of private persons. Such a determination is of the utmost juridical significance because unjust laws command whereas arbitrary power merely compels and may be resisted with right. Accordingly, if private persons are to act rightfully they must determine whether they occupy a highly unjust but valid legal condition, a valid legal condition in which some of the supposed laws are invalid, or a condition of outright barbarism. The distinction between legality and barbarism must be accessible to those who must act in light of it.

An accessible threshold is one that persons can both know and justify. Such persons span centuries, continents, and civilizations. They include the Athenians under the power of the Thirty Tyrants, the slaves of the antebellum South, and those confronted by Nazi power. If the threshold is not knowable, persons would have no basis on which to judge the lawfulness of their condition. Such persons would find themselves estranged from the very norms by which they are bound. If the threshold cannot be justified, then it would not be possible for private persons and public officials in an unjust but valid condition to persuade others that they occupy a legal condition that must be obeyed, just as it would not be possible for the occupants of a barbaric condition to persuade others of the lawlessness of the supposed authority and to plan the establishment of a valid legal order. By severing the principle of authority from the public culture of those who must act in accordance with it, Ebbinghaus requires that private persons act on the basis of norms that might be unknowable, unfathomable, or reprehensible. 
Perhaps Ebbinghaus would defend his static threshold with a further distinction: even though there was slavery in ancient Rome, it nevertheless was a valid legal condition because the slaves were not members of it. The difficulty with this response is both historical and conceptual. As a historical matter, the government in ancient Rome did claim governance over slaves by enforcing the proprietary rights of their masters, the contractual agreements that slaves entered into on behalf of their masters, and by punishing slaves for the commission of crimes. As a conceptual matter, such a response introduces contradictory notions of public authority. On the one hand, what distinguishes the public authority of government from mere private violence is that government represents the people as a whole by subjecting all private persons to common laws by which the rights of each are established, interpreted, and protected. On the other, if the persecuted are neither subject to law nor protected by it, then the line separating legality from barbarism fades. If public authority need neither bind nor protect all persons within its territory, then we can say that ancient Rome was a condition of public law that did not include its slaves, but also that Nazism was a condition of public law that did not include the members of a wide array of persecuted groups. In turn, those persons excluded from the condition of public law would be under a duty to create one even though the territory that they occupy is already a legal condition.

An alternative response might prove more promising. Ebbinghaus might deny that he is a static theorist. Instead of offering a static norm, he offers a highly abstract norm that must be brought to bear on particular instances through an act of judgment. The difficulty with this response is twofold. First, Ebbinghaus offers no resources for thinking about how this judgment is to occur, particularly in cases in which the public culture diverges markedly from the conception of legality defended in his own framework. Second, Ebbinghaus explicitly indicates that certain practices are incompatible with legality as such, regardless of the contingent features of the situation in which they arise. 
Ultimately, the static character of Ebbinghaus' framework is self-undermining. As we have seen, Ebbinghaus argues that private persons have a duty to enter into a legal condition. And yet Ebbinghaus repudiates the modes of legal ordering available in particular public cultures by imposing an unchanging standard of legal validity that applies to all times and places. But once publicly accepted modes of legal ordering are deemed barbarous by theoretical fiat, how can a valid legal order be established?

\section{The Standpoint of the Public Culture}

In what follows, I formulate a conception of the distinction between legality and barbarism that retains the binary but not the static character of Ebbinghaus' account. I will argue that private persons are under a duty to interact with others in a legal condition that secures the freedom of each in relation to every other, but the particular arrangements that constitute such a condition may vary. The public culture provides a standpoint from which persons are to distinguish between obligationimposing instances of public authority that secure each person from arbitrary power and mere instances of private violence that subject one or more persons to arbitrary power. While the threshold that public authority must satisfy has not always been as demanding as at present, the variability of the threshold must not be confused with the absence of one. The ancients did not perceive slavery to be barbaric, but it was not the case that they accepted the legality of all arrangements. Socrates was willing to comply with an unjust law even if it cost him his life, yet when the Thirty Tyrants exceeded the bounds of public authority by ordering Socrates to participate in the murder of an innocent man, he refused. $^{53}$

The conception of legality that one holds will affect how one conceives of barbarism. A conception of legality, however, is not devised ab initio, but is formulated and recognized within a

\footnotetext{
53 See notes $1-2$.
} 
public culture. A public culture is a particular standpoint from which the more general principles of public law are understood and justified and thereby made determinate for a people or for a plurality of private persons. Every public culture draws a distinction between public authority and private violence, but as I will argue, not every assemblage of persons shares a public culture. A shared public culture provides a basis for persons to make claims about legality that others can be reasonably expected to acknowledge. ${ }^{54}$ In the words of Justice Cardozo:

There is in each of us a stream of tendency, whether you choose to call it philosophy or not, which gives coherence and direction to thought and action. Judges cannot escape that current any more than other mortals. All their lives, forces which they do not recognize and cannot name, have been tugging at them - inherited instincts, traditional beliefs, acquired convictions; and the resultant is an outlook on life, a conception of social needs... In this mental background every problem finds it setting. We may try to see things as objectively as we please. None the less, we can never see them with any eyes except our own. ${ }^{55}$

A public culture forms the lens through which private persons distinguish between public authority and private violence. By appealing to the conceptions of legality at work in their public culture, private persons can determine whether the condition they occupy is lawful or lawless and, in turn, whether they are under an obligation to obey the supposed authority or whether they are instead under an obligation to create one.

The presence of a public culture does not generate an immediate and uncontroversial classification of whether particular conditions are lawful or barbaric. The history of the theory and practice of public law provides illustrations of the kinds of complexities and ambiguities that pervade the notion of a public culture.

\footnotetext{
${ }^{54}$ John Rawls, Justice as Fairness: A Restatement (Cambridge: The Belknap Press of Harvard University Press, 2001$), 27$.

${ }_{55}$ Benjamin N. Cardozo, The Nature of the Judicial Process (New Haven: Yale University Press, 1921), 12-13.
} 
First, a public culture may contain internal inconsistencies in which the justifications offered for some institutional arrangement conflict with the justifications accepted for others. ${ }^{56}$ The presence of a shared basis of justification does not ensure that justifications that emerge from it will arise within a fully coherent set of ideas. In The Subjection of Women, John Stuart Mill criticizes his own society for failing to realize the systematic implications of its own animating principle:

[W] hat is the peculiar character of the modern world - the difference which chiefly distinguishes modern institutions, modern social ideas, modern life itself, from those of times long past? It is that human beings are no longer born to their place in life, and chained down by an inexorable bond to the place they are born to, but are free to employ their faculties, and such favorable chances as offer, to achieve the lot which may appear to them most desirable. Human society of old was constituted on a very different principle. All were born to a fixed social position, and were mostly kept in it by law, or interdicted from any means by which they could emerge from it. ${ }^{57}$

Although Mill accepts the fundamental conviction of the prevailing public culture, he rejects the uneven way in which his society has applied it. Mill sees the subjection of women as a "monstrous contradiction to all the principles of the modern world". ${ }^{8}$ His aim is to spur the development of his own public culture by showing the systematic implications of its fundamental conviction. Persons who share a public culture have a common frame of reference, but may not be in agreement about its systematic implications. Yet even when agreement about particulars is absent, a shared public culture may provide a basis for extending the domain of agreement.

Second, private persons might interact in a shared territory without sharing a public culture. In cases in which the public cultures that persons affirm give rise to conflicting conceptions of legality, it may not be possible to construct a legal system that all would recognize as valid. When Nelson Mandela first negotiated with the apartheid leaders for the creation of a nonracial democracy that

\footnotetext{
56 Rawls, Political Liberalism, 9: "The public political culture may be of two minds at a very deep level."

${ }^{57}$ John Stuart Mill, The Subjection of Women (New York: Dover, 1997), 16.

58 Ibid., 79.
} 
would respect and protect the fundamental rights of all of its inhabitants, he quickly realized that they had not yet relinquished their belief in racial superiority or renounced their desire for political domination. Mandela saw that so long as the public culture underwriting apartheid persisted, it would be impossible to create a legal system that all South Africans, regardless of their racial status, could recognize as lawful. The only way to create such an authority was for a rights-based public culture to supplant the race-based public culture that sustained apartheid. ${ }^{59}$

Third, a public culture may lack a disposition towards a given social arrangement. Such an arrangement may appear to occupy the world of facts given by nature rather than the world of norms governed by law. Perhaps the ancient disposition towards slavery exemplifies this possibility: slavery was perceived not as a justified practice but as a practice that required no justification. ${ }^{60}$

Fourth, even in cases in which the legality of a critical aspect of legal ordering becomes suspect in the eyes of its public culture, it does not necessarily follow that private persons have a right to overthrow the regime in which it arises. In the ancient world, slavery was a form of social organization for which there was no apparent alternative. ${ }^{61}$ Since private persons have a duty to submit to public authority, no one can have a right to overthrow a legal order because it contains features that would be present in any legal system that was established in its place.

Fifth, even on those occasions in which a shared understanding obtains with respect to the general limits of legality within a public culture, disagreement may still remain about whether the

${ }^{59}$ Mandela, Long Walk to Freedom: The Autobiography of Nelson Mandela (London: Abacus, 2009), $609 \mathrm{ff}$.

${ }^{60}$ Robert Schlaifer, "Greek Theories of Slavery from Homer to Aristotle," in Slavery in Classical Antiquity: Views and Controversies, ed. M.I. Finley (Cambridge: Heffer, 1964), 112: "In the Homeric world slaves were simply accepted as facts." ${ }^{61}$ Why was there no abolition movement in the ancient world as there was in the modern? In Ideas of Slavery from Aristotle to Augustine, 238, Peter Garnsey answers: "It made a difference that there was no alternative and competing model against which the slave system could be measured. In antebellum America, the existence of a rival free-labour system to the North forced the slave-owning South to defend itself and its way of life, first with argument, and ultimately with weapons...Persia and Egypt were the most advanced neighbouring civilizations of the Graeco-Roman (and Jewish) world, but they were judged to be more completely slave societies than those of the Greeks and Romans: everyone was a slave in Persia apart from the King, everyone in Egypt apart from the Pharoah. These societies lacked political institutions and the fundamental concepts of citizenship and freedom." 
threshold between legality and barbarism has been crossed. ${ }^{62}$ Such ambiguity is unavoidable because no public institution can provide a common authoritative judgment for all private persons indicating that they occupy a lawless condition in which public authority is absent.

By distinguishing between legality and barbarism from the standpoint of the relevant public culture, the unified theory can integrate two insights that might otherwise appear to be contradictory. The first is that legal arrangements that are incompatible with the independence of persons are inherently wrongful, whether they involve the denial of proprietary or contractual rights or even the imposition of slavery. The second is that the wrongfulness of such practices does not itself establish their incompatibility with legality. A theory of public law provides a justification of the general principles that animate the public law relationship. The concrete meaning of these principles cannot be exhausted in abstraction from the publics to which they are applicable. Each of these insights can be found in the writings of Frederick Douglass, an American slave turned abolitionist. On the one hand, Douglass described slavery as "a system of lawless violence" that "never was lawful, and never can be made so..." ${ }^{63}$ On the other, Douglass acknowledges that the illegality of slavery was not always evident:

The idea that man cannot hold property in man, that all men are free, that human rights are inalienable, that the rights of one man are equal to those of another, that governments are ordained to secure human rights did not come all at once to the moral conscience of men, but have all come very slowly in the thoughts of the world. ${ }^{64}$

62 For a similar discussion of ambiguities surrounding legislative limits in Lockean political philosophy, see Jeremy Waldron, The Dignity of Legislation (Cambridge: Cambridge University Press, 1999), 84: "[L]ocating the sense of legislative limits in political culture rather than in an authoritative institution means that we are left with the prospect of disagreement, indeterminacy, controversy among the people as to what those limits are. People will disagree about what it is for the legislature to betray its trust, or even if they agree in the abstract they will disagree about when this has happened."

63 "Change of Opinion Announced", May 23, 1851, The North Star, Reprinted in The Liberator (emphasis in original). See also, Douglass, "The Address of Southern Delegates in Congress to their Constituents or, the address of John C. Calhoun and Forty Other Thieves", February 9, 1849.

${ }^{64}$ Frederick Douglass, quoted in Waldo E. Martin Jr,, The Mind of Frederick Douglass (Chapel Hill: University of North Carolina Press, 1984), 172. 
As these ideas permeate the public cultures of the world, arrangements once conceived of as unobjectionable and ubiquitous features of legality are now deemed barbarous. Conceptions of legality have become more demanding in public cultures around the world, while conceptions of barbarism have become more inclusive.

The distinction between legality and barbarism at work in the unified theory must not be confused with an all-permitting relativism. Relativism rejects the view that any juridical principle applies across cultures and time. In contrast, the unified theory posits a juridical principle incumbent on all private persons in every public culture: submit to a condition of public law, that is, a condition that secures the rights of each person in relation to every other. What this duty requires, however, cannot be formulated in abstraction from the public culture in which it is raised.

I close this section by contrasting the account of barbarism that emerges from the unified theory with the account that Fuller defends. In his famous debate with H.L.A. Hart, Fuller remarked: "To me there is nothing shocking in saying that a dictatorship which clothes itself with a tinsel of legal form can so far depart from the morality of order, from the inner morality of law itself, that it ceases to be a legal system." ${ }^{65}$ Fuller conceives of law as "the enterprise of subjecting human conduct to the governance of rules." ${ }^{96}$ In order to subject human conduct to the governance of rules, rules must possess certain moral qualities. As Fuller explains, to govern conduct a legal rule must, at least to some extent, be (1) general, (2) public, (3) prospective, (4) clear, (5) non-contradictory, (6) possible to obey, (7) constant in time, and (8) congruent with official action. ${ }^{67}$ These procedural principles form what Fuller calls the internal morality of law. A law or legal system is valid to the extent that it satisfies law's internal morality.

\footnotetext{
65 "Positivism and Fidelity to Law - A Reply to Professor Hart," Harvard Law Review 71 (1958): 660.

${ }^{66}$ Ibid., 106.

${ }^{67}$ Fuller, The Morality of Law, 39.
} 
The unified theory contrasts with Fuller's conception of legality in two respects. First, from the standpoint of the unified theory, the principle of authority is a binary norm. It forms the relevant standpoint for distinguishing between the validity or invalidity of a legal system or a particular law. In a valid legal order, all private persons are under a duty to obey all valid laws. In a lawless condition, private persons are under a duty to enter into a condition of public law in which public institutions secure private rights. The validity of laws and legal systems does not admit of degree. Turning from the constitutive to the regulative dimension of public law, considerations of public justice arise on a spectrum: a law or legal system may conform to its own internal standard of adequacy to a greater or lesser extent. Thus, one can sensibly say, 'This law is somewhat unjust', but one can neither say 'This law is somewhat invalid' nor 'This action is somewhat illegal.' Fuller runs these standpoints together by framing the question of validity, of whether a law or a legal system exists, in terms of a spectrum of aspiration. ${ }^{68}$ The more a legal system (or a particular law) conforms to the procedural morality that is internal to law, the more it can be said to exist. In Fuller's words, "both rules of law and legal systems can and do half exist." ${ }^{69}$ The difficulty that this structure raises is that Fuller both conceives of law in terms of subjecting human conduct to the governance of rules and suggests that the validity of law diminishes to the extent that it fails to accommodate law's internal morality. In existing societies, in which one or more of the eight principles that form the internal morality of law are not fully satisfied, it is not clear whether a given norm or legal system possesses sufficient validity to bind human conduct. When confronted by the implication of his view that the validity of laws and legal systems admits of degree, Fuller emphasizes that legal systems, like any "other complex human undertaking" may enjoy "varying degrees of success." " While I agree with Fuller that law has a regulative dimension, his attempt to capture law's constitutive and regulative dimensions on a single

\footnotetext{
${ }^{68}$ Ibid., 43 and 198-200.

${ }^{69}$ Ibid., 122.

70 Ibid.; cf. 198-200.
} 
plane is problematic. Within Fuller's framework, the sensible claim that a particular law is not fully congruent with the internal morality of law culminates in the strange conclusions that the law is therefore only somewhat valid and its violation is therefore only somewhat prohibited.

The second difference concerns the kinds of practices that fail to be lawful. For Fuller, the internal morality of law is exclusively procedural. ${ }^{71}$ Its concern is "not with the substantive aims of legal rules, but with the ways in which a system of rules for governing human conduct must be constructed and administered if it is to be efficacious and at the same time remain what it purports to be."72 Accordingly, Fuller may deny partial (or even full) legality to practices that conflict with one or more of the procedural principles that he articulates. But in cases in which these procedural principles are fully satisfied, no objection can be raised from the standpoint of the internal morality of law. Thus, Fuller explains that the internal morality of law has "nothing to say" about particular substantive aims that law might promote or alleviate, such as, for example, the "subjugation of women."73 Because Fuller's ideal of legality is exclusively procedural, ${ }^{74}$ he must hold that a condition in which some are subjugated to others might be not only a valid legal order but also one that fully satisfies the internal morality of law. In contrast, the unified theory conceives of barbarism as an arrangement that subjects the freedom of one or more persons to the arbitrary power of another private person. Such a conception of barbarism is not confined to procedural requirements: a norm or condition might fully satisfy each of Fuller's procedural principles of legality and yet nevertheless fail to be valid because it subjugates the freedom of some persons to the arbitrary power of others.

\footnotetext{
${ }^{71}$ Although Fuller presents his internal morality of law as a 'procedural' view, the term 'formal' perhaps better captures his view. On this point, see Jeremy Waldron, "Positivism and Legality: Hart's Equivocal Response to Fuller," New York University Law Review 83 (2008): 1145 (distinguishing between the form of a legal norm and the relevant procedure for applying that norm) and David Dyzenhaus, Hard Cases in Wicked Legal Systems: Pathologies of Legality (Oxford: Oxford University Press, 2010), 251-2.

${ }^{72}$ Fuller, The Morality of Law, 97.

73 Ibid., 96.

${ }^{74}$ For an argument that Fuller's procedural principles of legality condition the content of enacted laws, see David Dyzenhaus, Hard Cases in Wicked Legal Systems: Pathologies of Legality (Oxford: Oxford University Press, 2010).
} 


\section{THE BARBARISM OF NAZI POWER}

We can now consider whether Nazism was a lawful or a lawless power by considering its distinctive practices in relation to the public culture in which it arose. In assessing the legality of Nazism, theorists sometimes suggest that while its barbarism is apparent from the standpoint of our own public culture, its legality was equally apparent from the standpoint of the public culture in which it arose. $^{75}$ Although members of persecuted groups recognized Nazism to be an arbitrary rather than a lawful power, ${ }^{76}$ perhaps such persons did not partake of the general German public culture, which was compatible with Nazism, or, worse still, affirmed its legality. ${ }^{77}$ In this section I argue that the barbarism of Nazi power was evident not merely from the standpoint of our own public culture or from the standpoint of persecuted persons and groups, but from the standpoint of the general German public culture. To be sure, Germany's public culture — like those of its European neighbours displayed extraordinary prejudice towards the Jews and other persecuted minorities. But as Nazi

\footnotetext{
${ }^{75}$ See, for example, Dworkin, Law's Empire (Cambridge: Harvard University Press, 1986), 103-4.

${ }^{76}$ See Klemperor, I Will Bear Witness: A Diary of the Nazi Years (1933-1941), trans. Martin Chalmers (New York: Random House, 1988), 12 ("In [World War One] I was subject to [German] military law, but subject to law nevertheless; now I am at the mercy of an arbitrary power...") and 406 ("[T] oday there is no law in Germany anymore, only arbitrary power, there is also no equality anymore before arbitrary power, the Aryan pays, the Jew does time..."). Klemperer made the former comment in 1933 and the latter in 1941.

${ }^{77}$ The most well-known proponent of this thesis is Daniel Jonah Goldhagen, Hitler's Willing Executioners: Ordinary Germans and the Holocaust (New York: Alfred A. Knopf, 1996), 14: "[T]he perpetrators, 'ordinary Germans', were animated by antisemitism, by a particular type of antisemitism that led them to conclude that the Jews ought to die." For Goldhagen, at the core of Germany's public culture lay a distinctive genocidal strand of antisemitism that induced ordinary Germans to participate in systematic slaughter. Goldhagen's thesis has been decisively refuted by Holocaust historians. For overviews of the controversy between Goldhagen and his critics, see A.D. Moses, "Structure and Agency in the Holocaust: Daniel J. Goldhagen and His Critics," History and Theory 37(1998): 194-199 and István Deák, "Holocaust Views: The Goldhagen Controversy in Retrospect," Central European History 30 (1997): 295-307.

If Nazi barbarism cannot be attributed to a peculiarly virulent strain of German antisemitism, as Goldhagen alleges, then why did so many ordinary Germans participate in genocide? In Ordinary Men: Reserve Battalion 101 and the Final Solution in Poland (New York: HarperPerennial, 1993), Christopher Browning constructs a more nuanced account. Ordinary Germans participated in the genocide for a series of reasons of varying weight: careerism, deference to authority, the circumstances of war, dehumanization of the victims, antisemitic propaganda, and the pressure to conform to the group. Whereas Goldhagen traces genocide to a virulent strain of antisemitism peculiar to Germany's public culture, Browning emphasizes general psychological and sociological phenomena common to all human beings. Historians prefer Browning's explanation because it sheds light on why soldiers from across Europe who were not socialized in Germany were so willing to participate in violent acts against Jews as well as members of other groups and why German soldiers were, at least initially, hesitant to do so. Browning's explanation, however, is deeply disturbing because it suggests that under the appropriate circumstances, human beings are capable of committing barbarous acts.
} 
power increasingly repudiated accepted hallmarks of legality, ordinary Germans came to recognize Nazism not as an arrangement that secured each person from the arbitrary power of others, but as an arbitrary power to which all were subject. Given the theoretical orientation of this chapter, I will not attempt to isolate the particular historical moment at which Nazism became a lawless power.

In The Law under the Swastika, the German legal historian Michael Stolleis rejects "the myth that some areas [of law] remained entirely untouched by the political claims of the [Nazi] system". ${ }^{78}$ Earlier I illustrated Ebbinghaus' account of inhumanity with a discussion of how Nazism distorted private law by resolving private disputes on the basis of the racial identity of the disputants. Nazi power, however, did not merely subject the freedom of German Jews to the arbitrary power of German gentiles. Nazism rejected private law itself as liberal, individualistic, Roman, and Jewish and consequently sought to replace it with its own German brand of fascism. ${ }^{79}$ Consequently, even the legal disputes between German gentiles were to be resolved in accordance with the perceived requirements of Nazi ideology. As the German-born political scientist and constitutional theorist Karl Loewenstein observed in 1936:

The first principle of free access to the ordinary courts is to a large extent repudiated by the National Socialist regime. During the first two years of the regime numerous breaches of the existing civil law were committed in forcing the new political order on business life. Obligations of contract, vested rights, the right to dispose freely of property, were superseded by political coordination. Legal titles were voided and property confiscated under the pressure of party members and officials. The courts, invoked for redress of grievances, or for damages, were frequently bound to decide, according to existing laws, in favor of the dispossessed claimants. As such action taken by the courts threatened to frustrate the political results of the revolution in business life, a law of December 13, 1934, empowered the Minister of the Interior at his discretion to withdraw all civil claims from the ordinary courts even after they had become res judicata, and to settle them in the interests of the state without permitting appeal. The effect of the law was to deprive private individuals of the right to bring

\footnotetext{
78 Stolleis, The Law Under the Swastika: Studies on Legal History in Nazi Germany, trans. Thomas Dunlap (Chicago: University of Chicago Press, 1998), 9.

${ }^{79}$ Ibid., 51.
} 
their cases before the ordinary courts. Compensation for damages incurred through the revolution became a matter of arbitrary decision of the ministry. ${ }^{80}$

By subjecting all private interaction to the impulses of Nazi ideology, Nazism displaced familiar features of private law, including the rights of property and contract, the right to bring one's case before an impartial judiciary, and the right to a remedy proportional to the wrong. ${ }^{81}$ Persons were thereby denied a stable and calculable order in which to interact with one another. ${ }^{82}$

Just as Nazism sought to remove the constraints that legality imposes on private interaction, so too Nazism ignored or dismantled any positive law that constrained the conduct of supposed public officials. As a matter of criminal law, the Nazi regime meted out punishment for the violation of secret, vague, and retrospective laws, separated the notion of a wrong from an action, and, as early as 1934, engaged in the widespread murder of political opponents without criminal sanction. ${ }^{83}$ As a matter of administrative law, the Nazis routinely denied the jurisdiction of administrative courts to review police action by labeling an issue political. ${ }^{84}$ Finally, in constitutional law the Nazis transformed the parliamentary system into a dictatorship, disbanded the political parties through terror, violated the separation of powers by ruling through executive decree, purified the civil service of perceived

${ }^{80}$ Karl Loewenstein, "Law in the Third Reich," The Yale Law Journal 45 (1936): 807.

81 Ibid., 782.

82 Ibid., 780.

${ }^{83}$ Stolleis, 2 and 20. On the Nazi distortions of criminal law - including the use of retroactive laws, punishment by analogy, and the abandonment of the fundamental criminal law principle nullum crimen sine legal, nulla poëna sine lege - see Henry Lunau, "The Threat of Nazi Law to all Fundamental Legal Principles," Proceedings of the American Foreign Law Association 23 (1942): 6.

84 Stolleis, 2 and 134. On the unlimited power of the police to bypass judicial oversight, see Caenegem, 289: "Pronouncements have been recorded of police chiefs at meetings of lawyers to the effect that the police considered themselves justified in operating outside the law whenever the security of the state was at risk. The police did indeed interfere with the criminal justice in various ways and managed to bypass the courts. One technique was the long-term Schutzhaft ('protective custody') in the course of a trial or even outside any judicial procedure. The police even used Schutzhaft in cases where the accused had been acquitted by the courts; they were simply arrested polizeilich as they left the court room, and carted off to a camp. During discussion on this point in the official Commission for Criminal Justice the representative of the police frankly maintained that Schutzhaft in criminal cases was the police's good right and that they themselves decided on its use: they happened to have their own ideas and norms, and they did not feel bound by what the courts said. In other words, the police was a state within the state and that state was legibus solutus." 
political opponents and racial inferiors, and brought an end to German federalism (even though this violated the constitution). ${ }^{85}$ As Nazism increasingly rid itself of all legal constraints on the exercise of power, the dual character of Nazi governance - characterized by the tension between, on the one hand, the normative state directed towards safeguarding the legal order through statutes, judicial decisions, and administrative oversight, and, on the other, the prerogative state consisting of "unlimited arbitrariness and violence unchecked by any legal guarantees" prerogative state that retained a single aspect of legality, force. ${ }^{87}$ What the Nazis called law was an instrument through which power could be exercised but that was incapable of placing any constraints on the exercise of power. The result was that the exercise of power failed to adhere to law's constitutive dimension. As a general matter, power was neither exercised in accordance with law nor directed towards securing private rights.

The absence of legal constraint from the exercise of power created the condition in which the violence most characteristic of Nazi power became possible.

During the Nazi years, German public culture was certainly anti-Semitic, but its anti-Semitism did not underwrite the most extreme acts of Nazi violence. Holocaust historians distinguish between the traditional anti-Semitism prevalent in Germany and other European states, and the radical brand of anti-Semitism that fuelled Nazi violence. As Claudia Koonz explains:

Seen against the enormity of Nazi savagery, it is easy to imagine that German collaborators in persecution shared the seething paranoia of Adolf Hitler and his closest comrades. Extreme outcomes, it would seem, must result from extreme beliefs. But careful investigation of public opinion in Nazi Germany reveal that, while most Germans shared the 'polite' or 'cultured' anti-Semitism common in Western Europe and North America, they disapproved of diehard Nazis' coarse racist diatribes and pogrom-style tactics. ${ }^{88}$

\footnotetext{
${ }^{85}$ Stolleis, 12.

86 Fraenkel, xiii.

${ }^{87}$ Stolleis, 13.

88 The Nazi Conscience, 11.
} 
This distinction between Germany's cultured anti-Semitism and Nazi ideology is echoed by Saul Friedländer and Ian Kershaw. Friedländer notes that the prevailing culture of anti-Semitism legitimated economic and social forms of discrimination, but maintains that the majority of Germans "shied away from widespread violence against [Jews], urging neither their expulsion from the Reich nor their physical annihilation." 89 Similarly, Ian Kershaw emphasizes that the culture of anti-Semitism was sympathetic to discrimination but not to violence:

Very many, probably most, Germans were opposed to the Jews during the Third Reich, welcomed their exclusion from the economy and society, saw them as natural outsiders to the German 'National Community', a dangerous minority against who it was legitimate to discriminate. Most would have drawn the line at physical maltreatment. The Nazi Mayor of Mainstockheim...no doubt spoke for many when, in preventing violence and destruction by SA and Party fanatics during the pogrom of November 1938, he reportedly said: 'You don't have to have anything to do with the Jews. But you have got to leave them in peace.' Such an attitude was not violent. But it was discriminatory. And such 'mild' anti-Semitism was clearly quite incapable of containing the progressive radical dynamism of the racial fanatics and deadly bureaucratization of the doctrine of race-hatred..$^{90}$

As the Nazi program transitioned from socially accepted forms of discrimination to mass murder, the Nazis increasingly hid their activity from the German public. The reason why the Nazis chose to carry out their most extreme acts of violence in secrecy was that they were aware that the public would be appalled by their actions. ${ }^{91}$ When it became known that 70,000 disabled persons had been gassed in the Nazi euthanasia program, "public disquiet" erupted. ${ }^{92}$ The program was

\footnotetext{
${ }^{89}$ Nazi Germany and the Jens: The Years of Persecution, 1933-1939, vol. I (New York: Harper Collins Publishers, 1997), 3-4. ${ }^{90}$ Popular Opinion and Political Dissent in the Third Reich: Bavaria 1933-1945 (Oxford: Oxford University Press, 1983), 371. See also Saul Friedländer, "From Anti-Semitism to Extermination: An Historiographical Study of Nazi Policies Toward the Jews and an Essay in Interpretation," Yad V ashem Studies 16 (1984): 33.

${ }^{91}$ For an account of the difficulties that the Nazis encountered in gauging public opinion in the repressive environment they created, see Aryeh L. Unger, "The Public Opinion Reports of the Nazi Party", The Public Opinion Quarterly 29 (1966): 565.

92 Arthur L. Caplan in "How did Nazi Medicine go so Wrong?" in When Medicine Went Mad: Bioethics and the Holocaust, ed. Caplan (New Jersey: Humana Press, 1992), 87.
} 
subsequently cancelled because the "'German people' was not yet 'mature' enough for this kind of inner self-cleansing. It simply was not progressive enough yet to surrender responsibility for the apparently quite conservative dimensions of the social right of existence to a handful of scientifically prominent experts." ${ }^{93}$ Nevertheless, before the end of the war, a further 70,000 patients were killed through a covert program involving "starvation, drugs, and neglect.".94

Following the leak of the euthanasia program, Hitler sought to keep the extermination of the Jews "absolutely secret." 95 The systematic slaughter of European Jewry was executed "without the German people being told and without any legislative text being issued." 96 The order to exterminate issued from an oral command delivered by Hitler, most likely, to Goering, Himmler, and Heydrich. ${ }^{97}$ In a letter dated July 11, 1943, Bormann — the Head of the Nazi Party — wrote that the Führer demanded that " $[\mathrm{w}]$ here the Jewish Question is brought up in public, there may be no discussion of a future overall solution (Gesamtlösung)." S8 Similarly, in a secret speech delivered to the elite SS Gruppenführer on October 4, 1943, Himmler insisted that the SS must not discuss the extermination of the Jews: "This was an unwritten and never to be written page in our history." 99 In a subsequent speech to state and district leaders that occurred days later, Himmler lamented that even "respectable and decent National Socialist people all know their decent Jew." ${ }^{100}$ If the number of petitions

\footnotetext{
93 Götz Aly and Karl Heinz Roth, "The Legalization of Mercy Killings in Medical and Nursing Institutions in Nazi Germany from 1939 until 1941," International Journal of Law and Psychiatry 7 (1985): 162.

${ }^{94}$ Caplan, 87.

${ }^{95}$ Friedländer, 13.

${ }^{96}$ Van Caenegem, 290.

97 Ibid.

98 "Hitler Bans Public Reference to the 'Final Solution of the Jewish Question,' July 11, 1943," in Documents on the Holocaust: Selected Sources on the Destruction of the Jews of Germany and Austria, Poland, and the Soviet Union, ed. Yitzhak Arad, Israel Gutman, and Abraham Margaliot, trans. Lea Ben Dor (Lincoln: University of Nebraska Press, 1999), 342.

${ }^{99}$ Richard Breitman, "Secrecy and the Final Solution," in New Perspectives on the Holocaust, ed. Rochelle L. Millen (New York: New York University Press, 1996), 78. See also, Kershaw, 371: "Our examination of popular opinion on the Jewish Question has shown that in its anti-Jewish policies the Nazi regime acted not in plebiscitary fashion, but with increasing autonomy from popular opinion until the extermination policy in the east was carried out by the SS and SD as a 'never to be written glorious page of our history', as Himmler put it..."

100 Himmler, "A Secret Speech on the Jewish Question," in The Jew in the Modern World, ed. Paul R. Mendes-Flohr and Jehuda Reinharz (Oxford: Oxford University Press, 1995), 514.
} 
submitted to Nazi authorities was any indication, Himmler suggested that there must have been more decent Jews in Germany than the number of Jews in the whole country. The disposition of the public towards Nazi violence necessitated the secrecy of the extermination program. ${ }^{101}$ In Ernst Fraenkel's words, Nazism sustained itself "by veiling its true nature". ${ }^{102}$

In holding Nazism to be barbarous, we need not appeal to our own contemporary conceptions of justice or to an eternal conception of justice embodied by a suprastatutory law. The barbarism of Nazi power was evident in relation to the public culture that prevailed in Germany during the decline of Weimar and extended into the Nazi period. In a 1951 case, Germany's Supreme Federal Court considered whether those who organized and carried out the deportation of Jews to death camps in Poland had aided and abetted murder. Although a lower court held that the mens rea of the offence had not been established because it was the duty of the accused to perform government policies, the Supreme Federal Court held that the lower court had erred because the authority of the state is not unlimited. The court supported this statement by appealing to "certain maxims of human conduct regarded as inviolable which in the course of time have come to be recognized by all civilized nations on the basis of common ideas of morality and which are held to be legally obligatory, regardless of whether the laws of some particular nation permit them to be disregarded." 103 State power lacks the authority to violate fundamental normative principles by authorizing arbitrary arrest and deportation. The court went on to argue that the defendants must have been aware of the limits of state power given the public culture in which they were socialized. Edgar Bodenheimer summarized the judgment of the court: "It cannot be assumed...that the defendants, all of whom had received their education and moral upbringing in the period preceding National Socialist rule, were unaware of these general

\footnotetext{
101 Kershaw, 371.

102 Fraenkel, 39.

103 Edgar Bodenheimer, "Significant Developments in German Legal Philosophy since 1945," American Journal of Comparative Law 3 (1954): 390 (referring to Bendesgerichtshof BGSt 2, 235-7, (1951)).
} 
principles basic to human life in society."104 Having been socialized in a decent democratic society, knowledge of basic norms could be imputed to the defendants on the basis of their own public culture. While persons may claim ignorance of suprastatutory laws concocted by philosophers, they cannot claim ignorance of the limits that their own public culture imposes on state power.

On another occasion, the court engaged in detailed historical analysis to demonstrate that ordinary citizens understood Nazism to be a lawless power. ${ }^{105}$ In a well-known case involving a grudge informer who denounced her husband to the Nazi authorities so that she could continue her adulterous relationships, both the Supreme Court and a jury accepted as a "matter of common knowledge" that

[t] here was, despite the warped judgment of wide circles during the Nazi period, a lively awareness in the population that administrative and legal authority could be abused for the purpose of intimidation and suppression of opposition views. Sentences, which served the purpose of political terror rather than the realisation of the law, had actually led to a heightened popular sense of right and wrong rather than stifling it. ${ }^{106}$

As Nazism increasingly jettisoned every right, principle, institutional arrangement, and, in general, every legal constraint by which persons could distinguish lawful power from the mere imposition of lawless violence, the arbitrary character of its power became increasingly apparent. Instead of securing each person from the arbitrary power of all others, Nazism had itself become a lawless power to which all were subject.

I have argued that the barbarism of Nazism was evident from the standpoint of the actual public culture in which it arose. Turning from actuality to possibility, one may ask whether Nazism could be lawful. In other words, could there be a public culture so constituted that it might deem the

\footnotetext{
104 Ibid., 391.

105 H.O. Pappe, "On the Validity of Judicial Decisions in the Nazi Era," Modern Law Review 23 (1960): 273 (quoting BVerfGE 3, 58 et seq; 6, 132 et seq.).

106 Ibid., 267-8.
} 
practices characteristic of Nazism to be a lawful mode of securing the freedom of each private person from the arbitrary power of every other? It is difficult to conceive of a public culture in which persecuted persons would understand their own extermination as compatible with the security of their private rights. Throughout this chapter, I have drawn attention to various historical examples involving societies that draw the distinction between lawful and arbitrary power in different ways. Socrates denied that one could have a legal obligation to participate in the murder of an innocent person; Caligula's supposed subjects denied that secret laws could impose obligations; and Frederick Douglass rejected the legality of arrangements that denied the humanity of whole classes of persons. As Nazism shook off every vestige of legality except force, its violence ran afoul of each of these standards. The barbarism of Nazi power would therefore be evident not simply in the context of the public culture in which it arose - a modern European state with a sophisticated albeit prejudiced public culture - but also in a diverse array of public cultures scattered across the distances of space and time, including those with a far more inclusive conception of legality. The barbarism of Nazism would be evident in a variety of contexts not because a single static threshold distinguishes law from lawlessness in all times and places, but because the more Nazism cast off familiar characteristics of legality, the more barbarous it would appear from the standpoint of a diverse range of public cultures. ${ }^{107}$

\section{CONCLUSION}

The unified theory provides an alternative to two tendencies that arise in philosophic discussions concerning the distinction between legality and barbarism. The first is the tendency to conceive of barbarism - as Radbruch, Alexy, and Fuller propose - in terms of a departure from the

\footnotetext{
107 One of the most chilling features of Nazism is that it sought to create a public culture in its own image. The explicit purpose of nazifying public institutions - particularly public education - was to create a public culture amenable to Nazi power. As Hitler explained in 1933, “When an opponent says 'I will not come over to your side,' I calmly say, 'Your child belongs to us already...Y You will pass on. Your descendants, however, now stand in the new camp. In a short time they will know nothing but this new community." Quoted in Koonz, 131. Whereas Nazism had to conceal its activities from the actual German public culture, its aim was to create a public culture that would find the way in which it exercised power unobjectionable.
} 
regulative ideal of legality, whether conceived of in terms of justice, moral correctness, or the internal morality of law. In contrast, I have presented the distinction between legality and barbarism in terms of the violation of public law's constitutive principle rather than its regulative one. A legal system is that which secures the freedom of each person from the arbitrary power of others. Accordingly, that which subjects the freedom of persons to arbitrary power cannot be lawful and the question of public justice, which concerns the adequacy of valid laws and legal systems, cannot arise. Whereas the first tendency concerns the ground of the distinction between legality and barbarism, the second concerns how situated persons are to apply this distinction to particulars. Because the distinction between legality and barbarism must be apparent to those whose rights and duties are implicated by it, the unified theory rejects the view that the distinction between legality and barbarism is static. By concretizing the distinction between legality and barbarism from the standpoint of the relevant public culture, the unified theory indicates how private persons confronted by public authority or arbitrary power in a diverse range of settings can discern whether their juridical situation demands obedience or resistance. 


\section{CHAPTER 3:}

A Progressive Theory

ne of the defining features of contemporary political and legal philosophy is its progressive
character. Whereas earlier theories sought either to justify the adequacy of existing societies or to formulate the nature of a perfectly just one, contemporary theorists seek to articulate a framework for thinking about how existing societies can be brought into ever-deeper conformity with the demands of justice. The purpose of this chapter is to consider how a theory must be structured in order to make good on this progressive ambition.

A progressive theory must integrate three distinctive components into a coherent whole: (1) an underlying subject, for example political societies or legal systems; (2) a moral standard for critically assessing the adequacy of instances of the underlying subject, that is, a conception of justice; and (3) a framework for articulating what is required of instances of the underlying subject that are defective in relation to the relevant moral standard. Each of these components is essential to a progressive theory. In the absence of an underlying subject, the theory would fail to delineate a domain of inquiry. In the absence of a moral standard for critically assessing instances of the underlying subject, the theory would lack a standpoint for determining the adequacy of instances of the underlying subject and assessing whether alternative arrangements would be preferable. Finally, in the absence of a framework that articulates what is required of defective instances of the underlying subject, the theory would offer no guidance for thinking about how the defects that it identifies are to be addressed.

That a progressive theory must integrate components of this kind may seem obvious to some. However, I will argue that the leading theories in political and legal philosophy fail to provide an integrated account of these components, and, consequently, cannot make good on their progressive ambition. While a variety of theories could be explored, I will confine my remarks to what I take to be the leading paradigms in political and legal philosophy respectively, Rawls's justice as fairness and Hart's legal positivism. Once the difficulties that these theories encounter are in view, I present the 
unified theory of public law in terms of the components that make up a progressive theory. Finally, I defend the unified theory from a series of objections that target the relationship between the abstract conception of justice that it affirms and the particularity of the legal systems to which it applies.

A note of clarification is in order before I begin. Philosophic theories that invoke the notion of progress are often accused of harbouring a naïve belief in its inevitability. ${ }^{1}$ This chapter does not offer a philosophy of history that looks for patterns in the past to make predictions about the future, but an exploration of an approach to legal and political philosophy rooted in the view, as Rawls puts it, that the "limits of the possible are not given by the actual, for we can to a greater or lesser extent change political and social institutions, and much else."2 On the view that I will defend, progress is conceived of "not as an inevitable sequence of improvements but as aspiration and compelling obligation."3

\section{The Progressive Ambition of Rawls's Justice as Fairness}

At first glance, justice as fairness seems to fulfill the tripartite structure of a progressive theory. The underlying subject of justice as fairness is the basic structure of a modern constitutional democracy. The conception of justice appropriate for the basic structure is set out in what Rawls calls ideal theory. Lastly, the transitional framework for reforming defective instances of the basic structure forms a corresponding nonideal theory. In what follows, I briefly unpack each of these components, as presented

\footnotetext{
${ }^{1}$ See, for example, Bertrand Russell, Unpopular Essays (New York: Routledge, 2009), 9. For a defense of Enlightenment thinkers from this accusation, see Jonathan Israel, $A$ Revolution of the Mind: Radical Enlightenment and the Intellectual Origins of Modern Democracy (Princeton: Princeton University Press, 2009), 3-4 (arguing that the widespread criticism of Enlightenment naivety about human perfectibility is a "complete myth conjured up by early twentieth-century scholars unsympathetic to [Enlightenment] claims") and Susan Neiman, Moral Clarity: A Guide for Grown-up Idealists (New York: Harcourt, 2008), 120 (suggesting that what unites Enlightenment thinkers is not the acceptance of the view that progress is inevitable, but the rejection of the view that stagnation and regress are inescapable).

2 Rawls, Justice as Fairness: A Restatement (Cambridge: Harvard University Press, 2001), 5.

${ }^{3}$ Gabriel A. Almond, Marvin Chodorow, and Roy Harvey Pearce, "Progress and its Discontents," Bulletin of the American Academy of Arts and Sciences 35 (1981): 23.
} 
in Justice as Fairness: A Restatement, and argue that the relationship between these components raises a critical difficulty that undercuts the progressive orientation of the theory.

The first component, the basic structure of a well-ordered society, is the "primary subject" of justice as fairness and its unifying idea. ${ }^{4}$ The basic structure "is the way in which the main political and social institutions of society fit together into one system of social cooperation, and the way they assign basic rights and duties and regulate the division of advantages that arises from social cooperation over time." ${ }^{5}$ Justice as fairness focuses on the basic structure because of the deep and wide-ranging impact that a system of coercive institutions that assigns rights and duties and that allocates advantages and disadvantages has on the lives of citizens, from their attitudes and aspirations to their prospects and opportunities. ${ }^{6}$

The second component, ideal theory, sets out the conception of justice that is to regulate the basic structure of a well-ordered society. Rawls arrives at this conception by appealing to the

public political culture of a democratic society, and to the traditions and interpretations of its constitution and basic laws, for certain familiar ideas that can be worked up into a conception of political justice. It is assumed that citizens in a democratic society have at least an implicit understanding of these ideas as shown in everyday political discussion, in debates about the meaning and ground of constitutional rights and liberties, and the like.

The public political culture is a "fund of implicitly shared ideas and principles" basic structure of a constitutional regime and interpreted by the judiciary, political parties, statesmen, and jurists.' These include the idea of society as a fair system of intergenerational social cooperation,

4 Justice as Fairness, 10.

5 Ibid., 10; Political Liberalism (New York: Columbia University Press, 1996), 11.

${ }^{6}$ Justice as Fairness, 10.

7 Ibid., 5.

8 Political Liberalism, 14.

${ }^{9}$ Justice as Fairness, 5-6 and 19. 
and its companion ideas of citizens as free and equal persons engaged in social cooperation and of a well-ordered society in which the basic structure is regulated by a public conception of justice. ${ }^{10}$ Rawls formulates justice as fairness as the answer to a question raised by the presence of the fundamental ideas that characterize a modern constitutional democracy. If we acknowledge that society is a fair system of social cooperation between free and equal citizens, what would it mean for society to be well-ordered? ${ }^{11}$

The final component, nonideal theory, concerns the realization of the aim formulated in ideal theory:

Non-ideal theory asks how this long-term goal might be achieved, or worked toward, usually in gradual steps. It looks for policies and courses of action that are morally permissible and politically possible as well as likely to be effective. So conceived, nonideal theory presupposes that ideal theory is already on hand. For until the ideal is identified...non-ideal theory lacks an object, an aim, by reference to which its queries can be answered. ${ }^{12}$

Rawls divides nonideal theory into two subparts, each of which corresponds to an assumption within his ideal theory. ${ }^{13} \quad$ The assumption of strict compliance - that persons and institutions act in conformity with the obligations set out by justice as fairness - gives rise to a branch of nonideal theory concerned with partial or noncompliance. The assumption of favorable conditions - that historical, social, and economic conditions are conducive to the realization of a well-ordered society - yields a branch of nonideal theory responsive to the actual unfavorable conditions that frustrate the pursuit of a well-ordered society.

\footnotetext{
${ }^{10}$ Ibid., 5 and 25.

11 Ibid., 39.

12 Rawls, The Law of Peoples (Cambridge: Harvard University Press, 1999), 89-90.

${ }^{13}$ On the subparts of nonideal theory, see Rawls, A Theory of Justice (Cambridge: Harvard University Press, 1971), 246 and Rawls, Law of Peoples, 5 and 90. See also A. John Simmons, "Ideal and Nonideal Theory," Philosophy \& Public Affairs 38 (2010): 5-36 and Gopal Sreenivasan, "Non-ideal Theory: A Taxonomy with Illustration," (forthcoming).
} 
Although Rawls pioneered and popularized the distinction between ideal and nonideal theory, he did not develop a nonideal theory of domestic justice. ${ }^{14}$ In $A$ Theory of Justice Rawls acknowledges that the problems of nonideal theory are "pressing and urgent", but confines his discussion almost entirely to ideal theory because it provides "the only basis for the systematic grasp of these more pressing problems."15 Reflecting on that work, Rawls wrote: "The serious problems arising from existing discrimination and distinctions on gender and race are not on its agenda, which is to present certain principles of justice and then to check them against only a few of the classical problems of political justice as these would be settled within ideal theory." ${ }^{\prime 6}$ When Rawls does consider nonideal theory, he focuses not on domestic justice but on nonideal principles appropriate for individuals. ${ }^{17}$ Rawls all but ignores the distinction between ideal and nonideal theory in Political Liberalism ${ }^{18}$ and The Law of Peoples confines its extensive discussion of nonideal theory to international relations. ${ }^{19}$ Finally, in Justice as Fairness, Rawls again indicates that he will focus his inquiry on ideal theory because it engages the "current conflict in democratic thought", which asks "what conception of justice is most appropriate for a democratic society under reasonably favorable conditions." ${ }^{20}$ For Rawls, the problems of a nonideal theory of domestic justice may be pressing and urgent, but insofar as nonideal theory presupposes an ideal to be pursued, it remained an area of subsequent concern.

Rawls's distinction between ideal and nonideal theory has become the focal point for debates in political philosophy about progressive theorizing. In spite of the extensive literature that Rawls's

\footnotetext{
14 Justice as Fairness, 66.

${ }_{15}$ A Theory of Justice, 9.

16 Justice as Fairness, 66; cf. Political Liberalism, xxviii: "Among our most basic problems are those of race, ethnicity, and gender. These may seem of an altogether different character calling for different principles of justice, which Theory does not discuss."

${ }^{17}$ Rawls discusses two cases involving unjust laws, civil disobedience and the conscientious refusal to serve in an unjust war. See $A$ Theory of Justice, 371-382.

18 In Political Liberalism the term appears in passing on 18 and 285.

19 Law of Peoples, 89-120.

${ }^{20}$ Justice as Fairness, 13.
} 
distinction has generated, ${ }^{21}$ there remains no systematic formulation of a Rawlsian nonideal theory of domestic justice. ${ }^{22}$ Accordingly, those who accept Rawls's distinction and are eager to bring justice as fairness to bear on nonideal instances of domestic justice, seek to 'take up where Rawls left off by articulating nonideal principles for societies that are not well-ordered. Such societies include those in which the arrangement of background institutions that make up the basic structure "are unjust or do not exist at all" and in which the public political culture is mired in racism, sexism, and other forms of prejudice inimical to the realization of a well-ordered society. ${ }^{23}$ What I want to suggest is that the fundamental problem in formulating justice as fairness as a progressive paradigm lies not in Rawls's

21 For discussions of the Rawls's conception of the distinction between ideal and nonideal theory, the value of the distinction, and analogous distinctions in other philosophic frameworks, see Elizabeth Anderson, The Imperative of Integration (Princeton: Princeton University Press, 2010); Anderson, “Toward a Non-Ideal, Relational Methodology for Political Philosophy: Comments on Schwartzman's Challenging Liberalism," Hypatia 24 (2009): 130-145; Katherine Eddy, "Against Ideal Rights," Social Theory and Practice 34 (2008): 463-481; Colin Farrelly, "Justice in Ideal Theory: A Refutation," Political Studies 55 (2007): 844-864; Joel Feinberg, "Duty and Obligation in the Non-Ideal World," The Journal of Philosophy 70 (1973): 263-275; Pablo Gilabert, "Global Justice and Poverty Relief in Nonideal Circumstances," Social Theory and Practice 34 (2008): 411-438; Lisa L. Fuller, "Burdened Societies and Transitional Justice," Ethical Theory and Moral Practice (2011): 369-386; Robert E. Goodin, "Political Ideals and Political Practice," British Journal of Political Science 25 (1995): 37-56; Burke A. Hendrix, "Where Should We Expect Social Change in Non-Ideal Theory,"Political Theory 41 (2013): 116-143; Michael Kates, "Justice in Nonideal Theory," (on file with author); Christine M. Korsgaard, "The Right to Lie: Kant on Dealing with Evil," Philosophy \& Public Affairs 15 (1986): 325-349; Andrew Mason, "Just Constraints," British Journal of Political Science 34 (2004): 251-268; Charles W. Mills, “Ideal Theory' as Ideology," Hypatia 20 (2005): 165-184; Liam Murphy, Moral Demands in Nonideal Theory (Oxford: Oxford University Press, 2000); Michael Phillips, "Reflections on the Transition from Ideal to Non-Ideal Theory," Noûs 19 (1985): 551-570; Margaret Jane Radin, "Lacking a Transformative Social Theory: A Response," Stanford Law Review 45 (1993): 409-424; Anthony R. Reeves, "Judicial Practical Reason: Judges in Morally Imperfect Legal Orders," Law and Philosophy 30 (2011): 319-352; Ingrid Robeyns, "Ideal Theory in Theory and Practice," Social Theory and Practice 34 (2008): 341-362; Tamar Schapiro, "Compliance, Complicity, and the Nature of Nonideal Conditions," The Journal of Philosopby 100 (2003): 329-355; David Schmidtz, "Nonideal Theory: What It Is and What It Needs To Be," Ethics 121 (2011): 772-796; Amartya Sen, "What Do We Want From a Theory of Justice?" The Journal of Philosophy 103 (2006): 215-238; George Sher, Approximate Justice: Studies in Non-Ideal Theory (Lanham: Roman \& Littlefield, 1997); A. John Simmons, "Ideal and Nonideal Theory," 5-36; Gopal Sreenivasan, "Health and Justice in Our Non-Ideal World," Politics, Philosophy \& Economics 6 (2007): 218-236; Sreenivasan, "Non-ideal Theory: A Taxonomy with Illustration"; Zofia Stemplowska, "What's Ideal About Ideal Theory?" Social Theory and Practice 34 (2008): 319-340; Adam Swift, "The Value of Philosophy in Nonideal Circumstances," Social Theory and Practice 34 (2008): 363-387; Robert S. Taylor, "Rawlsian Affirmative Action," Ethics 119 (2009): 476-506; Laura Valentini, “On the Apparent Paradox of Ideal Theory," The Journal of Political Philosophy 17 (2009): 332-355.

22 Robeyns, "Ideal Theory in Theory and Practice," 348: “[T] he literature on theories of justice remains remarkably silent on what, then, precisely is needed in order to make the transition from ideal theory to nonideal theory and action design and implementation... To the best of my knowledge, there is no systematic and comprehensive account of what a nonideal theory of justice entails, or on which methodology it would rest. There are some scattered contributions to the question of how we could go about developing nonideal theory, and also some insightful work within nonideal theorizing about justice, yet this body of literature remains far removed from a systematic account of nonideal theory."

${ }^{23}$ Fuller, "Burdened Societies and Transitional Justice," 370. 
omission of a nonideal theory of domestic justice, as is often supposed, but in a feature of Rawls's ideal theory.

Recall that Rawls generates his ideal theory by appealing to fundamental ideas that are "deeply embedded" within the public culture of a modern constitutional democracy and working them up into a conception of justice. ${ }^{24}$ In Rawls's words:

A political conception of justice is formulated so far as possible solely in terms of fundamental ideas familiar from, or implicit in, the public political culture of a democratic society: for example, the idea of society as a fair system of cooperation and the idea of citizens as free and equal. That there are such ideas in their public culture is taken as a fact about democratic societies. ${ }^{25}$

Rawls does not offer justice as fairness as a general conception of justice appropriate for assessing the basic structure of society in all times and places. Justice as fairness is a conception of justice appropriate "for the special case of the basic structure of a modern democratic society", that is, a constitutional democracy in which citizens endorse, at least implicitly, certain fundamental ideas about the social order that they occupy. ${ }^{26}$ This is not to say that societies that are not constitutional democracies or in which citizens do not accept the fundamental ideas from which justice as fairness springs are adequate, but rather that justice as fairness does not provide the standard for assessing their adequacy. As Rawls explains, "justice as fairness is framed for a democratic society. Its principles are meant to answer the question once we view a democratic society as a fair system of social cooperation between citizens regarded as free and equal, what principles are most appropriate to it??27

\footnotetext{
24 Justice as Fairness, 5 and 25.

25 Ibid., 27.

${ }^{26}$ Ibid., 14 (my emphasis).

${ }^{27}$ Ibid., 39. The passage continues: "Alternatively: which principles are most appropriate for a democratic society that not only professes but wants to take seriously the idea that citizens are free and equal, and tries to realize that idea in its main institutions?"
} 
The argument takes the form of a conditional: if a given society falls within the special case, then these principles of justice are most appropriate to it.

That Rawls's ideal theory applies solely to instances of the special case of a modern constitutional democracy has important implications for the formulation of any corresponding nonideal theory. For Rawls, ideal theory provides principles for assessing the adequacy of the basic structure of a modern constitutional democracy. Since Rawls's ideal theory applies only to the special case of the basic structure of a modern constitutional democracy, it provides no resources for deeming societies that are not constitutional democracies (or in which one or more of the fundamental ideas is not present in the public political culture) to be defective. But if the ideal theory of justice as fairness provides no basis for deeming such societies defective, then nonideal theory lacks its condition of application. The problem with treating justice as fairness as a general theory of political development is not that it lacks a nonideal theory and that it is therefore incomplete. Even if such a theory were to materialize, it would not be applicable to societies that are not instances of the special case. The narrowness of Rawls's ideal theory of justice limits the domain to which any corresponding nonideal theory could apply to defective instances of the special case. A nonideal theory of domestic (as opposed to international) justice would not be applicable to what Rawls calls decent hierarchical societies because they do not conceive of persons as free and equal citizens. ${ }^{28}$ It would not apply to burdened societies because they "lack the political and cultural traditions to be well-ordered". ${ }^{29}$ It would not apply to benevolent absolutisms because even though they respect at least some human rights, they lack democratic institutions and traditions. ${ }^{30}$ Finally, it would not apply to outlaw states because they are not democratic and fail to honor human rights. ${ }^{31}$ Since each of these societies falls

\footnotetext{
${ }^{28}$ Law of Peoples, 66.

29 Ibid., 106.

${ }^{30}$ Ibid., 4, 63, and 92.

31 Ibid., 80-1, 94-5, and 105-6.
} 
beyond the special case, they cannot be defective with respect to the ideal that justice as fairness establishes.

Burton Dreben, Rawls's interlocutor and a defender of justice as fairness, considered it a strength of Rawls's theory that it made no attempt to justify modern constitutional democracy, but instead appealed to fundamental features of modern constitutional democracy to justify a conception of justice:

It is very important to understand that Rawls is a good enough thinker not to argue against those who do not believe in liberal constitutional democracy. Neither in $A$ Theory of Justice, nor surely in Political Liberalism, nor in any of the other works, is he engaged in the kind of struggle that, say, Locke was engaged in. The outcome of that struggle he takes for granted, just as I think any sensible person should today. You do not argue in political philosophy over the benefits of constitutional liberal democracy; what you try to do is see what that concepts leads to, what it entails, what it demands....You do not argue for it. You do not ground it. You see what it leads to. ${ }^{32}$

Dreben overlooks a problem latent within Rawls's strategy for generating his ideal theory. Because Rawls does not provide a justification of liberal constitutional democracy, his ideal theory cannot explain why societies that are not liberal constitutional democracies are defective on their own internal standard of adequacy. And in the absence of such an explanation, a Rawlsian nonideal theory could not apply to them. The reason that a progressive theory must attempt a justification of liberal constitutional democracy is not, as Dreben imagines, to convince fools and fascists who do "not see the virtue of that ideal". ${ }^{33}$ Rather, an account of why liberal constitutional democracy alone is adequate may shed light on two sets of issues. First, it may indicate the kinds of constitutional norms, institutional arrangements, and legal doctrines appropriate for a liberal constitutional democracy. I

\footnotetext{
32 "On Rawls and Political Liberalism," in The Cambridge Companion to Rawls, ed. Samuel Freeman (Cambridge: Cambridge University Press, 2003), 323.

33 Ibid., 328-9. Dreben continues: "[S]ometimes I am asked, when I go around speaking for Rawls, What do you say to an Adolph Hitler? The answer is [nothing]. You shoot him. You do not try to reason with him. Reason has no bearing on that question."
} 
return to this point in Chapter Four. Second, and more significantly for the present chapter, such an account avoids the tension between the theory of justice that Rawlsians affirm and the kinds of judgments that they make about obvious cases of injustice. Dreben rejects the adequacy of all alternatives to constitutional democracy, ${ }^{34}$ but nevertheless clings to a conception of justice that offers no resources for illuminating their inadequacy. Similarly, Rawls asserts that "we may assume that any actual society is more or less unjust - usually gravely so", ${ }^{35}$ even though many actual societies are not instances of the special case, which means that justice as fairness provides no basis for deeming them unjust.

The difficulty that undermines the progressive ambition of justice as fairness is suggestive. Considered as a progressive theory, justice as fairness goes off the rails at its initial step by identifying its underlying subject as the basic structure of a modern constitutional democracy. Such an underlying subject culminates in an ideal theory that is too narrow to fulfill its progressive ambition because it cannot apply to societies that are not modern constitutional democracies. Perhaps the problem that justice as fairness encounters can be avoided by beginning with a broader underlying subject - political societies in general or legal systems as such - and relating it to an appropriate conception of justice. With this strategy in mind, I now turn to consider a leading approach to progressive theorizing in contemporary legal philosophy.

\section{The Progressive Ambition of Hart’s Legal Positivism}

Unlike Rawls, who constructed his progressive theory from particular features of modern constitutional democracies and the public political culture that supports them, H.L.A. Hart sought to formulate a general jurisprudence that was "not tied to any particular legal system or legal culture." ${ }^{36}$

\footnotetext{
34 Ibid.

35 "Political Liberalism: Reply to Habermas," The Journal of Philosophy 92 (1995): 154.

${ }^{36}$ Hart, The Concept of Law (Oxford: Clarendon Press, 1994), 239.
} 
For Hart the development of a general theory of law is not merely a theoretical achievement, but is integral to the practical aim of reforming laws and legal systems. As in my discussion of Rawls, I will confine my discussion of Hart to the aspects of his framework that are relevant from the standpoint of progressive theorizing. From this standpoint, Hart's legal positivism raises a mirror image of the problem encountered in Rawls: justice as fairness is progressive but not general; Hart's legal positivism is general but not progressive.

In rejuvenating analytic jurisprudence, Hart emphasized that legal positivism offered more than a defensible theoretical thesis about the concept of law. Hart's claim was that legal positivism cultivated moral attitudes conducive to the reform of defective laws and legal systems. As Hart explained, the founders of analytic jurisprudence, Bentham and Austin, "were not dry analysts fiddling with verbal distinctions while cities burned, but were the vanguard of a movement which laboured with passionate intensity and much success to bring about a better society and better laws." 37 For Hart, as for his predecessors, the separation of law and morals was integral to the reformist project. By distinguishing the question of whether a particular norm is a valid law from the question of whether it is just, legal positivism yields the twin insights that what is law is not thereby just and that what is just is not thereby law. The validity of a legal norm depends not on its justice but on whether it was enacted in accordance with the appropriate social rule. Armed with these insights, positivist reformers are able to identify valid laws, assess their moral adequacy, and insist that morally defective laws yield to the enactment of progressive alternatives. The conceptual separation of law and morals provides positivist reformers with the intellectual clarity required to bring law and morals together by repealing unjust laws and enacting just ones.

When assessing whether legal positivism is a progressive theory of law, it is important to distinguish between the projects of particular legal positivists, on the one hand, and the theory of legal

37 "Positivism and the Separation of Law and Morals," Harvard Law Review 71 (1958): 596. 
positivism, on the other. Although some positivists have pursued an agenda of progressive reform, positivism is not itself a progressive paradigm. Positivism is the thesis that the concept of law is exhausted by its positivity. Accordingly, positivism holds that one can provide a comprehensive account of the concept of law without recourse to the endless controversies of morality. ${ }^{38}$ Indeed, part of positivism's widespread attraction is that the separation of law and morals enables its proponents to agree about the concept of law even when they disagree about the demands of morality. While proponents of positivism assert that it is "a radical theory of law, one unfriendly to the status quo", critics point out that the "banners of legal positivism" have marched both with those who sought to uproot an unjust status quo and those who sought to preserve it. ${ }^{40}$ But if the concept of law that the positivist endorses is compatible with a variety of views about morality, some progressive and others regressive, then positivism as such is not a progressive theory. For whether positivism is progressive or regressive depends on something extrinsic to the concept of law that positivists endorse, namely, an independent conception of morality. Of course, a positivist might reply that positivism can and must be coupled with an appropriate critical morality, but this simply restates the problem. How can positivism purport to be a progressive theory of law if it can be coupled with an inappropriate (or uncritical) morality? If it is a virtue of positivism that it can be coupled with a progressive conception of morality, then it is surely a vice if it can just as easily be coupled with a regressive conception.

Perhaps the positivist wishes to retreat to a more moderate claim about positivism's virtues. Because the concept of law is compatible with a variety of views about morality, positivism is not

\footnotetext{
38 Brian Leiter, “Why Legal Positivism?” (December 10, 2009). U of Chicago, Public Law Working. Available at SSRN: http://ssrn.com/abstract=1521761.

39 Brian Leiter, “The Radicalism of Legal Positivism," Guild Practitioner, 2010; U of Chicago, Public Law Working Paper No. 303. Available at SSRN: http://ssrn.com/abstract=1568333.

40 Ronald Dworkin, “Law's Ambition for Itself,” Virginia Law Review 71 (1985): 175.
} 
progressive as such, as its proponents have asserted, but, for the same reason, neither is it regressive as such, as its critics have alleged. ${ }^{41}$ Rather, the positivist might insist that insofar as positivism is compatible with a progressive approach to morality, it provides an alternative to regressive theories and this is something to be celebrated. With this claim, a classification emerges. A theory can be progressive, regressive, or morally variable. Theories of the first type would involve an underlying subject - whether legal systems or societies of a certain kind - that implicated a progressive moral standard for assessing the adequacy of its instances and directing their reform. Theories of the second type would mirror the first by offering an underlying subject that implicated a regressive moral standard. Quietist theories exemplify this possibility by holding that the features of an existing legal system (or society) forms the standard by which its adequacy is to be assessed, which means that no existing instance can fail to be fully adequate. Quietist theories are not progressive because, as Bentham once remarked, "if nothing is ever to be found fault with, nothing will ever be mended". ${ }^{42}$ Theories of the third type would involve an underlying subject, in Hart's case, legal systems, that was not tethered to any particular conception of morality and was, consequently, compatible with both progressive and regressive conceptions of morality. ${ }^{43}$

The problem that Hart encounters in formulating a progressive theory can be contrasted with the problem, discussed above, that arises in Rawls's justice as fairness. Hart formulates a general theory

41 On the conflict between those who allege that positivism is either a progressive or regressive theory, see David Dyzenhaus, Hard Cases in Wicked Legal Systems: Pathologies of Legality (Oxford: Oxford University Press, 2010), 1: "Like Dr Jekyll and Mr Hyde legal positivism seems to lead two distinct lives, one virtuous and one wicked. As Jekyll, and as its proponents claim, legal positivism is a doctrine about the nature of law that, correctly understood, can only help to inculcate morally desirable attitudes towards the law in both judges and citizens. As Hyde, and as its critics claim, positivism's slogan 'Law is law' is the legal ideology of authoritarianism, of governments which use the law as an instrument of oppression, of political conservative judges who adopt a mechanical approach to the interpretation of law...and of citizens who unquestioningly conclude from the mere fact that $\mathrm{L}$ is the law that $\mathrm{L}$ is worthy of their respect."

In Chapter One, I offered an alternative criticism of Hart's version of legal positivism. The problem with that theory, I argued, is not that Hart's theory is quietist, as the critics of positivism alluded to in the quoted passage maintain. Rather, the problem with positivism, at least in Hart's influential version of it, is that it is anarchist. Quietism is the view that what is obligatory is thereby just. Since Hart's positivism cannot account for the right of a legal system to impose obligations, his theory cannot be quietist. But for the same reason it must be anarchist.

42 A Fragment on Government (Cambridge: Cambridge University Press, 2001), 10.

${ }^{43}$ For the sake of completeness a further branch could be added to this classification: a theory that is dismissive of morality. 
applicable to legal systems as such, but this theory is morally variable rather than progressive. Rawls offers a progressive framework for the special case of a modern constitutional democracy, but the theory lacks generality. What I wish to consider in the next section is what a theory that was both general and progressive might look like.

\section{The Progressive CHARACTER OF THE UNIFIED THEORY}

A theory that is both general and progressive must bear a certain kind of structure. If the theory is to be general, the underlying subject of the theory must be legal systems or political societies as such, rather than those distinguished by some contingent feature, as in Rawls's account of the special case. Further, if the theory is to be progressive, it must appeal to some feature of the underlying subject to generate a conception of justice apposite to all of its instances. Such an approach would follow Hart (but not Rawls) in formulating a general theory rather than a theory of the special case. And it would follow Rawls (but not Hart) in formulating a theory that is progressive rather than morally variable.

The challenge of formulating such a theory lies in the relationship between its general and its progressive aspects. On one side lies Hart's theory, which holds that when one understands law as a general concept in abstraction from particular laws or legal systems, one sees that law has no necessary connection to morality. The generality of Hart's approach culminates in its moral variability. On the other lies Rawls's theory, which holds that the moral standard appropriate for assessing the adequacy of a particular political society or a legal community depends on facts about its practices. Justice as fairness retains its progressive orientation by confining the application of this approach to the special case of a modern constitutional democracy, thereby sacrificing the theory's generality. A theory that is both general and progressive must defend a position not found in the theories canvassed above: that a legal system (or a political order) as such contains its own internal standard of moral adequacy. 
In what follows, my strategy is to draw on the unified theory of public law to identify a feature that is constitutive of legal systems in general. Internal to this feature, I will argue, is the standard for critically assessing the adequacy of its instances and a principle of transition that articulates what is required of legal systems that are defective on their own internal standard of adequacy. Accordingly, the underlying subject of the theory is legal systems as such. The justification of the constitutive feature of a legal system indicates both the internal standard appropriate for critically assessing legal systems and the principle for directing the reform of legal systems that are defective on their own internal standard of adequacy. I call the former the ideal of public justice and the latter the duty of public justice.

The unified theory is a general theory of public law, the branch of law that concerns the relationship between the individual and the state. As a general theory, its underlying subject is legal systems as such rather than instances of legal systems distinguished by democratic institutions, rights protecting constitutional norms, or the commitments of the public culture. The unified theory identifies public authority as the constitutive feature of a legal system. Public authority is the right of government to impose, interpret, and enforce legal obligations on private persons through its institutions. Public authority is constitutive of a legal system because it creates the parties to it, a government comprised of public institutions and a people comprised of private persons bound by its lawgiving.

The right of government to exercise public authority over independent persons must be justified. As I argued in Chapter One, the justification of public authority is premised on the right of every person to independence, that is, to freely determine and pursue their own purposes in a manner compatible with the equal right of all others to the same. The right of government to exercise public authority over independent persons can be justified because independent persons cannot interact on 
terms of equal freedom in relation to one another in the absence of publicly authoritative institutions that establish interpret, and enforce legal obligations.

Since the public authority of government is justified on the basis of the right of every person to independence, internal to the justification of the constitutive feature of a legal system is the standard for critically assessing the adequacy of its instances. Public justice is the ideal of a legal system that fully conforms to the terms of its justification. A legal order consists in a set of public institutions that make the conduct of each person accountable to the independence of every other. In a just legal order, the arrangements that render persons accountable to one another are themselves compatible with the independence of each person who is bound by them. A legal system exemplifies this ideal to the extent that the procedures through which laws are enacted and the content of enacted laws are compatible with the independence of everyone among the people. In a just legal order, the members of a people are not passive citizens bound by laws of another's making but active citizens who act through their representatives to collectively author the laws by which all are bound. Turning from the procedure for enacting law to its content, the ideal of public justice involves laws that each could consent to as an independent member of the legal order. The ideal of public justice is satisfied when the system of law that citizens collectively enact is harmonious with the right of every person to equal freedom under law. Alternately, a legal system is defective or unjust to the extent that it fails to conform to the terms of its justification by securing the independence of all who are bound by its lawgiving.

The ideal of public justice is a system of law in which each particular feature of the legal order is directed towards the realization of the internal aim of the whole, the equal freedom of persons under law. Such an ideal encompasses the entire legal system from its fundamental norms to the institutions through which those norms are made effective and from the issuance of positive law to the construction of legal doctrine. A just legal order consists neither in a particular just law nor in the 
independence of a particular person because such arrangements would not exclude the possibility that other laws might treat other persons in a manner unbefitting of their independence, and, consequently, that the legal system as a whole would fail to conform to the terms of its justification.

The ideal of public justice is fundamentally different from the ideal of instrumental theories. Jeremy Bentham's utilitarianism, for example, begins by positing an ideal that exists apart from legal concepts, legal forms of reasoning, and legal institutions: "Nature has placed mankind under the governance of two sovereign masters, pain and pleasure." 44 On Bentham's view, an action is adequate to the extent that it produces utility, conceived of as pleasure and the absence of pain. ${ }^{45}$ Thus, Bentham writes that "A measure of government (which is but a particular kind of action, performed by a particular person or persons) may be said to be conformable to or dictated by the principle of utility, when in like manner the tendency which it has to augment the happiness of the community is greater than any which it has to diminish it." ${ }^{\prime 4}$ For Bentham, as for instrumental theories generally, a legal system is simply a tool for realizing something that is of value apart from it. Proponents of instrumental theories of law differ about the particular value that legal systems should pursue, but agree that if legal systems are of value, it is because they have a propensity to further the realization of some extrinsically valuable end. ${ }^{47}$ Unlike the ideal of an instrumental theory, the ideal of public justice is not conceivable apart from a legal system. The reason for this is that public justice consists in an adequate relationship between the parties to public law, a people, that is, a multitude of persons subject to common lawgiving, and its government, the publicly authoritative institutions that represent the people as a whole. When publicly authoritative institutions are absent, neither of the parties to this

\footnotetext{
${ }^{44}$ Bentham, An Introduction to the Principles of Morals and Legislation (New York: Prometheus Books, 1988), I.I.

45 Ibid., I.II-III.

46 Ibid., I.VII.

${ }^{47}$ For an elaboration of this distinction between instrumental and non-instrumental legal theories, see Ripstein, Force and Freedom (Cambridge: Harvard University Press, 2009), 7-11 and 255-6.
} 
juridical relationship is present and, consequently, questions about the adequacy of their relationship cannot arise. The internal ideal of a legal system cannot be realized apart from one.

The ideal of public justice forms the internal standard for assessing the adequacy of every existing legal system and every conceivable legal system. A legal system is adequate to the extent that it conforms to and defective to the extent that it deviates from its internal ideal of public justice. So conceived, the ideal of public justice does not follow from some contingent fact about a particular legal system, such as the textual provisions found in a written constitution, its democratic form of lawgiving, or the convictions that make up its public political culture. Rather, the ideal of public justice follows from an inherent feature of the public law relationship instantiated by all legal systems: the mere presence of public authority over independent persons. The ideal of public justice is internal to every legal system not because it stems from some contingent feature that all societies happen to share, but because it arises from the constitutive feature of a legal system as such, the juridical relation between publicly authoritative institutions and a people. Public justice is the internal ideal of every legal system simply by virtue of being a legal system. The ideal of public justice can of course be recognized by a publicly authoritative act - for example, the promulgation of constitutional norms recognizing the right of every person within the legal order to membership in a system of equal freedom and the corresponding duty that this right imposes on all public institutions - but the ideal can neither be established nor displaced by such an act.

The distinction between a legal system and its internal standard of adequacy explains how a legal system can be defective on its own internal standard of adequacy. Accordingly, we must ask what public justice requires of an unjust legal system.

The ideal of public justice and the duty of public justice draw out different aspects of the justification of public authority. The ideal of public justice delineates the features of a legal system that fully conforms to the terms of its justification by uniting the authority of a legal system with the 
independence of its members. The duty of public justice is the requirement that government exercise the right of public authority in accordance with the terms on which that right is justified. As we saw in Chapter One, the right to exercise public authority is accompanied by an obligation to bring the existing legal system into the deepest possible realization of the ideal of public justice. The basis of this obligation lies in the justification of public authority. Because the right of government to exercise public authority presupposes the right of every private person to independence, government cannot deny the right of persons to independence without thereby denying the justificatory basis of its own authority. Since the right of persons to independence grounds both the right of government to exercise authority over private persons and the right of private persons to just governance, every unjust exercise of public authority involves a moral incoherence.

The ideal of public justice must not be confused with the duty to realize it. The ideal of public justice is a legal system that fully conforms to the terms of its justification. Existing legal systems are adequate to the extent that they approximate this ideal. When we assess how just a legal system is, whether one legal system is more just than another, or whether a possible reform would improve existing arrangements, the ideal of public justice is the relevant measure. In contrast, the duty of public justice requires the government of an existing society to direct the exercise of public authority towards bringing the system of laws into the deepest possible conformity with its own internal ideal. At issue is not the degree of conformity between the existing legal system and the requirements of public justice at a particular moment, but whether the existing legal system has engaged in progressive reform to the fullest possible extent within a discrete period of time. The duty of public justice is satisfied to the extent that public authority is directed towards bringing the existing legal system as a whole into the greatest possible approximation of its own internal ideal. In turn, the duty of public justice is violated to the extent that the exercise of public authority fails to bring the existing legal system into the deepest possible conformity with its own internal ideal. Regardless of how closely a legal system approximates 
the ideal of public justice, it must exercise public authority in accordance with the duty of public justice.

The distinction between the ideal of public justice and the duty to approximate it forms a fundamental part of the discourse of politics, conceived of as a justified practice. Consider Abraham Lincoln's understanding of the Declaration of Independence, which famously proclaims the inherent right of equal persons to life, liberty, and the pursuit of happiness, and that government must secure these rights:

[The Founders] meant simply to declare the right, so that the enforcement of it might follow as fast as circumstances should permit. They meant to set up a standard maxim for free society, which should be familiar to all, and revered by all; constantly looked to, constantly labored for, and even though never perfectly attained, constantly approximated, and thereby constantly spreading and deepening its influence, and augmenting the happiness and value of life to all people of all colors everywhere. ${ }^{48}$

Lincoln conceived of the Founders as encapsulating an ideal conception of public justice internalized by the American people, or as he described it, "a philosophical cause...entwining itself more closely about the human heart." ${ }^{49}$ This ideal forms the 'standard maxim for a free society', which persons may look to in assessing the adequacy of the existing legal order. The duty of an existing society is not to do the impossible by perfectly instantiating this standard, but to approximate this standard 'as fast as circumstances should permit.'

Correlative to the duty of public justice is the right of everyone among the people to just governance. Government is not to regard members of the people as beings who must obey lawgiving but who have no right to just lawgiving. Nor are members of the people to regard themselves as

48 “The Dred Scott Decision: Speech at Springfield, Illinois, June 26, 1857," in Abraham Lincoln: His Speeches and Writings, ed. Roy P. Basler (Cleveland: Da Capo Press, 1946), 361. See also Gary J. Jacobsohn, "Abraham Lincoln 'On this Question of Judicial Authority': The Theory of Constitutional Aspiration," Western Political Science Association 36 (1983): 65. On the Declaration as a prescription for rather than a description of American society, see Giovanni Sartori, Democratic Theory (New York: Frederick A. Praeger: 1965), 53.

${ }^{49}$ Lincoln, "Fragment on the Constitution and Union," in The Collected Works of Abrabam Lincoln, vol. IV, ed. Roy Basler (New Brunswick: Rutgers University Press, 1977), 169. 
having a right to ideal justice. The former position overlooks that the right to exercise public authority is always accompanied by a duty to govern justly. The latter overlooks that a person may raise a claim to just governance only as a member of a legal system, in which every person subject to public authority has an equal claim. The right to just governance is the entitlement to be governed in accordance with the terms on which public authority is justified. The duty incumbent on government is not to realize the ideal of public justice at once, but rather to exercise public authority in a justifiable manner by creating a legal system that as a whole fulfills the independence of all who are bound by it to the greatest possible extent. The duty of public justice reflects the systematic structure of the ideal of public justice. The ideal of public justice is fulfilled not by a particular just law or institutional arrangement but by a just system of law. Since the duty of public justice requires government to direct its authority towards the deepest possible realization of its own internal ideal, the duty of the public authority is neither to address any particular defect within the legal order nor to safeguard the independence of any particular person. Rather, the duty of all public authority is to bring the entire system of constitutional norms, institutional arrangements, positive laws, and legal doctrines into the highest possible degree of agreement with the ideal of public justice.

Because the duty of public justice requires government to bring the legal system as a whole into the deepest possible degree of conformity with the ideal of public justice, it does not require government to address each of its particular defects at once. When circumstances obtain in which the reform of a particular injustice would counteract the duty to bring the legal system as a whole into the deepest possible conformity with the ideal of public justice, government is justified in temporarily delaying that reform. The delay is justified because it is itself required by the duty of public justice, which requires government to realize the ideal of public justice to the fullest possible extent by reforming the legal system as a whole, not to frustrate the reform of the whole for the sake of reforming a particular aspect of it. The justification is temporary because once circumstances arise in 
which the reform of the unjust particular is necessary to bring the existing legal system into the deepest possible conformity with the ideal of public justice, the justification for postponing reform dissolves and any further delay is simply the perpetuation of injustice. ${ }^{50}$

Similarly, government may introduce temporary programs that do not conform to the ideal of public justice but are required to bring the existing legal order as a whole into closer approximation of it. Consider how Jonathan Wolff conceptualizes the justification of affirmative action:

[A] world which includes affirmative action is not an ideal one. As a long-term policy, affirmative action is undesirable, and in certain respects unjust. People should be treated on their individual merits, as critics of affirmative action claim. But without a temporary policy of affirmative action it will be much harder to create a world in which affirmative action is unnecessary: in which people are treated on their individual merits. So we should see affirmative action as a transitional policy in a step towards a more just world. ${ }^{51}$

The unified theory provides a conceptual structure for Wolff's remark. Wolff's point is that given the unjust conditions of an existing society, affirmative action may be required by the duty of public justice as a temporary measure designed to bring the existing legal system into closer approximation with the ideal of public justice, of which affirmative action is not a part. The internal aim of public law is not to create a world without affirmative action, but a world in which such measures are no longer necessary because equality of opportunity has been transformed from rhetoric into reality. Affirmative action may be integral to the creation of such a world, but it has no place within it.

The duty of public justice is unremitting and transformative. The duty is unremitting because it accompanies the presence of public authority. Accordingly, the duty cannot be discharged through the performance of the very acts that it necessitates or through its violation. The duty is transformative because it requires government to formulate, implement, and refine a program for the progressive

\footnotetext{
${ }^{50}$ I elaborate on this idea in the context of Kant's theory of public right in "Permissive Laws and the Dynamism of Kantian Justice," Law and Philosophy (forthcoming 2013).

51 An Introduction to Political Philosophy (Oxford: Oxford University Press, 1996), 209.
} 
reform of an existing legal system. By acting in conformity with its duty, an existing society transforms itself to the greatest possible extent from a system of compulsion into an increasingly realized system of equal freedom.

What hope can we have for public law given the broad expanse that lies between existing societies and the ideal of public justice? The hope is that by acting in accordance with the duty of public justice, progressive reforms will create the conditions for further progress, and equal degrees of reform will occur in shorter and shorter successive intervals. That legal systems may be capable of reforming themselves at increasing rates is not a mere conceptual possibility but a familiar feature of legal experience. The maturation of a public culture, the increasing inclusivity of representative institutions, and the formulation of constitutional norms that tie the exercise of public authority to the realization of public justice ready the path for further progressive measures. Frederick Douglass - who dedicated all his efforts to the "great work of renovating the public mind, and building up a public sentiment, which should send slavery to the grave" - captured this hope when he observed: "Unlike the movement for the abolition of slavery, the success of the effort for the enfranchisement of the freedmen was not long delayed. It is another illustration of how any advance in pursuance of a right principle prepares and makes easy the way to another." ${ }^{2}$ Even if existing societies depart markedly from the ideal of public justice, it may nevertheless be possible to approximate the ideal of public justice at ever-increasing rates.

The unified theory departs from Rawls and Hart by holding that a legal system is defective on its own internal standard of moral adequacy to the extent that it fails to realize a system of equal freedom. Unlike Hart's legal positivism, which conceives of morality as extrinsic to the concept of law, the unified theory holds that a legal system as such contains its own internal morality: the justification of the constitutive feature of a legal system - the right of government to exercise authority

52 Douglass, Life and Times of Frederick Douglass (New York: Cosimo, 2008), 184 and 277. 
by enacting, interpreting, and enforcing legal obligations on independent persons - implicates a distinctive moral standard for the critical assessment of all legal systems. What a legal system is implicates a critical moral standard for assessing the adequacy of its instances. Thus, the unified theory retains the generality of Hart's approach, while eschewing its moral variability. Further, unlike Rawls, who seeks to formulate a moral standard internal to a particular kind of political order by appealing to its contingent features, the unified theory draws on the constitutive feature of a legal system to formulate a moral standard internal to legal systems generally. The unified theory thereby provides a standpoint for explaining why a legal system is defective on its own internal standard of adequacy to the extent that it fails to create a condition of equal freedom. Whereas Rawls maintains that a liberal legal or political order must govern in a liberal way, the unified theory provides resources for thinking about why a legal or political order must become liberal.

\section{PROGRESS AND PARTICULARITY}

The unified theory of public law is a liberal theory because it generates its principles of public authority and public justice from the right of every individual to determine the purposes that he or she will pursue. Liberalism leads a double life. On the one hand, it forms the backbone of a tradition that extends from Enlightenment thought to the emergence of modern constitutional states that make the dignity of their members the purpose and constraint of all exercises of public authority. On the other, liberalism is increasingly subject to the "old objections of formalism, emptiness, abstractness and absence of historical and cultural connections". ${ }^{53}$ Because the unified theory of public law arrives at a conception of justice by reflecting on what a legal system is rather than on contingent features present in a particular legal system, the unified theory may appear vulnerable to these old objections. The purpose of this section is to explore the connection between the progressive orientation of the

\footnotetext{
${ }^{53}$ Robert Alexy, "Discourse Theory and Human Rights," Ratio Juris 9 (1996): 210.
} 
unified theory of public law and the concrete particularity of existing legal systems. I will consider two objections that seek to sever this connection.

The first objection begins with the observation that the progressive development of an existing society arises within a particular context distinguished by legal, political, historical and sociological features. These features make up both the setting in which reform must occur and also the circumstances to which reform must respond. However, when the realization of a just society is given theoretical expression, what is typically imagined is not the reform of an existing society's defects, but rather the creation of a perfectly just society from scratch. As Ronald Dworkin formulates the objection:

The great classics of political philosophy...study social justice from the point of view of people committed in advance to no government or constitution, who are free to create the ideal state from first principles. So they imagine people living in a prepolitical state of 'nature' writing social contracts on blank slates. But real people in ordinary politics act within a political structure as well as on it. Politics, for us, is evolutionary rather than axiomatic; we recognize, in working toward a perfectly just state, that we already belong to a different one. ${ }^{54}$

In the theories that Dworkin describes, progressive development is presented in terms of the transition from the absence of a political order to the creation ex nibilo of a perfectly just one. In turn, governance involves the maintenance of a perfectly just political order in which public institutions and laws are perfectly adequate and fully endorsed by all who are bound by them. In actuality, progressive development takes a very different shape. The point of departure for progressive development is not a blank slate but an existing society. Governance, at best, involves not the maintenance of a perfectly just social order but the ongoing approximation of one. Further, this approximation must be carried out by imperfect public institutions in circumstances characterized by unjust laws and a public culture

54 Ronald Dworkin, Law's Empire (Cambridge: Harvard University Press), 164. 
with suspect commitments. Surely, the objection concludes, such theories distort the nature of reform instead of illuminating it.

Versions of this objection have been raised in a variety of contexts. In his prewar writings, Gustav Radbruch raised this criticism against theories of natural law, which he conceived of as affirming a formal ideal of legality while eschewing the matter or particularity of historically situated legal systems.

The theory of natural law assumes that the resisting power of the matter against the idea may be put at zero. It completely volatizes the matter of the law. In its view, the material of the legal idea is not a definite historical situation but the state of nature; and that state of nature is depicted not as a sociological relationship but rather as an unsociable side-by-sidedness of individuals; the first creation of social relations between them being reserved to the legal idea, unhampered by any pre-existing sociological ties. ${ }^{55}$

Thus, Radbruch repudiates natural law for failing to integrate the rational form of law with the variability of legally, politically, historically, and sociologically determined content. The same skepticism about the capacity of theory to engage with the contingent circumstances to which reform responds can be found in Bruce Ackerman's constitutional theory. Ackerman insists that the American Constitutional order defies theoretical illumination because it is the product of piecemeal reforms undertaken in response to successive historical crises rather than the wholesale implementation of a discrete philosophic program:

The modern [American] Constitution does not express a timeless philosophy of right revealed in the Declaration of Independence or some Herculean labor of philosophical reflection. It is the product of ongoing political struggle - generation after generation mobilizing itself to critique and reconstruct large chunks of the received constitutional understanding. The guiding image should be Neurath's Boat, not Kant's Critique. In the aftermath of Civil War, Americans ripped gaping holes in the traditional structure, replacing them with new planks that didn't fit the old design. The question was

55 Radbruch, Legal Philosophy in The Legal Philosophies of Lask, Radbruch, and Dabin, trans. Kurt Wilk (Cambridge: Harvard University Press, 1950), 121. 
whether the ship would keep sailing during such a shattering reconstruction, not whether its overall design would survive a philosophy seminar... ${ }^{56}$

For Ackerman, as for Dworkin and Radbruch, actual reform is an ongoing process that takes place within and responds to a particular context. Accordingly, any theory that conceives of reform in terms of a transition from a featureless condition to a fully just society fails to illuminate its subject.

The unified theory's central distinction between public authority and public justice enables it to sidestep the first objection. Public authority is the constitutive principle of public law. It requires private persons to submit themselves to the governance of public institutions that enact, interpret, and enforce legal obligations. The principle of authority is constitutive of public law because its satisfaction culminates in the creation of the parties to the public law relationship, a government and a people comprised of those bound by its lawgiving. In contrast, public justice is the regulative principle of public law. It concerns the right of all who are subject to public authority to just governance and the corresponding obligation incumbent on government. In the absence of a legal system, the corresponding right and duty implicated by the principle of justice lack their condition of application because neither of the parties whose juridical situation is affected by it are present. The right and duty encompassed by the principle of justice arise only within a legal system. It is the existing legal system, in all its particularity, that forms the point of departure from which the ideal of public justice must be pursued.

\footnotetext{
56 Ackerman, "Rooted Cosmopolitanism," Ethics 104 (1994): 520. For a further formulation of the criticism that attacks the capacity of social contract theories to illuminate constitutional transitions, see Jacob T. Levy, "Not So Novus an Ordo: Constitutions without Social Contracts," Political Theory 37 (2009): 192: "[S]omething essential is lost in the casual slippage between social contract theory and the practice of constitutionalism...Constitutions are enacted in ongoing societies (whether newly politically sovereign or otherwise) with preexisting laws and legal systems, political organizations, cultural and linguistic and religious divisions, and norms and mores. Moreover, the practice of constitutionalism is usually, at least in part, a practice of reconciling those legacies to a new political order...Most constitutions cannot be well understood by retrospectively characterizing them as the kind of complete and radical break with the past envisioned by social contract theory."
} 
What the duty of public justice requires in a particular legal system cannot be specified in abstraction from the circumstances that obtain within it. The duty of public justice requires the public authority to identify the ways in which the existing legal system is defective in relation to its own internal ideal, to reflect on how these defects can be addressed, and to implement a program of reform that brings the legal system as a whole into the closest possible conformity with its own internal ideal. Within the unified theory, politics - conceived of as a justifiable practice - is the art of drawing on experiential knowledge in order to exercise public authority as required by the duty of public justice. ${ }^{57}$ The duty of public justice and the practice of politics are inextricably bound. The specification of the duty of public justice requires political knowledge of the contingent features of an existing legal system. ${ }^{58}$ The practice of politics involves bringing knowledge about the contingent features of an existing legal system to bear on the exercise of public authority, which, given its justification, must be exercised in accordance with the duty of public justice. As the Swiss jurist Johann Caspar Bluntschli put the point: "All politics must be realistic; all politics should be idealistic. Both principles are true if they complement one another. Both principles are wrong if they exclude one another." 59 That politics must be directed towards the realization of the ideal of public justice does not mean that the contentious character of politics falls away when politics is carried out in a justifiable manner. Intense disagreements may persist about whether a particular practice is compatible with the ideal of public justice or about what the duty of public justice requires of the public authority in a given instance.

\footnotetext{
57 An exposition of this conception of politics appears in the work of the Czech dissident, playwright, and statesman Václav Havel. In The Art of the Impossible: Politics as Morality in Practice (Toronto: Alfred A. Knopf, 1997), Havel contrasts those who engage in politics to further their own advantage and moral politicians who engage in politics to govern on behalf of the governed, Havel remarks about the latter: "I have no idea whether I am such a person. I only know that I ought to be, because I have accepted this office" (74 and 82).

${ }^{58}$ For general discussions of the importance of bringing together normative philosophic resources with the contextual insights of the social sciences, see Goodin, 56; Robeyns, 349-352; Simmons, 19; Stemplowska, 339-340; and Thompson, 205-6.

${ }^{59}$ Bluntschli, Politike als Wissenschaft (Stuttgart, Verlag der J.G. Cotta'schen Buchhandlung, 1876), I, 4, 32.
} 
Once the relationship between the particularity of existing legal systems and the duty of public justice is expounded, a further objection arises. Although the duty of public justice applies only within the concrete setting of an existing legal system, if legal systems are to approximate the ideal of public justice, they must divest themselves of their distinctive particularity. Thus, the objection alleges that the "colorful variety of the legal views of different ages and nations" are to be repudiated as so many instances of "error" to be supplanted with uniformity. ${ }^{60}$ Since the particularity of an existing legal system must be cast aside to approximate the ideal of public justice, the unified theory must be hostile to all forms of particularity after all. Just legal systems may be distinguished by the territories that they occupy, but not by the content of their laws.

That the ideal of public justice is the internal aim of every legal system does not entail the uniformity of legal systems that must approximate it. The ideal of public justice is satisfied when the laws, institutional arrangements, and legal doctrines through which public power is exercised are compatible with the independence of all who are subject to them. Since the ideal of public justice is a normative standard rather than a blueprint, it may be satisfied by a variety of distinctive arrangements. The unified theory of public law articulates the justificatory standard that accompanies the exercise of public power. This justificatory standard directs but does not predetermine the practice of public law. ${ }^{61}$ Insofar as the practice of public law involves the exercise of public authority over independent persons, it must be directed towards the creation of a system of law that - to the greatest possible extent - conforms to this standard. Because different kinds of institutional arrangements, positive laws, and legal doctrines can contribute to the realization of this standard, it can be concretized

\footnotetext{
${ }^{60}$ Radbruch, Legal Philosophy, 60.

61 For an analogous argument in the private law context, see Ernest J. Weinrib, The Idea of Private Law (Cambridge: Harvard University Press, 1995), 204-229.
} 
in a range of different ways. ${ }^{62}$ Just as distinct societies must pursue the ideal of public justice from their own particular context, so too societies may approximate the ideal in their own distinctive way. Some may detect an air of paradox in this account of the ideal of public justice. On the one hand, the ideal of public justice is a normative ideal implicated by the justification of public authority and as such is incumbent on government in all times and places. On the other, the way in which the ideal of public justice is conceptualized reflects contingent features of particular legal systems at particular times. Thus, one might object that the ideal of public justice is incoherent: it is both beyond history and within it, universal and yet particular. These claims, however, occasion no contradiction. The ideal of public justice is a normative concept and as such, is not established by the occurrence of a particular event at a specific moment in time. While the ideal of public justice is unchanging, the way in which particular societies in particular moments understand that ideal and extend it to particulars is, of course, subject to historical forces, ${ }^{63}$ and may deepen with time, experience, and reflection as a legal system seeks to justify its coercive activity to all members of the legal order. When

\footnotetext{
${ }^{62}$ See, for example, Dieter Grimm, "Freedom of Speech in a Globalized World," in Extreme Speech and Democracy, ed. Ivan Hare (Oxford: Oxford University Press, 2009), 11-22. After noting that freedom of speech is an integral aspect of "individual self-determination and personal dignity" and a necessary feature of democratic self-government (12), Grimm observes that while freedom of expression is recognized around the world, "a consensus can be found only on a very high level of abstraction." (20) Even in the West, a variety of conceptions of freedom of expression obtain. Grimm illustrates this variability by contrasting the way in which the French and German legal systems conceptualize freedom of expression, its relation to public discourse, the role of the media in discussing issues of public importance, and how freedom of expression relates to other rights, such as the right to privacy. While the approach of each of these legal systems must be assessed on their merits, Grimm emphasizes "that when it comes to concretizing the right [of freedom of expression] and balancing it against other rights or interests, a variety of national solutions are compatible with the basic guarantee. Universal recognition of freedom of speech does not require uniform legal solutions or interpretation." (22)

${ }^{63}$ The ideal of public justice may be formulated in a variety of ways that conform to the underlying norm. Consider, for example, the distinctive ways in which the concept of inherent human dignity is understood in the very different legal cultures of Germany and South Africa. Human dignity is the core idea of the unified theory and, as I will discuss in Chapter Four, the central concept of modern constitutionalism. As modern constitutional states, both Germany and South Africa conceive of dignity as the foundational value of the legal order. Each, however, fills the notion of dignity with material drawn from its own distinctive public culture. In the aftermath of the Holocaust, the notion of dignity was interpreted in Germany in light of Kant's conception of the relationship between the free person and the legal community, which Nazism sought to systematically repudiate. On the German conception of dignity, see Donald P. Kommers, “German Constitutionalism: A Prolegomenon," Emory Law Journal 40 (1991): 873. In contrast, in post-apartheid South Africa, dignity is understood in terms of the African notion of $u b u n t u$, which denotes humaneness, personhood, and morality. On the meaning of ubuntu, see Port Elizabeth Municipality v. Various Occupiers, 2004 (12) BCLR 1268 (CC), para. 37, as well as S. v. Makwanyane and Another (1995) 3 SA 391 (CC), para. 223-227, and Christopher McCrudden, "Human Dignity and Judicial Interpretation of Human Rights,” European Journal of International Law 19 (2008): 688.
} 
a society's conception of the ideal of public justice is refined, further discrepancies between the existing contours of public authority and the demands of public justice may become evident and the duty incumbent on the public authority may become correspondingly heightened. ${ }^{64}$ Within the unified theory, it is not the ideal of public justice that must undergo development, but the way in which particular societies conceive of it. Thus, the unified theory of public law is progressive, but not in the Hegelian sense. The duty of public justice incumbent on public authority is correlative to the right of the people, not to World Spirit. In turn, the ideal of public justice is not developing in history, say, as World Spirit comes to know itself as free. Rather, the ideal of public justice is a public norm that arises in a sequenced juridical argument that proceeds from the right of every person to independence. The ideal is unchanging, but its public significance within particular societies can develop in accordance with a learning process that is responsive to, but not determined by, the occurrence of historical events. ${ }^{65}$

${ }^{64}$ For an illustration, see Germany's Life Imprisonment Case, 45 BVerfGE 187 (1977). An English translation of excerpts can be found in Donald P. Kommers, The Constitutional Jurisprudence of the Republic of Germany (Durham: Duke University Press, 1997), 304-311. In 1949, Germany adopted a new constitution that made the inherent dignity of the human person the purpose and constraint of all public power. Given Germany's experience of Nazi barbarism, the new constitution explicitly prohibited the death penalty, which was widely perceived to be incompatible with the state's duty to respect and protect human dignity. Consequently, as of 1949, life imprisonment became the most severe penal sanction in Germany. While the constitutionality of life imprisonment was not questioned at the time, a generation later, a constitutional complaint prompted the Federal Constitutional Court to consider whether life imprisonment was itself consistent with the constitutional commitment to dignity. The Court noted that it "was not until the furor over the death penalty had subsided that scientists in the late 1960s began to concern themselves with the problem of life imprisonment." Scientists then learned that imprisonment without hope of reintegration into society is deeply destructive of human personality. In its judgment, the Court wrote: "Since the adoption of the Basic Law, our understanding of the content, function, and effect of basic rights has deepened. Additionally, the medical, psychological and sociological effects of life imprisonment have become better known. Current attitudes are important in assessing the constitutionality of life imprisonment. New insights can influence and even change the evaluation of this punishment in terms of human dignity and the principles of a constitutional state..." Thus, the Court interpreted the constitutional commitment to dignity to require the state to create the legal conditions in which those who had atoned for their crimes and were no longer a danger to society could be reintegrated. Underlying the Court's decision is the view that as the internal aim of the legal order becomes more deeply understood, arrangements previously deemed unproblematic may be recognized to be unjust, and the duty that accompanies public power may therefore become more demanding. In time, a deeper appreciation of the institutional implications of human dignity may indicate the inadequacy of the requirements that the Court set out in the Life Imprisonment Case. Public justice is not a binary concept such that something either is or is not just, now and for all time. Rather, justice is an abstract principle that must be continuously refined in relation to particular cases that arise within the legal life of the state.

${ }^{65}$ For an analogous discussion of the relationship between Kant's ethics, philosophy of history, and its distinctiveness from Hegel, see Pauline Kleingeld, "Kant, History, and the Idea of Moral Development," History of Pbilosophy Quarterly 16 (1999): 59-80. 
The idea of a public political culture plays a different role in the unified theory than it plays in justice as fairness. For Rawls, the institutional structure and public culture of a modern constitutional democracy form the materials from which a conception of justice appropriate for such a society can be justified. Rawls's theory of justice emerges from this question: What conception of justice would be adequate for a modern constitutional democracy given its institutional framework and the convictions that are embedded in its public culture? The difficulty that this approach raises is that the materials from which Rawls justifies his conception of justice are not themselves justified. Consequently, as I noted above, justice as fairness has no resources to explain why states must adopt the constitutional norms and institutional arrangements of a modern constitutional democracy. Similarly, justice as fairness has no resources to explain why a public culture must endorse the fundamental ideas on which justice as fairness rests and why it would be defective to the extent that it fails to do so. The unified theory takes a different approach. Instead of treating the institutional framework or the convictions of a certain kind of public culture as conferring justification upon a conception of justice, the unified theory holds that these elements themselves require justification. ${ }^{66}$ Within the unified theory, a legal system is adequate to the extent that a people enacts laws that secure the independence of each of its members. The people must exercise public authority over itself in a manner that fully satisfies the duty of public justice. The satisfaction of this duty calls for a public culture of a certain character. If the people is to govern itself in accordance with the duty of public justice, the people must internalize the principles of public law by developing the capacity to distinguish between those arrangements that are merely publicly authoritative and those that are demanded by public justice. A public culture is adequate to the extent that it possesses the capacity, as well as the commitment, to govern itself in accordance with the duty of public justice owed to each

\footnotetext{
${ }^{66}$ Here I follow a distinction developed in Onora O’Neil, "Constructivism in Rawls and Kant," in The Cambridge Companion to Rawls, ed. Samuel Freeman (Cambridge: Cambridge University Press, 2003), 360.
} 
of its members. Far from denying the significance of the public culture, the unified theory indicates the indispensable role that the public culture plays in the pursuit of public justice and the measure of a public culture's adequacy.

The unified theory of public law presents an alternative to both acontextual theories that bypass the particular circumstances of existing societies and quietist theories eager to embrace the adequacy of the status quo. While the unified theory holds that public justice is an ideal common to legal systems as such, it is not an "ideal that is everywhere everlastingly the same." ${ }^{97}$ The approximation of the ideal of public justice requires the ongoing eradication of injustice, not the elimination of particularity.

\section{CONCLUSION}

The leading paradigms in contemporary political and legal philosophy share a progressive ambition to provide a theoretical standpoint for criticizing existing societies, institutions, and laws, and directing their reform. The purpose of this chapter has been to explore three central questions about progressive theorizing.

First, how would a theory have to be structured in order to make good on this progressive ambition? I have argued that a progressive theory must integrate three components: (1) an underlying subject, (2) a moral standard for assessing the moral adequacy of instances of the underlying subject, and (3) a norm articulating what is required of instances of the underlying subject that are defective in relation to their own internal standard of adequacy.

Second, do the leading political and legal theories possess such a structure? Rawls's theory fails to make good on its own progressive ambition because even though it encompasses all three components, the theory conceives of the first and second components in a manner too narrow to

\footnotetext{
${ }^{67}$ Radbruch, Legal Philosophy, 121.
} 
apply to the range of instances relevant to the third. The result is a theory of justice that is progressive but not general. Hart's theory raises the opposite problem: it is general insofar as its underlying subject is legal systems as such, but it is morally variable insofar as the conception of legality is compatible with a variety of different conceptions of morality, some progressive and others regressive.

Third, what would a theory look like that is both general and progressive? The unified theory is general insofar as its underlying subject is legal systems as such, but it is not morally variable. The fundamental idea that integrates its general and progressive components is that a legal system involves the right of government to exercise public authority over independent persons. The justification of this right indicates both the internal ideal of a legal system as such and what is required of a legal system that is defective in relation to its own internal ideal. While such an approach departs significantly from the theories canvassed above, it retains one of Rawls's most basic ideas, "that the correct regulative principle for anything depends on the nature of that thing". ${ }^{68}$

${ }^{68}$ A Theory of Justice, 29. 


\section{CHAPTER 4: \\ The Modern Constitutional Paradigm}

W

e live in a new age of public law. Since the end of the Second World War, countries from around the world have designed and implemented a ground-breaking model of constitutional governance. The emergence of this model has been described as "the most important public law event of the twentieth century", a "rights revolution", 2 and as "a fundamental innovation" that has reconfigured the practice of modern constitutional law. ${ }^{3}$ The innovation of the modern constitutional paradigm consists in the "adoption of a new kind of constitutional norms, institutions, and processes" designed to transform the right of every person within the legal order to just governance from a normative ideal into an effective constraint upon all public power. ${ }^{4}$ By the beginning of the twenty-first century, the modern constitutional paradigm has become the leading response to the various pathologies of public law, from the barbarous inhumanity of failed states to the injustices of autocratic, oligarchic, and majoritarian forms of government.

In his influential essay on South Africa's transition from the degradation of apartheid to a constitutional regime premised on the inherent dignity and equal rights of each of its inhabitants, Etienne Mureinik drew a distinction between a culture of authority and a culture of justification. ${ }^{5}$ Mureinik characterized apartheid as a culture of authority, in which a Parliament of the minority enacted laws that were valid regardless of whether they were justified to all who were bound by them. ${ }^{6}$

\footnotetext{
${ }^{1}$ Juan Colombo Campbell, “Constitutional Court Judges' Roundtable,” International Journal of Constitutional Law 3 (2005): 545 (citing Louis Favoreu, “Justicia y Jueces Constitucionales,” Revista de Derecho Publico 61 (1999): 10-16).

${ }^{2}$ Charles R. Epp, The Rights Revolution: Lanyers, Activists, and Supreme Courts in Comparative Perspective (Chicago: University of Chicago Press, 1998), 2 (emphasis removed from original).

3 Mauro Cappelletti, "Repudiating Montesquieu? The Expansion and Legitimacy of 'Constitutional Justice'," Catholic University Law Review 35 (1986): 6 [“Constitutional Justice”].

4 Ibid. 5.

5 “A Bridge to Where? Introducing the Interim Bill of Rights," South African Journal on Human Rights 10 (1994): $31-48$.

${ }^{6}$ Ibid., 32. See also Mureinik's "Emerging from Emergency: Human Rights in South Africa," Michigan Law Review 92 (1977): 1985, in which Mureinik argues that the racist parliamentary supremacy that prevailed during apartheid was "incapable of justification" and the legal system therefore declared that the "enterprise of justification itself was unimportant."
} 
Mureinik's hope was that the new constitutional order would be characterized by a culture of justification, "in which every exercise of power is expected to be justified" and in which the authority of law rests not on the force that the powerful command but on the power of the justifications offered to all who are commanded. ${ }^{7}$ Central to the transition to a culture of justification was the Bill of Rights of the new constitutional order, which provided a "compendium of values empowering citizens affected by laws or decisions to demand justification."

Mureinik's remarks about South Africa's transition to modern constitutionalism are suggestive, but they raise a series of questions that he does not address. Why do persons subject to public authority have a right to justification and what does this right amount to? How does a modern constitutional state create the conditions in which every person bound by public authority can insist on the justifiability of its exercise? Is it possible to create a culture of justification apart from the norms, institutions, and processes of a modern constitutional state? How are the constitutional norms, institutions, and processes that enable each person within the legal order to demand justification compatible with democratic self-government? The purpose of this chapter is to address these questions by relating the unified theory of public law to the modern constitutional paradigm, the dominant mode in which public law is practiced in the world today.

I argued in Chapter One that public law is a juridical relationship between a state and its members. This relationships has both a constitutive and a regulative dimension. A regime of public law is constituted by a system of publicly authoritative legislative, executive, and judicial institutions that create the conditions in which private persons can enjoy their independence in relation to one another. The regulative dimension requires government to direct all public authority towards the realization of a legal order that leaves the independence of each of its members undiminished. The

\footnotetext{
7 “A Bridge to Where? Introducing the Interim Bill of Rights," 32.

8 Ibid.
} 
constitutive and regulative dimensions of public law stand in a relation of mutual implication. The right of government to exercise public authority over independent persons must be justified. In turn, the justification of public authority implicates its own internal standard of adequacy. Public authority is exercised in accordance with the terms of its justification when it is directed towards bringing the existing legal system itself into the deepest possible agreement with the independence of each person bound by its lawgiving.

In what follows, I argue that the modern constitutional state is a systematic response to a problem latent in the normative structure of a regime of public law, the problem of accountability. The problem is occasioned by the interplay between the right of government to exercise public authority over private persons and the right of private persons to just governance. Even though the justification of public authority culminates in the right of each person to just governance and a corresponding duty incumbent on all branches of government, the right of persons to just governance might nonetheless be violated with impunity because the validity of a publicly authoritative act does not depend on its compatibility with the right of persons to just governance. The modern constitutional project is a systematic attempt to create, maintain, and refine legal orders that enable each person to stand on his or her right to just governance and thereby hold the exercise of public authority accountable to the terms of its justification. The distinctive features of a modern constitutional state - a written constitution that empowers and constrains all branches of government, a constitutionally entrenched bill of rights that secures the inherent dignity of each person in relation to public authority, and a politically independent judicial body that is both empowered and obligated to review the constitutionality of state action - transform the right of each person to just governance from a mere normative ideal into a justiciable right capable of constraining the exercise of public authority. Modern 
constitutionalism is nothing less than, as Mureinik put it, a "real effort to bring government action under the discipline of accountability.",

By drawing on the normative structure of public law to justify and illuminate the practice of modern constitutionalism, I depart from familiar justifications formulated by constitutional comparativists and political and legal theorists. In justifying a legal order committed to the inherent dignity and fundamental rights of human persons, constitutional comparativists sometimes suggest that modern constitutionalism is necessitated by the occurrence of unjust or even barbaric acts. For example, the transition to modern constitutionalism was necessitated in Germany because of the horrors of Nazi power, in South Africa because of the indignity of apartheid, and in Canada because of the excesses of majoritarian democracy. While constitutional comparativists are correct that injustice or barbarism often forms the impetus for the transition to the modern constitutional paradigm, I will argue that these variegated events are illustrations of a more general problem inherent in the normative structure of public law. If the normative structure of public law itself requires modern constitutionalism, then modern constitutionalism would be necessary even in circumstances in which unjust or even barbarous events had not occurred.

Whereas constitutional comparativists sometimes claim that modern constitutionalism is required because of the occurrence of a regrettable event, legal and political theorists often argue that constitutionalism is required to bring about some desirable outcome, whether just governance or some state of affairs conducive to it. Ronald Dworkin, for example, argues that judicial review is justified by the desirable results that it brings. Judicial review improves the quality of public debate by framing issues of public importance not in terms of their popularity or expediency, as a legislature so often does, but as "questions of political morality." 10 In turn, the judiciary responds to the questions of

${ }^{9}$ Ibid. 37.

${ }^{10}$ Dworkin, Freedom's Law (Cambridge: Harvard University Press, 1996), 344. 
political morality that it formulates by generating "the best answers". ${ }^{11}$ For Dworkin, the American experiment with judicial review has been justified because the "United States is a more just society than it would have been had its constitutional rights been left to the conscience of majoritarian institutions." 12 Those who join Dworkin in defending constitutional governance appeal to different desirable outcomes that it might bring, but retain Dworkin's conviction that if constitutional governance is justifiable, it is because of the benefits that follow in its wake. ${ }^{13}$

Such justifications offer an easy target for critics of constitutionalism, who note that the desirable outcomes that justify judicial review can be realized in its absence and might fail to be realized in its presence. Accordingly, Jeremy Waldron has responded to Dworkin's "result-driven"14 justification of judicial review by drawing attention to, on the one hand, instances in which regimes without judicial review have engaged in elevated public debate ${ }^{15}$ that culminated in the legislature enacting a just outcome, ${ }^{16}$ and, on the other, instances in which regimes with judicial review have engaged in debates of low quality ${ }^{17}$ that culminated in questionable or outright unjust decisions. ${ }^{18}$ Waldron's view is that Dworkin's result-driven argument about judicial review "may in the end be impossible to verify."19 After all, verification would require weighing the perhaps incalculable balance of just and unjust outcomes that have accumulated in the presence of judicial review against the

\footnotetext{
11 Ibid., 34.

12 Dworkin, Law's Empire (Cambridge: Harvard University Press, 1986), 356. See also, Freedom's Law, 34.

13 See, for example, John Rawls, Justice as Fairness: A Restatement (Cambridge: Harvard University Press, 2001), 146 (arguing that constitutional democracy yields educative benefits because the constitution articulates fundamental norms that reverberate through the public political culture as they are interpreted by courts, affirmed by political parties, and, ultimately, publicly debated by citizens themselves) and Samuel Freeman, "Constitutional Democracy and the Legitimacy of Judicial Review," Law and Philosophy 9 (1990): 345 (arguing that judicial review is an expedient for safeguarding equal rights in social and historical circumstances in which legislative power might be used to "subvert the public interest in justice and to deprive classes of individuals of the conditions of democratic equality").

${ }^{14}$ Dworkin, Freedom's Law, 34.

15 Waldron, Law and Disagreement (Oxford: Oxford University Press, 1999), 290.

16 Waldron, "The Core of the Case Against Judicial Review," Yale Law Journal 115 (2006): 1349-1350.

17 Waldron, Law and Disagreement, 290 and 220 (noting that the verbal rigidity of constitutional formulations may stifle principled moral debate).

18 Waldron, "Freeman's Defense of Judicial Review," Law and Philosophy 13 (1994): 28.

${ }_{19}$ Waldron, Law and Disagreement, 288.
} 
unknowable balance of just and unjust outcomes that would have occurred in a majoritarian democracy, in which the judiciary lacked the capacity to review legislation on the basis of its conformity to constitutional norms.

This chapter offers a different approach by considering the practice of modern constitutionalism in relation to the normative structure of public law. Such an approach departs from the justifications offered by both constitutional comparativists and legal and political theorists. It departs from the justification offered by comparative constitutionalists because it does not accept that modern constitutionalism is rendered necessary by the occurrence of a contingent event, however regrettable. If the structure of public law contains a defect that must be addressed but can be addressed only by modern constitutionalism, then every legal system must ultimately become a modern constitutional state. The approach diverges from the justification offered by legal and political theorists because it does not claim that modern constitutionalism is required to bring about a desirable result that could, in principle, be realized in its absence. Precursors to the modern constitutional state might engage in principled debates and, as I argued in the prior chapter, just governance is, at least to some extent, possible within them. But precursors nevertheless possess a defect that is addressed by modern constitutionalism and that cannot be addressed apart from it.

I proceed in four parts.

The first explores the defect common to all precursors to modern constitutionalism, the problem of accountability. From the standpoint of the unified theory of public law, a legal order is accountable if it creates the conditions in which each person can constrain the exercise of public authority to the terms of its justification by standing on his or her right to just governance. In contrast, a legal order is unaccountable if it is organized in a manner that leaves one or more persons subject to public power unable to insist upon this right. On such a conception of accountability, monarchic and aristocratic regimes of public law are necessarily unaccountable, but by the same token, so are 
majoritarian democracies. I develop this distinctive conception of accountability and distinguish it from a prevalent alternative conception, in which government is accountable to the people if it must answer to the preferences of the majority of its citizens.

In the second section, I present the norms and institutional arrangements of the modern constitutional state as a systematic attempt to address the problem of accountability. The problem of accountability is occasioned by the interrelationship between the right of government to exercise public authority and the right of persons to just governance. Modern constitutional states address the problem of accountability by reconfiguring the relationship between public authority and public justice. In precursors to modern constitutionalism, government can violate the right of persons to just governance with impunity because the validity of a publicly authoritative act is not affected by its compatibility with the right of persons to just governance. In contrast, the modern constitutional state makes just governance the condition for the valid exercise of public authority. To render the exercise of public authority accountable to the right of every person within the legal order to just governance, modern constitutional states create a legal and institutional framework that enables anyone who believes that his or her right to just governance has been violated to hold government to account by challenging the validity of the supposed authoritative act. Precursors to modern constitutionalism may succeed in enacting just laws, but only a modern constitutional state creates the legal and institutional conditions in which the exercise of public authority is accountable to the right of every person within the legal order to just governance.

In the third section, I distinguish the approach of the modern constitutional paradigm from American constitutional practice. I argue that this practice departs significantly from the modern constitutional paradigm in both its conception of rights and its approach to the law of standing. Consequently, the American constitutional order does not create the conditions in which the exercise of public authority is accountable to the right of every person within it to just governance. 
In the fourth section, I defend modern constitutionalism from objections raised by its leading critic, Jeremy Waldron. Waldron's objections to constitutionalism can be divided into two kinds. Objections of the first kind attack justifications of constitutionalism that rest on disputable empirical claims. Objections of the second kind attack the practice of constitutionalism directly by arguing that it is undemocratic and therefore illegitimate. I respond to objections of the first kind by noting that the unified theory justifies modern constitutionalism by appealing to the normative structure of public law rather than to empirical claims. Thus, even if Waldron is successful in casting doubt on the empirical claims to which some proponents of constitutionalism appeal, the justification of modern constitutionalism that proceeds from the unified theory remains unaffected. I respond to objections of the second kind by explaining that even though modern constitutionalism is not a majoritarian democracy, it is nonetheless a democratic form of government. It is democratic insofar as citizens exercise political rights and thereby govern themselves through their representatives. It is not majoritarian insofar as it creates a legal and institutional context in which the legislative power of the citizenry is accountable to all who are bound by it.

Two clarifications are in order before I begin. First, if my argument is correct, then every legal system must ultimately become a modern constitutional state. ${ }^{20}$ What I do not claim, however, is that

\footnotetext{
${ }^{20}$ In a recent essay, David Dyzenhaus argues that the idea of constituent power is paradoxical, dangerous, and ultimately superfluous. See "Constitutionalism in an old key: Legality and constituent power," Global Constitutionalism 1 (2012): 229260. For Dyzenhaus, constituent power is paradoxical when invoked to ground the authority of a legal order: in imagining the people acting to establish an authoritative legal order, scholars overlook that the notion of a people acting as a unified whole presupposes the existence of such an order (230-1 and 233-4). The idea of constituent power is dangerous when scholars argue that existing constitutional arrangements are sanctified by the fact that the people (or the nation) chose them because even if the people chose wisely in the past, it retains the constituent power to choose otherwise (237). Finally, the idea is superfluous because the kinds of principles typically captured in constitutions are, for Dyzenhaus, internal to the morality of law and thus present in every legal system regardless of the constitutional arrangements that it happens to have (253).

While Dyzenhaus exposes some problematic uses of the idea of constituent power and the difficulty that certain theories have in accounting for it, his argument does not amount to a condemnation of the idea itself. This is not the place to provide a comprehensive response to Dyzenhaus, but I will say this. The unified theory of public law does not appeal to an act of constituent power to ground the authority of government. Instead, the unified theory explains why private persons must submit to the authority of public institutions and why public institutions are authoritative even if established coercively rather than consensually. Public institutions create a people by subjecting a plurality of persons to
} 
the transition to modern constitutionalism must occur in every legal system at once. In the prior chapter

I argued that states must address their defects in accordance with the duty of public justice, which requires that existing legal systems be brought into the closest possible conformity with the ideal of public justice, equal freedom under law. The emergence of the modern constitutional paradigm alters what is possible by introducing a new mode of governance that addresses a fundamental problem in public law. Whether a delay in transitioning to modern constitutionalism is rightful depends on the compatibility of that delay with the duty of public justice. Second, throughout this chapter my purpose is not to elaborate a fine-grained theory of modern constitutionalism, but merely to sketch the connection between the normative structure of public law and the dominant practice of public law in the contemporary world.

\section{The Problem of AcCountability}

What do we mean when we say that government must be accountable to the people? According to a majoritarian tradition of political thought that culminated in the French and American revolutions of the eighteenth century and persists in some quarters to this day, government is accountable to the people if government is constituted in such a way that a majority (or plurality) of citizens can direct

\footnotetext{
common laws; a people cannot create public institutions. As for the danger, it is not peculiar to constituent power: the discussion of quietism in Chapter One indicates that the same danger accompanies the right to enact ordinary positive law, which Dyzenhaus, of course, does not reject. In any event, by drawing a fundamental distinction between the principles of authority and justice, the unified theory repudiates the view that whatever arrangement is selected through the exercise of constituent power is fully adequate. Since the exercise of constituent power is a publicly authoritative act, it must be directed towards the realization of public justice regardless of whether the act is exercised autocratically or democratically. The distinction between the principle of authority and the principle of justice provides resources for thinking about how an exercise of constituent power can be authoritative even if it is not just and how even a people acting through transparent and inclusive procedures can commit an injustice through the exercise of its constituent power. Thus, no inconsistency is raised by accepting the idea of constituent power and holding, with Dyzenhaus, that the appropriate standard for assessing the adequacy of a legal system cannot be a reflection of a contingent act (254-5). As I argued in Chapter Three, the duty to govern justly follows from the presupposition of the right to exercise public authority rather than from facts about the historical origin of the legal order or subsequent events that occur within it. Finally, while I agree with Dyzenhaus that a legal order as such contains an internal morality that dovetails with liberal constitutional norms, I reject his deflationary conclusion that constituent power is a superfluous notion (233-4). My central claim in this chapter is that modern constitutionalism addresses a fundamental problem latent in the structure of public law that cannot be addressed in its absence.
} 
the exercise of public power towards the fulfillment of its preferences. ${ }^{21}$ So conceived, a democratic government in which the majority of citizens direct the exercise of public power is inherently accountable, while aristocracy and monarchy are inherently unaccountable because each fails to place the reins of public power in the hands of the many.

At the core of the majoritarian view lies the capacity of rational persons to formulate their own preferences about how public power should be exercised. ${ }^{22}$ Since persons are capable of formulating their own preferences regarding the exercise of public power, the legitimate state does not subjugate persons to the preferences of rulers, but instead creates the conditions in which citizens can guide the exercise of public power towards the fulfillment of their shared preferences. Because it is unrealistic to suppose that citizens will invariably agree about what preferences public power should serve, a procedure is required that both recognizes the capacity of citizens to formulate their own preferences and that affords each citizen an equal say in determining what preferences public power should pursue. Majoritarian democracy is that procedure. In a majoritarian democracy, preferences are legitimated not by the merit of their content, which might culminate in disagreement, but by attracting the assent of the many, that is, a majority or plurality of adult citizens at the ballot box. The popular assent of the many transforms any preference from a private wish into a public purpose.

For proponents of the majoritarian view of accountability, the postwar emergence and global proliferation of modern constitutionalism is a deeply mysterious phenomenon. The modern constitutional project involves the creation, maintenance, and refinement of legal systems in which public power must answer neither to the preferences of the few (as in the practices that the majoritarian view repudiates) nor to the many (as in the practices that the majoritarian view affirms),

\footnotetext{
21 Francis Fukuyama, The Origins of the Political Order (New York: Farrar, Straus, and Girous, 2011), $321-2$ and 420. Fukuyama attributes this insight to Alexandre Kojève, Introduction to the Reading of Hegel (Ithaca: Basic Books, 1969).

${ }^{22}$ For an overview of this conception of democracy, see Gregory H. Fox and George Nolte, "Intolerant Democracies," Harvard International Law Journal 36 (1995): 14-16.
} 
but to the equal right of every individual within the legal order to just governance. By establishing a legal framework designed to effectuate the right of every person to just governance, a modern constitutional state departs from the majoritarian view in both its procedural framework and its substantive commitments. As a substantive matter, modern constitutional states seek to realize a particular purpose, a legal order adequate to the inherent dignity of its free and equal inhabitants. As a matter of procedure, the modern constitutional state empowers the judiciary (or a specialized constitutional court) to invalidate legislation that conflicts with constitutional norms. For some proponents of the majoritarian view of accountability, such a power is wholly illegitimate insofar as it seems to substitute the preferences that the people have enacted into law through their elected and accountable representatives for the preferences of a few judges, who are neither elected by nor accountable to anyone. ${ }^{23}$ In empowering the few to disregard the preferences of the many, modern constitutionalism creates an unaccountable form of government. ${ }^{24}$ Other proponents of the majoritarian view suggest that the arrangements of the modern constitutional state are legitimate to the extent that they reflect a preference that the people adopted in the past and may relinquish in the future. $^{25}$ Thus, majoritarians from across the political spectrum claim that if the people become disillusioned with the features of the existing constitutional regime, the people may amend the constitution to severely curtail the powers of the judiciary ${ }^{26}$ or even dissolve $i t,{ }^{27}$ just as the people may

\footnotetext{
${ }^{23}$ See, for example, John Hart Ely, Democray and Distrust (Cambridge: Harvard University Press, 1980), 4-5 and Jeremy Waldron, "The Core of the Case Against Judicial Review," 1349.

${ }^{24}$ Waldron, Law and Disagreement, 293.

25 Alexander Hamilton, "The Federalist No. 78," in Hamilton, John Jay, and James Madison, The Federalist: A Commentary on the Constitution of the United States (Philadelphia: J.B. Lippincott, 1864), 580 (noting the "fundamental principle of republican government" that the people can "alter or abolish the established Constitution, whenever they find it inconsistent with their happiness").

${ }^{26}$ Robert Bork, Sloucbing Towards Gemorrab: Modern Liberalism and American Decline (New York: HarperCollins, 1996), 319: "[T]he only practical way of reigning in the Supreme Court is a constitutional amendment making its rulings subject to democratic review. As matters now stand, the Court's assumption of complete governing power is intolerable, and yet, absent a constitutional amendment, we have no way of refusing to tolerate it."

${ }^{27}$ Michael Walzer, "Philosophy and Democracy," Political Theory 9 (1981): 392: "[П] the people come to feel oppressed by the new authorities that they had established, they could always disestablish them. The amending process would still be available..."
} 
amend the constitution to repeal the rights that it protects. ${ }^{28}$ Such claims, however, misconceive the practice of modern constitutionalism. The core features of modern constitutionalism - inherent dignity, fundamental rights, democratic governance, and judicial review - are not mere preferences that the people may affirm in one moment and abandon in the next, but are instead perpetual features of the legal order that cannot be relinquished through law. The practice of modern constitutionalism thereby affirms what the majoritarian view of accountability must deny, that there are features of the constitutional order that even a majority of 100 percent cannot lawfully repudiate. ${ }^{29}$

Modern constitutionalism therefore stands as a counterexample to Joseph Raz's claim that "the law provides ways of changing the law and of adopting any law whatsoever..."30 Article 79(3) of Germany's Basic Law, known as the eternity or perpetuity clause, establishes that there is no lawful way to amend certain features of the constitutional order, including the inviolable dignity of human persons, the supremacy of the rule of law, federalism, and the sovereignty of the people in a democratic system of government. Germany's perpetuity clause is not an isolated occurrence, but a pervasive feature of modern constitutionalism. The constitutions of France and Italy, for example, explicitly state that constitutional amendments may not change the republican form of government. The Portuguese Constitution is even more explicit in placing the pillars of the modern constitutional state beyond the power of amendment, including the republican form of government, the separation of church and state, the rights and freedoms of citizens and of workers, the separation of powers, and an independent judiciary empowered to review the constitutionality of legal provisions. ${ }^{31}$ The basis of such constitutional arrangements is intelligible in light of the normative structure of modern

\footnotetext{
${ }^{28}$ Bruce Ackerman, "Rooted Cosmopolitanism," Ethics 104 (1994): 517 (arguing that in the American constitutional order, majoritarian procedures take precedence over fundamental rights) and Ackerman, We The People: Foundations (Cambridge: Harvard University Press, 1991), 13-15 (claiming that the procedural character of the American Constitution enables the people to repeal the rights that they previously enacted, including, for example, those contained in the First Amendment).

${ }^{29}$ Dieter Grimm, "The German and American Constitutionalism: A Comparison," The Berlin Journal 7 (2003): 11.

${ }^{30}$ The Morality of Freedom (Oxford: Oxford University Press, 1986), 77.

${ }^{31}$ For an overview of such arrangements in Europe, see Víctor Ferreres Comella, Constitutional Courts \& Democratic Values: A European Perspective (New Haven: Yale University, 2009), 106-7.
} 
constitutionalism. As we will see below, modern constitutionalism recognizes that the duty to govern justly accompanies all exercises of public authority and denies validity to exercises of public authority that are incompatible with this duty. Insofar as amendments to the constitutional order involve the exercise of public authority, they cannot be valid if they conflict with the duty to govern justly. Since amendments that abrogate fundamental features of the constitutional state conflict with this duty, they must be invalid. Accordingly, the modern constitutional state is not an instrument that can be directed towards the pursuit of any purpose or the adoption of any law.

The unified theory of public law provides an alternative to the majoritarian conception of accountability. I argued in Chapter One that the unified theory articulates the normative architecture of a legal system. Every legal system as such involves principles of authority and justice, which formulate the rights and duties of the parties to the public law relationship. The principle of authority relates the right of government to enact, interpret, and enforce law to the corresponding duty of the governed to obey valid law. The principle of justice relates the right of the governed to just governance to the corresponding duty incumbent on government. This duty requires all branches of government - legislative, executive, and judicial - to direct their lawful power towards bringing the legal system as a whole into the deepest possible accord with the ideal of public justice, the unity of the authority of law and the independence or equal freedom of all who are bound by it. The problem of accountability reflects the interrelation between the right conferred by the principle of authority and the duty imposed by the principle of justice. The right of government to exercise public authority is always accompanied by a duty to govern justly, but persons subject to public authority have no legal mechanism that enables them to stand on their right to just governance and hold the exercise of public authority to the terms of its justification. 
The problem of accountability is a distinctive feature of the public law relationship. In private law, which concerns the rights and duties apposite to the interaction of private persons, ${ }^{32}$ the problem of accountability is addressed by the presence of public institutions. When one suffers a private wrong at the hands of another, the sufferer can bring her case before the impartial authority of a judge and demand to be made whole by the wrongdoer. A different structure, however, obtains in the public law relationship between rulers and ruled. When one suffers a wrong at the hands of the public authority, the public authority is both a party to the dispute and judge in its own case. ${ }^{33}$ Accordingly, the public authority might ignore one's grievance, deny that the grievance amounts to a wrong, or even concede the commission of a wrong but withhold a corresponding remedy. Every person subject to public authority has a right to just governance, but whether that right will be respected depends on the very party that is under an obligation with respect to it. Public institutions make private persons accountable to the independence of one another, but public institutions generate a problem of accountability because they can violate the right of persons to just governance with impunity.

The history of the theory and practice of public law is a testament to the pervasiveness of the problem of accountability. When Aristotle surveyed the constitutions of the ancient world, he discerned three ways in which public authority could be constituted within a legal system. Public authority can be exercised by "one ruler or few or the majority". ${ }^{4}$ From the standpoint of the unified theory, each of these modes of exercising public authority shares a common defect, the failure to

\footnotetext{
${ }^{32}$ For a classification of the kinds of juridical relationships that arise in private law, see Jacob Weinrib, "What can Kant Teach us about Legal Classification?" The Canadian Journal of Law and Jurisprudence 23 (2010): 203-231.

33 See, for example, Thomas Paine, The Rights of Man (Indianapolis: Hackett Publishing, 1992), 46 (my emphasis): "Everything in the English government appears to me the reverse of what it ought to be, and of what it is said to be. The Parliament, imperfectly and capriciously elected as it is, is nevertheless supposed to hold the national purse in trust for the nation; but in the manner in which an English Parliament is constructed it is like a man being both mortgagor and mortgagee, and in the case of misapplication of trust it is the criminal sitting in judgment upon himself. If those who vote the supplies are the same persons who receive the supplies when voted, and are to account for the expenditure of those supplies to those who voted them, it is themselves accountable to themselves..."

34 Aristotle, Politics in Selected Works, trans. Hippocrates G. Apostle and Lloyd P. Gerson (Iowa: The Peripatetic Press, 1991), III.7, $1279 \mathrm{a} 27$.
} 
address the problem of accountability. Whether public authority over all private persons is placed in the hands of a single person, a virtuous or wealthy few, or the majority of citizens, public authority remains unaccountable to each person owed a duty of public justice. When public authority is exercised by one, government is unaccountable to every person who is bound by its lawgiving. When public authority is exercised by a few, government is unaccountable to the many. And when public authority is exercised by the many, government remains unaccountable to those who may find themselves among the few. ${ }^{35}$ The problem that arises when public authority is exercised by one or few or many is not that public authority is necessarily exercised in an unjust manner. Rather, even if the exercise of public authority is exercised justly, the exercise of public authority remains unaccountable to one or more persons owed a duty of public justice. ${ }^{36}$

The problem of accountability is conceptual, not causal. Alexander Hamilton makes a causal claim in his remark, "Give all the power to the many, they will oppress the few. Give all the power to the few, they will oppress the many." ${ }^{37}$ Hamilton's remark is causal because it suggests that if there is a discrepancy between those who exercise power and those on whom power is exercised, the former will oppress the latter. The problem of accountability, in contrast, is conceptual because it arises not

${ }^{35}$ Lorraine E. Weinrib, “The Supreme Court of Canada in the Age of Rights: Constitutional Democracy, the Rule of Law and Fundamental Rights under Canada's Constitution," The Canadian Bar Review (2001): 705 ["Supreme Court of Canada in the Age of Rights"]: "The doctrine of legislative sovereignty, which precludes judicial review of statute, is not...necessarily inimical to the objectives of the constitutional state. It may work well under optimal conditions...However, it leaves the fundamentals rights and freedoms necessary to the constitutional state dependent on the good will, selfrestraint, and sensitivity of the majoritarian, temporarily elected governments. These rights and freedoms are thus viewed, not as legally entrenched entitlements that any citizen can insist upon, but as privileges contingent on the continuing endorsement of the majority."

${ }^{36}$ On the generality of the problem of accountability, see Alexis de Toqueville, Democracy in America (New York: Alfred A. Knopf, 1994), 259: "A majority taken collectively is only an individual, whose opinions and frequently whose interests, are opposed to those of another individual, who is styled a minority. If it be admitted that a man possessing absolute power may misuse that power by wronging his adversaries, why should not a majority be liable to the same reproach?" See also Alec Walen, "Judicial Review in Review," International Journal of Constitutional Law 7 (2009): 343-4: "A democrat who accepts unlimited majority rule accepts that the majority has the power to impose duties on him; indeed, he accepts that they can impose any duties, no matter how oppressive. If one is not part of the democratic majority, then one can be as dominated by the others who constitute a majority as by any who claim the right to rule as a birthright under a hierarchical model of government."

${ }^{37}$ Debates on the Adoption of the Federal Constitution, ed. Jonathan Elliot (New York: Burt Franklin, 1888), 203. 
from the likelihood that public authority will be exercised unjustly, but from the mere possibility that the right of persons to just governance might be violated. The problem of accountability would therefore arise even if circumstances were so fortuitously arranged that public authority had always been exercised justly because those entitled to just governance would nevertheless remain vulnerable to the unjust exercise of public authority. ${ }^{38}$ The problem of accountability arises in any legal system in which there is an incongruity between those who are subject to public authority and those who are empowered to hold the exercise of public authority to the terms of its justification.

On the majoritarian view, accountability means that public power must answer to the preferences of the many, that is, a majority or plurality of adult citizens, as expressed periodically at the ballot box. The conception of accountability at work in the unified theory departs from the majoritarian conception of accountability in three respects.

First, the unified theory denies that preferences determine whether an exercise of public power is appropriate. Within the unified theory, the right of government to exercise public authority by imposing coercible duties on independent persons must be justified. The justification of public authority indicates the public purpose to which it must be directed. As we saw in Chapters One and Three, all public authority must be directed towards the realization of its own internal ideal, a legal order that unites to the greatest possible extent the authority of law and the independence of all who are bound by it. The unified theory thereby departs from the majoritarian view in a critical respect: public power is not to be directed towards the furtherance of preferences, no matter how popular.

Second, the unified theory and the majoritarian view offer divergent accounts of what it means for government to be accountable to the people. On the majoritarian view, government is accountable to the people if public power must answer to the preferences of the majority of adult citizens. In

\footnotetext{
38 On the distinction between the propensity towards injustice and vulnerability to it, see Alexis de Toqueville, Democracy in America, 261-2: "I do not say that there is a frequent use of tyranny in America at the present day; but I maintain that there is no sure barrier against it..."
} 
contrast, the unified theory of public law holds that government is accountable to the people if public power must answer to the right of every person within the legal order to just governance. The people encompasses all adult citizens, but also children, immigrants, refugees, and guest workers. Such an inclusive conception of accountability is puzzling to defenders of the majoritarian view. If government is accountable to preferences and different persons affirm incompatible preferences, then it is impossible for government to be accountable to the preferences of every person who is bound by its lawgiving. The next best thing is for government to be accountable, in Justice Oliver Wendell Holmes's words, to the "right of a majority to embody their opinions in law." 39 Because the unified theory denies that public power must answer to opinions or preferences, it sidesteps the problem of their possible incompatibility. The duty of government is not to impose the particular opinions or preferences affirmed by "the dominant forces of the community" upon all others, ${ }^{40}$ but to create a system of law that - to the greatest extent possible - vindicates the purposiveness of each person, that is, the right of each person to pursue their purposes in a manner compatible with the same right of every other within a legal system. ${ }^{41}$ Given the terms of its justification, public authority must be directed towards creating a legal order that unites the independence of everyone under law rather than an order in which, as Justice Holmes would have it, some dominate while others are dominated.

Third, the unified theory rejects the intermittent character of the accountability at work in the majoritarian view. On this view, persons are to hold government accountable by exercising their political rights at the ballot box during elections that take place every few years. ${ }^{42}$ The unified theory

\footnotetext{
39 Lochner v. New York, 198 U.S. 45, 75-76 (1905) (Holmes, J., dissenting). For an exploration of the judicial philosophy that animates Holmes's approach to the First Amendment, see Steven J. Heyman, “The Dark Side of the Force: The Legacy of Justice Holmes for First Amendment Jurisprudence," William \& Mary Bill of Rights Journal 19 (2011): 661-723.

40 Gitlow v. New York, 268 U.S. 652, 673 (1925) (Holmes, J., dissenting).

${ }^{41}$ On the distinction between conceiving of freedom as the right to do whatever one wishes and in terms of a set of reciprocal limits on conduct, see Arthur Ripstein, Force and Freedom: Kant's Legal and Political Philosophy (Cambridge: Harvard University Press, 2009), 16-17.

42 See, for example, Bruce Ackerman, We the People: Foundations, 6.
} 
does not conceive of accountability in terms of the right of persons to occasionally register their preferences by endorsing the representative or party whose preferences on a variety of issues coincide most closely with their own, but as bearers of a right to just governance that places an ongoing obligation on the exercise of public power. ${ }^{43}$ Within the unified theory, political accountability refers not to the character of a government that must answer to the preferences of the majority of persons as tabulated periodically at the ballot box, but to the character of a legal order that enables every person within it to stand on his or her right to just governance, regardless of whether an election has just concluded, is presently occurring, or will soon occur.

From the standpoint of the unified theory of public law, a legal system is defective on its own internal standard of adequacy to the extent that it fails to create the conditions in which each person can hold the exercise of public power accountable to the terms of its justification by standing on his or her right to just governance. This rigorous conception of accountability is not satisfied by the outcomes of the American and French revolutions of the eighteenth century, which placed public power in the hands of white propertied adult men, or by the subsequent extension of the franchise to persons traditionally excluded from it on the basis of religion, race, class, or gender. These events rendered public power accountable to the preferences of an increasingly expanding citizenry, and yet failed to create a system of law that enabled each and every person to hold the exercise of public authority accountable to the right to public justice. The problem of accountability raises the question of how a regime of public law could be ordered to render the collective exercise of public authority accountable neither to the preferences of the many nor of the few, but to the equal right of every person to just governance. The practice of modern constitutionalism is a systematic response to this question.

\footnotetext{
${ }^{43}$ Lorraine Eisenstat Weinrib, "Canada's Constitutional Revolution: From Legislative to Constitutional State," Israel Law Review 33 (1999): 46.
} 


\section{A NEW FORM OF GOVERNMENT}

In the aftermath of the Second World War, peoples throughout the world reflected on "barbarous acts which have outraged the conscience of mankind" and set out to design legal systems committed to the "recognition of the inherent dignity and of the equal and inalienable rights of all members of the human family." ${ }^{44}$ From diverse experiences of unconstrained power, peoples turned to the modern constitutional paradigm as a versatile model for addressing the problem of accountability. In this section, I will explain how the features of the modern constitutional paradigm address the problem of accountability by exploring the transition to modern constitutionalism in Germany, South Africa, and Canada.

Prior to their respective transitions to modern constitutionalism, Germany, South Africa, and Canada illustrate that whether public power is exercised by a single person, a minority of persons, or by the majority of citizens, public power remains unaccountable to all who are bound by it. In Germany, authority was exercised by one and was unaccountable to all, in South Africa authority was exercised by the few and unaccountable to the many, and in Canada authority was exercised by the many and unaccountable to the few. Following the descent of Weimar into Nazism, the Führer exercised power in accordance with the totalitarian slogan "Du bist nichts, dein Volk ist alles?" ('You are nothing, your nation is everything!’). The Führer determined how persons were to be treated in accordance with his perception of the objectives of the nation. Whereas in Nazi Germany power was exercised by one and unaccountable to all, ${ }^{45}$ apartheid South Africa placed state power in the hands

44 UN General Assembly, Universal Declaration of Human Rights, 10 December 1948, 217 A (III), available at: http://www.unhcr.org/refworld/docid/3ae6b3712c.html [accessed 5 March 2011]. For discussions of this provision see Mary Ann Glendon, "Knowing the Universal Declaration of Human Rights," Notre Dame Law Review 73 (1998): 1163-4; Laurie Ackermann, "The Soul of Dignity: A Reply to Stu Woolman," in Constitutional Conversations, ed. Woolman and Michael Bishop (Pretoria: Pretoria University Press, 2008), 223; and Johannes Morsink, "World War'Two and the Universal Declaration," Human Rights Quarterly 15 (1993): 358-9.

45 I argue in Chapter Two that as Nazism persisted it ultimately crossed the threshold that separates an unjust legal system from a condition of lawless violence. The same may be true of apartheid South Africa, but I cannot pursue this issue here. 
of the few, a white minority that was empowered to enact law "without a need to justify even to those governed by the law." 46 Those who were excluded from contributing to the enactment of law "were treated as not having inherent worth; as objects whose identities could be arbitrarily defined by those in power...In short they were denied recognition of their inherent dignity." ${ }^{47}$ Although the majority of the population was denied political and other rights, the judiciary "accepted that parliament could make laws that, expressly or by necessary implication, sanctioned discrimination and the deprivation of rights." 48 Unlike South Africa, in which the few exercised power in a manner unaccountable to the many, Canada presented the opposite problem, in which the many exercised public authority in a manner that was unaccountable to the few. Prior to the enactment of the Charter of Rights and Freedoms, persons enjoyed the right to ask the legislature to govern in a manner compatible with their freedom, equality, and human dignity, but "Canada's constitutional order protected these norms only in the interstices of its parliamentary system of government and its federal structure." ${ }^{49}$ So long as government acted intra vires, public power could be directed towards the "discriminatory denial of employment opportunities and the franchise; the removal of the right of citizens, natural born and naturalized, to remain in Canada; restrictions on basic political rights and social benefits." ${ }^{\prime 0}$ In sum, a common problem of accountability pervaded the disparate modes of exercising power in Germany, South Africa, and Canada prior to their

\footnotetext{
${ }^{46}$ Mureinik, "A Bridge to Where? Introducing the Interim Bill of Rights," 32.

${ }^{47}$ Prinsloo v. van der Linde (1997) 6 BCLR 759(CC), para. 31. On the inhumanity of apartheid power, see Lourens W.H. Ackermann, "The Legal Nature of the South African Constitutional Revolution," New Zealand Law Review 4 (2004): 645 (arguing that state power denied "blacks that which is definitional to being human, namely, the ability to understand or at least define oneself through one’s own powers and to act freely as a moral agent pursuant to such understanding or selfdefinition").

48 Arthur Chaskalson, "From Wickedness to Equality: The Moral Transformation of South Africa Law," International Journal of Constitutional Law 1 (2003): 592 [“Moral Transformation”].

${ }^{49}$ Lorraine Eisenstat Weinrib, “Canada’s Constitutional Revolution: From Legislative to Constitutional State,” 14. See also Bertha Wilson, "Constitutional Advocacy," Ottawa Law Review 24 (1992): 266.

${ }^{50}$ L.E. Weinrib, "Canada's Constitutional Revolution: From Legislative to Constitutional State," 16.
} 
transitions to modern constitutionalism: in each case power was exercised in such a way that persons could not constrain its exercise to the terms of its justification.

Modern constitutionalism is a mode of legal organization designed to transform the right of every person to just governance from "a mere guideline of a political, moral, or philosophical nature" into an effective constraint on all public power. ${ }^{51}$ A modern constitutional state is distinguished by three components. The first is a constitution that exhaustively sets out the conditions for the valid exercise of public authority by any branch of government, whether the legislature, the executive, or the judiciary. The second is the constitutional entrenchment of the right of every person to just governance and the corresponding duty incumbent on all branches of the legal order. Modern constitutional states employ the notion of human dignity to capture what I have called independence, the right of each person to membership in a system of equal freedom. In turn, the abstract notion of human dignity is concretized through a set of constitutional rights that elaborate the appropriate relationship between the individual and government. The first and second components create a legal order in which just governance is the condition for the valid exercise of public authority. The third component transforms the constitutionally recognized right of every person to just governance from a normative ideal into an effective constraint upon state power. Any person within the legal order who believes that his or her constitutional right to just governance has been violated may bring a constitutional complaint to a politically independent judicial body that the constitution both empowers and obligates to uphold constitutional norms. I will consider each of these components in turn.

A modern constitution constitutes government by exhaustively establishing the conditions for the valid exercise of public authority within a given legal system. Because the constitution is exhaustive in establishing the conditions for the valid exercise of public authority, all public authority descends

\footnotetext{
51 Mauro Cappelletti, “The Expanding Role of Judicial Review in Modern Societies," in The Role of Courts in Society, ed. Simon Shetreet (Dordrecht: Martinus Nijhoff Publishers, 1988), 89.
} 
from the constitution: there can be no "extra-constitutional mode of exercising public power". ${ }^{2}$ Further, because the constitution determines the conditions of the valid exercise of public authority within a given legal system, the constitution denies the validity of any act of government - legislative, executive, or judicial - that conflicts with constitutional standards. ${ }^{53}$ Thus, Germany's Basic Law indicates that the rights and duties that it recognizes bind the legislature, the executive and the judiciary. ${ }^{54}$ Similarly, the Constitution of the Republic of South Africa holds that "law or conduct inconsistent with it is invalid; and the duties imposed by it must be fulfilled." ${ }^{55}$ Because the Constitution is the supreme law, a court "must declare that any law or conduct that is inconsistent with the Constitution is invalid to the extent of its inconsistency". ${ }^{56}$ In the Canadian context, the British North America Act declares that the "Constitution of Canada is the supreme law...any law that is inconsistent with the provisions of the Constitution is, to the extent of the inconsistency, of no force or effect." 57 As the Supreme Court of Canada explained in an unanimous decision: "The Constitution binds all governments, both federal and provincial...They may not transgress its provisions: indeed, their sole claim to exercise lawful authority rests in the powers allocated to them under the Constitution, and can come from no other source."58 Since the constitution alone empowers government, government may not exercise the rights that the constitution affords while ignoring the duties that it imposes.

\footnotetext{
52 Grimm, "The German and American Constitutionalism: A Comparison," 8. See also Grimm, "The Achievement of Constitutionalism and its Prospects in a Changed World," in The Twilight of Constitutionalism, ed. Petra Dobner and Martin Loughlin (Oxford: Oxford University Press, 2010), 9.

53 See, for example, Alexander Hamilton, "Federalist No. 78," in The Federalist, 577: "There is no position which depends on clearer principles, than that every act of a delegated authority, contrary to the tenor of the commission under which it is exercised, is void. No legislative act, therefore, contrary to the Constitution, can be valid. To deny this, would be to affirm, that the deputy is greater than his principal; that the servant is above his master; that the representatives of the people are superior to the people themselves; that men acting by virtue of powers, may do not only what their powers do not authorize, but what they forbid."

${ }^{54}$ Grundgesetz. (English translation of The Basic Law for the Federal Republic of Germany (Berlin: German Bundestag, 2001)), art 1(3) and 20(3). On constitutional supremacy in Germany, see Jutta Limbach, "The Concept of the Supremacy of the Constitution," Modern Law Review 64 (2001): 1-10, and Donald P. Kommers, The Constitutional Jurisprudence of the Republic of Germany (Durham: Duke University Press, 1989), 39 [Constitutional Jurisprudence of Germany].

55 Constitution of the Republic of South Africa, 1996, s. 2; Chaskalson, "Moral Transformation", 599; and Ackermann, "The Legal Nature of the South African Constitutional Revolution," 643.

${ }^{56}$ Constitution of the Republic of South Africa, 1996, s. 172(1)(a).

${ }^{57}$ British North America Act, 1867, 30-31 Vict., c. 3 (U.K.), s. 52(1).

58 Reference re Secession of Quebec [1998] 2 S.C.R. 217, 258.
} 
Modern constitutionalism addresses the problem of accountability by establishing the appropriate relationship between the right of government to exercise public authority and its duty to govern justly in positive law. In precursors to modern constitutionalism, public justice could be realized through the valid exercise of public authority, but the valid exercise of public authority could also violate the right of persons to just governance with impunity. In the modern constitutional state, the realization of public justice forms the legal condition for the valid exercise of public power. The modern constitutional state achieves this reorientation between public authority and public justice by recognizing, on the one hand, that every person within the legal order - by virtue of his or her inherent dignity - imposes a duty on all public authority, and, on the other, that compliance with this duty is a constitutional condition for the valid exercise of public authority. Thus, Article 1 of Germany's Basic Law declares: "Human dignity shall be inviolable. To respect and protect [human dignity] shall be the duty of all state authority". ${ }^{59}$ That the state must respect human dignity precludes the state from interfering with persons in a manner unbefitting of their dignity. That the state must protect human dignity requires the state to create the conditions in which all persons within the legal order may lead a dignified life. ${ }^{60}$ Human dignity, is both the basis on which public authority is justified and the purpose to which it must be directed: “The dignity of man is the legitimizing basis of the State and its legal order. The State's respect for and protection of human dignity constitute its purpose." ${ }^{61}$ In South Africa the "touchstone of the new political order" is the recognition of the inherent dignity of

\footnotetext{
${ }^{59}$ Grundgesetr, art. 1(1). On the conception of human dignity at work in the Grundgesetr, see Edward Eberle, "Human Dignity, Privacy and Personality in German and American Constitutional Law" Utab Law Review (1997): 964-1056.

${ }^{60}$ Kommers, Constitutional Jurisprudence of Germany, 31. On the affirmative duty to protect human dignity, see Grimm, "The Basic Law at 60 - Identity and Change," German Law Journal 11 (2010): 43-4 (my emphasis): “The state's duty to respect fundamental rights is fulfilled by omitting certain acts that would constitute a violation of the fundamental right. The duty to protect rights is fulfilled by taking action in favour of the threatened liberty. Consequently, the legislature was no longer free to decide whether or not to legislate. If a fundamental right was threatened, the legislature had an obligation to legislate. Hence, a law could not only violate the constitution if it went too far in limiting a right, it could also be unconstitutional if it did too little to protect it. This duty is enforced by the Constitutional Court, which, according to this understanding of fundamental rights, gained the power to obligate the legislature to make laws."

${ }^{61}$ Eckhart Klein, "Human Dignity in German Law," in The Concept of Human Dignity in Human Rights Discourse, ed. David Kretzmer and Klein (The Hague: Kluwer Law International, 2002), 146.
} 
all South Africans, which the apartheid regime denied. ${ }^{62}$ The South African Constitution is premised on the values of "human dignity, equality and freedom." Although Canada's Charter of Rights and Freedoms does not explicitly entrench human dignity, it holds that the rights and freedoms that it guarantees are grounded in the values of a "free and democratic society". ${ }^{64}$ Chief Justice Dickson elucidated both the aim and the foundation of such a society: "A free society is one which aims at equality with respect to the enjoyment of fundamental freedoms... Freedom must surely be founded in respect for the inherent dignity and the inviolable rights of the human person." ${ }^{65}$ In a modern constitutional state, the right of government to exercise public authority is to be constrained by the terms of its justification, the right of every inhabitant of the legal order to equal freedom by virtue of his or her inherent dignity.

By recognizing that the inherent dignity of human persons forms the purpose and constraint of all public power, a modern constitutional state repudiates any arrangement that ties the right of persons to just governance or their capacity to hold public power accountable to characteristics that some possess but others lack, whether a particular gender, race, religious worldview, or class, or favorable standing with respect to the dominant forces of the community. ${ }^{66}$ Since dignity is an inherent feature of the human person, just governance must be extended to every inhabitant of the

\footnotetext{
62 S. v. Makwanyane and Another (1995) 3 SA 391 (CC), para. 329.

${ }^{63}$ Constitution of the Republic of South Africa (Act 108 of 1996), s. 7; s. 1.

${ }^{64}$ Canadian Charter of Rights and Freedoms, s. 1, Part I of the Constitution Act, 1982, being Schedule B to the Canada Act 1982 (U.K.), 1982, c. 11, s. 1 [Charter].

${ }^{65}$ R. v. Big M Drug Mart Ltd., [1985] 1 S.C.R. 295, 336.

${ }^{66}$ Grundgesetz, art. 1(1). On the inclusiveness of human dignity in the Basic Law, see the Foreword, 5-6: "The most important sentence in the Basic Law will always be Article 1...The founding fathers and mothers of the Basic Law purposely did not refer to the state or state authority, or to the nation, in this opening sentence. On the contrary, it concerns the human person and the dignity of the individual. It is an explicit rejection of every ideology which sacrifices human life or life chances to a supposedly higher cause. And it is a rejection, too, of every form of discrimination on grounds of origin, colour, creed or conviction. Article 1 does not say: 'The dignity of the German people shall be inviolable'. Nor does it refer to the dignity of the healthy or wealthy. It is a clear commitment to the inviolability of buman dignity. This is not an abstract philosophical concept, but a binding obligation and an enduring mission for all those who bear political responsibility in our democratic and social state under the rule of law."
} 
legal order and every inhabitant of the legal order must have the capacity to hold the public authority to account.

In modern constitutional states, the general duty of state power to respect and protect human dignity is concretized by a set of constitutional rights that specify the appropriate relationship between the free individual and the coercive state. Germany's Basic Law sets out the relationship between human dignity and constitutional rights in article 1. The recognition that human dignity is "inviolable" is immediately followed by the statement that the "German people therefore acknowledge inviolable and inalienable human rights as the basis of every community, of peace and of justice in the world." ${ }^{97}$ Accordingly, each person possesses a set of basic rights, including the general right to liberty, which entitles each person to the free development of his or her personality in concert with others in the legal order. ${ }^{68}$ The rights contained in the Basic Law are "not mere proclamations or slogans" as they were under the Weimar Constitution, ${ }^{69}$ but "directly applicable law" that binds all branches of government. ${ }^{70}$ This conception of the relationship between the inherent dignity of the human person and constitutional rights is echoed by the constitutional orders of South Africa and Canada. The South African Constitution presents inherent human dignity not only as the foundational value of the legal order ${ }^{71}$ but also as a justiciable right ${ }^{72}$ that "is at the heart of individual rights in a free and democratic society". ${ }^{73}$ Similarly, Canada's Charter grounds the rights and freedoms it elaborates in the

67 Grundgesetr, art. 1(1) and 1(2) (my emphasis). For discussions of the relationship between dignity and constitutional rights, see Eckhardt Klein, "Human Dignity in German Law," 146 ff.; Dieter Grimm, "Proportionality in Canadian and German Constitutional Jurisprudence," University of Toronto Law Journal 57 (2007): 387 (“According to art. 1, all fundamental rights are rooted in the principle of human dignity.").

${ }^{68}$ Grundgesetz, art. 2(1).

${ }^{69}$ Günter Dürig, "An Introduction to the Basic Law of the Federal Republic of Germany" in Ulrich Karpen, ed., The Constitution of the Federal Republic Of Germany (Nomos Verlagsgesellschaft, Baden-Baden, 1998), 13.

${ }^{70}$ Grundgesetr, art. 1(3)

71 Francois Venter, Constitutional Comparison: Japan, Germany, Canada \& South Africa as Constitutional States (Cambridge: Kluwer Law International, 2000), 139-147. See Constitution of the Republic of South Africa, 1996, 7.

72 Constitution of the Republic of South Africa, 1996, 10.

73 Prinsloo v. Van der Linde, 1997 (6) BCLR 759 (CC); 1997 (3) SA 1012 (CC), para 32. See also Chaskalson, "Human Dignity as a Constitutional Value," in The Concept of Human Dignity in Human Rights Discourse, 136 and Chaskalson, "Human Dignity as a Foundational Value of our Constitutional Order," South African Journal of Human Rights 16 (2000): 204. 
values of a free and democratic society, which is interpreted to include the "inherent dignity of the human person". ${ }^{74}$ Within the modern constitutional paradigm, constitutional rights are not - as proponents of the majoritarian conception of accountability would assert - simply a catalogue of past agreements enacted into law, but an elaboration of the more general duty that each person, as a dignified being entitled to equal freedom, imposes on public power.

A constitution that makes the duty to govern justly the condition for the valid exercise of public power is necessary to render government accountable to each of its members but it is not sufficient. It is necessary because it establishes a legal order in which the right of government to validly exercise public authority must be directed towards the realization of public justice. It is not sufficient because establishing a legal order in which just governance is the constitutional condition of the valid exercise of public authority creates no institutional mechanism capable of enabling persons who believe that their right to just governance has been violated to hold the legal order to account. If public power is to be accountable to each person owed a duty of just governance, there must be an institution capable of assessing constitutional complaints on their merits, providing a public determination of the constitutionality of state action, invalidating state action (or inaction) that violates constitutional standards, and imparting remedies to those who have suffered public wrongs. ${ }^{75}$ Such an institutional forum must possess legal expertise in constitutional interpretation and rights adjudication. Further, it must be politically independent so that constitutional complaints are considered on their legal merits rather than in reference to the preferences of the government of the

\footnotetext{
${ }^{74}$ R. v. Oakes, [1986] 1 S.C.R. 103, 136. On the relations between human dignity and constitutional rights in Canada, see Wilson J.'s concurring opinion in R. v. Morgentaler, [1988] 1 S.C.R. 30, 166: “The idea of human dignity finds expression in almost every right and freedom guaranteed in the Charter. Individuals are afforded the right to choose their own religion and their own philosophy of life, the right to choose with whom they will associate and how they will express themselves, the right to choose where they will live and what occupation they will pursue. These are all examples of the basic theory underlying the Charter, namely that the state will respect choices made by individuals and, to the greatest extent possible, will avoid subordinating these choices to any one conception of the good life."

75 Mauro Cappelletti, “The Expanding Role of Judicial Review in Modern Societies," in The Role of Courts in Society, ed. Simon Shetreet (Dordrecht: Martinus Nijhoff Publishers, 1988), 89.
} 
day. Finally, it must render the legal order as a whole accountable to any individual within it whose right to just governance has been violated.

The judiciary (or a specialized constitutional court) is uniquely suited to render the legal system as a whole accountable to each of its members. The legal expertise of the judiciary enables it to interpret constitutional law and adjudicate rights claims. The political independence of the judiciary insulates it from political pressure and thereby enables it to assess constitutional complaints against government on their legal merits in accordance with the normative framework established by the constitution. Further, unlike the legislature, which owes a duty of just governance to each person in the constitutional order but is accountable only to a majority (or plurality) of adult citizens at election time, the role of the judiciary is to render the legal system as a whole accountable to the ongoing right of each of its members to just governance. The right of each person to bring a constitutional complaint before a politically independent judicial body empowered and obligated to effectuate constitutional norms reflects the most basic commitment of the modern constitutional paradigm that the right of each person to just governance calls for legal and institutional arrangements that enables each person to constrain the exercise of public power to the terms of its justification.

Following the horrors of Nazism and the failure of Weimar to make constitutional norms “judicially enforceable", ${ }^{76}$ Germany created a constitutional court to transform constitutional norms into a constitutional reality: “In the spirit of 'Never again' the framers were convinced that a constitution, as good as it may be, is of little value if it is not accompanied by an independent institution that enforces constitutional law...So a court with a very wide range of powers was foreseen in the Basic Law..."77 The Basic Law states that "Should any person's rights be violated by public authority,

\footnotetext{
${ }^{76}$ Kommers, Constitutional Jurisprudence of the Federal Republic of Germany (Durham: Duke University Press, 1997$), 33$.

77 Grimm, "Values in German Constitutional Law," (forthcoming).
} 
he may have recourse to the courts." $" 78$ In turn, the Constitution of South Africa affirms that "Everyone has the right to have any dispute that can be resolved by the application of law decided in a fair public hearing before a court or, where appropriate, another independent and impartial tribunal or forum.’79 Canada's Charter of Rights and Freedoms establishes that "Anyone whose rights or freedoms, as guaranteed by this Charter, have been infringed or denied may apply to a court of competent jurisdiction to obtain such remedy as the court considers appropriate and just in the circumstances." 80 Modern constitutional states empower and obligate the judiciary (or a specialized constitutional court) to respond to constitutional complaints by ensuring that all public power authorized by the constitution is exercised in accordance with constitutional norms.

The legitimacy of judicial review hinges on the conception of accountability that one endorses. On the majoritarian view of accountability, articulated in the prior section, judicial review of legislation is a suspect practice insofar as it involves judges, who are accountable to no one, dismissing the preferences that the people's representatives have enacted into law while imposing their own preferences upon the people. The conception of accountability at work in the unified theory casts judicial review in a different light. Neither the legislature nor the judiciary enjoys an unconstrained right to exercise public authority by enacting its preferences into law. The legislature must enact laws that fulfill the right of every person to just governance, while the judiciary must preserve the constitutional order by upholding the relationship between public authority and public justice that the constitution establishes. To this end, the judiciary must assess constitutional complaints on their merits and when legislative or executive power is found to depart from the constitutional conditions

\footnotetext{
78 Grundgesetz, art 19(4); 93(1)(4a). On the contrast between the justiciability of constitutional rights under the Weimar Constitution and the Grundgesetr, see Kommers, "German Constitutionalism: A Prolegomenon," Emory Law Journal 40 (1991): 853.

${ }^{78}$ Grundgesetz, art. 97(1). See also Kommers, "The Basic Law and its Interpretation,” 37.

${ }^{79}$ Constitution of the Republic of South Africa, 1996, s. 34 and 165(2).

${ }^{80}$ Charter, s. 24 (1). For a discussion of how s. 24(1) of the Charter and s. 52(1) of the Constitution Act transform the role of Canada's judiciary, see Vriend v. Alberta, [1998] 1 S.C.R. 493, para. 134-5.
} 
of its exercise, the constitution itself requires the judiciary to uphold constitutional norms by denying the validity of the unconstitutional act. As Justice Iacobucci explained in a landmark decision of the Supreme Court of Canada:

It is suggested that this appeal represents a contest between the power of the democratically elected legislatures to pass the laws they see fit, and the power of the courts to disallow those laws, or to dictate that certain matters be included in those laws. To put the issue in this way is misleading and erroneous. Quite simply, it is not the courts which limit the legislatures. Rather, it is the Constitution, which must be interpreted by the courts, that limits the legislatures. This is necessarily true of all constitutional democracies. Citizens must have the right to challenge laws which they consider to be beyond the powers of the legislatures. When such a challenge is properly made, the courts must, pursuant to their constitutional duty, rule on the challenge. $^{81}$

The invalidation of unconstitutional legislation by the judiciary does not usurp the unconstrained right of the majority to enact its preferences into law. For the constitutional state recognizes no such right. Rather, when the judiciary responds to a constitutional complaint by rigorously assessing the constitutionality of state action, the judiciary acts in accordance with its own constitutional duty to hold the exercise of public authority to constitutional standards. In so doing, the judiciary renders the exercise of public power accountable to each person within the legal order, and so to the people considered as a whole. While proponents of the majoritarian view of accountability call for a passive judiciary deferential to legislative power, a judiciary that fails to hold the exercise of public authority to constitutional standards would both violate its own constitutional duty and resurrect the very problem of accountability that the modern constitutional state exists to address.

The modern constitutional paradigm is a fundamentally new form of government. Its innovation consists in addressing the problem of accountability by reordering the relationship between public authority and public justice. In precursors to the modern constitutional paradigm, the violation

\footnotetext{
${ }^{81}$ Vriend v. Alberta, para. 56.
} 
of the duty to govern justly is simply an injustice, which alone does not invalidate an otherwise authoritative act. In the modern constitutional state, a public injustice also violates the supreme positive law of the legal order, which makes conformity to the demands of public justice a condition for the valid exercise of public authority. Because the modern constitutional state makes the realization of public justice a condition for the valid exercise of public authority, it is a system of positive law in which the natural law maxim 'Lex iniusta non est lex' - 'Unjust law is not law'82 - is, in its strict sense, true. Laws that fail to conform to the duty of public justice are not to be regarded as merely defective insofar as they involve an exercise of public authority that departs from the terms of its justification, but rather as violating the supreme law of the legal order and therefore subject to invalidation. So conceived, what distinguishes a modern constitutional state from other regimes of public law is neither the justice of its existing arrangements nor the justice of the laws that it will one day enact. For as Rawls rightly remarked, "there is no human institution - political or social, judicial or ecclesiastical - that can guarantee that legitimate (or just) laws are always enacted and just rights always respected." ${ }^{83}$ Every legal order must govern justly and yet any legal order, modern constitutional states included, might fail to do so. Rather, what distinguishes a modern constitutional state from other regimes of public law is the way it reorients the relationship between public authority and public justice and the legal and institutional arrangements that it establishes to effectuate this reorientation. A constitutional state is a legal order that is accountable neither to the preferences of one or few or many, but to the right of every person to just governance. In such a legal order, any individual can challenge the validity of a law solely on the grounds that it violates a determination of the right to public justice.

\footnotetext{
82 Finnis, "Natural Law Theories", The Stanford Encyclopedia of Philosophy (Fall 2008 Edition), Edward N. Zalta (ed.), URL = <http://plato.stanford.edu/archives/fall2008/entries/natural-law-theories/>.

83 "Political Liberalism: A Reply to Habermas," The Journal of Philosophy 92 (1995): 166.
} 
The modern constitutional project can fail in a number of ways. The judiciary might shrink from the arduous task that the constitution imposes upon it by bowing to public pressure and assessing the constitutionality of state action on the basis of considerations of political expediency rather than the constitutional merit of the complaint. And even if the judiciary fulfills the demands of its own role, the separation of powers means that the judiciary cannot enforce its determinations on the legislature or the executive. ${ }^{84}$ The modern constitutional project cannot succeed if the legislature does not internalize constitutional norms and seek to further their realization through its lawgiving or if the executive fails to carry out the judgments of the judiciary and the laws enacted by the legislature. What is crucial to note, however, is that even though the modern constitutional state cannot exclude the possibility of these failings occurring, it is a legal order that makes their occurrence a violation of the highest positive law.

The ultimate safeguard of the modern constitutional project lies neither in the generalities of the constitutional text nor in the powers of the judiciary. Rather, the ultimate safeguard of modern constitutionalism lies in the continuity between the normative principles that the constitution seeks to effectuate and the people's reasoned convictions about the appropriate relationship between public authority and public justice. In a flourishing constitutional state, the people itself adopts the standpoint of public law by cultivating the capacity to distinguish between the exercise of public authority and the requirements of public justice and by insisting that the former correspond to the latter. As Dieter Grimm explains:

In the last resort, respect for the law in general and the constitution in particular depends on roots that stretch deeper than legal precautions. The willingness to comply

\footnotetext{
84 See, for example, Dieter Grimm, "Constitutional Adjudication and Democracy," in Judicial Review in International Perspective, ed. Mads Tønnesson Andenæs and Duncan Fairgrieve (The Hague: Kluwer Law International, 2000), 109 ("the courts have no means to enforce respect for the constitution vis-à-vis the rulers. There is no bailiff for constitutional matters"); Kommers, Constitutional Jurisprudence of Germany, 62-3 ("the Constitutional Court's rulings are exclusively declaratory").
} 
with the constitution even if it interferes with one's political plans and even if one is in a position to neglect it without risk is, to a large extent, a cultural achievement. There are societies where this respect is more deeply rooted in the citizens than in others. In these societies, democratic politicians will usually be less inclined to neglect the law, and the general public will react in a more hostile manner to governmental violations. $^{85}$

The more the members of a public culture are capable of assessing the constitutionality of state action and committed to the ongoing realization of constitutional norms, the more public officials will be pressed to direct their constitutional powers to the just governance of every person within the legal order. Since modern constitutionalism is often implemented prior to the emergence of such a public culture, the hope of the modern constitutional project is that the practice of modern constitutionalism will contribute to its creation. In any event, however, the development of such a public culture is, as I argued in the prior chapter, itself a public duty.

I have presented the core components of modern constitutionalism: the constitutional entrenchment of the right of persons to just governance by virtue of their inherent dignity, the corresponding duty of all branches of government, and a system of judicial review that makes the exercise of public authority accountable to all who are entitled to just governance. Further supporting structures are required for the modern constitutional project to succeed. These structures include access to publicly funded legal counsel and a broad law of standing that enables every person to stand on his or her right to just governance by raising a constitutional complaint. I discuss the importance of the latter consideration in the next section.

\footnotetext{
85 See Grimm, "Constitutional Adjudication and Democracy," 108. See also, Grimm, "The Basic Law at 60 - Identity and Change," German Law Journal 11 (2010): 40-41; Matthias Mahlmann, "The Basic Law at 60 - Human Dignity and the Culture of Republicanism," German Law Journal 11 (2010): 25; and Klein, “Human Dignity in German Law,” 159.
} 


\section{AMERICAN EXCEPTIONALISM}

Americans might be surprised to learn that the modern constitutional paradigm is a fundamentally new form of governance that did not appear until after the Second World War. After all, the United States has had both a constitutionally entrenched Bill of Rights and a practice of judicial review for well over two hundred years. However, the modern constitutional paradigm makes significant departures from both the theory and practice of American constitutionalism. These departures diminish the accountability of the American legal system to each of its members. This diminished notion of accountability is evident in the conception of rights that flows through the American constitutional order and its approach to the law of standing. I will discuss each of these issues briefly, in turn.

In American constitutional practice, judicial review was not generally directed towards securing the "enforcement of certain basic civil rights of individuals and minority groups against reluctant majorities in the states, and against the inaction of political branches at the federal level" until after the Second World War when the Warren Court attempted to bring the United States into conformity with the modern constitutional paradigm. ${ }^{86}$ The subsequent repudiation of the judicial philosophy of the Warren Court has distanced American constitutionalism from the modern constitutional paradigm in several respects. Because the orienting concept of American constitutionalism is often taken to be the experiment in self-government, ${ }^{87}$ constitutional rights are

\footnotetext{
${ }^{86}$ Cappelletti, "Constitutional Justice," 5. On the transformation of American constitutional law following the Second World War, see Epp, The Rights Revolution: Lawyers, Activists, and Supreme Courts in Comparative Perspective, 2: "As late as the mid [1930s], less than 10 percent of the Court's decisions involved individual rights other than property rights; the Court instead devoted its attention to business disputes and often supported property-rights claims brought by businesses and wealthy individuals The Court's attention and support eventually shifted to modern individual rights. By the late [1960s], almost 70 percent of its decisions involved individual rights, and the Court had, essentially, proclaimed itself the guardian of the individual rights of the ordinary citizen." For a discussion of the Warren Court's development of modern constitutionalism within the United States, see Lorraine Weinrib, “The Postwar Paradigm and American Exceptionalism," in The Migration of Constitutional Ideas, ed. Sujit Choudhry (New York: Cambridge University Press, 2006), 83-113.

${ }^{87}$ Ackerman, "Rooted Cosmopolitanism," 517.
} 
typically interpreted as an aggregate of isolated constraints on state power that reflect past instances of constitutional agreement rather than as a specification of the general principle of "ordered liberty" ${ }^{88}$ Thus, the scope of protections that rights afford their bearers are often understood as frozen at the moment of their enactment. In contrast, as I discuss in the next chapter, modern constitutional states employ modes of interpretation in which the scope of each particular right is determined in light of the purpose of securing the general right of persons to equal freedom. So conceived, constitutional rights are not only negative constraints on state action but also impose a positive obligation on government to create a legal order adequate to the dignity of all of its inhabitants. Thus, modern constitutional states depart from the dominant American conception of constitutional rights, in which rights provide individuals with piecemeal constraints against the intrusions of state power, but do not constrain public authority to the terms of its justification by requiring the creation of a legal order that to the greatest extent possible unites the authority of law with the independence of all who are bound by it. On the American approach, judicial review is confined to the determination of whether public power has interfered with a list of negative rights. Beyond this requirement, legislative power may be directed towards the pursuit of whatever preferences the many endorses. ${ }^{89}$

A further discrepancy obtains with respect to the law of standing. Whereas the modern constitutional state frames the law of standing broadly to enable any individual who believes that his

\footnotetext{
88 Poe et al. v. Ullman, State's Attorney, 367 U.S. 497, 518.

89 See, for example, John Rawls, Political Liberalism (New York: Columbia University Press, 1996), 227-230. Rawls draws a distinction between constitutional essentials (which include "equal basic rights and liberties of citizenship that legislative majorities are to respect: such as the right to vote and to participate in politics, liberty of conscience, freedom of thought and of association, as well as the protections of the rule of law") and basic matters of distributive justice (which concern equal opportunity as well as "social and economic inequalities"). In arguing that constitutional essentials alone should be subject to judicial review and that basic matters of distributive justice are confined to the legislative domain, Rawls departs from the modern constitutional paradigm. This departure consists in holding that even though the state owes a duty to each citizen with respect to basic matters of distributive justice, the performance of this duty is solely a legislative issue and, as such, accountable only to the many. Modern constitutional states, in contrast, render basic issues of distributive justice subject to judicial review by including both what Rawls calls equal rights and liberties as well as basic matters of distributive justice in a justiciable bill of rights. If the state's duty to govern justly is to be accountable to every person to whom it is owed, aspects of that duty must not be carved out and insulated from judicial oversight.
} 
or her right to just governance has been violated to bring a constitutional complaint challenging the validity of state action, the United States employs a narrower approach to the law of standing. In Poe v. Ullman, ${ }^{90}$ the United States Supreme Court assessed the constitutionality of a Connecticut statute prohibiting persons from using contraception and doctors from giving advice about the use of contraception. The facts of the case could not be more sympathetic to the anonymous appellants. Mrs. Poe had suffered three consecutive pregnancies culminating in the birth of infants with multiple congenital abnormalities, who died shortly thereafter. In turn, Mrs. Poe's past pregnancy had very nearly taken her life and resulted in partial paralysis and other health problems. In both cases, their doctor recommended the use of contraceptives. Writing for the majority, Justice Frankfurter emphasized that the statute had not been enforced in decades, that the appellants therefore could not have been directly injured by it, and, consequently, that they lacked the standing to challenge its constitutionality: "The fact that Connecticut has not chosen to press the enforcement of this statute deprives these controversies of the immediacy which is an indispensable condition of constitutional adjudication. This Court cannot be umpire to debates concerning harmless, empty shadows." "91 The modern constitutional paradigm resolutely rejects Justice Frankfurter's narrow approach to the law of standing. Within the modern constitutional paradigm, all who are bound by law have a right to just governance that corresponds to the constitutional duty of the public authority. To determine whether the public authority has acted constitutionally, the case must be presented to the judiciary and someone must have standing to present it. In cases in which no person is particularly affected by a law, anyone may bring a constitutional complaint. To deny standing to challenge a suspect statute when no one is particularly affected insulates the exercise of public authority from judicial review and thereby vitiates the right of all persons to just governance. Justice Laskin of the Supreme Court of Canada anticipated

90367 U. S. 497 (1961).

91 Ibid., 508. 
the approach of the modern constitutional paradigm towards the law of standing: "It would be strange and, indeed, alarming if there was no way in which a question of alleged excess of legislative power, a matter traditionally within the scope of the judicial process, could be made the subject of adjudication." 92 A broad approach to the law of standing is crucial in creating the conditions in which the exercise of public authority is accountable to all who are bound by it.

Turning from American constitutional practice to American constitutional theory, the modern constitutional state departs from the leading paradigms of American constitutional thought. In directing democratic institutions to the fulfillment of substantive norms, modern constitutionalism departs from both the proceduralism that forms the dominant understanding of American constitutional law and the opposing tendency, which Bruce Ackerman refers to as rights-foundationalism. For Ackerman, the difference between the American constitutional order and its German counterpart can be illuminated by contrasting the relationship in each system between democratic procedures and substantive rights. ${ }^{93}$ The United States is a proceduralist constitutional order because it renders substantive commitments to rights-protection subordinate to democratic procedures. In contrast, Germany is a rights-foundationalist constitutional order because it renders democratic procedures subordinate to the protection of substantive rights. Ackerman's distinction, however, relies on a selective interpretation of both constitutions. When reading the American Constitution, Ackerman notes that rights are not protected from amendment and assumes that procedures must therefore trump rights (although democratic procedures are also not protected from amendment). When reading Germany's Basic Law, Ackerman notes that rights are placed beyond the power of amendment and assumes that rights must therefore trump democracy (although democratic procedures are also placed beyond the power of amendment). Ackerman's distinction between proceduralist and rights-

92 Thorson v. Attorney General of Canada, [1975] 1 S.C.R. 138, 145.

93 We the People Foundations, 13-15. 
foundationalist constitutional orders cannot be exhaustive because modern constitutional states fall in neither camp. In Germany, the foundational value is neither fundamental rights nor democratic procedures. Rather, both fundamental rights and democratic procedures are valued because of the state's commitment to realize a legal order adequate to the dignity of its members. Insofar as amendments involve an exercise of public authority, and the constitution indicates that no exercise of public authority can be valid if it is incompatible with dignity, the constitution establishes that both democracy and fundamental rights are permanent features of the legal order that cannot be abrogated through amendment.

The unified theory offers an alternative to the one-sided conceptions of democracy that characterize constitutional theory in the United States. Some, like Ackerman, conceive of democracy in procedural terms as majority rule. Because the practice of constitutionalism imposes constraints on majority rule, a majoritarian conception of legitimacy culminates in a countermajoritarian difficulty. ${ }^{94}$ The difficulty concerns the compatibility of democracy and judicial review, the power of the unelected judiciary to declare that laws enacted by the people's elected representatives are unconstitutional. Those who accept the majoritarian conception of democracy must either reject judicial review as an illegitimate constraint on majority rule ${ }^{95}$ or argue that, despite appearances, judicial review actually bolsters majoritarian procedures $^{96}$ or preserves the outcome of majoritarian determinations. ${ }^{97}$ Others, led by Ronald Dworkin, reject the majoritarian premise altogether and the countermajoritarian difficulty that it occasions by defining democracy not as a majoritarian procedure but as a society committed to a particular substantive aim, ${ }^{98}$ for example, the ideal of equal concern

\footnotetext{
94 Alexander Bickel, The Least Dangerous Branch (Indianapolis: Bobbs-Merrill, 1962), 16-17.

95 Waldron, Law and Disagreement.

${ }^{96}$ John Hart Ely, Democracy and Distrust: A Theory of Judicial Review (Cambridge: Harvard University Press, 1980).

${ }^{97}$ Bruce Ackerman, We The People: Foundations (Cambridge: Harvard University Press, 1991).

${ }_{98}$ Dworkin, Freedom's Law (Cambridge: Harvard University Press, 1996), 17-18. For a critical discussion of Dworkin's approach, see Noah R. Feldman, “Unresolved Tensions,” Yale Law Journal 106 (1996): 229-234.
} 
and respect for all citizens. ${ }^{99}$ The unified theory of public law rejects the procedural conception of democracy as majority rule, but it does not thereby affirm that democracy is to be identified in terms of the commitment to a particular substantive ideal. Each of these conceptions of democracy fails to integrate two indispensable aspects of public law, public authority and public justice. The unified theory rejects a procedural conception of democracy because democratic arrangements involve the capacity to exercise public authority, and the justification of this capacity indicates the substantive purpose to which it must be directed, the ideal of public justice. The interrelationship between public authority and public justice also prompts rejecting theories that identify democracy in terms of the pursuit of a particular substantive ideal. All legal systems, whether democratic or otherwise, involve the capacity to exercise public authority, and so all must commit themselves to the realization of the ideal of public justice. What distinguishes democracy from other forms of government is not its internal aim but the consistency between its internal aim and the means that it employs to increasingly achieve it. Democracy is the only mode of governance in which the procedure through which laws are enacted is compatible with the purpose of all lawgiving, securing the independence of persons under law. Citizens of a democratic order are active citizens governed by the laws that they collectively enact rather than passive subjects bound by laws of another's making.

\footnotetext{
99 Taking Rights Seriously (Cambridge: Harvard University Press, 1978), 272-3. Dworkin's ideal of equal concern and equal respect departs from the unified theory in three main respects. The first involves the relationship between freedom and equality. The unified theory conceives of equality as an implication of the right to freedom. Because each person has a right to freedom, and the freedom of each must be compatible with the freedom of others, each person is entitled to a domain of freedom equal to that of every other. Whereas in the unified theory, equality is relevant from the standpoint of freedom, for Dworkin, freedom (or liberty) is relevant from the standpoint of equality. The first difference culminates in the second. The unified theory rejects the view that freedom may be limited for the sake of any extrinsic value. In contrast, Dworkin's theory involves two kinds of goods: equal concern involves the human capacity for frustration and suffering; equal respect involves the capacity to determine and pursue one's own purposes. An implication of Dworkin's view is that the liberty that forms the subject of equal respect may be limited on the basis of the utilitarian considerations that form the subject of equal concern. The final difference concerns the relationship between the ideal of each theory and public power. The unified theory establishes that the internal ideal of a legal system as such is equal freedom under law. In contrast, Dworkin's ideal of equal concern and respect is internal to some legal systems, but external to others. As I argued in the Introduction, for Dworkin, the moral principles apposite to a particular legal system must fit the prevailing practices, and so in cases in which the legal practices of a particular community depart radically from the postulates of political morality, those postulates are not relevant to the assessment of that legal system's adequacy.
} 


\section{OBJECTIONS AND REPLIES}

The preceding sections argued that there is a connection between the normative structure of public law and the practice of modern constitutionalism. Modern constitutionalism is necessary because every government has a duty to address its defects and a legal order is defective to the extent that it fails to address the problem of accountability. Modern constitutional states address the problem of accountability by creating the legal and institutional conditions in which each person can insist on just governance and thereby constrain the exercise of public power to the terms of its justification.

In this section, I will draw on the unified theory of public law to defend modern constitutionalism from the objections of Jeremy Waldron. Waldron's objections proceed from the claim that majoritarian democracy is a legitimate arrangement insofar as it gives each person an equal say regarding the decisions of the community as a whole. With this conception of a legitimate political order in place, Waldron raises two kinds of objections to modern constitutionalism. ${ }^{100}$ The first kind of objection concerns how proponents of constitutional government might justify departures from majoritarian democracy. Each of the specific justifications that Waldron considers employs a common strategy in which attention is drawn to some empirical fact or tendency that makes constitutional government preferable to majoritarian democracy. One justification roots this preference in factual claims about human nature, another in factual claims about human beings who serve as public officials, while a further line of justification rests on claims about the tendency of a constitutional state to produce desirable outcomes. Waldron responds to each of these justifications by casting doubt on the relevant facts and thereby undermining the justification for departing from majoritarian arrangements. Whereas criticisms of the first kind target justifications of constitutionalism, criticisms

\footnotetext{
100 For a short summary of Waldron's attacks, see Wil Waluchow, “Constitutions as Living Trees: An Idiot Defends," Canadian Journal of Law and Jurisprudence 18 (2005): 211-220. Neither Waldron nor Waluchow organizes the objections as I do here.
} 
of the second kind concern the moral adequacy of the practice of constitutionalism, which Waldron characterizes as undemocratic, unaccountable, and deeply illegitimate. I respond to each cluster of objections by appealing to the relationship between the normative structure of public law and the practice of modern constitutionalism. In response to objections of the first kind, I argue that modern constitutionalism is justified by the normative structure of public law rather than by the empirical facts that Waldron challenges. Thus, even if Waldron is correct to reject the empirical claims on which some justifications rely, the justification of modern constitutionalism that emerges from the unified theory remains unscathed. As for objections of the second kind, I argue that the justification that emerges from the unified theory of public law calls for a legal order that is democratic but not, as Waldron would have it, majoritarian. The legitimacy of the modern constitutional state consists in its accountability not to the preferences of the majority of its adult citizens, but to the right of every inhabitant of the legal order to just governance. Far from being an "unaccountable" form of government, ${ }^{101}$ modern constitutionalism is a form of democratic ordering that answers to a distinctive and demanding conception of accountability latent in the normative structure of public law. I will discuss each kind of objection that Waldron raises to modern constitutionalism in turn.

According to one justification of modern constitutionalism that Waldron considers, the reason why rights require constitutional protection is because human beings are hostile creatures that are incapable of restraining themselves in light of the interests of others. ${ }^{102}$ Since human beings cannot be entrusted to exercise self-restraint towards others, they must not be "let loose in the arena of democratic politics". ${ }^{103}$ For Waldron, such a justification for placing rights beyond the domain of democratic politics is self-undermining. On the one hand, defenders of constitutionalism attribute

\footnotetext{
101 Waldron, Law and Disagreement, 293.

102 Ibid., 282 and 222.

103 Ibid., 222.
} 
rights to persons by virtue of their capacity to engage in moral deliberation that transcends "particular or sectional interests." 104 It is this capacity for responsible agency that qualifies persons to engage in an ongoing project of self-government in a manner consistent with the interests of all. ${ }^{105}$ On the other, defenders of constitutionalism justify the entrenchment of rights by conceiving of persons as "selfish and irresponsible predators" that cannot be trusted to respect the rights of others. Such a justification of constitutionalism is incoherent because the conception of the person invoked to justify the attribution of rights conflicts with the conception of the person invoked to justify the entrenchment of rights. ${ }^{106}$ Once we eliminate this inconsistency, the justification for entrenching rights dissolves. If persons were angels, there would be no reason to entrench their rights. If they were predators, they would have no rights to entrench.

The distinction between virtuous and vicious propensities of persons raises a further reason for departing from majoritarian democracy. Waldron notes that when defenders of constitutionalism observe the legislature, they perceive ordinary persons "vulnerable to political pressures of manifold kinds, both financial and political," which undermine their ability to protect "the rights of politically unpopular groups."107 But when defenders of constitutionalism turn their gaze toward the judiciary, they perceive an elite "distinguished by education, intellectual refinement, thoughtfulness, and responsibility", ${ }^{108}$ who alone should be entrusted with the important moral issues of the day. ${ }^{109}$ Waldron responds by accusing proponents of constitutionalism of employing a double-standard in

\footnotetext{
104 Ibid.

105 Ibid., 258.

106 Waldron's criticism of the incoherence of modern constitutionalism echoes the structure of Hans Kelsen's criticism of how natural law theorists establish the necessity of positive law. See "The Natural-Law Doctrine Before the Tribunal of Science," Western Political Science Quarterly 2 (1949): 486: “On the one hand [natural lawyers] maintain that human nature is the source of natural law, which implies that human nature must be basically good. On the other hand [natural lawyers] can justify the necessity of positive law with its coercive machinery only by the badness of man."

107 Dworkin, Freedom's Law, 34.

108 Jeffrey Goldsworthy, "Questioning the Migration of Constitutional Ideas: Rights, Constitutionalism, and the Limits of Convergence," in The Migration of Constitutional Ideals, 122.

109 Waldron, Law and Disagreement, 213.
} 
which the vices of legislators and the virtues of judges are grossly inflated, while the virtues of legislators and the vices of judges are overlooked. ${ }^{110}$ Waldron purports to offer a more realistic picture that acknowledges that both judges and legislators share the moral and intellectual virtues of ordinary persons. ${ }^{111}$ As Thomas Jefferson observed, "judges are as honest as other men" and have the "same passions for party, power, and privilege of their corps."112 In light of this observation, Jefferson characterizes the view that judges should be the "ultimate arbiters of all constitutional questions" as a "very dangerous doctrine". 113

A similar justification of constitutional arrangements appears in Dworkin's constitutional writings. As mentioned above, Dworkin argues that judicial review is justified by the beneficial consequences that it brings, including high quality debates on issues of political morality that culminate in just outcomes. ${ }^{114}$ Such a justificatory strategy invites criticism because, as Waldron notes, judicial review may fail to culminate in these outcomes and these outcomes may be realized in the absence of judicial review.

The unified theory of public law takes a different approach to justifying modern constitutionalism. Unlike the justifications of modern constitutionalism that Waldron canvasses, the unified theory does not attempt to justify the departure from majoritarian democracy by appealing to contested facts about human nature, by asserting that the intellectual and moral qualities of judges exceed those of legislators, or by appealing to desirable consequences that modern constitutionalism might bring.

\footnotetext{
110 Ibid., 9.

${ }^{111}$ For a criticism that Waldron's depiction of the legislature is as unrealistic as his opponents' depiction of the judiciary, see Richard A. Posner, "Review of Jeremy Waldron, Law and Disagreement," Columbia Law Review 100 (2000): 591.

112 Letter to William Jarvis, in The Writings of Thomas Jefferson, vol. 10, ed. P.L. Ford (1899), 160-1.

113 Ibid.

${ }^{114}$ For Dworkin's defense of judicial review and Waldron's rebuttal, see Dworkin, Freedom's Law, 34, 344-345; Dworkin, Law's Empire, 356; Waldron, Law and Disagreement, 220-1, 288-291, and 294; Waldron, "The Core of the Case Against Judicial Review," 1346, 1353, and 1381. For Freeman's defense of judicial review and Waldron's response, see Freeman, "Constitutional Democracy and the Legitimacy of Judicial Review," 327-370 and Waldron, "Freeman's Defense of Judicial Review," Law and Philosophy 13 (1994): 27-41 and Waldron, Law and Disagreement, 306 and 255 ff.
} 
The unified theory of public law does not justify modern constitutionalism on the basis of the virtuous or vicious propensities of human beings. The duty of government to recognize and entrench public rights follows from a conceptually sequenced argument that begins with the right of every person to independence in relation to every other. Public rights are attributed to persons not because of their good-nature but because the right of government to exercise public authority by imposing coercible obligations on independent persons is accompanied by a duty to unite the authority of law with the independence of all who are bound by it. The rights that modern constitutions secure delineate the more general right of each person to independence in relation to state power. Public rights are to be constitutionally protected and subject to judicial review not because of the hostility of persons, but because a problem of accountability persists as long as the right of each person to just governance can be violated with impunity. Thus, the recognition and entrenchment of rights stem from a common juridical conception of the person. The systematic implications of independence justify public authority, the justification of public authority implicates a duty to govern justly, the duty to govern justly is concretized by public rights, and the constitution constrains the exercise of public authority to the terms of its justification by entrenching public rights and rendering them justiciable. The unified theory of public law relies on a single conception of the person, but one that is not reducible to either of the conflicting conceptions at work in the view that Waldron rejects.

Just as the unified theory does not conceive of persons as angels or predators, so too it does not imagine that judges are philosopher-kings who alone comprehend what justice demands and are moved by it, while dismissing the legislature as incapable of recognizing what justice demands and unwilling to carry it out. Insofar as the legislature exercises public authority, it is bound by the duty to govern justly, and if ought implies can, the legislature must have the capacity to engage in such governance. Modern constitutionalism is necessary not because majoritarian democracies often govern in an unjust manner, but because even if a majoritarian democracy governs justly, it nonetheless 
fails to address the problem of accountability. Majoritarian democracy necessarily fails to address the problem of accountability because even though the legislature owes a duty of just governance to every inhabitant of the legal order, it is accountable only to the many. Modern constitutionalism, as I argued above, addresses the problem of accountability by making just governance the condition for the valid exercise of public authority and creating an institutional forum in which any person who believes that his or her right to just governance has been infringed may hold the exercise of public authority to account. The unified theory neither degrades the legislature nor idealizes the judiciary. The legislature must give laws that fulfill the duty of public justice. The judiciary must uphold the supreme norm of the constitutional order by maintaining the relationship between public authority and public justice that a modern constitution envisions by assessing constitutional complaints on their merits.

Finally, the unified theory does not join Dworkin in arguing that modern constitutionalism is justified because of some benefit that it brings that could in principle be achieved in its absence, such as debates of high quality or just outcomes. Instead, the unified theory presents modern constitutionalism as a response to a problem inherent in the structure of public law, the problem of accountability. Since the problem concerns the relationship between the right of government to exercise public power and the right of persons to just governance, the problem cannot be systematically addressed without reconfiguring this relationship. This is what modern constitutionalism does, and what cannot be done in its absence. Precursors to modern constitutionalism may, as Waldron illustrates, enjoy high levels of public debate. They may even enact laws that generally respect the fundamental rights of all who are bound by them. There is, however, one problem that precursors to modern constitutionalism cannot address: the problem of accountability.

Since the justification of modern constitutionalism offered by the unified theory is not susceptible to Waldron's factual objections, Waldron might turn to objections of the second kind, 
which maintain that a legitimate political order is democratic, a democratic political order is majoritarian, and to the extent that a constitutional regime departs from majoritarian arrangements it is both undemocratic and illegitimate. Waldron alleges that constitutionalism is undemocratic and illegitimate in a variety of different ways.

In one formulation, Waldron claims that the entrenchment of constitutional norms imposes a disability on the legislature hindering its "normal function of revision, reform, and innovation in the law."115 Waldron is correct that the entrenchment of constitutional norms imposes a disability on the legislature insofar as it denies the legislature the legal power to abrogate certain features of the constitutional order, such as its commitment to respect and protect the inherent dignity and fundamental rights of persons, and even to maintain the democratic character of the legal order. But it does not follow that the imposition of this disability constrains the legislature's 'normal function'. I have argued that continuity obtains between the normative structure of public law and modern constitutionalism. Modern constitutional states entrench the duty of all branches of government, including the legislature, to exercise public authority in a manner that fulfills the right of every person to just governance, but this duty is not a new constraint on the normal function of legislative power. For the power of the legislature to enact laws binding on all is an instance of public authority and the right to exercise public authority is always accompanied by a duty to govern justly. The disability that modern constitutionalism imposes simply prevents the legislative power from doing what the duty to govern justly prohibits. Far from imposing new constraints on public institutions, modern constitutionalism effectuates a duty implicit in any regime of public law. The modern constitutional state introduces a novel legal and institutional framework to effectuate this duty, but the duty itself inheres in all legal systems.

\footnotetext{
115 Waldron, Law and Disagreement, 221.
} 
In another formulation of the objection from democracy, Waldron suggests that constitutionalism diminishes democratic rights by placing "issues of high principle" in the judicial domain, while leaving the people's elected representatives the less important task of sorting out "interstitial matters of social and economic policy." relegate the legislature to mundane matters. The duty to realize a legal order that to the greatest possible extent unites the authority of law with the independence of each person bound by it is incumbent on all branches of government, including the legislature. While the legislature does not have the final say in issues of constitutional interpretation, it does not follow that issues of high principle are the preserve of the judiciary alone. All branches of government are bound by constitutional norms.

On other occasions, Waldron formulates the objection from democracy in this way: the problem with judicial review is that it excludes citizens from participating in important decisions regarding their own rights, and citizens will rightly feel "slighted" by this exclusion because the constitutional order, in effect, says to them that they are not up to the task of making important decisions regarding their own governance. ${ }^{117} \mathrm{I}$ do not know if Waldron is correct in asserting that judicial review makes citizens feel slighted. If he is, then the global proliferation and acceptance of judicial review is all the more puzzling. The unified theory presents another possibility, which I offer not as a claim about how persons actually feel about modern constitutional norms and practices, but how it would be reasonable for them to feel. When people see that they live in a legal order that acknowledges the inherent dignity of each of its members, that entrenches as its highest law the duty of all public institutions to extend just governance to each member of the legal order, and that creates the conditions in which any person who believes that his or her right to just governance has been

\footnotetext{
116 Ibid., 213.
}

117 Ibid., 239. 
violated may hold public power to account by presenting arguments in a politically independent forum that is both empowered and obligated to render judgment on the legal merits, the constitutional order may be recognized by its members as a form of legal organization designed to systematically constrain the exercise of public power to the terms of its justification. No one should feel slighted if the rights of every person are limited to secure the entitlement of each to equal freedom and the accountability of the legal system as a whole to each of its members.

Finally, Waldron sometimes falls back on the familiar claim that in a majoritarian democracy the legislature is elected and accountable to the people, while in a constitutional state the judiciary is "unelected and unaccountable". ${ }^{118}$ Waldron is correct that in a modern constitutional state, the judiciary is unelected and thus unaccountable to the many. This is not an accident of constitutional design. The modern constitutional state is not a haphazard attempt to render the exercise of public power accountable to the intermittently registered preferences of the many, as Waldron assumes. Rather, the animating purpose of the modern constitutional state is to respond to a problem inherent in the normative structure of public law, the problem of accountability. Waldron's suggestion that the judiciary, like the legislature, be accountable to the many is inadmissible because such a proposal would regenerate the problem of accountability by depriving the legal order of a politically independent public institution to which any individual who believes that his or her right to just governance has been violated could turn. Thus, the judiciary can neither be accountable in the same way as the legislature, nor can the judiciary be accountable to the legislature. To insist that the judiciary be accountable to anything other than the constitutional norms themselves is to demand the impossible of the modern constitutional state. After all, if the problem of accountability is to be addressed there must be an independent judicial institution empowered to assess constitutional complaints on their legal merits, but the insistence that the judiciary be held accountable to a higher power is inconsistent

\footnotetext{
118 Ibid., 293.
} 
with judicial independence. As the guardian of the constitutional order, the judiciary of a modern constitutional state cannot be accountable to the many. What the judiciary can and must do, however, is make the constitutional order as a whole accountable to each of its members.

\section{CONCLUSION}

Modern constitutionalism is a ground-breaking paradigm in public law. Its innovation consists in creating the legal and institutional conditions in which public power is accountable neither to the preferences of the few nor to the preferences of the many, but to the right of every inhabitant of the legal order to just governance. This innovation is made possible by reorienting the relationship between the two pillars of a regime of public law, public authority and public justice. In all precursors to modern constitutionalism, the practice of public law is defective because even though each member of the legal order has a right to just governance, the legal order is arranged in such a way that one or more persons subject to its governance are incapable of standing on this right. The modern constitutional state is a systematic attempt to constrain the exercise of public authority to the terms of its justification by establishing a supreme positive law that makes just governance the condition for the valid exercise of public authority, specifying just governance through a set of constitutional rights that set out the appropriate relationship between the freedom of the individual and the power of government, and rendering these rights justiciable before a politically independent judicial forum so that any person within the constitutional order may challenge the validity of a publicly authoritative act by raising a constitutional complaint. The constitutional norms and institutional framework of the modern constitutional state culminate in a legal order in which each individual has standing to insist that the right to exercise public authority and the duty of just governance that accompanies its exercise 
be jointly satisfied. In Mureinik's terms, a constitutional state is a legal order "in which every exercise of power is expected to be justified" to all who are bound by it. ${ }^{119}$

119 "A Bridge to Where? Introducing the Interim Bill of Rights," 32. 


\section{CHAPTER 5: \\ RightS AND LIMITS IN A CONSTITUTIONAL STATE}

Then it comes to constitutional rights and limits, theory and practice seem to be moving in
opposite directions. As a matter of constitutional practice, courts in constitutional states

from around the world have increasingly converged on a common doctrine for delineating the limits of constitutional rights. ${ }^{1}$ The doctrine of proportionality consists in a set of conditions that government must satisfy in order to justify a law that limits a constitutional right. ${ }^{2}$ In the Canadian formulation of the doctrine, to initiate the proportionality analysis, government must demonstrate that the impugned law pursues a purpose that is "pressing and substantial in a free and democratic society". 3 To satisfy the proportionality analysis, government must demonstrate (1) that the means that the law employs are rationally connected to the relevant purpose, (2) that the law pursues this purpose in a manner that minimally impairs the right, and (3) that the law is proportional in the strict sense, which means that the values underlying the constitutional right are realized to a greater extent by limiting the right than by invalidating the law that infringes it. In constitutional states around the world,

\footnotetext{
${ }^{1}$ Proportionality originated in the Prussian administrative courts in the late $19^{\text {th }}$ century, reemerged in postwar Germany in the late 1950s in the Lïth Case (1958), 7 BVerfGE 198, and has since migrated to the European Court of Human Rights, Canada, South Africa, Israel, the United Kingdom, New Zealand, Australia, India, Turkey, Switzerland, Spain, Portugal, Latin America, Brazil, Hong Kong, South Korea, Hungary, and Poland. Dieter Grimm describes proportionality as Germany's most significant constitutional export. See Grimm, "The Basic Law at 60 - Identity and Change," 42. On the convergence of constitutional states on the doctrine of proportionality, see Aharon Barak, Proportionality: Constitutional Rights and Their Limitations (Cambridge: Cambridge University Press, 2012), 145-210; Moshe Cohen-Eliya and Iddo Porat, "Proportionality and the Culture of Justification," American Journal of Comparative Law 59 (2011): 463-490; and Grimm, "Proportionality in Canadian and German Constitutional Jurisprudence," University of Toronto Law Journal 57 (2007): 384. On the historical origins of proportionality, see David P. Currie, The Constitution of the Federal Republic of Germany (Chicago: University of Chicago Press, 1994), 307 ff.; Madhav Khosla, "Proportionality: An Assault on Human Rights?: A Reply," International Journal of Constitutional Law (2010): 298; Matthias Kumm, "Political Liberalism and the Structure of Rights: On the Place and Limits of the Proportionality Requirement," in Law, Rights, and Discourse, ed. George Pavlakos (Oxford: Hart Publishing, 2007), 132-3; and especially Alec Stone Sweet and Jud Mathews, "Proportionality Balancing and Global Constitutionalism," Columbia Journal of Transnational Law 47 (2008): 98 ff.

2 Barak, 3: "Proportionality...can be defined as the set of rules determining the necessary and sufficient conditions for a limitation of a constitutionally protected right by law to be constitutionally permissible."

${ }^{3}$ R. v. Oakes, [1986] 1 S.C.R. 103, 138-9.
} 
proportionality has "achieved the status of a received idea". When legal practitioners raise questions about proportionality, they invariably concern how best to conceptualize the various branches of the proportionality analysis and apply it to particulars, not "whether it should be rejected in favour of an altogether alternative approach." 5

As a matter of constitutional theory, however, proportionality has encountered persistent opposition. ${ }^{6}$ Critics of proportionality often unite around the view that rights are entrenched to place them beyond the bounds of government interference. From this standpoint, a doctrine claiming that constitutional rights may be justifiably limited appears as nothing more than an illicit end-run around the protections that the constitutional order seeks to extend to its members. In the eyes of its critics, proportionality undercuts the protection of the very rights that a constitutional state exists to secure. If proportionality is objectionable because it admits the possibility of justifying the limitation of a constitutional right, the solution is clear: the doctrine should be rejected in favour of an approach in which each right is absolute within its own domain.

In this chapter, I argue that the worldwide proliferation of proportionality analysis is neither an accidental occurrence nor a regrettable mistake. Proportionality analysis is the most sophisticated and demanding approach to rights-protection yet devised, but its structure and normative significance is not fully intelligible apart from an account of the modern constitutional state.

I argued in the prior chapter that a modern constitutional state is distinguished by the presence of three interrelated components. The first is a written constitution that exhaustively sets out the

\footnotetext{
${ }^{4}$ Grégoire C.N. Webber, "Proportionality, Balancing, and the Cult of Constitutional Rights Scholarship," Canadian Journal of Law and Jurisprudence 23 (2010): 191.

${ }^{5}$ Ibid.

${ }^{6}$ On the discrepancy between constitutional theory and practice, see Denise Réaume, "Limitations on Constitutional Rights: The Logic of Proportionality" (forthcoming); Tor Inge-Harbo, "The Function of the Proportionality Principle in EU Law," European Law Journal 16 (2010): 167-9; Mattias Kumm, “Constitutional Rights as Principles: On the Structure and Domain of Constitutional Justice," [Review of Robert Alexy, A Theory of Constitutional Rights] International Journal of Constitutional Law 2 (2004): 590; Stavros Tsakyrakis, "Proportionality: An Assault on Human Rights," International Journal of Constitutional Law 7 (2009): 473; and especially Webber, 201.
} 
conditions for the valid exercise of public authority by any branch of government, whether the legislature, the executive, or the judiciary. The second is the entrenchment of constitutional norms establishing both an ideal of public justice and a duty of public justice. The former is the aim of the constitutional order, the creation of a system of law in which public authority is so constituted that it leaves the freedom and equality of all who are bound by it undiminished. The latter reflects the general right that each person, as a free and equal member of the legal order, imposes on government: the duty of public justice requires that all public authority be directed towards bringing the existing legal order into the deepest possible conformity with the ideal of public justice. Taken together, the first and second components of a modern constitutional state establish a legal order in which the satisfaction of the duty of public justice is a condition for the valid exercise of public authority. The third component transforms the right of every person to public justice from constitutional rhetoric into constitutional reality. Any person within the legal order who believes that his or her constitutional right to public justice has been violated may bring a constitutional complaint to a politically independent judicial body that the constitution both empowers and obligates to uphold constitutional norms. The interrelation of these components creates a fundamentally new form of government. Whereas earlier forms of government rendered the exercise of public authority accountable to the few or to the many, the modern constitutional state renders public authority accountable to all who are bound by it. Any inhabitant of the legal order may challenge the validity of an authoritative act by claiming a violation of his or her right to public justice.

My central claim in this chapter is that each of the justificatory conditions that make up the doctrine of proportionality are unified by the duty of public justice. Proportionality is a doctrinal distillation of what this duty requires in cases in which a particular constitutional right conflicts with another determination of the ideal of public justice. If such conflicts are an unavoidable feature of modern constitutional governance, then modern constitutional states would require a doctrine for 
determining the duty of government with respect to them. Proportionality is that doctrine. It should therefore come as no surprise that wherever modern constitutional governance emerges, proportionality seems to follow in its wake.

I present my argument in four sections. The first explains why constitutional conflicts are unavoidable within a modern constitutional state. The second section argues that the various conditions that make up the doctrine of proportionality provide a sequenced determination of what the duty of public justice requires in cases of constitutional conflict. To justify a law that limits a constitutional right is to establish that the duty of public justice necessitates the limitation of the right. Such a conception of what it means to justify the limitation of a constitutional right provides an alternative to the way in which proportionality's leading defenders and critics conceptualize the relationship between rights and limitations. In the third section, I contrast the conception of proportionality elaborated in the previous section with the influential theory of proportionality developed by Robert Alexy. My claim is that Alexy's theory fails to illuminate what it means, in the context of a modern constitutional state, to justify the limitation of a constitutional right because his account proceeds from a conception of rights that is alien to the modern constitutional project. The fourth and final section responds to critics of proportionality, including Jürgen Habermas and Ronald Dworkin, who claim that a regime that does not treat constitutional rights as trumps or as absolutes fails to take them seriously. Although critics of proportionality purport to offer a more principled approach, I will argue that the alternatives that they elaborate diminish the right of persons to public justice and the corresponding duty incumbent on government.

\section{The Rise of CONSTITUtional CONFlicts}

In Chapter Four, I presented the modern constitutional state as a mode of legal ordering designed to transform the right of every inhabitant of the legal order to public justice into an effective constraint on the exercise of public power. In order to make this general right effective, modern 
constitutional states must make this normative abstraction sufficiently determinate for public officials to apply it to particulars. To this end, modern constitutional states delineate a set of constitutional rights that characterize the relationship between the free individual and the coercive state. A constitutional right crystallizes the more general right of each person to public justice by delineating a particular domain in which public power must conform to the duty of public justice. These domains include rights to freedom of expression, religion, conscience, association, democratic rights, socioeconomic rights, and a right to access judicial review, which enables any individual in the legal order to stand on the various rights that the constitution establishes and insist on just governance.

A constitutional right is a legal norm that is, at once, general and particular. It is general when considered in relation to its instances. It must be general because norms that are to guide and constrain state conduct must be broader than the instances to which they apply. Thus constitutional rights are formulated in the language of "majestic generalities"” recognizing, for example, the right of every person to the "free development of his personality", 8 or the right "not to be treated or punished in a cruel, inhuman, or degrading way."' Such pronouncements do not themselves exhaustively specify the particular arrangements that they prohibit or require. For example, Germany's Basic Law does not indicate whether the right to the free development of one's personality includes the right to ride horses through a public forest, ${ }^{10}$ nor does the Constitution of the Republic of South Africa set out a blueprint elaborating what it means for an arrangement to be 'cruel, inhuman or degrading'. ${ }^{11}$ Because constitutional rights are more general than the particulars to which they apply, they must be brought to bear on their particulars through interpretation.

\footnotetext{
${ }^{7}$ Fay v. New York, 332 US 261, 282 (1947) (Jackson, J.).

${ }^{8}$ Grundgesetz (English translation of The Basic Law for the Federal Republic of Germany (Berlin: German Bundestag, 2001)), art. 2(1).

${ }^{9}$ Constitution of the Republic of South Africa, 1996, s. 12(1)(e).

${ }^{10}$ BVerfGE 80, 137.

11 S. v. Makwanyane and Another (1995) 3 SA 391 (CC), para. 8.
} 
While constitutional rights must be more general than the particular instances to which they apply, they are in turn more particular than the normative abstraction to which they give effect. In a modern constitutional state, constitutional rights are specifications of the general right that each person, as a free and equal member of the legal order, has to public justice. By formulating the general right to public justice in terms of a set of constitutional rights, the normative abstraction of inherent human dignity gains sufficient determinacy for public officials to apply it to particulars. So conceived, constitutional rights occupy an intermediary position between the abstraction of inherent human dignity and the concrete particulars implicated by it. Because constitutional rights relate an abstract norm to particulars, they can neither be wholly general (like the normative abstraction that they delineate) nor wholly particular (like the instances to which they apply).

Since the rights articulated in the text of a modern constitution are determinations of dignity, the contextual meaning of a right with respect to a legal particular must be considered in reference to the normative purpose underlying constitutional rights. Thus, Dieter Grimm explains that Germany’s Federal Constitutional Court

understands constitutional rights as legal expressions of values, and these values guide the determination of the meaning of a legal norm. However, the purpose ought to be fulfilled in the real world, and this world is constantly changing. The goal of interpretation is to fulfil the purpose of the norm to the utmost extent under changing conditions. This means that the segment of social reality in which a constitutional norm shall take effect must be taken into account. It becomes an integral part of interpretation. The consequence is a three-dimensional understanding of constitutional norms: text plus purpose plus context. Analysis of the social reality to which a norm applies is part of the determination of its meaning. ${ }^{12}$

Similar approaches to the interpretation of constitutional rights have emerged in other constitutional states. The Supreme Court of Canada, for example, conceives of the Charter of Rights and Freedoms as "a purposive document. Its purpose is to guarantee and to protect, within the limits of reason, the

\footnotetext{
12 Grimm, "The Basic Law at 60 - Identity and Change,” 44.
} 
enjoyment of the rights and freedoms it enshrines. It is intended to constrain governmental action inconsistent with those rights and freedoms." ${ }^{\prime 3}$ Accordingly, the Court maintains that interpretation of a constitutional right should be "a generous rather than legalistic one, aimed at fulfilling the purpose of a guarantee and securing for individuals the full benefit of the Charter's protection."14 Through interpretation, enduring constitutional norms are applied "to meet new social, political, and historical realities often unimagined by its framers." ${ }^{\text {"15 }}$ While purposive interpretation has become the interpretive standard in German and Canadian constitutional jurisprudence, the Constitution of the Republic of South Africa explicitly requires it: the interpretation of the Bill of Rights "must promote the values that underlie an open and democratic society based on human dignity, equality and freedom". ${ }^{16}$ As determinations of the more basic right of each inhabitant of the legal order to public justice, constitutional rights must be interpreted in a manner that relates abstract notions surrounding the right of all dignified beings to public justice to the concrete features of the existing legal order. ${ }^{17}$

The aim of purposive interpretation is to determine the protections that each constitutional right affords by considering the right from the standpoint of the values that underlie it so that individuals are given "the full measure of the fundamental rights and freedoms" entrenched in the constitution. ${ }^{18}$ If rights are to be interpreted with reference to their underlying values, they will often

\footnotetext{
${ }^{13}$ Hunter et al. v. Southam Inc., [1984] 2 S.C.R. 145, 156.

${ }^{14}$ R. v. Big M Drug Mart Ltd., [1985] 1 S.C.R. 295, 344.

15 Hunter et al. v. Southam Inc., 155.

${ }^{16}$ Constitution of the Republic of South Africa, 1996, s. 39(1)(a).

${ }^{17}$ Lorraine E. Weinrib, "The Supreme Court of Canada in the Age of Rights: Constitutional Democracy, the Rule of Law and Fundamental Rights under Canada's Constitution," Canadian Bar Review 80 (2001): 747: "Purposive interpretation is the standard approach in the postwar model...It explicates the normative principles and values that legitimate elevating certain fundamental interests as supreme law and thus as situated beyond the reach of the ordinary political process...Against this background, the Court can focus on the claim put forward by the claimant that state action of some sort, in purpose or effect, breached the deepest norms of the political community."

${ }_{18}$ Minister of Home Affairs v. Fisher, [1980] A.C. 319, 328.
} 
require a broad interpretation. ${ }^{19}$ But the more broadly particular constitutional rights are interpreted, the more likely it is that constitutional conflicts will emerge. ${ }^{20}$

Constitutional conflicts involve a clash between competing determinations of the ideal of public justice. In the context of constitutional adjudication, constitutional conflicts arise between a constitutional right and an obligatory public purpose, that is, a purpose that is integral to the maintenance and refinement of a legal order that respects and protects the right of each of its inhabitants to public justice. Such purposes include the democratic and rights-protecting character of the state, public education, public order, public safety, and public health. ${ }^{21}$ Conflicts between constitutional rights and these obligatory public purposes are a familiar feature of modern constitutional governance. Privacy rights might conflict with public safety, just as liberty rights might conflict with the requirements of public health. In other cases, persons might choose to exercise their rights in a manner that undermines the democratic or rights-protecting character of the modern constitutional state. For example, persons might exercise their political rights by creating and participating in political parties hostile to the democratic or rights-protecting character of the legal order. Alternately, a particular constitutional right might conflict with the state's duty to respect and protect other constitutional rights. For example, one's right to free expression might conflict with another's right to privacy, reputation, or a fair trial. Since the purposive interpretation of constitutional rights generates constitutional conflicts, a question arises about whether there are conditions in which the constitutional state would be justified in limiting the very constitutional rights that it entrenches. And, if so, what are these conditions? I address these questions in the next section.

\footnotetext{
${ }^{19}$ See also Barak, 70-1: "The language of the constitutional text protecting rights should be interpreted according to its purpose from a generous point of view. Therefore the text should be interpreted in a way that realizes the reasons underlying the right itself. It should reflect the full scope of the ideals that a particular right is seeking to achieve within a given society."

${ }_{20}$ Moshe Cohen-Eliya and Iddo Porat, 481 and Barak, 81-2.

21 Barak characterizes these "proper purposes" as "principles essential to the shared existence of the people in a democracy”. See Proportionality: Constitutional Rights and Their Limitations, 256.
} 
The problem of justifying the limitation of a constitutional right cannot be sidestepped by repudiating purposive interpretation, conceiving of rights as trumping obligatory public purposes, or by conceiving of obligatory public purposes as trumping rights.

Constitutional conflicts may not be avoided by repudiating purposive interpretation and adopting a narrow approach to the interpretation of constitutional rights. Modern constitutional states, as I have argued, seek to transform the right of every person to public justice into an effective constraint on the exercise of public power. Because this right must be determinate if it is to be effective, the modern constitutional state delineates a set of particular constitutional rights and interprets each particular right broadly in order to secure the normative purpose underlying its entrenchment. A narrower mode of interpretation might succeed in avoiding constitutional conflicts by emptying particular rights of the extensive protections that they afford to their bearers. But the adoption of a narrower approach to the interpretation of constitutional rights would sever the connection between the general right of each person to public justice and the protections that particular constitutional rights afford. Since constitutional rights are posited to make the general right of each person to public justice effective, constitutional rights may not be interpreted in a manner that fails to give effect to their underlying normative purpose.

Nor can constitutional conflicts be avoided by retaining purposive interpretation, but conceiving of rights as trumps that enjoy priority over utilitarian considerations of policy, expediency, or preference. For constitutional conflicts do not involve a clash between a constitutional rights and utilitarian considerations, but rather a clash between a constitutional right and an obligatory public purpose integral to the maintenance of a system of rights. In cases in which the relevant obligatory public purpose involves the duty of government towards another constitutional right, conceiving of rights as trumps merely perpetuates the conflict by suggesting that each of the rights must prevail in the dispute. A similar problem arises with respect to other cases of constitutional conflict. Since 
obligatory public purposes are integral to the maintenance and refinement of a legal order in which rights are protected, the constitutional conflict obtains between a particular constitutional right and the system that enables particular constitutional rights to be enjoyed. In such cases, the impetus for limiting a constitutional right lies not in utilitarian considerations of preference or convenience but rather in competing considerations of public justice. To hold that constitutional rights should always trump public purposes is to suggest that constitutional rights cannot be limited even in cases in which their exercise poses a serious threat to the ongoing viability of the constitutional order as a whole.

Finally, constitutional conflicts cannot be avoided by maintaining purposive interpretation but conceiving of obligatory public purposes as trumping constitutional rights. It is objectionable to suggest that the infringement of a constitutional right is justified in all cases in which government maintains that the rights-infringing law pursues an obligatory public purpose. The problem is not simply that government might mischaracterize something as an obligatory public purpose. Rather, even if a genuine obligatory public purpose is identified, the government's claim that the law contributes to its realization might be dubious. And even if the law furthers the realization of an obligatory public purpose, it remains possible that the purpose could be achieved through means that leave constitutional rights undiminished or that diminish a constitutional right to a lesser extent. It also remains possible that the law imposes a grievous infringement on a constitutional right for the sake of realizing an obligatory public purpose to a trivial extent. Treating public purposes as trumps over constitutional rights would undermine the modern constitutional project because the protections that rights extend to their bearers could be swept away whenever a constitutional conflict emerges. I will return to this point in my discussion of Ronald Dworkin's approach to rights, below.

Since the modern constitutional state is committed to purposive interpretation and purposive interpretation generates a multiplicity of constitutional conflicts, the modern constitutional state 
requires a doctrine that formulates the duty of government in cases of constitutional conflict. In the next section, I will present proportionality as that doctrine.

\section{Proportionality and the Duty of Public Justice}

Every student of constitutional law remembers their first encounter with the strange vocabulary and sprawling steps that make up the doctrine of proportionality. Although proportionality is, at first glance, a baffling doctrine, it is not simply a miscellaneous aggregate of unrelated requirements. It is instead a conceptually sequenced doctrinal distillation of the set of conditions under which government is justified in limiting a constitutional right through law.

The normative structure of modern constitutionalism frames what it means to justify the limitation of a constitutional right. A modern constitutional state makes the satisfaction of the duty to govern justly the legal condition for the valid exercise of public authority. In turn, the duty to govern justly requires that government direct its public authority towards bringing the legal order as a whole into the deepest possible conformity with the ideal of public justice. Because constitutional rights are determinations of this ideal, to justify a law that limits a constitutional right, government must establish that the limitation is required by its duty to govern justly. It is possible to justify the limitation of a right because the duty incumbent on government is not to regard any particular determination of the ideal of public justice as absolute, but to bring the existing legal order as a whole into the deepest possible conformity with public justice. ${ }^{22}$

The abstract question of whether the realization of this ideal is furthered to a greater extent by upholding a right or limiting it through law is difficult for public officials to conceptualize and relate to legal particulars. Just as a bill of rights renders the right of persons to public justice more determinate so that public officials can apply it to legal particulars, so the doctrine of proportionality

\footnotetext{
${ }^{22}$ For an elaboration of this point in the context of Kant's theory of public right, see Jacob Weinrib, "Permissive Laws
} and the Dynamism of Kantian Justice," Law and Philosophy (forthcoming 2013). 
renders the idea of a justification more determinate by setting out the conditions that government must satisfy to demonstrate that a law limiting a constitutional right is required by the duty to govern justly.

I will present the justification for the limitation of a constitutional right in three stages. The first stage, which precedes the proportionality analysis, asks whether the impugned law pursues the kind of purpose that could justify the limitation of a constitutional right, an obligatory public purpose. The steps that make up the second stage focus on the relationship between the purpose that the law pursues and the rights-infringing means that it employs. At issue is whether the rights-infringing means that the law employs contribute to the purpose that the law pursues and whether these means pursue the purpose in a manner that minimally impairs the right. Whereas the first stage concerns the purpose of the law and the second concerns the relationship between the purpose that the law pursues and the rights-infringing means that it employs, the third and final stage considers the extent of both the rights-infringement and the realization of the obligatory public purpose and asks whether the ideal of public justice would be furthered to a greater extent by limiting the right or by invalidating the law.

The conditions for justifying the limitation of a constitutional right form a conceptual sequence. The first stage concerns the possibility of a constitutional conflict, the second concerns the actuality of a constitutional conflict, and the third concerns the necessity of responding to the conflict by limiting a constitutional right. Each of these stages is increasingly demanding and presupposes the satisfaction of the preceding stage. In the absence of an actual constitutional conflict between a right and an obligatory public purpose, the duty to govern justly cannot necessitate the limitation of a constitutional right. In turn, there cannot be an actual constitutional conflict if the impugned law does not pursue the kind of purpose that makes a constitutional conflict possible. Because each stage presupposes the satisfaction of the preceding stages, the failure to establish a particular link in the 
chain of justification indicates not only that the infringement of the right cannot be justified, but also that no subsequent link in the chain of justification can be forged.

At each stage of this justificatory sequence, the onus lies upon the government. ${ }^{23}$ The placement of the onus reflects the relationship between public authority and public justice that lies at the heart of the modern constitutional paradigm. Since modern constitutionalism makes public justice the condition for the valid exercise of public authority and conceives of constitutional rights as determinations of the ideal of public justice, the validity of a law that infringes a constitutional right is called into question. Accordingly, if government seeks to uphold the validity of legislation that infringes a constitutional right, it must displace the presumption of invalidity by demonstrating that the infringement accords with its duty to govern justly. Alternately, if government could uphold the validity of legislation that infringes a constitutional right without establishing that the legislation is compatible with its duty to govern justly, modern constitutionalism would not be true to its animating idea that public justice forms the standard for the valid exercise of public authority. ${ }^{24}$

In what follows, I provide a theoretical exposition of the doctrine of proportionality. My claim is that its components comprise a sequenced elaboration of the conditions under which the duty of public justice mandates the limitation of a particular constitutional right. Since each component must

${ }^{23}$ R. v. Oakes, 136-7: "The onus of proving that a limit on a right or freedom guaranteed by the Charter is reasonable and demonstrably justified in a free and democratic society rests upon the party seeking to uphold the limitation." For a similar approach in South African context, see S. v. Makwanyane and Another, para. 102.

${ }^{24}$ Competing theories of proportionality often fail to appreciate the significance of this onus. Mattias Kumm, for example, presents proportionality as an institutionalization of a Socratic process of public reasoning about whether a coercive act might reasonably be accepted by the free and equal citizens affected by it. See Kumm, "The Idea of Socratic Contestation and the Right to Justification: The Point of Rights-Based Proportionality Review," Law \& Ethics of Human Rights 4 (2010): 141-175. While Kumm's Socratic analogy captures an aspect of the rationality to which proportionality aspires, it fails to capture a crucial feature that underlies proportionality analysis. The parties to a Socratic debate, being equal citizens, enter the debate on symmetrical terms: no party carries an argumentative burden that the other parties to the debate lack. The public law context of constitutional adjudication is fundamentally different because the burdens that each party must discharge are determined by the position that each occupies in the public law relationship. Within this relationship, private persons have a right to just governance that imposes a corresponding obligation on all public power. Since the modern constitutional state makes the satisfaction of this obligation the condition for the valid exercise of public power, when government has infringed a constitutional right, government bears the onus of justification. What counts as an adequate engagement in public reasoning is determined by the juridical structure of the relationship that obtains between the parties. 
be satisfied for the limitation of the right to be consistent with the duty of public justice, the failure to satisfy even a single component indicates that government has violated the duty of public justice. Within the modern constitutional state, such a failure indicates that the impugned law has not satisfied the constitutional standard of legal validity.

In this section, I will focus primarily on the Canadian formulation of the doctrine, in which a purpose requirement precedes the application of the three proportionality conditions. While the application of the proportionality doctrine in Canadian courts differs slightly from the German approach, ${ }^{25}$ the difference between the conditions that make up the doctrine of proportionality in each jurisdiction is largely terminological. Accordingly, I will illustrate my discussion of these conditions by drawing on cases from both Canada and Germany.

\section{The Possibility of a Constitutional Conflict: The Purpose Requirement}

Not every purpose can justify the limitation of a constitution right. Recall that a limitation is justifiable only if it is consistent with the duty of public justice, which requires government to bring the existing legal order into the deepest possible conformity with the ideal of public justice. Each constitutional right is a determination of this ideal. Since the duty of government is to bring the legal order as a whole into the deepest possible conformity with the ideal of public justice rather than to safeguard any particular determination of that ideal, particular determinations of it may, in principle, be justifiably limited. However, the very notion of a justifiable limitation applies only to cases in which the limitation is itself directed towards a determination of the ideal of public justice (or what I have called an obligatory public purpose). For if the purpose of the limitation is extrinsic to this ideal, then the limitation constrains a particular determination of this ideal without furthering another. The realization of the ideal of public justice is not advanced by measures that simply constrain one (or

${ }^{25}$ Grimm, "Proportionality in Canadian and German Constitutional Jurisprudence,” 383-397. 
more) of its determinations. Within the modern constitutional state, considerations of public justice underlie all constitutional rights and all justifiable limitations. ${ }^{26}$

An illustration of the purpose requirement arises in R. v. Big M Drug Mart. ${ }^{27}$ At issue was the constitutionality of the Lord's Day Act, which prohibited persons from engaging in "work, business, or labour" on Sunday. ${ }^{28}$ After interpreting the "freedom of conscience and religion" provisions entrenched in Canada's Charter of Rights and Freedoms purposively as reflecting the "valuation of human dignity", ${ }^{29}$ the Supreme Court of Canada held that the Act violated the right of each Canadian to choose his or her own religious practices. The problem with the Lord's Day Act was not that the rights at issue brook no limitation, but that they cannot be justifiably limited for the sake of purposes that are extrinsic to the ideal of public justice, or what the Supreme Court of Canada terms the values or principles of a free and democratic society. As Chief Justice Dickson would explain on a subsequent occasion, the infringement of a constitutional right may not be justified by "objectives which are trivial or discordant with the principles of a free and democratic society...It is necessary, at a minimum, that an objective relate to concerns which are pressing and substantial in a free and democratic society before it can be characterized as sufficiently important."30 By affirming "religious values rooted in Christian morality and, using the force of the state" to impose them on "believers and non-believers alike", ${ }^{1}$ the Lord's Day

${ }^{26}$ Canada (Human Rights Commission) v. Taylor [1990] 3 S.C.R. 892, 916. See also Barak, "Proportional Effect: The Israeli Experience," University of Toronto Law Journal 57 (2007): 382: "human rights and the limitations on them derive from the same source. They reflect the same values."

27 [1985] 1 S.C.R. 295.

${ }^{28}$ Lord's Day Act, R.S.C. 1970, c. L-13, s. 4.

${ }^{29}$ R. v. Big M Drug Mart Ltd., 346.

${ }^{30}$ R. $v$. Oakes, 138-9. For an account of private purposes that cannot lawfully constrain the enjoyment of rights under the Charter, see Lorraine Eisenstat Weinrib, "Canada's Constitutional Revolution: From Legislative to Constitutional State," Israel Law Review 33 (1999): 33: “The limitation clause involves the values of a 'free and democratic society', as the standard of justification for limits on rights. The Supreme Court has read this standard as embodying the values that constitute the genesis of the rights guarantees themselves. Accordingly, the court has dismissed arguments based on non-prohibitive cost, convenience, administrative expediency, and tradition..."

${ }^{31}$ R. v. Big M Drug Mart Ltd., 337. 
Act subordinated a right that was integral to a free and democratic society to a purpose that was "fundamentally repugnant" to that ideal. ${ }^{32}$

That a rights-infringing law pursues an obligatory public purpose establishes the possibility of a constitutional conflict between determinations of the ideal of public justice. The subsequent stages, which form the doctrine of proportionality, center on whether a constitutional conflict actually obtains and whether it necessitates the limitation of a constitutional right.

\section{The Actuality of a Constitutional Conflict: The Rational Connection and Minimal Impairment Requirements}

The initial steps of the proportionality analysis establish the actuality of a constitutional conflict by considering the relationship between the rights-infringing means that the law employs and the obligatory public purpose that the law pursues. These steps include the rational connection and minimal impairment requirements.

To satisfy the rational connection requirement, the government must establish that the rightsinfringing means that the law employs are conducive to the realization of the law's purported purpose. $^{33}$ If the government fails to satisfy this condition, the impugned law cannot be justified because it employs means that limit a constitutional right for the sake of realizing a public purpose

\footnotetext{
32 Ibid., 352.

While a law that limits a constitutional right for the sake of a purpose antithetical to the realization of public justice cannot be justified, one might ask about the constitutional status of a law that pursues a purpose that is neither hostile to the ideal of public justice nor itself an aspect of that ideal. Different constitutional states implement the public purpose requirement in different ways, which may be compatible with a rigorous approach to justifying the limitation of constitutional rights. In Canada, to satisfy the public purpose requirement, government must establish that the impugned law pursues a pressing and substantial purpose, that is, a purpose of sufficient importance to justify the limitation of a constitutional right. Thus, Dickson C.J. indicates in Oakes that not only will objectives that are "discordant" with the principles of a free and democratic society fail to satisfy the requirement, but also principles that are merely "trivial." In Germany, in contrast, the standard is lower: the impugned law must merely pursue a lawful purpose, that is, a purpose that the constitution does not prohibit. The question of whether a lawful purpose has sufficient weight to justify the limitation of a constitutional right is addressed in the final stage of the proportionality analysis. On these points of contrast, see Dieter Grimm, "Proportionality in Canadian and German Constitutional Jurisprudence," 388-9.

33 Barak, Proportionality: Constitutional Rights and Their Limitations, 315; Patrick Quirk, "An Australian Looks at German 'Proportionality'," University of Notre Dame Australia Law Review 1 (1999): 42 (“...the appropriateness requirement strikes at a lack of causal connection between chosen means and the desired end").
} 
that the rights-infringing means do not advance. In such cases, the justification for limiting the constitutional right fails because no matter how just the law's purpose, the realization of this purpose is not furthered by the means that the law employs. ${ }^{34}$ The actuality of a constitutional conflict is not established by the mere assertion that a law pursues an obligatory public purpose.

An example of the failure to satisfy the rational connection requirement (or what in Germany is called suitability) arises in Germany's Falconer Hunting License case. ${ }^{35}$ An amendment to the Federal Hunting Act required falconers to demonstrate both "technical knowledge" of guns and "proficiency on a firing range" in order to obtain a falconry license. A falconer raised a constitutional complaint alleging that the amendment was unconstitutional because it violated his right to the free development of his personality. ${ }^{36}$ The Federal Constitutional Court of Germany held that even though government may regulate hunting for the sake of public safety, the amendment was unconstitutional because falconry does not involve the use of guns to hunt falcons but the use of falcons to hunt other animals. Accordingly, the requirement that falconers pass a test indicating their knowledge of and proficiency with guns was an arbitrary restriction on their freedom that did nothing to advance the purpose of public safety. In the words of the Court, "No apparent reason can be found for the amendment...It is not justifiable to establish barriers completely extraneous to the exercise of falconry." ${ }^{37}$

The presence of a rational connection between the rights-infringing means that the law employs and the obligatory public purpose that the law pursues is not sufficient to justify the limitation of a constitutional right. Even when a rational connection has been established, it remains possible

\footnotetext{
34 See Denise Réaume (forthcoming): "The proffered objective might well be important, but it does not ground the impugned provision; it therefore cannot transfer its justificatory power to that provision."

${ }^{35}$ See BVerfGE 55, 159 (1980), http:/ /www.servat.unibe.ch/dfr/bv055159.html. Brief synopses of this case can be found in Grimm, "Proportionality in Canadian and German Constitutional Jurisprudence," 389; Quirk, "An Australian Looks at German 'Proportionality'," 42-3; and Kommers, Constitutional Jurisprudence of the Federal Republic of Germany, 323-4.

${ }^{36}$ Quirk, "An Australian Looks at German 'Proportionality'," 42.

37 BVerfGE 55, 159 ("Für die Gesetzesänderung lasse sich kein einleuchtender Grund finden. ...Es sei aber nicht gerechtfertigt, völlig sachfremde Barrieren gegen die Ausübung der Beizjagd zu errichten”).
} 
that the obligatory public purpose could be achieved through legislative means that are less injurious of the constitutional right. To satisfy the minimal impairment requirement, government must demonstrate the absence of alternative means that would achieve the purpose of the impugned law to a similar extent while imposing a lesser infringement on the constitutional right. ${ }^{38}$ When a variety of means are equally effective in achieving an obligatory public purpose, government must employ the means that are least intrusive of constitutional rights. ${ }^{39}$ The failure to do so violates the duty of public justice because no matter how integral the purpose of a law is to the realization of public justice, a law that is not minimally impairing gratuitously infringes a constitutional right. Government cannot claim to bring the legal order into the deepest possible conformity with the ideal of public justice when it gratuitously infringes a determination of that ideal.

The justificatory sequence cannot end with the satisfaction of the minimal impairment requirement. If the proportionality analysis concluded with minimal impairment, then it would be possible that "a quite negligible public interest could lead to a severe rights infringement, without being unlawful." ${ }^{40}$ Dieter Grimm provides an example of such a possibility. Suppose that a law "allows the police to shoot a person to death if this is the only means of preventing a perpetrator from destroying property." 41 The protection of property forms an important public purpose of a legal order. A rational connection certainly obtains between killing perpetrators and protecting property. The minimal impairment requirement is also satisfied insofar as the law specifies that shooting is permitted only in cases in which there are no other means of protecting property. If the proportionality analysis concluded with the minimal impairment requirement, then any obligatory

\footnotetext{
${ }^{38}$ R. v. Big M Drug Mart Ltd., 352; R. v. Oakes, 139.

39 Sweet and Matthews, 105 (quoting Rupprecht von Krauss, Der Grundsatz der Verbältnismässigkeit in seiner Bedeutung für die Notwendigkeit des Mittels in Verwaltungsrecht (Hamburg: 1955): 25: “П] would be a contradiction to raise personal freedom to the leading state principle and at the same time to permit unnecessary restrictions of this freedom by the state to be considered lawful...”).

${ }^{40}$ Ibid. (citing Krauss, 15).

${ }^{41}$ Grimm, "Proportionality in Canadian and German Constitutional Jurisprudence," 396.
} 
public purpose could justify the limitation of any constitutional right to any extent. But as Grimm's example indicates, even a minimally impairing rights-infringement can have grave implications for rights bearers. The reason why the minimal impairment requirement cannot conclude the justificatory sequence of proportionality is that minimal impairment, like rational connection, simply concerns the relationship between the means that the law employs and the purpose that the law pursues. Since the minimal impairment requirement focuses on whether there is a way of achieving the relevant purpose to a comparable extent that is less rights-infringing, the availability of alternative means that are less rights-infringing but that achieve the relevant purpose to a lesser extent are without significance. As Barak observes, "[o]nly if it is possible to realize the objects of the statute by less drastic means does this step grant protection to human rights." ${ }^{42}$

The satisfaction of the minimal impairment requirement establishes a genuine constitutional conflict between determinations of public justice. A constitutional conflict involves a collision between particular determinations of public justice that cannot be jointly satisfied. The conflict is genuine because both the purpose that the impugned law pursues and the constitutional right that the law infringes are determinations of public justice and it is not possible for government to pursue the purpose without infringing a constitutional right. Since these determinations of public justice cannot both be realized undiminished, we must ask what the duty of public justice requires with respect to them. This question occupies the final stage of the proportionality analysis.

\section{The Necessity of Limiting a Constitutional Right: The Proportionality Stricto Sensu Requirement}

The proportionality stricto sensu requirement encapsulates the duty of public justice in cases of constitutional conflict. The term 'proportionality stricto sensu' was coined by the German administrative law scholar Rupprecht Krauss, who conceived of it in terms of "relating two or more quantities that

\footnotetext{
42 "Proportional Effect: The Israeli Experience," 373.
} 
can be set against a common yardstick". ${ }^{43}$ I have argued that the common yardstick that underlies both the purposive interpretation of constitutional rights and the purposes on which limitations of constitutional rights must be justified is public justice. In a modern constitutional state, the ideal of public justice forms the moral basis of all constitutional rights and all purposes that justify their limitation. As Chief Justice Dickson explained in Canada's seminal case on the limitation of constitutional rights:

The underlying values and principles of a free and democratic society are the genesis of the rights and freedoms guaranteed by the Charter and the ultimate standard against which a limit on a right or freedom must be shown, despite its effect, to be reasonable and demonstrably justified. ${ }^{44}$

To satisfy the proportionality stricto sensu requirement, government must establish that the law limiting a constitutional right nevertheless furthers the realization of the ideal of public justice within the constitutional order. It is in this sense that the doctrine of proportionality justifies the limitation of a constitutional right. The limitation of a constitutional right is justified in those cases of constitutional conflict in which the limitation of the particular constitutional right is necessary to advance the realization of public justice within the legal order as a whole. In the Canadian formulation, proportionality stricto sensu "provides an opportunity to assess, in light of the practical and contextual details which are elucidated in the [preceding] stages, whether the benefits which accrue from the limitation are proportional to its deleterious effects as measured by the values underlying the Charter." 45 The more deeply a law infringes a constitutional right, the greater the justificatory burden incumbent on government. ${ }^{46}$

\footnotetext{
43 Sweet and Matthews, 105 (citing Krauss, 14).

44 R. v. Oakes, 136.

45 Thomson Newspapers Co. v. Canada (Attorney General), [1998] 1 S.C.R. 877, 969.

${ }^{46}$ R. $v$. Oakes, 140.
} 
One of the reasons that the doctrine of proportionality is so troubling for legal philosophers and constitutional theorists is that it emerges at the intersection of two sets of issues that they typically prefer to keep separate. The first issue concerns the ends that government may legitimately pursue. The second concerns the means that government may legitimately employ. If one thinks about each of these issues in isolation from the other, then one is led to the conclusion that state action is unobjectionable so long as it employs legitimate means to pursue a legitimate end. This is exactly what the proportionality stricto sensu requirement denies. A law that pursues an obligatory public purpose by employing means that are both rationally connected to that purpose and minimally impairing of an infringed constitutional right may nevertheless be unjustified because, given the extent of the rightsinfringement and the extent to which the limitation realizes (or is likely to realize) an obligatory public purpose, the ideal of public justice is furthered more by the right than it would be by the limitation.

Proportionality stricto sensu constitutes the final link in a chain of increasingly demanding justificatory conditions that form the doctrine of proportionality. Because each condition is more demanding than the one that preceded it, the failure to satisfy a single condition renders it impossible to satisfy any of the subsequent ones. Government cannot satisfy the proportionality stricto sensu condition if the minimal impairment condition remains unsatisfied because to the extent that the rights infringement is gratuitous, the importance of realizing the obligatory public purpose cannot justify it. Government cannot satisfy the minimal impairment condition if the rational connection condition that precedes it remains unsatisfied because if the rights-infringing means do not further the realization of the purpose, the purpose could be achieved without limiting a right, which means that the law is not minimally impairing. Finally, government cannot satisfy the rational connection condition by establishing that the rights-infringing means contribute to the realization of an obligatory public purpose if the law does not pursue such a purpose. Because each stage of the justificatory sequence raises a condition that presupposes the satisfaction of any earlier stage, the failure to satisfy a single 
stage culminates in the failure to satisfy all subsequent ones. In any failed justification, the proportionality stricto sensu condition remains unsatisfied.

While proportionality stricto sensu is the most demanding stage in the justificatory sequence, the justification for limiting a constitutional right cannot be reduced to it. Proportionality stricto sensu applies to cases of constitutional conflict in which the demands of competing determinations of public justice collide. Accordingly, the application of proportionality stricto sensu presupposes a set of prior determinations. The very notion of a constitutional conflict obtaining between determinations of public justice presupposes, on the one hand, that purposive interpretation of the relevant right has revealed an infringement and, on the other, that the means that the impugned law employs are rationally connected to an obligatory public purpose and minimally impairing of the right. Since proportionality stricto sensu requires the judiciary to assess whether the limitation of the constitutional right is necessary to advance the realization of public justice within the constitutional order, the judiciary must consider each pole of the constitutional conflict from the standpoint of public justice. The prior purposive interpretation of a constitutional right makes it possible for the judiciary to consider the significance of the infringement from the standpoint of the ideal of public justice. In turn, the obligatory public purpose requirement enables the judiciary to consider the law that infringes a constitutional right from the same standpoint. The proportionality stricto sensu analysis must also be preceded by the rational connection and minimal impairment conditions. For the proportionality stricto sensu condition sets out the duty of government in cases of constitutional conflict, but if government has not satisfied the rational connection and minimal impairment conditions, then it is not clear that the case at hand involves a constitutional conflict. Accordingly, the determination of whether the proportionality stricto sensu condition has been satisfied cannot be carried out in abstraction from the earlier stages of the justificatory sequence that it concludes. 
The duty of public justice integrates each of the conditions that make up the doctrine of proportionality into a justificatory sequence. Together, the various stages of proportionality analysis constitute a sequenced normative inquiry in which no stage is redundant and no stage is applicable apart from any of the others. This account therefore departs from those who reduce proportionality to its initial stages while deeming proportionality stricto sensu to be superfluous, ${ }^{47}$ or who conceive of proportionality solely in terms of its stricto sensu aspect, ${ }^{48}$ or who suggest that the logic running through the earlier stages is intelligible in isolation from the concluding one. ${ }^{49}$ Further, the theory of proportionality that I have presented departs from those who conceive of proportionality as a doctrine that transforms controversial questions of value into simple "questions of fact." 50 Insofar as proportionality involves a clash between determinations of public justice, it cannot be a purely factual inquiry devoid of normativity. It is instead a normative inquiry that establishes the relevance of certain factual considerations.

\footnotetext{
${ }^{47}$ Because of the small role that proportionality stricto sensu has played in Canadian constitutional jurisprudence, Canadian constitutional theorists sometimes suggest that proportionality stricto sensu is a redundant stage in the proportionality analysis. On this point, see P.W. Hogg, Constitutional Law of Canada, vol. II (Toronto: Thomson Carswell, 2007) 153: "If the objective is sufficiently important, and the objective is pursued by the least drastic means, then it must follow that the effects of the law are an acceptable price to pay for the benefit of the law. I conclude, therefore, that an affirmative answer to the first step - sufficiently important objective - will always yield an affirmative answer to the fourth step - proportional effect." Like Hogg, Alan Brudner conceives of the proportionality stricto sensu as a redundant stage in the analysis that repeats the public purpose requirement. See Brudner, "What Theory of Rights Best Explain the Oakes Test?", in The Limitation of Charter Rights: Critical Essays on R. v. Oakes, ed. Gregoire Webber and Luc Tremblay (Montreal: Les Editions Themis, 2009), 59-74. Brudner defends a pluralist-paradigm theory of proportionality rooted in a Hegelian account of the relationship between individual autonomy and the common good. After disqualifying competing theories for failing to illuminate the practice of proportionality, Brudner concedes that within his own framework "no further justificatory work is left" for the proportionality stricto sensu condition (73). In contrast, I have suggested that the overarching justification that traverses the doctrine of proportionality cannot end with minimal impairment. Minimal impairment merely establishes that there is no way of pursuing the relevant purpose without infringing a constitutional right. It does not establish that the realization of public justice within the constitutional order is advanced by the limitation.

48 Tsakyrakis, 474.

${ }^{49}$ Réaume, "Limitations on Constitutional Rights: The Logic of Proportionality".

50 See D.M. Beatty, The Ultimate Rule of Law (Oxford: Oxford University Press, 2004), 170. Beatty claims that proportionality makes the controversies surrounding, for example, abortion or discrimination on the basis of religion or gender or even socio-economic entitlements entirely dependent "on the factual details of each case." For criticisms of Beatty's exposition of proportionality, see Brudner, "What Theory of Rights Best Explain the Oakes Test?”, 69-70; CharlesMaxime Panaccio, "In Defence of Two-Step Balancing and Proportionality in Rights Adjudication," Canadian Journal of Law and Jurisprudence 24 (2011): 118; Barak, Proportionality: Constitutional Rights and Their Limitations, 476-480; Webber, 186190; Tsakyrakis, 468-493.
} 
In this section, I have argued that proportionality is a doctrine for determining the duty of government in cases of constitutional conflict. The purpose condition establishes the possibility of a constitutional conflict between a constitutional right and a law that seeks its limitation. The rational connection and minimal impairment conditions establish the actuality of a constitutional conflict between the right and the limit. The proportionality stricto sensu condition requires the judiciary to determine whether government has established that its duty to govern justly necessitates the limitation of a constitutional right. In the section that follows, I will elaborate upon this conception of the proportionality stricto sensu requirement by contrasting it with the conception that flows from a competing theory.

\section{ALEXY'S THEORY OF PROPORTIONALITY}

The theory of proportionality that I outlined in the prior section emerges from an account of the duty that accompanies the exercise of public authority in a modern constitutional state. By illuminating the doctrine of proportionality from the standpoint of the duty of public justice, I depart from Robert Alexy's influential theory of proportionality. This section explains what it means within each theory to justify the limitation of a constitutional right. My claim is that Alexy's conception of justification is incompatible with the conception of rights at work in modern constitutional states in general, including Germany.

In $A$ Theory of Constitutional Rights, Alexy develops "a general legal theory of the constitutional rights of [Germany's] Basic Law." ${ }^{21}$ The theory is general insofar as its purpose is not to consider "specific problems of specific rights," but to explore "problems common to all constitutional rights". ${ }^{2}$ The theory is legal insofar as it engages with the "evaluative questions which have been left open by

51 (Oxford: Oxford University Press, 2002), 5.

52 Ibid., 10. 
the authoritative materials at hand." 53 These materials include the constitutional rights entrenched in Germany's Basic Law. ${ }^{54}$ By focusing on the constitutional rights found in Germany's Basic Law, Alexy distinguishes his project from those who offer historical theories of constitutional rights valid in prior ages and those who offer philosophical theories of constitutional rights "independent of positive law". ${ }^{55}$ The general, legal, and constitutional aspects of Alexy's project enable him to raise a general question about particular constitutional cases: Given a certain factual and legal context, what is the morally correct decision ${ }^{56}$

The basis of Alexy's theory lies in a distinction between two kinds of norms, principles and rules:

The decisive point in distinguishing rules from principles is that principles are norms which require that something be realized to the greatest extent possible given the legal and factual possibilities. Principles are optimization requirements, characterized by the fact that they can be satisfied to varying degrees, and that the appropriate degree of satisfaction depends not only on what is factually possible but also on what is legally possible. The scope of the legally possible is determined by opposing principles and rules.

By contrast, rules are norms which are always either fulfilled or not. If a rule validly applies, then the requirement is to do exactly what it says, neither more nor less. In this way rules contain fixed points in the field of the factually and legally possible. This means that the distinction between rules and principles is a qualitative one and not one of degree. Every norm is either a rule or a principle. ${ }^{57}$

\footnotetext{
${ }^{53}$ Ibid., 8

${ }^{54}$ Ibid., 5.

55 Ibid., 3.

56 Ibid., 8.

57 Ibid., 47-8. Alexy's distinction between rules and principles echoes Dworkin's account in Taking Rights Seriously (Cambridge: Harvard University Press, 1978). Dworkin argues that rules “are applicable in an all-or-nothing fashion” (24). If a rule is valid and the facts that it stipulates are given, then the outcome that the rule requires must be accepted. In contrast, principles do not require a certain outcome in a certain context, but rather are reasons that carry weight. Alexy, like Dworkin, holds that valid rules cannot conflict and that conflicts between principles are to be resolved by considering their relative weight.
} 
The distinction between principles and rules turns on the respective conditions of their satisfaction. A principle is satisfied when it is optimized, that is, realized to the greatest extent possible. Whereas a principle can be satisfied to varying extents, a rule is a binary norm: it is either satisfied or unsatisfied.

Alexy deepens his distinction between rules and principles by setting out what each kind of norm requires in cases of conflict. Given the binary structure of a rule, a conflict between rules can be resolved only by declaring one of the rules invalid or by narrowing the scope of one of the rules by reading an exception into it. ${ }^{58}$ In Alexy's example, the rule requiring students to remain in class until the bell rings conflicts with the rule requiring students to leave the class at once when the fire alarm sounds. Since one cannot both remain in class until the bell rings and leave before the bell rings, one must either read an exception into the former rule by requiring persons to remain in class until the bell rings unless the fire alarm sounds or declare that one of the rules is invalid. In contrast, when principles come into conflict, the conflict is resolved by asking which principle, in the context of the prevailing circumstances, outweighs the other. ${ }^{59}$ A principle must yield when it is confronted by a competing principle that, in the situation at hand, carries greater weight. ${ }^{60}$

Alexy's "central thesis" is that "constitutional rights are principles and that principles are optimization requirements." ${ }^{\prime 1}$ As optimization requirements, conflicts between principles are to be resolved in terms of balancing the competing principles on the basis of their weight in the relevant instance. Alexy formulates this weighing of principles in terms of what he calls the Law of Balancing: "The greater the degree of non-satisfaction of, or detriment to, one principle, the greater must be the importance of satisfying the other." ${ }^{2}$ Alexy claims that the Law of Balancing is "identical" to the final stage of proportionality analysis, proportionality stricto sensu. ${ }^{63}$

\footnotetext{
58 A Theory of Constitutional Rights, 49.

59 Ibid., 50.

${ }^{60}$ Ibid., 58.

${ }^{61}$ Ibid., 388.

62 Ibid., 401.

${ }^{63}$ Ibid.
} 
At first glance, Alexy's theory of proportionality may seem to coincide with the approach formulated in the prior section. Alexy claims that the constitutional rights in Germany's Basic Law are optimization principles that must be realized to the greatest extent possible. I have argued that government must optimize the extent to which the existing legal system as a whole conforms to the ideal of public justice. While both theories involve the notion of optimization, a subtle but significant distinction obtains with respect to what each theory seeks to optimize. The unified theory is a general theory of public law that culminates in an account of why it is obligatory for states to adopt modern constitutional arrangements. Within the unified theory, what government must optimize is the extent to which the existing legal system as a whole conforms to the ideal of public justice. Since constitutional rights and obligatory public purposes are aspects of this ideal, the duty of the state is to arrange them in such a manner that the legal order as a whole stands in the greatest possible conformity to the ideal of public justice. In contrast, Alexy's theory begins by taking for granted the existence of certain constitutional norms and adjudicative arrangements within the Federal Republic of Germany, asserting that rights are principles or optimization requirements, and then considering what moral correctness requires in cases in which a conflict obtains between discrete constitutional principles when each calls for optimization. Such an approach generates a distinctive conception of constitutional rights. Where the unified theory conceives of constitutional rights as determinations of an overarching conception of public justice that must itself be optimized, Alexy conceives of particular constitutional rights as discrete principles that require optimization.

These divergent conceptions of constitutional rights culminate in divergent interpretations of the final step of the proportionality analysis, proportionality stricto sensu. When the proportionality stricto sensu requirement is formulated - whether in the arguments of lawyers, the judgments of courts, or the frameworks of constitutional theorists - formulations bearing two distinctive meanings are often invoked as though they were equivalent. Some implicitly follow Alexy's approach, captured in 
his Law of Balancing, in which proportionality is conceived of in terms of striking an appropriate balance between two discrete principles that conflict with one another. On this view, in cases of conflict, what must be optimized are the particular principles that stand in conflict. ${ }^{64}$ The unified theory of public law provides a theoretical basis for the contrasting view that, in a modern constitutional state, constitutional conflicts obtain not between competing particulars that must be optimized, but between conflicting determinations of an underlying norm. When such conflicts arise, the duty of government is to optimize the realization of the underlying norm rather than the particular determinations of it.

The divergence between these conceptions of the proportionality stricto sensu requirement may seem to be merely rhetorical, but laws can stand and fall on the basis of how courts conceptualize the proportionality stricto sensu requirement. In R. v. Keegstra, ${ }^{65}$ the Supreme Court of Canada considered the constitutionality of a provision of the Criminal Code that prohibited public acts that wilfully promoted hatred against identifiable groups. ${ }^{66}$ James Keegstra, a former high school teacher, was charged under this provision for anti-Semitic teachings, which claimed that Jews were "inherently evil", hostile to Christians, and responsible for all the evils of the world, whether moral, political, or economic. ${ }^{67}$ The majority and dissenting judgments of the Supreme Court of Canada agreed that Keegstra's right to freedom of expression was infringed and that the provision pursued a pressing and substantial purpose by promoting dignity, equality, and multiculturalism and opposing racial, ethnic, and religious hatred. However, in considering whether the infringement of freedom of expression was justified, the Court split 4-3, with the majority and the dissent each appealing to a distinctive conception of the proportionality stricto sensu requirement. McLachlin J.'s dissent illustrated Alexy's approach by conceiving of rights and limits as discrete particulars that call for optimization. In contrast, Dickson C.J.'s majority followed the

\footnotetext{
${ }^{64}$ For similar conception of proportionality, see Bruce Chapman, "Law, Incommensurability, and Conceptually Sequenced Argument," University of Pennsylvania Law Review 146 (1998): 1492.

65 [1990] 3 S.C.R. 697.

${ }^{66}$ Criminal Code, R.S.C. 1985 , c. C-46, s. $319(2)$.

${ }^{67}$ R. $v$. Keegstra [1990] 3 S.C.R. 697, 714.
} 
approach that I have elaborated by conceiving of the proportionality stricto sensu requirement as involving the determination of whether the realization of Charter values are furthered more by the right or by its limitation. While there are a variety of bases on which these judgments can be contrasted both in the way they interpret the right and in the way they conceptualize and apply the earlier stages of the proportionality analysis, I will focus on the distinctive conceptions of proportionality stricto sensu that arise in each.

Dickson C.J.'s majority judgment presents the "underlying values of a free and democratic society" ${ }^{88}$ as forming, on the one hand, the basis of Charter rights and freedoms, and, on the other, "the ultimate standard against which a limit on a right or freedom must be shown, despite its effect, to be reasonable and demonstrably justified." ${ }^{99}$ These values, as Dickson C.J. elaborated in Oakes, include

respect for the inherent dignity of the human person, commitment to social justice and equality, accommodation of a wide variety of beliefs, respect for cultural and group identity, and faith in social and political institutions which enhance the participation of individuals and groups in society. ${ }^{70}$

Because rights and limits are grounded in the constitutional values of a free and democratic society, Dickson C.J. proceeds to assess whether these values are more fully realized by the right or by its limitation. The Chief Justice notes that the kind of expressive activity that the provision prohibits involves the wilful and public promotion of hatred against members of identifiable groups. Since the purpose of such expression is to establish that "members of identifiable groups are not to be given equal standing in society, and are not human beings equally deserving of concern, respect and consideration", ${ }^{71}$ Dickson C.J. concludes that the prohibited expressive activity is "only tenuously connected with the values underlying the guarantee of freedom of speech." ${ }^{, 72}$ In contrast, the limitation seeks to diminish racism

\footnotetext{
68 Slaight Communications Inc. v. Davidson, [1989] 1 S.C.R. 1038, 1056.

${ }^{69}$ R. v. Oakes, 136.

70 Ibid.

${ }^{71}$ R. v. Keegstra, 756.

72 Ibid., 787.
} 
and "bolster the notion of mutual respect necessary in a nation which venerates the equality of all persons." ${ }^{, 73}$ As the constitutional conflict involves an expressive activity that is "wholly inimical" to the values of a free and democratic society and a limitation that furthers a purpose "central" to their realization, the Chief Justice concludes that the limitation is justified. ${ }^{74}$ The values that underpin freedom of expression are more fully realized by limiting the right than by invalidating the law that infringes it.

McLachlin J. conceived of proportionality stricto sensu in a strikingly different manner. Whereas Dickson C.J. approaches the proportionality stricto sensu requirement by considering both the right and the limitation in relation to the values of a free and democratic society, McLachlin J. echoes Alexy's approach by conceiving of both the right and the limitation as discrete values that must be balanced against one another. As McLachlin J. explains the proportionality stricto sensu requirement:

The analysis is essentially a cost-benefit analysis. On the one hand, how significant is the infringement of the fundamental right or freedom in question? On the other hand, how significant is the benefit conferred by the impugned legislation? Weighing these countervailing considerations, has the state met the burden upon it of establishing that the limit on the constitutionally guaranteed freedom or right is reasonable and demonstrably justified in a free and democratic society ${ }^{75}$

By considering both the severity of the rights infringement and the benefit conferred by the limitation as discrete values, McLachlin J. arrives at a different set of conclusions than Dickson C.J. Because McLachlin J. considers the severity of the infringement of freedom of expression in abstraction from the values of a free and democratic society, she deems the hateful character of the expression at issue to be of no significance in the proportionality analysis. ${ }^{76}$ Thus, where Dickson C.J. holds that the extent of the infringement is slight because the freedom to engage in hateful expression is antithetical to the values of

\footnotetext{
73 Ibid., 756.

${ }^{74}$ Ibid., 764.

75 Ibid., 863.

76 Ibid., 849.
} 
free and democratic society premised on the dignity of each of its members, McLachlin J. conceives of the infringement as severe simply because it imposes a content-based restriction on freedom of expression. Having characterized the cost of the infringement as severe and the prospect of benefits ensuing from the limitation as "questionable", McLachlin J. concludes that the infringement cannot be justified. ${ }^{77}$ For McLachlin, as for Alexy, rights and limits constitute distinct values rather than instances of an underlying norm.

Alexy's approach to proportionality stands in tension to the conception of rights at work in modern constitutional states, including Germany. Alexy presents a structural theory of rights, ${ }^{78}$ in which rights are conceptualized as an aggregate of individual principles, each of which calls for optimization. Such an approach clashes with the conception of rights found in Germany's Basic Law. As I noted in Chapter Four, Germany's Basic Law conceives of the rights that it entrenches as determinations of the juridical relationship between the dignified person and the coercive state. ${ }^{79}$ Article 1(1) of the Basic Law establishes the inviolability of human dignity and proclaims the duty of all state authority to respect and protect it. ${ }^{80}$ Having recognized the duty that human dignity places on all state authority, Article 1(2) ties the idea of human dignity to human rights: "The German people therefore acknowledge inviolable and inalienable human rights as the basis of every community, of peace and of justice in the world." ${ }^{\prime 1}$ Because human dignity imposes a duty on all state power, and the recognition of dignity involves a commitment to respect and protect rights, Article 1(3) establishes

\footnotetext{
${ }_{77}$ Ibid., 865.

${ }^{78}$ Alexy, $A$ Theory of Constitutional Rights, 11-13. For discussions of the moral neutrality of Alexy's structural conception of rights, see Mattias Kumm, "Constitutional Rights as Principles: On the Structure and Domain of Constitutional Justice," 575; Kai Möller, "Balancing and the Structure of Constitutional Rights," International Journal of Constitutional Law 5 (2007): 458 and 467; and David Bilchitz, "Does Balancing Adequately Capture the Nature of Rights?" South African Public Law 25 (2010): 423-444; Zucca, Constitutional Dilemmas: Conflicts of Fundamental Legal Rights in Europe and the US A, 21.

${ }^{79}$ Grimm, "Proportionality in Canadian and German Constitutional Jurisprudence," 387: "According to art. 1, all fundamental rights are rooted in the principle of human dignity."

${ }^{80}$ Grundgeset:

${ }^{81} \mathrm{Ibid}$.
} 
that the rights entrenched in the Basic Law themselves impose a duty on all state power: "The following basic rights shall bind the legislature, the executive and the judiciary as directly applicable law." 82 The articles that follow concretize the idea of human dignity by elaborating the constitutional rights that it involves.

One's conception of what a constitutional right is affects one's conception of what it would mean to justify the limitation of one. If constitutional rights are best conceived of as a series of particular optimization requirements, then Alexy's Law of Balancing provides the appropriate approach. But if constitutional rights are instead determinations of a more fundamental ideal that must itself be optimized, then a different approach is required. In cases of constitutional conflict, what must be optimized is not particular rights or obligatory public purposes but the underlying ideal that these particulars instantiate, human dignity or equal freedom under law. Insofar as Germany's Basic Law presents the idea of human dignity as imposing a fundamental duty on all public authority, which particular constitutional rights instantiate, neither the protections that rights extend to their bearers nor the justification for their limitation can be considered in abstraction from the idea of human dignity. The same point can be put in terms of Alexy's Law of Balancing. Because constitutional rights are determinations of human dignity, neither the importance of the right nor the importance of the competing principle can be considered in abstraction from the normative basis on which all rights rest. The duty of the modern constitutional state to perfect the legal order as a whole is not reducible to a list of isolated optimization requirements. By conceiving of rights in structural terms as discrete optimization requirements, Alexy distorts the normative structure of constitutional adjudication in a modern constitutional state.

Alexy conceives of proportionality stricto sensu in terms of striking an appropriate balance between rights and limits. I have avoided discussing the doctrine of proportionality in these terms

\footnotetext{
${ }^{82}$ Ibid.
} 
because the metaphor of balancing invites two kinds of misunderstandings. First, the metaphor suggests that any consideration that carries weight can be balanced against any other. This is exactly what the purpose requirement that precedes the proportionality analysis denies. There are certain kinds of considerations that cannot justify the limitation of a constitutional right, regardless of their degree or intensity. A determination of public justice cannot be justifiably limited to further the realization of a purpose extrinsic to that ideal. Second, the balancing metaphor suggests that proportionality is a scale on which the cost of infringing a constitutional right is weighed against the benefit obtained thereby. I have argued that when constitutional rights are conceived of as determinations of public justice, justification involves not weighing the importance of two particulars in abstraction from an overarching normative ideal, but the consideration of the place of each particular within a legal order committed to the deepest possible realization of a normative whole, the ideal of public justice. To the extent that the metaphor of a balance involves the weighing of particulars but makes no reference to the normative whole to which these particulars contribute, it distorts the conception of justification that traverses constitutional adjudication from the purposive interpretation of rights to the final step of the proportionality analysis.

Because proportionality seeks to maximize the realization of the ideal of public justice, which underlies both constitutional rights and obligatory public purposes, it might be confused with another monistic and maximizing theory, utilitarianism. The resemblance, however, is only apparent. As I noted in Chapter Three, a utilitarian theory posits some good - for example, pleasure, preference satisfaction, or welfare - that is of value apart from a legal system. On the utilitarian view, a legal system is of value to the extent that it contributes to the realization of some extrinsically valuable outcome. The ideal of public justice, in contrast, is internal to legal systems as such because it sets out what it would mean for a legal system to be adequate given the terms on which public authority, the constitutive feature of a legal system, is justified. Unlike a utilitarian theory, which specifies a 
conception of the good that is valuable apart from a legal system, the ideal of public justice or equal freedom under law is not of value (nor is it even conceivable) apart from a legal system. The distinction between the ideal of public justice and a utilitarian conception of the good is significant for thinking about rights and limitations in a modern constitutional state. Particular constitutional rights are valuable because they are an integral feature of legal ordering that is accountable to the right of persons to public justice. Purposive interpretation relates the scope of protections that a constitutional right offers not to a utilitarian conception of the good, but rather to public law's internal ideal of the appropriate relationship between the free individual and the coercive state. In turn, proportionality does not subject constitutional rights to utilitarian considerations. For utilitarian goods, whether the satisfaction of the preferences of the many or the greatest pleasure for the greatest number are not determinations of public justice and therefore cannot constitute an obligatory public purpose. Since the public purpose requirement precedes the proportionality analysis, questions about whether the limitation of a constitutional right is proportional to realization of some utilitarian good cannot arise. Proportionality is not an exercise in utilitarian calculus. Nor is utilitarianism the sole theory that seeks to give effect to morals ideals. As I have argued, the duty of public justice, which underwrites both constitutional rights and justified limitations, requires government to bring the existing legal order as a whole into the deepest possible conformity with its own internal standard of adequacy, equal freedom under law. I further distinguish proportionality from utilitarianism in the ensuing section.

\section{CRITICS OF PROPORTIONALITY}

While proportionality has enjoyed widespread acceptance in constitutional practice, it has generated widespread opposition from constitutional theorists who reject the very notion that the limitation of a constitutional right can be justified. Dworkin is representative of this view. He claims that there "would no point in the boast that we respect individual rights unless that involved some 
sacrifice, and the sacrifice in question must be that we give up whatever marginal benefits our country would receive from overriding these rights when they prove inconvenient." ${ }^{\text {"3 }}$ Thus proportionality's critics hold that the doctrine must be rejected because in rendering principles vulnerable to policy, it fails to recognize the priority that rights should enjoy over other considerations. ${ }^{84}$

In this section, I will survey some of the objections raised by critics of proportionality, as well as the alternative approaches to rights-protection that they offer in its place. I begin by clearing away criticisms that stem from an inaccurate grasp of proportionality. Once these objections are set aside, I will assess the adequacy of proportionality against the approaches of its critics. While those who reject proportionality by conceiving of rights as 'trumps' or 'absolutes' claim to take rights more seriously than those who admit the possibility of their justified limitation, I will argue that these alternatives to proportionality diminish the right of persons to public justice and the corresponding duty incumbent on government. They are therefore inadmissible from the standpoint of a modern constitutional state.

Critics allege that the doctrine of proportionality is both irrational and unjust. These objections proceed from a common presupposition: because constitutional rights must enjoy priority over considerations of policy, the former cannot be limited for the sake of the latter. In cases of conflict between rights and policies, policies must yield to rights. I will respond to each of these objections in turn by noting that the doctrine of proportionality, appropriately conceived, accepts the presupposition of its supposed critics. Constitutional rights may not be justifiably limited for the sake of furthering the realization of a purpose extrinsic to the ideal of public justice. The problem that

\footnotetext{
${ }^{83}$ Dworkin, Taking Rights Seriously, 193.

${ }^{84}$ See, for example, Jürgen Habermas, Between Facts and Norms: Contributions to a Discourse Theory of Law and Democracy [Between Facts and Norms], trans. William Rehg (Cambridge: MIT Press, 1998), 258-9 and Jeremy Waldron, "A Rights-Based Critique of Constitutional Rights," Oxford Journal of Legal Studies 13 (1993): 30: "To believe in rights is to believe that certain key interests of individuals, in liberty and well-being, deserve special protection, and that they should not be sacrificed for the sake of greater efficiency or prosperity or for any aggregate of lesser interests under the heading of the public good."
} 
proportionality confronts involves conflicts between competing principles rather than, as its critics suppose, conflicts between principles and policies.

Proportionality is often presented as a doctrine for balancing a constitutional right against a policy that seeks its limitation. Habermas and others allege that such balancing is necessarily irrational because it seeks to weigh rights, which are rooted in considerations of principle, against policies, which are rooted in considerations of expediency or convenience, custom or tradition, preference or inclination. The result is that principles of right, as Habermas puts it, "must compete with" considerations of policy "at the same level for priority." ${ }^{85}$ Because principles and policy are not commensurable, it is not possible to engage in the rational balancing of one against the other. When incommensurables are balanced, "weighting takes place either arbitrarily or unreflectively..." resulting balance, "the fire wall erected in legal discourse by a deontological understanding of legal norms and principles collapses" into unconstrained "policy arguments". 87

While the charge of irrationality presents a challenge for certain reductionist theories of proportionality that draw no distinction between principle and policy, ${ }^{88}$ it poses no threat to the present account. Whereas critics of proportionality distinguish between principles and policies, the unified theory draws a parallel distinction between two kinds of objectives that government might pursue. What I have called obligatory publicpurposes are analogous to principles because they are objectives that are integral to the ongoing operation of a rights-protecting constitutional democracy. Such purposes are, as we saw earlier in this chapter, determinations of the ideal of public justice. In turn, purposes that are extrinsic to that ideal - such as convenience, custom, or preference - are analogous to what Habermas calls policies. Proportionality is a doctrinal distillation of what the duty of public

\footnotetext{
${ }^{85}$ Habermas, Between Facts and Norms, 258-9.

86 Ibid., 259.

${ }^{87}$ Ibid., 258. For a discussion of Habermas' criticism, see Tor Inge-Harbo, 167-8.

88 See, for example, Beatty, The Ultimate Rule of Law, 92-3.
} 
justice requires of government in cases in which competing principles collide. That proportionality, as I have presented it, does not justify policies that conflict with principles is evident from the fact that to initiate the proportionality analysis, government must demonstrate that the rights-infringing law pursues an obligatory public purpose. The satisfaction of this condition requires government to establish, in effect, that a consideration of principle lies on each side of the conflict. If this is not the case, then proportionality lacks its condition of application. Habermas' objection to proportionality poses no threat to versions of the doctrine that presuppose the presence of a purpose of principle.

A similar line of objection alleges that proportionality is unjust because it flouts the purpose of affording rights constitutional protection. Constitutions, the objection alleges, entrench rights in order to set boundaries on legitimate state action. But if those rights may be limited through law in accordance with the requirements of proportionality, then anything that the constitution prohibits may in actuality be permitted. ${ }^{89}$ Proportionality is problematic because it means that "everything, even those aspects of our life most closely associated with our status as free and equal, is, in principle, up for grabs." 90 By emptying rights of the categorical protections that they offer to their bearers, "proportionality does violence to the idea of a constitution.","1

The objection can be challenged from the standpoint of both constitutional design and constitutional theory. From the standpoint of constitutional design, it is difficult to maintain that the limitation of a constitutional right 'does violence to the idea of a constitution' when many modern constitutions anticipate constitutional conflicts and provide limitation clauses that indicate how they are to be resolved. The limitation clause of the Canadian Charter of Rights and Freedoms "guarantees the rights and freedoms set out in it subject only to such reasonable limits prescribed by law as can be

\footnotetext{
89 Webber, 198.

90 Tsakyrakis, 489.

91 Webber, 198.
} 
demonstrably justified in a free and democratic society." 92 The constitutional text thereby indicates that both rights and limits must be understood in "reference to principles fundamental in a free and democratic society". ${ }^{93}$ The doctrine of proportionality is interpreted as setting out the conditions that must be satisfied to demonstrably justify that the limitation of a constitutional right is consonant with the fundamental principles of a free and democratic society. The Constitution of the Republic of South Africa is even more explicit. The limitation clause specifies that limits on constitutional rights are to be determined in accordance with the requirements that comprise the doctrine of proportionality. ${ }^{94}$ When limitation clauses are present, one cannot argue that the possibility of justifying a law that limits a constitutional right is itself at odds with constitutional commitments.

From the standpoint of constitutional theory, the objection overlooks that both purposive interpretation and proportionality have a categorical core. A modern constitution makes the satisfaction of the duty to govern justly the condition of the valid exercise of public authority. As I argued above, this duty requires government to either uphold constitutional rights or to justify any law that limits them. The justification involves establishing that the law limiting a constitutional right furthers the realization of the very normative ideal that the right instantiates. In the modern constitutional state, the duty to govern justly is absolute; the potentially conflicting determinations of that duty cannot be.

\footnotetext{
92 Canadian Charter of Rights and Freedoms, s. 1, Part I of the Constitution Act, 1982, being Schedule B to the Canada Act 1982 (U.K.), 1982, c. 11, s. 1 [Charter].

${ }_{93}$ Canada (Human Rights Commission) v. Taylor, 916.

${ }^{94}$ Constitution of the Republic of South Africa (1996), s. 36: "(1) The rights in the Bill of Rights may be limited only in terms of law of general application to the extent that the limitation is reasonable and justifiable in an open and democratic society based on human dignity, equality and freedom, taking into account all relevant factors, including (a) the nature of the right; (b) the importance of the purpose of the limitation; (c) the nature and extent of the limitation; (d) the relation between the limitation and its purpose; and (e) less restrictive means to achieve the purpose. (2) Except as provided in subsection (1) or in any other provision of the Constitution, no law may limit any right entrenched in the Bill of Rights."
} 
In the philosophical literature on rights, the most familiar alternative to proportionality is the rights as trumps model. ${ }^{95}$ According to this model, a right establishes a limit to what individuals must suffer for the sake of benefiting others or advancing their interests. ${ }^{96}$ So conceived, constitutional rights identify domains in which their bearers are insulated from the preferences of others. ${ }^{97}$ Although such a conception of rights is often presented as marking a radical departure from the doctrine of proportionality employed by modern constitutional states, ${ }^{98}$ the thesis that rights trump considerations of preference or policy conflicts with some conceptions of proportionality, but echoes others. While the thesis conflicts with the German approach to proportionality, in which any lawful purpose can, in principle, limit a constitutional right, the thesis echoes the Canadian approach. As I noted above, the purpose requirement is the precondition for applying the doctrine of proportionality because a law that infringes a constitutional right but that does not pursue an obligatory public purpose cannot generate a constitutional conflict and is therefore incapable of justification. As the Supreme Court of Canada noted in Big M., insofar as freedom of religion is a constitutional right, it cannot be justifiably limited for the sake of furthering "objectives which are trivial or discordant with the principles of a free and democratic society." 99 From the standpoint of the Canadian approach, the question that proportionality addresses is not whether rights trump considerations of utility, as is sometimes thought, but rather how to think about the duty of government in cases of constitutional conflict in

\footnotetext{
${ }_{95}$ Dworkin, "Rights as Trumps," in Theories of Rights, ed. Jeremy Waldron (Oxford: Oxford University Press, 1984), 153167.

96 Waldron, "Rights in Conflict," Ethics 99 (1989): 508.

97 Richard H. Pildes, "Dworkin's Two Conceptions of Rights," The Journal of Legal Studies 29 (2000): 311 (distinguishing the immunities view of rights from a structural conception).

98 See, for example, Webber, 201; Tsakyrakis, 489.

${ }_{99}$ R. $v$. Oakes, 138-9. For an account of private purposes that cannot lawfully constrain the enjoyment of rights under the Charter, see Lorraine Eisenstat Weinrib, “Canada's Constitutional Revolution: From Legislative to Constitutional State," Israel Law Review 33 (1999): 33: “The limitation clause involves the values of a 'free and democratic society', as the standard of justification for limits on rights. The Supreme Court has read this standard as embodying the values that constitute the genesis of the rights guarantees themselves. Accordingly, the court has dismissed arguments based on non-prohibitive cost, convenience, administrative expediency, and tradition..."
} 
which a trump lies on each side of the dispute. Dworkin has provided two distinct responses to this problem, which I will consider in turn.

In Taking Rights Seriously, Dworkin argues that the state is never justified in overriding a right for the sake of producing a "benefit to the community" because admitting such a justification would mean that individual rights would be incapable of constraining government. ${ }^{100}$ While Dworkin holds that the state may never interfere with rights to promote a communal benefit, he is careful not to "Overstate the point" by claiming that "the State is never justified in overriding the right." Dworkin suggests, may be overridden "when necessary to protect the rights of others, or to prevent a catastrophe". ${ }^{102}$ Thus Dworkin notes that the law of defamation, in which the fundamental right of free speech is "limited" in order to protect the "competing rights...of others not to have their reputations ruined by a careless statement." ${ }^{103}$ Dworkin is clear that defamation is not an isolated example; conflicts of rights are a frequent occurrence and when they arise "it is the job of government to discriminate." In cases in which rights conflict, "Government can do nothing but estimate the merits of competing claims, and act on its estimate."105

Dworkin's response to this problem brings his framework of rights as trumps closer to the doctrine of proportionality, but a significant gulf remains between the two doctrines. In rejecting that rights may be limited for the sake of communal benefit and accepting that fundamental rights may be limited to fulfill other rights or to prevent catastrophe, Dworkin seems to recognize something resembling the obligatory public purpose requirement that precedes proportionality analysis. But once this requirement is satisfied, Dworkin's framework requires nothing more than that government address conflicts by doing whatever seems best in its own eyes. Modern constitutional states require

\footnotetext{
100 Dworkin, Taking Rights Seriously, 191-2.

101 Ibid., 191.

102 Ibid.

103 Ibid., 193.

104 Ibid., 193-4.

105 Ibid., 199.
} 
more for government to justify the limitation of a constitutional right. In addition to satisfying the purpose requirement, government must demonstrate that there is a rational connection between the means that the law employs and the realization of the relevant purpose, that the purpose is pursued through means that minimally impair the enjoyment of constitutional rights, and that the realization of public justice is furthered by upholding the validity of the rights infringing law. Within a modern constitutional state, the assertion that a right conflicts with another right or that it must be limited in response to an emergency does not give the government a free hand to limit any constitutional right to any extent. Instead, laws seeking to limit a constitutional right must be justified, proportionality sets out the conditions of justification, and government bears the onus of establishing that each of these conditions is justified in terms of the constitutional values that underlie constitutional rights. In cases of constitutional conflict, the difference between Dworkin's approach and modern constitutional states is stark. For Dworkin, no moral standard exists for assessing the adequacy of government action (or inaction) in cases of constitutional conflict. But if there is no moral standard in such cases, no one can be wronged by government when they arise. In contrast, from the standpoint of a modern constitutional state, the presence of a constitutional conflict does not suspend the general duty of government to bring the existing legal order into the closest possible conformity with the ideal of public justice. Rather, the doctrine of proportionality sets out what this duty requires in cases of constitutional conflict. In so doing, the doctrine of proportionality makes it possible for individuals to challenge the constitutionality of state action in these cases.

Dworkin later reformulated his theory of rights. As in his earlier view, Dworkin holds that rights are absolute in relation to considerations of policy. But Dworkin's later view maintains that we should strive to avoid what I have called constitutional conflicts, whether between different rights ${ }^{106}$

106 Sovereign Virtue: The Theory and Practice of Equality (Cambridge: Harvard University Press, 2002), 131. 
or liberal values. ${ }^{107}$ On this view, each right should be treated as a moral absolute that excludes the possibility of justified limitations. Conflicts between absolute rights are to be avoided by adjusting the protections that rights provide their bearers. Accordingly, each right is absolute within its own domain, but the domain of each right must be carefully tailored so that it does not encroach on the domain of another.

While the absolutist approach is a distinctive alternative to proportionality, it cannot be reconciled with the notion of rights at work in a modern constitutional state. Recall that constitutional rights are determinations of the more general right of each member of the legal order to public justice. Accordingly, the protections that particular rights offer must be responsive to the reason for having rights at all. Modern constitutional states, as I noted above, determine the protections that particular rights offer through a purposive mode of interpretation that brings the general right of persons to just governance to bear on a particular legal context. Such a mode of interpretation provides constitutional rights with broad protections which may come into conflict with other determinations of the ideal of public justice. Thus the modern constitutional state requires a doctrine for determining how the ideal of public justice can be most fully realized in cases in which its determinations conflict. In contrast, the absolutist model holds that what falls within the scope of a constitutional right is incapable of being justifiably limited. Constitutional rights can be absolute only if the protections that they afford to their bearers are incapable of entering into a conflict. Rights can, of course, be interpreted in a manner that tailors the protections that each offers in order to ensure that no conflict arises in relation to any other right or legitimate public purpose. But such an approach is not admissible in a modern constitutional state. For the purpose to which the interpretation of rights must give effect is not the imperative of avoiding constitutional conflicts but the duty to interpret particular rights purposively in accordance with the general right of persons to just governance. By severing the protections that

107 Justice in Robes (Cambridge: Harvard University Press, 2006), 105-116. 
rights offer from the purpose of having rights at all, Dworkin provides constitutional rights with the strongest possible protection, but from the standpoint of the duty of the modern constitutional state, the protections that Dworkinian rights offer are arbitrary.

The eagerness to avoid constitutional conflicts raises a danger of evasion in the determination of the scope of a right. In cases in which principles are present on both sides of a dispute, Dworkin exhibits a tendency to recognize the rights-based claim of one side, while suggesting that only utilitarian arguments support the other. Thus, Dworkin's conceptualization of the right to pornography has been criticized for pitting freedom of speech against the community preferences that seek to silence it in order to avoid disgust or discomfort that such materials elicits. Dworkin thereby overlooks the possibility of a "rights-based argument against pornography". ${ }^{108}$ As Rae Langton notes, when Dworkin "raises the possibility of any link between pornography and harm to women of a concrete and familiar sort, he fails to take it seriously."109 A similar problem arises in Dworkin's discussion of hate speech. Dworkin argues that since free speech is integral to the moral independence of persons, it cannot be limited "on the ground that their officials or fellow-citizens think that their opinions about the right way for them to lead their own lives are ignoble or wrong". ${ }^{110}$ Hate speech, Dworkin concludes, must be permitted because its prohibition would violate the moral independence of speakers while its permission does not violate the moral independence of anyone. Just as Dworkin avoids considering rights-based arguments for limiting the right to pornography, so too he avoids rights-based arguments for prohibiting hate speech. As Susan J. Brison notes, restrictions on hate speech are generally motivated "by concern for the rights of victims of hate speech not to be harmed unjustly by it, rather than, as Dworkin assumes, by moral disapproval of those who engage in, or

\footnotetext{
108 Rae Langton, "Whose Right? Dworkin, Women and the Pornographers," Philosophy and Public Affairs 19 (1990): 326.

109 Ibid., 327.

${ }^{110}$ See Ronald Dworkin, A Matter of Principle (Cambridge: Harvard University Press, 1986), 353 ff.; Dworkin, “The Coming Battles over Free Speech," The New York Review of Books, June 11, $1992,57$.
} 
willingly listen to, such speech". ${ }^{111}$ Dworkin's discussion of hate speech recognizes the rights-claim of the speaker, but reduces rights-based arguments for restricting speech into nothing more than censorship for the sake of communal preference. In hard cases, the imperative to avoid a conflict between rights seems to amount to nothing more than a willingness to ignore one of the rights that conflict.

Dworkin's absolutist conception of rights resurrects the same problem that undermined his theory of rights as trumps. The rights as trumps view is problematic because it holds that in the event of a conflict, government must simply do what seems best in its own eyes. In the absence of moral standard to assess the adequacy of government conduct in cases of conflict, government can do no wrong when they arise. Within the rights as absolutes view, the same problem arises in a new context. In the absence of a general moral standard for considering what protections should be included within the scope of a particular right, government can do no wrong in determining what falls within and what falls beyond the scope of a particular constitutional right. From the standpoint of a modern constitutional state, each of Dworkin's distinctive conceptions of rights is problematic for the same reason. The rights as trumps model renders government unaccountable with respect to the limitation of constitutional rights. The rights as absolutes model renders government unaccountable with respect to the determination of what falls within the scope of a particular right. In contrast, modern constitutionalism introduces accountability into these domains by coupling purposive interpretation with proportionality analysis. Dworkin's rights as trumps and rights as absolute paradigms share a common problem: they dilute what the modern constitutional state exists to effectuate, the right of every person to public justice and the corresponding duty of all public power.

Proportionality is the most sophisticated and demanding framework for rights-protection yet devised. The doctrine is not irrational because it does not admit that the limitation of a constitutional

\footnotetext{
111 Susan J. Brison, “The Autonomy Defense of Free Speech,” Ethics 108 (1998): 325.
} 
right may be justified on the basis of considerations of policy. It is not unjust because the conception of justification that flows through the doctrine of proportionality articulates what the duty of public justice requires in cases of constitutional conflict. By coupling interpretation of constitutional rights with proportionality analysis, modern constitutional states recognize a far more robust right to just governance and a correspondingly more robust duty incumbent on government than the frameworks affirmed by proportionality's critics.

\section{CONCLUSION}

A modern constitutional state seeks to transform the general right of every person to public justice into an effective constraint on all public power. In order to make this general right effective, a modern constitutional state must make it determinate so that public officials can apply it to the concrete features of an existing state. As determinations of the general right of each person to public justice, particular constitutional rights must be interpreted broadly in order to effectuate their underlying purpose. But the more broadly constitutional rights are interpreted, the greater is the possibility that constitutional conflicts will arise between determinations of the ideal of public justice. Since such conflicts cannot be avoided by interpreting rights narrowly (for this would undermine the purpose of entrenching rights at all), the modern constitutional state requires a doctrine that indicates what the state's duty to govern justly requires in cases of constitutional conflict. Proportionality is that doctrine. It is a conceptually sequenced elaboration of the conditions under which the duty of government to bring the legal order as a whole into the deepest conformity with the ideal of public justice itself requires the limitation of a constitutional right. Proportionality is often criticized for failing to treat constitutional rights as absolute. What critics overlook is that particular constitutional rights may be justifiably limited only because the modern constitutional state conceives of them as determinations of a more fundamental right, that is, the right of every member of the legal order to 
public justice. It is because the general right of each person to public justice is absolute that the conflicting determinations of that right cannot be. 


\section{CONCLUSION: \\ Public LAW IN THE POSTWAR WORLD}

$\mathrm{I}$

$\mathrm{n}$ the decades since the Second World War, the theory and practice of public law have undergone

a dramatic transformation. As a matter of legal theory, Hart's rejuvenation of legal positivism in the Anglo-American world motivated novel forms of nonpositivist thought, from Fuller's conception of law's internal morality to Dworkin's interpretive model of adjudication. The result is that the classical problems of legal philosophy are now debated, in large part, from the standpoint of theoretical frameworks unknown to earlier generations. The practice of public law has undergone a similarly profound reorientation. Since the end of the Second World War, a diverse and growing number of states from around the world have converged on a versatile new model of constitutional ordering. The purpose of this modern constitutional paradigm is to establish the legal, institutional, and doctrinal conditions in which inherent human dignity and fundamental rights form an effective constraint on all public power. The comparative constitutionalist Mauro Cappelletti characterized the "unprecedented character of this ongoing development" as "perhaps, the most phenomenal societal transformation trend that has ever occurred in human history."

When the postwar innovations in the theory and practice of public law are considered side by side, a puzzle emerges. While legal theory is often conceived of as an attempt to explain the fundamental ideas that structure and animate legal practice, the foremost legal theories of the postwar period are neither inspired by nor responsive to the emergence of modern constitutional practices. When Hart considers features of the American legal order that conform to this paradigm, he dismisses them as legal eccentricities that are confined to the singular case of the United States and that are, in any event, "particularly hard to justify in a democracy."2 Fuller regards the institutional arrangements

\footnotetext{
${ }^{1}$ Mauro Cappelletti, "Repudiating Montesquieu? The Expansion and Legitimacy of 'Constitutional Justice'," Catholic University Law Review 35 (1986): 29-30.

${ }^{2}$ Hart, "American Jurisprudence through English Eyes: The Nightmare and the Noble Dream," in Essays in Jurisprudence and Philosophy (Oxford: Oxford University Press, 1983), 125.
} 
and substantive commitments of the modern constitutional state as needless because the ideal of legality that emerges from his theory can be fully satisfied in their absence. Dworkin's emphasis on individual rights and constitutional adjudication brings him into closer proximity with the modern constitutionalism paradigm, but his preoccupation with American constitutionalism leads him to overlook the significant ways in which modern constitutional practice rejects the American approach. The disjunction between the postwar theory and practice of public law raises the question: Why did public law's most innovative theorists regard the innovations in the postwar practice of public law as unacceptable, unnecessary, or as unworthy of theoretical exploration? More generally, is there some shared feature of these theories that left their originators unable to discern or appreciate the significance of the radical developments in governance that were emerging in their day?

I will begin by discussing how Hart, Fuller, and Dworkin conceived of fundamental components of modern constitutional practice, such as constitutional supremacy, rights protection, and judicial review. I then argue that the reason why these theorists overlooked the groundbreaking significance of modern constitutional practices is not accidental but systematic. Modern constitutionalism is a response to a fundamental problem inherent in the structure of public law, a problem that concerns the interrelationship between the most basic components of a legal system, public authority and public justice. So long as the character and interrelationship of these components is not evident, the problem to which modern constitutionalism responds remains invisible. By sidestepping the fundamental theoretical problem in public law, the leading postwar legal theorists deprived themselves of the resources to appreciate the practices developing in the world around them. The logic of modern constitutional practice is not fully intelligible apart from the normative structure of public law. 
Hart's essay, “American Jurisprudence through English Eyes: The Nightmare and the Noble Dream" appeared in 1977, ${ }^{3}$ in the aftermath of the Warren Court's (ultimately unsuccessful) attempt to bring the United States into conformity with the institutional roles, normative structure, and doctrines of the modern constitutional paradigm. Hart explains that from the perspective of an English lawyer, the striking feature of the American legal system is the Supreme Court, which has "a role and a status unlike that of any English court and indeed unlike any courts anywhere." ${ }^{4}$ First, the American Supreme Court enjoys the right to invalidate legislation, whether enacted by Congress or by state legislatures. Second, the grounds on which legislation may be invalidated extend from considerations of "form or procedure" to the

content of legislation, so that, to an English lawyer's astonishment, even a statute of Congress of impeccable clarity, passed by an overwhelming majority and conforming to all procedural requirements specified in the constitution, might still be held invalid because its interference with individual liberty or with property did not satisfy the requirement of a vague undefined standard of reasonableness or desirability, a doctrine which came to be called 'substantive due process'.

Hart notes that the practice of exercising judicial review on substantive grounds has cast "the American courts afloat on a sea of controversial moral judgments." ${ }^{\prime}$ Such a practice stands in need of justification both because it is "something very different from what conventional legal thought in all countries conceives as the standard judicial function" and because the practice "seems to the English lawyer" difficult to reconcile with democratic governance. ${ }^{7}$

In claiming that the United States alone enables Courts to strike down legislation on the basis of its conformity to substantive norms, Hart indicates his unfamiliarity with the constitutional

${ }^{3}$ Essays in Jurisprudence and Philosophy (Oxford: Oxford University Press, 1983).

4 "American Jurisprudence through English Eyes: The Nightmare and the Noble Dream," 124.

5 Ibid., 124-5.

6 Ibid., 125.

${ }^{7}$ Ibid. I respond to the objection that modern constitutionalism is undemocratic in the final section of Chapter Four. 
practices materializing in the world around him. As Cappelletti observed in his 1971 work, Judicial Review in the Contemporary World:

Our own time has seen the burgeoning of 'constitutional justice,' which has in a sense combined the forms of legal justice and the substance of natural justice. Desirous of protecting the permanent will rather than the temporary whims of the people, many modern states have reasserted higher law principles through written constitutions. Thus there has been a synthesis of three separate concerns: the supremacy of certain higher law principles, the need to put even the higher law in written form, and the employment of the judiciary as a tool for enforcing the constitution against ordinary legislation. This union of concepts first occurred in the United States, but it has since come to be considered by many as essential to the rule of law (Rechtsstaat) anywhere. ${ }^{8}$

The practices that Hart found so conspicuous in American constitutionalism had, since the end of the Second World War become commonplace features of the postwar practice of public law. Within a handful of years after the Second World War, Austria, Germany, and Italy adopted written constitutions that bound all branches of government, placed substantive constraints on the amendment process, entrenched a bill of rights to regulate the relationship between the individual and state power, and established an independent judicial body to make constitutional norms effective. ${ }^{9}$ By the time Hart observed the singularity of the Warren Court, modern constitutionalism had spread to Greece and Portugal and was influencing Eastern European reformers. ${ }^{10}$ While Hart seems to be generally unaware of these broader developments, he does not seem, in principle, to oppose them. In discussing the judicial powers of American Courts, Hart is content to ask how these developments are compatible with democratic governance and whether there is a "general conception of the nature of law" that is compatible with them. ${ }^{11}$

\footnotetext{
8 (New York, Bobbs-Merrill, 1971), 42.

9 Cappelletti, "Repudiating Montesquieu? The Expansion and Legitimacy of 'Constitutional Justice'," 5-6.

10 Ibid., 7-8.

11 "American Jurisprudence through English Eyes: The Nightmare and the Noble Dream,” 125.
} 
Fuller too viewed the emergence of modern constitutionalism with suspicion, but in his case the suspicion was rooted not in the disorienting features of a foreign practice, but in the commitments of his own legal theory. For Fuller, "law is the enterprise of subjecting human conduct to the governance of rules."12 If human conduct is to be subject to the governance of rules, then those rules must be, at least to some extent, (1) general, (2) public, (3) prospective, (4) clear, (5) non-contradictory, (6) possible to obey, (7) constant in time, and (8) congruent with official action. ${ }^{13}$ These requirements form a procedural ideal of legality, which Fuller calls the internal morality of law.

The procedural character of Fuller's legal ideal stands in tension with the substantive commitments of the modern constitutional state. In elaborating the procedural character of his legal ideal, Fuller explains that the internal morality of law "is, over a wide range of issues, indifferent toward the substantive aims of law and is ready to serve a variety of such aims with equal efficacy." ${ }^{14}$ Because the internal morality of law is solely procedural, Fuller notes that it is indifferent to the prohibition of contraception, ${ }^{15}$ the criminalization of homosexuality, ${ }^{16}$ or even the "subjugation of women". ${ }^{17}$ The same cannot be said about modern constitutionalism, which directs all public authority towards a substantive aim, the realization of a legal system adequate to the inherent dignity of each of its free and equal inhabitants.

Fuller might respond that his legal theory nevertheless shares the fundamental commitment of modern constitutionalism, that legal ordering must answer to the human dignity of all who are bound by it:

I have repeatedly observed that legal morality can be said to be neutral over a wide range of ethical issues. It cannot be neutral in its view of man himself. To embark on

12 The Morality of Law (New Haven: Yale University Press, 1994), 96 and 106.

13 Ibid., 39.

14 Ibid., 153.

15 Ibid.

16 Ibid., 132-3.

17 Ibid., 96. 
the enterprise of subjecting human conduct to the governance of rules involves of necessity a commitment to the view that man is, or can become, a responsible agent, capable of understanding and following rules, and answerable for his defaults. Every departure from the principles of the law's inner morality is an affront to man's dignity as a responsible agent. ${ }^{18}$

Although Fuller embraces the language of human dignity employed in modern constitutional states around the world, he attaches a qualitatively different meaning to it. For Fuller, dignity consists in the capacity to be subject to the governance of rules. The duty incumbent on government is to respect this capacity by enacting rules that conform to the procedural principles that are internal to legality. ${ }^{19}$ From the standpoint of modern constitutionalism, Fuller captures one aspect of dignity but overlooks another: the rules to which human conduct is subject must be compatible with the independence of all who are bound by them. The commitment of a modern constitutional state to creating a regime of equal freedom results in the repudiation of certain substantive aims that are compatible with Fuller's ideal of legality. Modes of legal ordering that deny the equality of persons on the basis of their gender or that impose arbitrary restrictions on the kinds of purposes that free persons can pursue - whether, for example, by prohibiting same-sex relationships or access to contraceptives - must be invalidated by a modern constitutional state. ${ }^{20}$

Given that Fuller's ideal of legality can be satisfied by laws and legal systems that pursue a range of substantive aims through a variety of lawgiving processes, democratic and otherwise, one would expect Fuller to hold that the internal morality of law sets out an ideal of legality that neither requires constitutional rights protection nor democratic modes of lawgiving, but is nevertheless compatible with them. Surprisingly, this is not the position that Fuller adopts. In both his reply to

\footnotetext{
18 Ibid., 162.

19 Ibid., 40.

${ }^{20}$ For a discussion of how the normative structure of a modern constitutional state is more substantive than Fuller's internal morality of law, see David Dyzenhaus, "The Juristic Force of Injustice," in Calling Power to Account: Law, Reparations and the Chinese Head Tax, eds. Dyzenhaus and Mayo Moran (Toronto: University of Toronto Press, 2005), 264 and $280-1$.
} 
Hart and in The Morality of Law, Fuller expresses his unease with substantive constitutional norms. In his reply to Hart, Fuller mentions that substantive norms may be enacted into ordinary statutes, but should be excluded from a written constitution in societies "emerging from a period of violence". ${ }^{21}$ Fuller thus laments that the "constitutions that have come into existence since World War II" typically "incorporate a host of economic and political measures". ${ }^{22}$ While the measures that Fuller refers to are not entirely clear, the legal context suggests that what is at issue are constitutional provisions protecting socio-economic rights and the democratic character of the constitutional order. Fuller seems to find such measures objectionable because he suspects that these substantive aims have been inserted into the constitution not because they are generally affirmed but because "they would not be able to survive the vicissitudes of an ordinary exercise of parliamentary power." 23 The danger that Fuller sees in the constitutional entrenchment of substantive aims that are not generally affirmed is that the internal morality of law requires congruence between legal rules and official action. But if the people who must effectuate the constitution are not committed to its substantive aims, discrepancies between rule and official action might emerge. In The Morality of Law, Fuller extends his opposition to substantive constitutional norms beyond the special case of transitional societies to legal systems more generally. In discussing the American constitution, Fuller recognizes that it entrenches substantive norms but suggests that judges should avoid appealing to them in reviewing the constitutionality of legislation. ${ }^{24}$ It is striking that having formulated a legal ideal that insists upon the importance of congruity between legal rule and official action, Fuller suggests that judges should avoid invalidating legislation on the basis of its failure to conform with substantive norms entrenched within the constitution. Fuller's discussions of constitutionalism reveal a general indifference towards the

\footnotetext{
${ }^{21}$ Fuller, "Positivism and Fidelity to Law - A Reply to Professor Hart," Harvard Law Review 71 (1958): 642.

22 Ibid., 643.

${ }^{23}$ Ibid.

24 The Morality of Law, 104-5.
} 
substantive aims of law, but a particular hostility to the inclusion of substantive aims in written constitutions.

Fuller's skepticism towards modern constitutional practice echoes Hart's, but does not stem from the same basis. Hart objects to substantive judicial review because he cannot reconcile it with his own understanding of institutional roles within a democracy. Since Fuller's ideal of legality can be fully satisfied by a non-democratic state, his antagonism to modern constitutionalism must have another source. The issue seems to originate in the relationship between Fuller's procedural ideal of legality and the notion of a written constitution. Fuller describes the internal morality of law as “essentially a branch of constitutional law, largely and properly developing outside the framework of our written constitutions." 25 The internal morality of law is constitutional in nature because it concerns the "authority to enact rules and to reach decisions that will be regarded as properly binding on those affected by them." 26 The internal morality of law is the unwritten constitution of every legal order because the procedural principles that Fuller sets out accompany the subjection of human conduct to the governance of rules. But in conceiving of the internal morality of law as an unwritten constitution composed exclusively of procedural norms, Fuller seems to reject the propriety of a written constitution being committed to the pursuit of substantive norms. He holds that "a written constitution defines basic lawmaking procedure" and suggests that a written constitution should be conceived of as "establishing a basic procedural framework for future governmental action in the enactment and administration of laws. ${ }^{27}$ For Fuller, the features of a written constitution should not exceed the procedural parameters of the unwritten constitution common to legal systems as such. From this standpoint, modern constitutionalism is problematic: in making conformity to substantive norms the

\footnotetext{
25 Ibid., 128.

${ }^{26}$ Ibid.

${ }^{27}$ Fuller, "Positivism and Fidelity to Law - A Reply to Professor Hart," Harvard Law Review 71 (1958): 642-3.
} 
condition for the valid exercise of public power, modern constitutionalism distorts the morality that makes law possible.

Unlike Hart and Fuller, Dworkin is eager to affirm the model of constitutional governance that emerged in the United States under the leadership of the Warren Court. However, in confining his study of constitutionalism to the American experience, Dworkin's work presents a halfway house between earlier approaches to constitutional governance and the modern constitutional approach. While both the United States and modern constitutional states involve judicial review and the entrenchment of rights, as I discussed in Chapter Four and Five, the differences between these models are stark. Modern constitutions explicitly establish that the democratic order is committed to the realization of substantive norms of equal freedom, that the judiciary is required to uphold these constitutional norms, that constitutional rights are instances of this commitment, that rights impose duties on government not only to refrain from interfering with persons but an affirmative obligation to realize a legal order adequate to the dignity of its members, and that rights may be justifiably limited in cases in which government can establish that the infringement is necessary to further the realization of the constitutional values that underlie the rights themselves. In contrast, in the United States the constitution is typically understood to protect self-government rather than to require the pursuit of substantive norms. Judicial review is depicted as an illegitimate constraint on majority rule because the judiciary gave itself the power to review the validity of legislation enacted by the people's representatives. Finally, constitutional rights are conceived of as (1) isolated instances of past agreement rather than determinations of a more general normative principle, (2) entitling their bearers to be free of government interference but not entitled to government action, and as (3) having a scope of protection that, once determined, cannot be justifiably limited.

While Dworkin rejects majoritarian notions of democracy and procedural interpretations of the constitution, he does not fully escape the distinctive shadow cast by American constitutionalism. 
Dworkin's focus on American constitutionalism and his lack of engagement with the broader developments in the postwar world of modern constitutionalism undermines both his theory of rights and his commitment to substantive judicial review. In Chapter Five, I noted that Dworkin's various iterations of the rights as trumps model provides significantly less protection to rights bearers than the standard approach developed in modern constitutional states around the world. In Chapter Four, I noted that Dworkin's approach to judicial review is also problematic. Dworkin initially argued that judicial review is justified because of the morally beneficial outcomes that it produces: judicial review raises the level of public debate by formulating pressing issues as questions of political morality and then selecting the morally best answer. ${ }^{28}$ This justification of judicial review is open to a devastating objection. As Dworkin's critics were quick to point out, the benefits that judicial review is purported to bring may be enjoyed in its absence, while the presence of judicial review provides no guarantee that the benefits that Dworkin describes will ensue. The criticism's strength was compounded by the fact that in the years since Dworkin began defending judicial review, the decisions of the United Supreme Court became increasingly objectionable in his eyes. ${ }^{29}$

Rather than look to well-ordered constitutional states for guidance in the establishment of institutional roles, the selection of judicial appointments, or the employment of rights-protecting legal doctrines, Dworkin responded to his critics by diluting his own constitutional commitments. While maintaining his rejection of the view advanced by "many lawyers and political scientists" that "judicial review is inevitably and automatically a defect in society", Dworkin distanced himself from his earlier view that judicial review contributes to the legitimacy of a democratic state. ${ }^{30}$ Within any given legal setting, the appropriateness of judicial review rests on pragmatic considerations "that vary from place

\footnotetext{
28 Dworkin, Freedom's Law (Cambridge: Harvard University Press, 1996), 344 and 34.

${ }^{29}$ Dworkin, Justice for Hedgehogs (Cambridge: Harvard University Press, 2011), 399.

30 Ibid.
} 
to place", which include a country's track record in protecting individual and minority rights, as well as "the strength of the rule of law, the independence of the judiciary, and the character of the constitution judges are asked to enforce."31

With Dworkin's retreat to this more modest position, the space between Dworkin and his opponents shrinks in two important respects. First, Dworkin joins his opponents by conceiving of judicial review not as a constitutional essential of any well-ordered regime that is accountable to the inherent dignity and fundamental rights of each of its members, but as an arrangement that may be rightfully adopted or rejected. ${ }^{32}$ Whether the United States will, in the final analysis, have chosen wisely by adopting judicial review depends, Dworkin explains, "on the character of future Supreme Court nominations. We must keep our fingers crossed."33 Second, Dworkin accepts the standpoint of constitutional critics who frame the merits of the choice in terms of promoting the best outcome in a complex matrix of factual circumstances. ${ }^{34}$ The remaining disagreement seems confined to the narrow question: What arrangements would produce the best outcome in relation to which facts? But once the question is framed in this way, it is more profitably explored by the empirical investigations of political scientists rather than the moral argumentation of legal and political philosophers. In a world in which judicial review had solidified as an integral feature of modern constitutional governance, Dworkin gave up the project of defending judicial review as a general feature of a wellordered legal system.

In short, since the end of the Second World War the most prominent Anglo-American legal theorists formulated frameworks that either rejected postwar constitutionalism whole cloth or failed to recognize its significance for their own projects. I believe that this disjunction between the theory

\footnotetext{
31 Ibid., 398.

32 Waldron, “The Core of the Case Against Judicial Review," Yale Law Journal 115 (2006): 1360.

33 Justice for Hedgehogs, 399.

34 Waldron, $1359 \mathrm{ff}$.
} 
and practice of public law in the postwar era is not accidental. Modern constitutionalism is a response to a problem inherent in the structure of public law. Because the theories of Hart, Fuller, and Dworkin do not perceive the problem, they fail to see how the various innovations of modern constitutional practice systematically address it.

Any theory of public law must confront a fundamental problem. The practice of public law seems to involve the interrelationship of two ineliminable components, authority and justice, which appear to stand in a relationship of opposition. On the one hand, the practice seems to require persons to act in conformity with legal obligations enacted through the contingent exercise of public authority. On the other, the same practice seems to require persons to act in conformity with timeless ideals of public justice. The theoretical puzzle at the core of public law stems from the incompatibility of these convictions. Because enacted laws are often unjust and just laws are rarely enacted, persons often find themselves simultaneously pulled in one direction by the demands of public authority and pulled in another by the demands of public justice.

The unified theory of public law resolves this problem by drawing a pair of distinctions. First, the unified theory delineates the juridical situation of the parties to the public law relationship. Public law is a juridical relationship between rulers and ruled in which each party bears distinctive rights and duties. The notion of public authority concerns the right of rulers to establish, interpret, and implement legal obligations that bind the ruled. The notion of public justice concerns the right of the ruled to governance that brings the existing legal order into conformity with the freedom and equality of all who are bound by it. Thus, it is not the case that persons are bound both by the particular laws that happen to have been enacted in their legal order and by general considerations of justice. Rather, persons are divided into rulers and ruled; the ruled have a duty to obey enacted law and the rulers have a duty to govern justly. Second, the unified theory distinguishes the character of the principles that structure the public law relationship. The principle of authority that empowers rulers and binds the 
ruled is the constitutive principle of public law. A regime of public law consists in publicly authoritative institutions that establish, interpret, and implement legal obligations incumbent on the ruled. The principle of justice, which concerns the right of the ruled to just governance and the corresponding obligation of the rulers, is the regulative principle of public law. Whereas the principle of authority sets out the standard for determining whether something is a legal system, the principle of justice provides a standard for determining the adequacy of an existing legal system. Once the rights and duties of the parties to the public law relationship and the principles that constitute and regulate this relationship are untangled, the tension that lies at the heart of public law disappears.

The distinguishing feature of the unified theory of public law is the view that the right of government to exercise public authority is always accompanied by a duty to create a regime of equal freedom. The basis of this relationship lies in the justification of public authority advanced in Chapter One. Public authority requires justification because the division of persons into rulers and ruled clashes with our conviction that each person, as a free being, has the right to determine his or her own purposes, consistent with the right of other equal persons to the same. Public authority, however, can be justified because in the absence of institutions that make, interpret, and implement law, persons would be incapable of interacting with one another on terms of equal freedom. Such a justification of the right of government to exercise public authority implicates a particular conception of public justice. Since the justification of public authority is premised on the right of each person to equal freedom, internal to the justification of public authority is a conception of an ideal legal order and a duty to approximate it. A legal order is just to the extent that public authority is consistent with the right of every person bound by it to equal freedom. A legal order is governed justly to the extent that it directs the exercise of public authority towards the realization of equal freedom under law. So conceived, the principles of public law are mutually implicating. There is no right to exercise public 
authority that is not accompanied by a duty to govern justly. There is no possibility of just governance in the absence of publicly authoritative institutions.

In maintaining that the moral right of a ruler to exercise public authority is accompanied by a duty to create a regime of equal freedom, the unified theory of public law makes a critical departure from competing theories. While Hart describes a practice in which legal officials change the normative situation of others by exercising public authority over them, he avoids the problem of how someone could have the moral authority to change the normative situation of another. Having provided a description of public authority rather than a justification of it, Hart treats the question of what moral purpose legal power should pursue as a wholly independent one. Positivism, as a theory of law's nature, leaves its advocates free to affirm a range of competing views about the nature of morality. Fuller conceives of the act of a ruler imposing obligations on the ruled as implicating a series of moral requirements internal to law, but takes for granted that one person could have the right to impose obligations on others by ruling them. When pressed about the substantive purposes that law should pursue, Fuller holds that this issue belongs to the external morality of law. ${ }^{35}$ For Fuller, as for Hart, a legal system as such does not contain its own implicit substantive moral aim. The same is true of Dworkin. According to his interpretive model, the appropriate moral standard for assessing the adequacy of a particular legal system arises not from something common to legal systems in general, but from the distinctive practices that characterize the particular legal system at issue. In Dworkin's terms, only an interpretive principle that fits the contingent contours of a given legal practice can justify it. ${ }^{36}$ While this approach generates liberal norms of justification when applied to the context of societies characterized by liberal practices, as I noted in the Introduction, the more illiberal a society is, the more illiberal the relevant justificatory standard must be. The unified theory of public law

35 The Morality of Law, 96.

${ }^{36}$ Law's Empire (Cambridge: Harvard University Press, 1986), 52. 
avoids the variability of Dworkin's legal ideal by holding that the morality internal to law follows not from the contingent practices that characterize a particular legal system, but from a feature common to legal systems as such, the right to exercise public authority. The same strategy also provides an alternative to the substantive moral indeterminacy of the legal theories of Hart and Fuller. Every exercise of public authority is accompanied by a duty to realize a regime of equal freedom. This duty is the subject of Chapter Three.

Once public law is conceived of in terms of mutually implicating principles of authority and justice, the problem of accountability comes into view. As I explained in Chapter Four, the problem of accountability is that even though every person subject to public authority has a right to just governance, this right may nevertheless be violated with impunity because the validity of government action does not rest on its conformity to the right of each individual within the legal order to just governance. The problem arises in any legal system that fails to create the conditions in which each person is capable of constraining the exercise of public authority to the terms of its justification by standing on his or her right to just governance. The problem of accountability is inescapable so long as public authority rests in the hands of a single person (as in a monarchy), a few persons (as in an aristocracy), or many persons (as in a majoritarian democracy). A monarchy is unaccountable to every person bound by its lawgiving, an aristocracy is unaccountable to the many, and a majoritarian democracy is unaccountable to the few. The problem of accountability is not that these forms of government necessarily exercise public authority in an unjust manner, but that persons within them remain susceptible to injustice through the valid exercise of public authority. Because every legal order has a duty to bring itself into the closest possible conformity with public justice, every legal system must ultimately address the problem of accountability.

The modern constitutional state is a systematic legal framework for rendering the exercise of public authority accountable neither to the many nor to the few, but to the right of every member of 
the legal order to just governance. A modern constitutional state addresses the problem of accountability by transforming the right of the ruled to just governance from a mere philosophic truth or from the empty words of a constitutional text into a constitutional reality that forms an effective constraint on the exercise of all public power. To this end, the modern constitutional state involves (1) a written constitution that exhaustively specifies the conditions for the valid exercise of public authority by any branch of government, (2) a body of constitutional norms establishing that conformity to the right of each individual to just governance is the condition for the valid exercise of all public authority, and (3) a judicial institution that is both politically independent and constitutionally required to uphold constitutional norms by enabling any individual in the legal order who believes that his or her right to just governance has been infringed to bring a constitutional complaint challenging the validity of an authoritative act. Any legal system might succeed in enacting just law, but only a modern constitutional state creates the constitutional, institutional, and doctrinal conditions in which the exercise of public authority is made accountable to the right of every person within the legal order to just governance. Judicial review is integral to modern constitutionalism not because it produces desirable outcomes that could nevertheless be realized in its absence, as Dworkin would have it, but because it creates the conditions in which any individual within the legal order can challenge the validity of an authoritative act on the basis of its failure to conform to the constitutionally mandated duty to govern justly. The revolution in the postwar practice of public law consists in the legal innovations that render the exercise of public authority accountable neither to the many nor the few, but, for the first time in the long history of the practice of public law, to the right of every inhabitant of the legal order to just governance. In a modern constitutional state, everyone who exercises public authority must be answerable to anyone who is bound by it.

Competing theories fail to appreciate the innovations of modern constitutional practice because they lack the theoretical resources to discern the problem to which this practice responds. As 
noted above, competing legal theories do not recognize that the right of government to exercise public authority must always be directed towards fulfilling the right of persons to just governance, conceived of as equal freedom under law. Accordingly, competing theories fail to observe the problem of accountability that persists so long as the right of persons to just governance can be violated by valid exercises of public authority. And if the problem of accountability is not unearthed, the systematic way in which the modern constitutional state addresses this problem remains hidden from view. Hart fails to discern the problem of accountability because he seeks to explicate law's authority in abstraction from moral concepts. If morality is extrinsic to legality, then the question of how the exercise of public authority can be constrained to the moral boundaries of its own justification cannot arise. Fuller, in contrast, holds that law contains its own internal standard of adequacy. But by characterizing this standard as wholly procedural, Fuller maintains that it is possible, on the one hand, for legal systems that are neither democratic nor rights-protecting to fully satisfy this ideal, and, on the other, for legal systems that are both democratic and rights-protecting to depart from it. Finally, Dworkin's interpretive model commits him to a variable conception of political morality that does not direct the right to exercise public authority to the fulfillment of the duty to realize a regime of equal freedom. Even in a legal system characterized by liberal political morality, constitutionalism remains an extraneous feature of Dworkin's theory. Having attempted to justify a modest set of constitutional practices by pointing to beneficial outcomes that are realizable apart from them, Dworkin is ultimately pressed to concede that those constitutional practices are not integral to a well-ordered legal system. In the end, constitutional governance is just another tool for producing outcomes that could, in principle, be realized in its absence.

In the postwar world, the theory and practice of public law seem to be moving in opposite directions. As a matter of practice, since the end of the Second World War a growing chorus of lawyers, judges, and statesmen from around the world have observed the emergence of a new 
paradigm of constitutional governance. In countries as diverse as Germany, South Africa, and Canada, the distinguishing mark of this versatile new paradigm is the creation of constitutional norms, institutional arrangements, and legal doctrines that transform the right of persons to just governance from an empty ideal into an effective constraint on the exercise of public power. In the practice of legal systems around the world, modern constitutionalism has established itself as the leading response to the various pathologies of public law, from the barbarism of failed states to the injustices of majoritarian ones. But as a matter of constitutional theory, modern constitutionalism is increasingly subject to criticism from theorists committed to earlier models of government, which fail to render the exercise of public power accountable to the right of each and every member of the legal order to just governance. The result is a chasm that separates the practice of modern constitutionalism from a theory that could explain and guide it. In this context, legal practitioners seeking to cultivate modern constitutional governance in a variety of settings have had to find their way without theoretical illumination.

The overarching purpose of this project has been to take the first steps in bringing the theory and practice of public law back together. By resolving the conflict between notions of authority and justice that lies at the heart of public law, the unified theory exposes a problem latent in the structure of public law to which modern constitutionalism systematically responds. Earlier systems of public law succeeded in making public authority accountable to the few or to the many. The groundbreaking significance of the modern constitutional state consists in creating the legal conditions in which the exercise of public authority is accountable to each member of the legal order. In articulating the duty of existing states to bring themselves into increasing conformity with the modern constitutional paradigm, the unified theory connects the general normative structure of public law to the most innovative practices of the postwar world. Such a connection can be forged because what a legal system is indicates what a legal system must become. 


\section{BIBLIOGRAPHY}

Ackerman, Bruce. “Rooted Cosmopolitanism.” Ethics 104 (1994): 516-535.

—. We The People: Foundations. Cambridge: Harvard University Press, 1991.

Ackermann, Lourens W.H. “The Legal Nature of the South African Constitutional Revolution.” New Zealand Law Review 4 (2004): 633-678.

— . "The Soul of Dignity: A Reply to Stu Woolman." In Constitutional Conversations, edited by Stu Woolman and Michael Bishop, 217-230. Pretoria: Pretoria University Press, 2008.

Alexy, Robert. The Argument From Injustice: A Reply to Legal Positivism. Translated by Bonnie Litschewski Paulson and Stanley L. Paulson. Oxford: Clarendon Press, 2002.

_. "On the Concept and Nature of Law." Ratio Juris 21 (2008): 281-299.

. "A Defence of Radbruch's Formula." In Recrafting the Rule of Law: The Limits of Legal Order, edited by David Dyzenhaus, 15-39. Oxford: Hart Publishing, 1999.

—. "Discourse Theory and Human Rights." Ratio Juris 9 (1996): 209-235.

—. "Effects of Defects—Action or Argument? Thoughts about Deryck Beyleveld and Roger Brownsword's Law as Moral Judgment." Ratio Juris 19 (2006): 169-179.

—. "On the Necessary Relations Between Law and Morality.” Ratio Juris 2 (1989): 167-183.

—. A Theory of Constitutional Rights. Oxford: Oxford University Press, 2002.

Allan, T.R.S. "Law, Justice, and Integrity: The Paradox of Wicked Laws." Oxford Journal of Legal Studies 29 (2009): 705-728.

Allison, J.W.F. Review of The Idea of Public Law, by Martin Loughlin. The Modern Law Review 68 (2005): 344-348.

Almond, Gabriel A., Marvin Chodorow, and Roy Harvey Pearce. "Progress and its Discontents." Bulletin of the American Academy of Arts and Sciences 35 (1981): 4-23.

Aly, Götz and Karl Heinz Roth. "The Legalization of Mercy Killings in Medical and Nursing Institutions in Nazi Germany from 1939 until 1941." International Journal of Law and Psycbiatry 7 (1985): 145-163.

Anderson, Elizabeth. The Imperative of Integration. Princeton: Princeton University Press, 2010.

— "Toward a Non-Ideal, Relational Methodology for Political Philosophy: Comments on Schwartzman's Challenging Liberalism.” Hypatia 24 (2009): 130-145. 
Arad, Yitzhak, Israel Gutman, and Abraham Margaliot, ed. Documents on the Holocaust: Selected Sources on the Destruction of the Jews of Germany and Austria, Poland, and the Soviet Union. Translated by Leah Ben Dor. Lincoln: University of Nebraska Press, 1999.

Aristotle. Politics. In Selected Works, translated by Hippocrates G. Apostle and Lloyd P. Gerson, 557615. Iowa: The Peripatetic Press, 1991.

Aron, Raymond. Main Currents of Sociological Thought, vol. 2. New Brunswick, NJ: Transaction Publishers, 2009.

Austin, John. Lectures on Jurisprudence. New York: Henry Holt and Company, 1875.

—. The Province of Jurisprudence Determined. London: John Murray, 1832.

Barak, Aharon. "Proportional Effect: The Israeli Experience." University of Toronto Law Journal 57 (2007): 369-382.

- Proportionality: Constitutional Rights and Their Limitations. Cambridge: Cambridge University Press, 2012.

Barber, N.W. "Professor Loughlin's Idea of Public Law." Oxford Journal of Legal Studies 25 (2005): 157167.

Basler, Roy P., ed. Abraham Lincoln: His Speeches and Writings. Cleveland: Da Capo Press, 1946.

- The Collected Works of Abrabam Lincoln, vol. IV. New Brunswick: Rutgers University Press, 1977.

—. The Collected Works of Abraham Lincoln. New Brunswick: Rutgers University Press, 1953.

Beatty, David M. The Ultimate Rule of Law. Oxford: Oxford University Press, 2004.

Bentham, Jeremy. A Fragment on Government. Cambridge: Cambridge University Press, 2001.

- An Introduction to the Principles of Morals and Legislation. New York: Prometheus Books, 1988.

Berman, Harold J. Law and Revolution: The Formation of the Western Legal Tradition. Cambridge: Harvard University Press, 1983.

Bertea, Stefano. "How Non-Positivism can Accommodate Legal Certainty." In Law, Rights, and Discourse: The Legal Philosophy of Robert Alexy, edited by George Pavlakos, 69-82. Oxford: Hart Publishing, 2007.

Bickel, Alexander. The Least Dangerous Branch. Indianapolis: Bobbs-Merrill, 1962.

Bilchitz, David. "Does Balancing Adequately Capture the Nature of Rights?" South African Public Law 25 (2010): 423-444. 
Bluntschli, Johann Caspar. Politik als Wissenschaft. Stuttgart: Verlag der J.G. Cotta'schen Buchhandlung, 1876.

Bodenheimer, Edgar. "Significant Developments in German Legal Philosophy since 1945.” American Journal of Comparative Law 3 (1954): 379-396.

Bork, Robert. Slouching Towards Gemorrah: Modern Liberalism and American Decline. New York: HarperCollins, 1996.

Bradley, Keith. Slavery and Society in Rome. Cambridge: Cambridge University Press, 1994.

Breitman, Richard. "Secrecy and the Final Solution." In New Perspectives on the Holocaust, edited by Rochelle L. Millen, 70-90. New York: New York University Press, 1996.

Brison, Susan J. “The Autonomy Defense of Free Speech.” Ethics 108 (1998): 312-339.

Browning, Christopher. Ordinary Men: Reserve Battalion 101 and the Final Solution in Poland. New York: HarperPerennial, 1993.

Brudner, Alan. "What Theory of Rights Best Explain the Oakes Test?" In The Limitation of Charter Rights: Critical Essays on R. v. Oakes, edited by Gregoire Webber and Luc Tremblay, 59-74. Montreal: Les Editions Themis, 2009.

van Caenegem, R.C. An Historical Introduction to Western Constitutional Law, translated by David Johnston. Cambridge: Cambridge University Press, 1996.

Campbell, Juan Colombo. "Constitutional Court Judges' Roundtable." International Journal of Constitutional Law 3 (2005): 544-550.

Caplan, Arthur L. "How did Nazi Medicine go so Wrong?" In When Medicine Went Mad: Bioethics and the Holocaust, edited by Caplan. New Jersey: Humana Press, 1992.

Cappelletti, Mauro. “The Expanding Role of Judicial Review in Modern Societies.” In The Role of Courts in Society, edited by Simon Shetreet, 79-96. Dordrecht: Martinus Nijhoff Publishers, 1988.

—. Judicial Review in the Contemporary World. New York, Bobbs-Merrill, 1971.

- "Repudiating Montesquieu? The Expansion and Legitimacy of 'Constitutional Justice'." Catholic University Law Review 35 (1986): 1-32.

Cardozo, Benjamin N. The Nature of the Judicial Process. New Haven: Yale University Press, 1921.

Chapman, Bruce. "Law, Incommensurability, and Conceptually Sequenced Argument." University of Pennsylvania Law Review 146 (1998): 1487-1528.

Chaskalson, Arthur. "Human Dignity as a Constitutional Value." In The Concept of Human Dignity in Human Rights Discourse, edited by David Kretzmer and Eckhart Klein, 133-144. The Hague: Kluwer Law International, 2002. 
. "Human Dignity as a Foundational Value of our Constitutional Order." South African Journal of Human Rights 16 (2000): 193-205.

- "From Wickedness to Equality: The Moral Transformation of South Africa Law." International Journal of Constitutional Law 1 (2003): 590-609.

Christodoulidis, Emilios. "Public Law as Political Jurisprudence: Loughlin's 'Idea of Public Law'.” In Public Law and Politics: The Scope and Limits of Constitutionalism, edited by Christodoulidis and Stephen Tierney, 47-65. Burlington, VT: Ashgate Publishing Company, 2008.

Cohen-Eliya, Moshe and Iddo Porat. "Proportionality and the Culture of Justification." American Journal of Comparative Law 59 (2011): 463-490.

Coleman, Jules L. and Brian Leiter. "Legal Positivism." In A Companion to Philosophy of Law and Legal Theory, edited by Dennis Patterson, 228-248. Oxford: Blackwell Publishing, 1999.

Comella, Víctor Ferreres. Constitutional Courts \& Democratic Values: A European Perspective. New Haven: Yale University, 2009.

Cook, Maeve. "Law's Claim to Correctness." In Law, Rights, and Discourse: The Legal Philosophy of Robert Alexy, edited by George Pavlakos, 225-248. Oxford: Hart Publishing, 2007.

Currie, David P. The Constitution of the Federal Republic of Germany. Chicago: University of Chicago Press, 1994.

Davis, David Brion. The Problem of Slavery in Western Culture. Oxford: Oxford University Press, 1966.

Deák, István. "Holocaust Views: The Goldhagen Controversy in Retrospect." Central European History 30 (1997): 295-307.

Douglass, Frederick. "The Address of Southern Delegates in Congress to their Constituents or, the address of John C. Calhoun and Forty Other Thieves.” The North Star, February 9, 1849.

. "Change of Opinion Announced.” The North Star, May 23, 1851.

- Life and Times of Frederick Douglass. New York: Cosimo, 2008.

Dreben, Burton. "On Rawls and Political Liberalism." In The Cambridge Companion to Rawls, edited by Samuel Freeman, 316-346. Cambridge: Cambridge University Press, 2003.

Dürig, Günter. "An Introduction to the Basic Law of the Federal Republic of Germany." In The Constitution of the Federal Republic Of Germany, edited by Ulrich Karpen, 11-24. Baden-Baden: Nomos Verlagsgesellschaft, 1998.

Dworkin, Ronald. "The Coming Battles over Free Speech." The New York Review of Books, June 11, 1992. 
- Freedom's Law: The Moral Reading of the American Constitution. Cambridge: Harvard University Press, 1997.

—. Justice for Hedgehogs. Cambridge: Harvard University Press, 2011.

- Justice in Robes. Cambridge: Harvard University Press, 2006.

—. "Law’s Ambitions for Itself." Virginia Law Review 71 (1985): 173-187.

—. Law's Empire. Cambridge: Harvard University Press, 1986.

-. A Matter of Principle. Cambridge: Harvard University Press, 1985.

—. "Rights as Trumps." In Theories of Rights, edited by Jeremy Waldron, 153-167. Oxford: Oxford University Press, 1984.

- Sovereign Virtue: The Theory and Practice of Equality. Cambridge: Harvard University Press, 2002.

—. Taking Rights Seriously. Cambridge: Harvard University Press, 1978.

—. “Thirty Years On.” Harvard Law Review 115 (2002): 1655-1687.

Dyson, Matthew. Review of The Idea of Public Law, by Martin Loughlin. The Cambridge Law Journal 64 (2005): 503-4.

Dyzenhaus, David. "Constitutionalism in an Old Key: Legality and Constituent Power." Global Constitutionalism 1 (2012): 229-260.

—. "The End of the Road to Serfdom?” University of Toronto Law Journal 63 (2013): 310-326.

—. Hard Cases in Wicked Legal Systems: Pathologies of Legality. Oxford: University Press, 2010.

- "Hobbes on the Authority of Law." In Hobbes and the Law, edited by Dyzenhaus and Thomas Poole, 186-209. Cambridge: Cambridge University Press, 2012.

. "How Hobbes Met the 'Hobbes Challenge'." Modern Law Review 72 (2009): 488-506.

—. "The Juristic Force of Injustice." In Calling Power to Account: Law, Reparations and the Chinese Head Tax, edited by Dyzenhaus and Mayo Moran. Toronto: University of Toronto Press, 2005.

Ebbinghaus, Julius. “The Law of Humanity and the Limits of State Power." Philosophical Quarterly 3 (1953): 14-22.

Eberle, Edward. "Human Dignity, Privacy and Personality in German and American Constitutional Law." Utah Law Review (1997): 964-1056.

Eddy, Katherine. “Against Ideal Rights.” Social Theory and Practice 34 (2008): 463-481. 
Elliot, Jonathan, ed. Debates on the Adoption of the Federal Constitution. New York: Burt Franklin, 1888.

Ely, John Hart. Democracy and Distrust: A Theory of Judicial Review. Cambridge: Harvard University Press, 1980.

Epp, Charles R. The Rights Revolution: Lawyers, Activists, and Supreme Courts in Comparative Perspective. Chicago: University of Chicago Press, 1998.

Farrelly, Colin. “Justice in Ideal Theory: A Refutation.” Political Studies 55 (2007): 844-864.

Favoreu, Louis. “Justicia y Jueces Constitucionales.” Revista de Derecho Publico 61 (1999): 10-16.

Feinberg, Joel. "Duty and Obligation in the Non-Ideal World." The Journal of Philosophy 70 (1973): 263275.

Feldman, Noah R. “Unresolved Tensions.” Yale Law Journal 106 (1996): 229-234.

Finnis, John. "Natural Law Theories." The Stanford Encyclopedia of Philosophy (Fall 2008 Edition), edited by Edward N. Zalta, URL = <http://plato.stanford.edu/archives/fall2008/entries/naturallaw-theories $/>$.

Ford, P.L., ed. The Writings of Thomas Jefferson, vol. 10. 1899.

Fox, Gregory H. and George Nolte. "Intolerant Democracies." Harvard International Law Journal 36 (1995): 1-70.

Fraenkel, Ernst. The Dual State: A Contribution to the Theory of Dictatorship. New York: Oxford University Press, 1941.

Freehling, William. The Road to Disunion: Secessionists at Bay: 1776-1854. Oxford: Oxford University Press 1990.

Freeman, Samuel. "Constitutional Democracy and the Legitimacy of Judicial Review." Law and Philosophy 9 (1990): 327-370.

Friedländer, Saul. "From Anti-Semitism to Extermination: An Historiographical Study of Nazi Policies Toward the Jews and an Essay in Interpretation." Yad V ashem Studies 16 (1984): 1-50.

- Nazi Germany and the Jews: The Years of Persecution, 1933-1939, vol. I. New York: Harper Collins Publishers, 1997.

Friedman, Richard. "Michael Oakeshott and the Elusive Identity of the Rule of Law." In The Intellectual Legacy of Michael Oakeshott, edited by Corey Abel and Timothy Fuller, 160-181. Charlottesville: Imprint Academic, 2005.

Fukuyama, Francis. The Origins of the Political Order. New York: Farrar, Straus, and Girous, 2011. 
Fuller, Lisa L. "Burdened Societies and Transitional Justice." Ethical Theory and Moral Practice (2011): 369-386.

Fuller, Lon L. The Morality of Law. New Haven: Yale University Press, 1994.

—. "Positivism and Fidelity to Law: A Reply to Professor Hart." Harvard Law Review 71 (1958): 630-672.

—. "Reason and Fiat in Case Law." Harvard Law Review 59 (1946): 376-395.

Gardner, John. "Legal Positivism: 51/2 Myths.” The American Journal of Jurisprudence 46 (2001): 199-227.

Garnsey, Peter. Ideas of Slavery from Aristotle to Augustine. Cambridge: Cambridge University Press, 1996.

Gilabert, Pablo. "Global Justice and Poverty Relief in Nonideal Circumstances." Social Theory and Practice 34 (2008): 411-438.

Glendon, Mary Ann. "Knowing the Universal Declaration of Human Rights." Notre Dame Law Review 73 (1998): 1153-1190.

Goldhagen, Daniel Jonah. Hitler's Willing Executioners: Ordinary Germans and the Holocaust. New York: Alfred A. Knopf, 1996.

Goldsworthy, Jeffrey. "Questioning the Migration of Constitutional Ideas: Rights, Constitutionalism, and the Limits of Convergence." In The Migration of Constitutional Ideals, edited by Sujit Choudhry, 115-141. Cambridge: Cambridge University Press, 2006.

Goodin, Robert E. "Political Ideals and Political Practice." British Journal of Political Science 25 (1995): 37-56.

Grant, James. "Control and Self-Control.” Review of Foundations of Public Law, by Martin Loughlin. The Times Literary Supplement (2010).

Green, Leslie. The Authority of The State. Oxford: Clarendon Press, 1990.

- "Law and Obligations." In The Oxford Handbook of Jurisprudence and Philosophy of Law, edited by Jules Coleman and Scott Shapiro, 514-547. Oxford: Clarendon Press, 2001.

Grimm, Dieter. "The Achievement of Constitutionalism and its Prospects in a Changed World." In The Twilight of Constitutionalism, edited by Petra Dobner and Martin Loughlin), 3-22. Oxford: Oxford University Press, 2010.

—. "The Basic Law at 60 - Identity and Change." German Law Journal 11 (2010): 33-46.

- "Constitutional Adjudication and Democracy." In Judicial Review in International Perspective, edited by Mads Tønnesson Andenæs and Duncan Fairgrieve, 103-120. The Hague: Kluwer Law International, 2000. 
- "Freedom of Speech in a Globalized World." In Extreme Speech and Democracy, edited by Ivan Hare, 11-22. Oxford: Oxford University Press, 2009.

. "The German and American Constitutionalism: A Comparison." The Berlin Journal 7 (2003): 8-12.

- "Proportionality in Canadian and German Constitutional Jurisprudence." University of Toronto Law Journal 57 (2007): 383-397.

—. "Values in German Constitutional Law." Forthcoming.

Habermas, Jürgen. Between Facts and Norms: Contributions of a Discourse Theory of Law and Democracy. Translated by William Rehg. Cambridge: MIT Press, 1999.

Haldemann, Frank. "Gustav Radbruch vs. Hans Kelsen: A Debate on Nazi Law.” Ratio Juris 18 (2005): 162-178.

Hamilton, Alexander and John Jay, and James Madison. The Federalist: A Commentary on the Constitution of the United States. Philadelphia: J.B. Lippincott, 1864.

Hart, H.L.A. The Concept of Law. Oxford: Clarendon Press, 1994.

- Essays on Bentham: Jurisprudence and Political Theory. Oxford: Oxford University Press, 1982.

—. Essays in Jurisprudence and Philosophy. Oxford: Oxford University Press, 1983.

—. "Legal and Moral Obligation." In Essays in Moral Philosophy, edited by A.I. Melden, 82-107. Seattle: University of Washington Press, 1958.

- "Positivism and the Separation of Law and Morals." Harvard Law Review 71 (1958): 593-629.

Havel, Václav. The Art of the Impossible: Politics as Morality in Practice. Toronto: Alfred A. Knopf, 1997.

Hendrix, Burke A. "Where Should We Expect Social Change in Non-Ideal Theory.” Political Theory 41 (2013): 116-143.

Heyman, Steven J. "The Dark Side of the Force: The Legacy of Justice Holmes for First Amendment Jurisprudence." William \& Mary Bill of Rights Journal 19 (2011): 661-723.

Hickman, Tom R. "In Defence of the Legal Constitution.” Review of The Idea of Public Law, by Martin Loughlin. University of Toronto Law Journal 55 (2005): 981-1025.

Himma, Kenneth Einar. "Positivism and the Problem of Explaining Legal Obligation." American Philosophical Association Newsletter 5 (2006): 13-18.

Hobbes, Thomas. Leviathan, edited by Edwin Curley. Indianapolis: Hackett Publishing, 1994. 
Hogg, P.W. Constitutional Law of Canada, vol. II. Toronto: Thomson Carswell, 2007.

Hume, David. “Of the Original Contract.” In Essays, Moral, Political, Literary, edited by E. F. Miller, 465-487. Indianapolis: Liberty Classics, 1985.

Inge-Harbo, Tor. “The Function of the Proportionality Principle in EU Law." European Law Journal 16 (2010): 158-185.

Israel, Jonathan. A Revolution of the Mind: Radical Enlightenment and the Intellectual Origins of Modern Democracy. Princeton: Princeton University Press, 2009.

Jacobsohn, Gary J. "Abraham Lincoln 'On this Question of Judicial Authority': The Theory of Constitutional Aspiration.” Western Political Science Association 36 (1983): 52-70.

Joly, Fábio Duarte. “Spartacus Revolt.” In Encyclopedia of Antislavery and Abolition, edited by Peter Hinks, John McKivigan, and R. Owen Williams, 648-651. Westport: Greenwood Press, 2007.

Kant, Immanuel. Anthropology from a Pragmatic Point of View. Edited by Robert P. Louden. Cambridge: Cambridge University, 2006.

- Practical Philosophy. Translated by Mary J. Gregor. Cambridge: Cambridge University Press, 1996.

Kates, Michael. "Justice in Nonideal Theory." On file with the author.

Kelsen, Hans. An Introduction to the Problems of Legal Theory. Translated by Bonnie Litschewski Paulson and Stanley L. Paulson. Oxford: Oxford University Press, 1997.

- "The Natural-Law Doctrine Before the Tribunal of Science." Western Political Science Quarterly 2 (1949): 481-513.

Kershaw, Ian. Popular Opinion and Political Dissent in the Third Reich: Bavaria 1933-1945. Oxford: Oxford University Press, 1983.

Khosla, Madhav. "Proportionality: An Assault on Human Rights?: A Reply." International Journal of Constitutional Law (2010): 298-306.

Klatt, Matthias and Moritz Meister. The Constitutional Structure of Proportionality. Oxford: Oxford University Press, 2012.

Klein, Eckhart. "Human Dignity in German Law." In The Concept of Human Dignity in Human Rights Discourse, edited by David Kretzmer and Klein, 145-159. The Hague: Kluwer Law International, 2002.

Kleingeld, Pauline. "Kant, History, and the Idea of Moral Development.” History of Philosophy Quarterly 16 (1999): 59-80. 
Klemperor, Victor. I Will Bear Witness: A Diary of the Nazi Years (1933-1941). Translated by Martin Chalmers. New York: Random House, 1988.

Kojève, Alexandre. Introduction to the Reading of Hegel. Ithaca: Basic Books, 1969.

Kommers, Donald P. The Constitutional Jurisprudence of the Republic of Germany. Durham: Duke University Press, 1989.

Koonz, Claudia. The Naz̧i Conscience. Cambridge: Harvard University Press, 2003.

Korsgaard, Christine M. "The Right to Lie: Kant on Dealing with Evil." Philosophy \& Public Affairs 15 (1986): 325-349.

von Krauss, Rupprecht. Der Grundsatz der Verhältnismässigkeit in seiner Bedeutung für die Notwendigkeit des Mittels in Verwaltungsrecht. Hamburg: 1955.

—. The Constitutional Jurisprudence of the Republic of Germany. Durham: Duke University Press, 1997.

—. "German Constitutionalism: A Prolegomenon.” Emory Law Journal 40 (1991): 837-873.

Kumm, Mattias. "Constitutional Rights as Principles: On the Structure and Domain of Constitutional Justice." Review of A Theory of Constitutional Rights, by Robert Alexy. International Journal of Constitutional Law 2 (2004): 574-596.

. "The Idea of Socratic Contestation and the Right to Justification: The Point of Rights-Based Proportionality Review.” Law \& Ethics of Human Rights 4 (2010): 141-175.

- "Political Liberalism and the Structure of Rights: On the Place and Limits of the Proportionality Requirement." In Law, Rights, and Discourse, edited by George Pavlakos, 131166. Oxford: Hart Publishing, 2007.

Langton, Rae. "Whose Right? Dworkin, Women and the Pornographers." Philosophy and Public Affairs 19 (1990): 311-359.

Leib, Ethan J. Review of The Idea of Public Law, by Martin Loughlin. Law \& Politics Book Review 14 (2004): 458-464.

Leiter, Brian. "The Radicalism of Legal Positivism." Guild Practitioner (2010). Available at SSRN: http://ssrn.com/abstract $=1568333$.

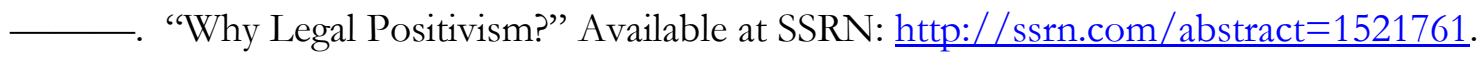

Levy, Jacob T. "Not So Novus an Ordo: Constitutions without Social Contracts." Political Theory 37 (2009): 191-217.

Limbach, Jutta. "The Concept of the Supremacy of the Constitution.” Modern Law Review 64 (2001): $1-10$. 
Loesener, Bernard. Legislating the Holocaust: The Bernard Loesener Memoirs and Supporting Documents, edited by Karl A. Schleunes, translated by Carol Scherer. Boulder, Colorado: Westview Press, 2001.

Loewenstein, Karl. "Law in the Third Reich.” The Yale Law Journal 45 (1936): 779-815.

Loughlin, Martin. Foundations of Public Law. Oxford: Oxford University Press, 2010.

—. The Idea of Public Law. Oxford: Oxford University Press, 2003.

Lunau, Henry. "The Threat of Nazi Law to all Fundamental Legal Principles." Proceedings of the American Foreign Law Association 23 (1942): 1-11.

Madison, James. Records of the Federal Convention, vol. 1, edited by Max Farrand. New Haven: Yale University Press, 1966.

Mahlmann, Matthias. "The Basic Law at 60 - Human Dignity and the Culture of Republicanism." German Law Journal 11 (2010): 9-32.

Mandela, Nelson. Long Walk to Freedom: The Autobiography of Nelson Mandela. London: Abacus, 2009.

Martin, Douglas. "Sidney Morgenbesser, 82, Kibitzing Philosopher, Dies." The New York Times, April 4, 2004.

Martin Jr., Waldo E. The Mind of Frederick Douglass. Chapel Hill: University of North Carolina Press, 1984.

Mason, Andrew. “Just Constraints.” British Journal of Political Science 34 (2004): 251-268.

McCrudden, Christopher. "Human Dignity and Judicial Interpretation of Human Rights." European Journal of International Law 19 (2008): 655-724.

Mendes-Flohr, Paul R. and Jehuda Reinharz, ed. The Jew in the Modern World. Oxford: Oxford University Press, 1995.

Mertens, Thomas. "Darker Legacies of Law in Europe: The Shadow of National Socialism and Fascism over Europe and its Legal Traditions." Ratio Juris 18 (2005): 285-291.

—. "Nazism, Legal Positivism and Radbruch's Thesis on Statutory Injustice." Law and Critique 14 (2003): 277-295.

Mill, John Stuart. The Subjection of Women. New York: Dover, 1997.

Mills, Charles W. “'Ideal Theory’ as Ideology.” Hypatia 20 (2005): 165-184.

Möller, Kai. "Balancing and the Structure of Constitutional Rights." International Journal of Constitutional Law 5 (2007): 453-468. 
Morsink, Johannes. "World War Two and the Universal Declaration." Human Rights Quarterly 15 (1993): 357-405.

Moses, A.D. "Structure and Agency in the Holocaust: Daniel J. Goldhagen and His Critics." History and Theory 37 (1998): 194-199.

Müller, Ingo. Hitler's Justice. Cambridge: Harvard University Press, 1991.

Mureinik, Etienne. "A Bridge to Where? Introducing the Interim Bill of Rights." South African Journal on Human Rights 10 (1994): 31-48.

_. "Emerging from Emergency: Human Rights in South Africa." Michigan Law Review 92 (1977): 1977-1988.

Murphy, Liam. Moral Demands in Nonideal Theory. Oxford: Oxford University Press, 2000.

Neiman, Susan. Moral Clarity: A Guide for Grown-up Idealists. New York: Harcourt, 2008.

Oakeshott, Michael. On History and Other Essays. Oxford: Basil Blackwell, 1983.

-. On Human Conduct. Oxford: Clarendon Press, 1975.

O’Neil, Onora. "Constructivism in Rawls and Kant." In The Cambridge Companion to Rawls, edited by Samuel Freeman, 347-367. Cambridge: Cambridge University Press, 2003.

Paine, Thomas. "African Slavery in America." Pennsylvania Journal and the Weekly Advertiser, March 8, 1775.

—. The Rights of Man. Indianapolis: Hackett Publishing, 1992.

Panaccio, Charles-Maxime. "In Defence of Two-Step Balancing and Proportionality in Rights Adjudication." Canadian Journal of Law and Jurisprudence 24 (2011): 109-128.

Pappe, H.O. "On the Validity of Judicial Decisions in the Nazi Era." Modern Law Review 23 (1960): 260-274.

Paulson, Stanley L. "On the Background and Significance of Gustav Radbruch's Post-War Papers." Oxford Journal of Legal Studies 26 (2006): 17-40.

- Review of Law as a Moral Judgment, by Deryck Beyleveld and Roger Brownscord. Ratio Juris 7 (1994): 111-116.

—. "Radbruch on Unjust Laws: Competing Earlier and Later Views?" Oxford Journal of Legal Studies 15 (1995): 489-500.

Perry, Stephen R. "Associative Obligations and the Obligation to Obey the Law." In Exploring Law's Empire: The Jurisprudence of Ronald Dworkin, edited by Scott Hershovitz, 183-206. Oxford: Oxford University Press, 2006. 
- "Political Authority and Political Obligation." In Oxford Studies in Philosophy of Law, vol. II, edited by Leslie Green and Brian Leiter (forthcoming).

Phillips, Michael. "Reflections on the Transition from Ideal to Non-Ideal Theory." Noûs 19 (1985): 551-570.

Pildes, Richard H. “Dworkin's Two Conceptions of Rights.” The Journal of Legal Studies 29 (2000): 309315.

Plato. Complete Works, edited by J.M. Cooper and D.S. Hutchinson. Indianapolis: Hackett Publishing, 1997.

Posner, Richard A. Review of Jeremy Waldron, Law and Disagreement. Columbia Law Review 100 (2000): 582-592.

Quirk, Patrick. “An Australian Looks at German 'Proportionality'.” University of Notre Dame Australia Law Review 1 (1999): 39-55.

Radbruch, Gustav. "Five Minutes of Legal Philosophy.” Oxford Journal of Legal Studies 26 (2006): 1315.

—. Kulturlehre des Sozialismus, edited by Arthur Kaufmann. Frankfurt: Athenäum, 1970.

—. Legal Philosophy in The Legal Philosophies of Lask, Radbruch, and Dabin. Translated by Kurt Wilk. Cambridge: Harvard University Press, 1950.

—. "Statutory Lawlessness and Supra-Statutory Law (1946)." Oxford Journal of Legal Studies 26 (2006): 1-11.

Radin, Margaret Jane. "Lacking a Transformative Social Theory: A Response.” Stanford Law Review 45 (1993): 409-424.

Rawls, John. Justice as Fairness: A Restatement. Cambridge: Harvard University Press, 2001.

—. The Law of Peoples. Cambridge: Harvard University Press, 1999.

—. Political Liberalism. New York: Columbia University Press, 1996.

—. "Political Liberalism: Reply to Habermas." The Journal of Philosophy 92 (1995): 132-180.

—. A Theory of Justice. Cambridge: Harvard University Press, 1971.

Raz, Joseph, ed., Authority. New York: New York University Press, 1990.

—. "Authority and Justification." Philosopby and Public Affairs 14 (1985): 3-29.

—. The Authority of Law. New York: Oxford University Press, 2009. 
—. "Kelsen's Theory of the Basic Norm." American Journal of Jurisprudence 19 (1974): 94-111.

- The Morality of Freedom. Oxford: Oxford University Press, 1986.

Réaume, Denise. "Limitations on Constitutional Rights: The Logic of Proportionality." On file with the author.

Reeves, Anthony R. "Judicial Practical Reason: Judges in Morally Imperfect Legal Orders." Law and Philosophy 30 (2011): 319-352.

Ripstein, Arthur. “Authority and Coercion” Philosophy and Public Affairs 32 (2004) 2-35.

- Force and Freedom: Kant's Legal and Political Philosophy. Cambridge: Harvard University Press, 2009.

Robeyns, Ingrid. "Ideal Theory in Theory and Practice.” Social Theory and Practice 34 (2008): 341-362.

Rousseau, Jean-Jacques. On the Social Contract in The Basic Political Writings, translated by Donald A. Cress. Indianapolis: Hackett Publishing Company, 1987.

Rundle, Kristen. "The Impossibility of an Exterminatory Legality: Law and the Holocaust.” University of Toronto Law Journal 59 (2009): 65-125.

Russell, Bertrand. Unpopular Essays. New York: Routledge, 2009.

Sartori, Giovanni. Democratic Theory. New York: Frederick A. Praeger: 1965.

Schapiro, Tamar. "Compliance, Complicity, and the Nature of Nonideal Conditions." The Journal of Philosophy 100 (2003): 329-355.

Schlaifer, Robert. "Greek Theories of Slavery from Homer to Aristotle.” In Slavery in Classical Antiquity: Views and Controversies, edited by M.I. Finley, 93-132. Cambridge: Heffer, 1964

Schmidtz, David. "Nonideal Theory: What It Is and What It Needs To Be.” Ethics 121 (2011): 772796.

Sen, Amartya. "What Do We Want From a Theory of Justice?” The Journal of Philosophy 103 (2006): 215-238.

Shapiro, Scott. Legality. Cambridge: Harvard University Press, 2010.

—. "What is the Internal Point of View?" Fordham Law Review 75 (2006): 1157-1170.

Sher, George. Approximate Justice: Studies in Non-Ideal Theory. Lanham: Roman \& Littlefield, 1997.

Simmons, A. John. "Ideal and Nonideal Theory." Philosophy \& Public Affairs 38 (2010): 5-36. 
—. "The Principle of Fair Play." Philosophy and Public Affairs 8 (1979): 307-337.

Shelley, Robert. “Stuntman for the State: Loughlin's Idea of Public Law." Ratio Juris 19 (2006): 479-488.

Soper, Phillip. “Dworkin’s Domain.” Harvard Law Review 100 (1987): 1166-86.

Sreenivasan, Gopal. "Health and Justice in Our Non-Ideal World." Politics, Philosophy \& Economics 6 (2007): 218-236.

—. "Non-ideal Theory: A Taxonomy with Illustration." In Global Justice and Bioethics, edited by Joseph Millum and Ezekiel J. Emanuel, 135-152. Oxford: Oxford University Press, 2012.

de Ste. Croix, G.E.M. The Class Struggle in the Ancient Greek World: From the Archaic Age to the Arab Conquests. Ithaca: Cornell University Press, 1981.

Stemplowska, Zofia. "What's Ideal About Ideal Theory?” Social Theory and Practice 34 (2008): 319-340;

Stolleis, Michael. The Law Under the Swastika: Studies on Legal History in Nazi Germany, translated by Thomas Dunlap. Chicago: University of Chicago Press, 1998.

Stone, Martin. "Legal Positivism as an Idea about Morality." University of Toronto Law Journal 61 (2011): 313-341.

Stone Sweet, Alec and Jud Mathews. "Proportionality Balancing and Global Constitutionalism." Columbia Journal of Transnational Law 47 (2008): 73-165.

Swift, Adam. "The Value of Philosophy in Nonideal Circumstances." Social Theory and Practice 34 (2008): 363-387.

Taylor, C.C.W. “A Note on Ancient Attitudes Towards Slavery.” Analysis 43 (1983): 40-43.

Taylor, Robert S. "Rawlsian Affirmative Action.” Ethics 119 (2009): 476-506.

Thornhill, C. Review of Foundations of Public Law, by Martin Loughlin. Public Law (2011): 651-657.

Tierney, Stephen. "Sovereignty and the Idea of Public Law." In Public Law and Politics: The Scope and Limits of Constitutionalism, edited by Emilios Christodoulidis and Tierney, 15-26. Burlington, VT: Ashgate Publishing Company, 2008.

de Toqueville, Alexis. Democracy in America. New York: Alfred A. Knopf, 1994.

Tsakyrakis, Stavros. "Proportionality: An Assault on Human Rights." International Journal of Constitutional Law 7 (2009): 468-493.

Unger, Aryeh L. "The Public Opinion Reports of the Nazi Party." The Public Opinion Quarterly 29 (1966): 565-582. 
Valentini, Laura. "On the Apparent Paradox of Ideal Theory." The Journal of Political Philosophy 17 (2009): 332-355.

Veitch, Scott. "Authority, Exploitation and the Idea of Public Law." In Public Law and Politics: The Scope and Limits of Constitutionalism, edited by Emilios Christodoulidis and Stephen Tierney, 27-34. Burlington, VT: Ashgate Publishing Company, 2008.

Venter, Francois. Constitutional Comparison: Japan, Germany, Canada \& South Africa as Constitutional States. Cambridge: Kluwer Law International, 2000.

Waldron, Jeremy. "The Core of the Case Against Judicial Review.” Yale Law Journal 115 (2006): 13461406.

—. The Dignity of Legislation. Cambridge: Cambridge University Press, 1999.

. "Freeman’s Defense of Judicial Review." Law and Philosophy 13 (1994): 27-41.

- Law and Disagreement. Oxford: Oxford University Press, 1999.

—. "Positivism and Legality: Hart's Equivocal Response to Fuller." New York University Law Review 83 (2008): 1135-1169.

. "A Rights-Based Critique of Constitutional Rights.” Oxford Journal of Legal Studies 13 (1993): 18-51.

—. "Rights in Conflict." Ethics 99 (1989): 503-519.

Walen, Alec. “Judicial Review in Review.” International Journal of Constitutional Law 7 (2009): 329-354.

Walters, Mark D. “Is Public Law Ordinary?” The Modern Law Review 75 (2012): 894-913.

Waluchow, Wil. "Constitutions as Living Trees: An Idiot Defends." Canadian Journal of Law and Jurisprudence 18 (2005): 211-220.

Walzer, Michael. "Philosophy and Democracy." Political Theory 9 (1981): 379-399.

Webber, Grégoire C.N. "Proportionality, Balancing, and the Cult of Constitutional Rights Scholarship." Canadian Journal of Law and Jurisprudence 23 (2010): 179-202.

Weinrib, Ernest. The Idea of Private Law. Cambridge: Harvard University Press, 1995.

Weinrib, Jacob. "Kant on Citizenship and Universal Independence." Australian Journal of Legal Philosophy 33 (2008): 1-25.

. "Permissive Laws and the Dynamism of Kantian Justice." Law and Philosophy (forthcoming 2013). 
- "What can Kant Teach us about Legal Classification?" The Canadian Journal of Law and Jurisprudence 23 (2010): 203-231.

Weinrib, Lorraine Eisenstat. “Canada's Constitutional Revolution: From Legislative to Constitutional State.” Israel Law Review 33 (1999): 13-50.

- "The Postwar Paradigm and American Exceptionalism." In The Migration of Constitutional Ideas, edited by Sujit Choudhry, 83-113. New York: Cambridge University Press, 2006.

. "The Supreme Court of Canada in the Age of Rights: Constitutional Democracy, the Rule of Law and Fundamental Rights under Canada’s Constitution.” Canadian Bar Review (2001): 699748.

Westermann, William Linn. "Between Slavery and Freedom.” American Historical Review 50 (1945): 213227.

- "Slavery and the Elements of Freedom in Ancient Greece." In Slavery in Classical Antiquity: Views and Controversies, edited by M.I. Finley, 17-32. Cambridge: W. Heffer and Sons, 1964.

Williams, Bernard. Shame and Necessity. Berkeley: University of California Press, 2008.

Wilson, Bertha. “Constitutional Advocacy.” Ottawa Law Review 24 (1992): 265-273.

Wolff, Jonathan. An Introduction to Political Philosophy. Oxford: Oxford University Press, 1996.

Zipursky, Benjamin C. "Legal Obligations and the Internal Aspect of Rules.” Fordham Law Review 75 (2006):1229-1253.

Zucca, Lorenzo. Constitutional Dilemmas: Conflicts of Fundamental Legal Rights in Europe and the USA. Oxford: Oxford University Press, 2007. 


\section{Cases, Legislation, and Constitutions}

BVerfGE 7, 198.

BVerfGE 23, 98.

BVerfGE 45, 187.

BVerfGE 55, 159.

BVerfGE 80, 137.

The Basic Law for the Federal Republic of Germany [Grundgeseta]. Berlin: German Bundestag, 2001.

British North America Act, 1867, 30-31 Vict., c. 3

Canada (Human Rights Commission) v. Taylor [1990] 3 S.C.R. 892.

Canadian Charter of Rights and Freedoms, s. 1, Part I of the Constitution Act, 1982, being Schedule B to the Canada Act 1982 (U.K.), 1982, c. 11.

Constitution of the Republic of South Africa (1996).

Criminal Code, R.S.C. 1985, c. C-46.

Fay v. New York, 332 US 261 (1947).

Gitlow v. New York, 268 U.S. 652, 673 (1925).

Hunter et al. v. Southam Inc., [1984] 2 S.C.R. 145.

Lochner v. New York, 198 U.S. 45, 75-76 (1905).

Lord's Day Act, R.S.C. 1970, c. L-13.

Minister of Home Affairs v. Fisher, [1980] A.C. 319.

Poe et al. v. Ullman, State's Attorney, 367 U.S. 497 (1961).

Port Eliqabeth Municipality v. Various Occupiers, 2004 (12) BCLR 1268 (CC).

Prinsloo v. van der Linde (1997) 6 BCLR 759(CC)

R. v. Big M Drug Mart Ltd., [1985] 1 S.C.R. 295.

R. v. Keegstra [1990] 3 S.C.R. 697.

R. v. Oakes, [1986] 1 S.C.R. 103. 
R. v. Morgentaler, [1988] 1 S.C.R. 30.

Reference re Secession of Quebec [1998] 2 S.C.R. 217.

S. v. Makwanyane and Another (1995) 3 SA 391 (CC).

Slaight Communications Inc. v. Davidson, [1989] 1 S.C.R. 1038.

Southern Pac. Co. v. Jensen, 244 U.S. 205 (1917).

Thomson Newspapers Co. v. Canada (Attorney General), [1998] 1 S.C.R. 877.

Thorson v. Attorney General of Canada, [1975] 1 S.C.R. 138.

UN General Assembly, Universal Declaration of Human Rights, 10 December 1948, 217 A (III), available at: http://www.unhcr.org/refworld/docid/3ae6b3712c.html [accessed 13 March 2013].

Vriend v. Alberta, [1998] 1 S.C.R. 493. 